\title{
Intestinal fat and eating behavior: role of the ileal brake
}

Citation for published version (APA):

Maljaars, J. (2010). Intestinal fat and eating behavior: role of the ileal brake. [Doctoral Thesis, Maastricht University]. Datawyse / Universitaire Pers Maastricht. https://doi.org/10.26481/dis.20101022jm

Document status and date:

Published: 01/01/2010

DOI:

10.26481/dis.20101022jm

Document Version:

Publisher's PDF, also known as Version of record

\section{Please check the document version of this publication:}

- A submitted manuscript is the version of the article upon submission and before peer-review. There can be important differences between the submitted version and the official published version of record.

People interested in the research are advised to contact the author for the final version of the publication, or visit the DOI to the publisher's website.

- The final author version and the galley proof are versions of the publication after peer review.

- The final published version features the final layout of the paper including the volume, issue and page numbers.

Link to publication

\footnotetext{
General rights rights.

- You may freely distribute the URL identifying the publication in the public portal. please follow below link for the End User Agreement:

www.umlib.nl/taverne-license

Take down policy

If you believe that this document breaches copyright please contact us at:

repository@maastrichtuniversity.nl

providing details and we will investigate your claim.
}

Copyright and moral rights for the publications made accessible in the public portal are retained by the authors and/or other copyright owners and it is a condition of accessing publications that users recognise and abide by the legal requirements associated with these

- Users may download and print one copy of any publication from the public portal for the purpose of private study or research.

- You may not further distribute the material or use it for any profit-making activity or commercial gain

If the publication is distributed under the terms of Article $25 \mathrm{fa}$ of the Dutch Copyright Act, indicated by the "Taverne" license above, 


\title{
Intestinal fat and eating behavior:
}

\author{
role of the ileal brake
}


(c) 2010 Jeroen Maljaars, Maastricht

Layout: Tiny Wouters

Cover: Datawyse

Production: Datawyse | Universitaire Pers Maastricht

ISBN: 9789052789835

The studies described in this thesis were financially supported by Unilever Research \& Development, Vlaardingen, The Netherlands

Printing of this thesis was financially supported by Unilever Research and Development, Clinical Trial Centre Maastricht, Ferring, ABBOTT Immunology, Norgine, Tramedico, AstraZeneca, Orbis Medisch Centrum. 


\title{
Intestinal fat and eating behavior:
}

\author{
role of the ileal brake
}

\author{
PROEFSCHRIFT
}
ter verkrijging van de graad van doctor aan de Universiteit Maastricht, op gezag van de Rector Magnificus, Prof. mr. G.P.M.F. Mols, volgens het besluit van het College van Decanen, in het openbaar te verdedigen op vrijdag 22 oktober 2010 om 14.00 uur

door

Pieter Wolter Jeroen Maljaars

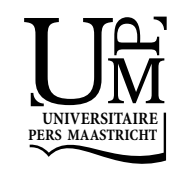


Promotor:

Prof. dr. A.A.M. Masclee

Co-promotor:

Dr. H.P.F. Peters

\section{Beoordelingscommissie:}

Prof. dr. W.H. Saris, voorzitter

Prof. dr. W.A. Buurman

Prof. dr. H. Pijl, Leids Universitair Medisch Centrum

Prof. dr. C.D.A. Stehouwer

Prof. dr. M.S. Westerterp 


\section{Contents}

Chapter 1 Introduction, aims and outline of the thesis 7

Chapter 2 Review article: The gastrointestinal tract: neuroendocrine 13 regulation of satiety and food intake

Chapter 3 Ileal brake: a sensible food target for appetite control. A review 31

Chapter $4 \quad$ Effect of ileal fat perfusion on satiety and hormone release $\quad 59$ in healthy volunteers

Chapter 5 The effect of lipid droplet size on satiety and food intake is 75 intestinal site-specific

Chapter 6 Effect of fat saturation on satiety, hormone release and food intake

Chapter 7 Both intestinal site and timing of fat delivery affect appetite in humans

Chapter 8 Small intestinal fat distribution influences satiation and food intake

Chapter 9 Intragastric layering of lipids delays lipid absorption and increases plasma CCK but has minor effects on gastric emptying and appetite

Chapter 10 Summary and general discussion

Samenvatting

List of publications

Dankwoord

Curriculum Vitae 



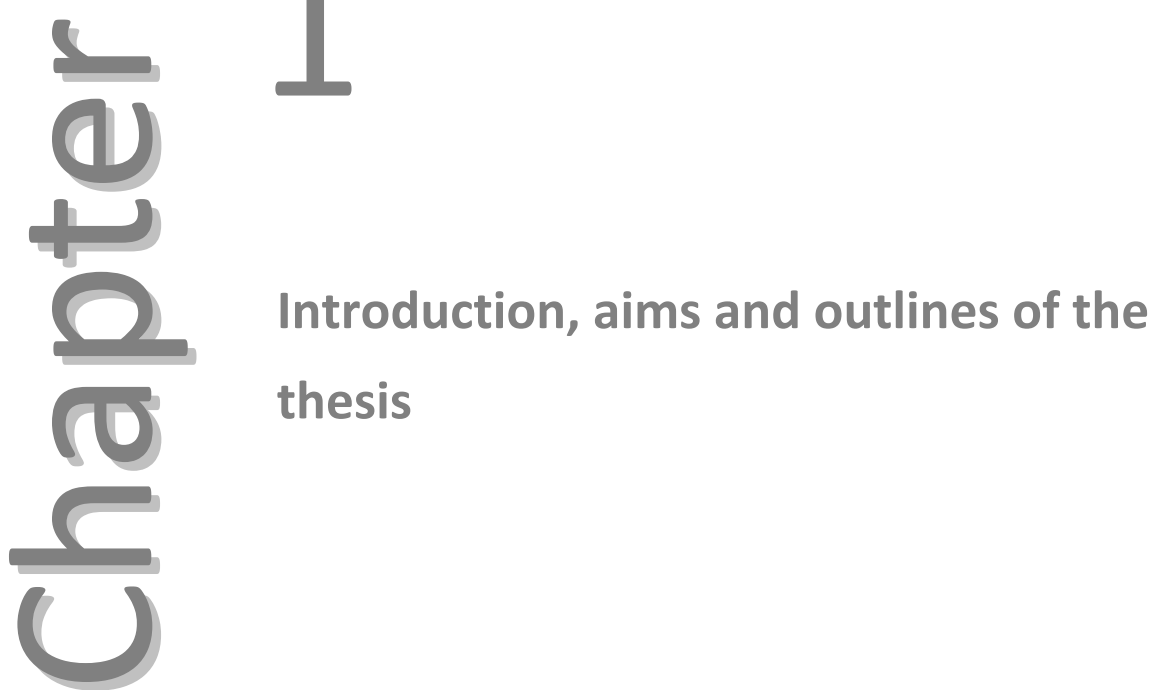

Maljaars PWJ, Masclee AAM 
8 Chapter 1 


\section{Introduction}

The gastrointestinal (gi) tract is the source of a large number of signals and mechanisms that play a role in satiety and (cessation of) food intake. This renders the GI tract an obvious physiological target of strategies aimed at weigh management and weight loss ${ }^{1}$. In the gastrointestinal tract, the signals that influence satiety and food intake, the so-called satiety signals, are generated by various types of stimuli. These stimuli are either mechanical or chemical. Mechanical stimulation is provided by distension of the luminal wall. Chemical stimulation is provided by the presence of nutrients in the small intestine. These stimuli then result in release of gut peptides or activation of local vagal afferents.

Within the small intestine, differences exist with regard to the satiety signals that are released. When the proximal small intestine is exposed to nutrients, this leads to secretion of cholecystokinin (CCK), a gut peptide that is known to reduce food intake and increase satiety. The enteroendocrine cells that are responsible for the secretion of CCK are found predominantly in the duodenum and jejunum, although the presence of these cells has also been demonstrated in the terminal ileum ${ }^{2}$. In the distal small intestine, the dominant enteroendocrine cell is the L-cell, that produces a number of peptides, including peptide YY (PYY), Glucagon-like peptide-1 and -2 (GLP-1, GLP-2) and oxyntomodulin. Secretion of gut peptides, when combined with neural signals from the stomach and small intestine during and after meal ingestion, leads to meal termination, a process which is called satiation. These signals also influence between-meal hunger, which is called satiety.

In this thesis, we will focus on the effects of ileal brake activation on satiety and food intake. The term 'lleal Brake' was first used to describe the phenomenon that gastric and small intestinal motility and transit are inhibited by ileal infusion of nutrients ${ }^{3,4}$, but later studies have also demonstrated that infusion of nutrients into the ileum reduces hunger and food intake ${ }^{5,6}$. 


\section{Aims and outlines of the thesis}

In Chapter 2, we will review the current knowledge on the different mechanisms and signals, emanating from the gastrointestinal tract, that influence satiety and food intake, and in Chapter 3, we will focus in detail on the effects of ileal brake activation on gastrointestinal function, and the role of the ileal brake in gastrointestinal physiology. The effects of ileal brake activation on food intake and satiety will be discussed, both in animals and in humans. In that chapter we also discuss the potential clinical relevance of ileal brake activation for weight loss.

Previous studies examined the effects of ileal infusion of large amounts of fat on satiety. Whether infusion of small amounts of fat, infused at rates that mimic the physiological fat delivery after meal ingestion also could affect satiety, was not known. In the study described in Chapter 4, we examined the effects of 3 and $10 \mathrm{~g}$ of fat, infused in the ileum, on satiety and gut peptide secretion. In that way we were able to explore whether the effects on the ileal brake are dose-dependent.

When fat is infused in the duodenum, it is well known that the physicochemical properties of the fat influence the effects on satiety and food intake and on gut function $^{7-9}$. Recently, it has been demonstrated that the droplet size of a fat emulsion affects its emptying from the stomach ${ }^{10}$. As the rate of gastric emptying may have pronounced effects on satiety and food intake ${ }^{11}$, we have examined the effects of the droplet size of a fat emulsion on satiety and food intake, and how this effect may differ between duodenum and ileum (Chapter 5). In Chapter 6, we tested another physicochemical property of fat, the degree of triacylglycerol fatty acid saturation on satiety, food intake and peptide secretion. The degree of triacylglycerol fatty acid saturation has been shown to affect food intake when the fat is infused into the duodenum ${ }^{7}$.

In the previous studies, described in chapters 4-6, we scheduled the fat ileal infusion at the time point during which the physiological postprandial exposure of the ileum to nutrients is supposed to be at its maximum. In the study described in Chapter 7, we examined whether the timing of the ileal infusion, relative to a preceding meal, also affects the effects on satiety and food intake. In addition, we compared these results to duodenal infusions.

As we learned from the study described in chapter 7 that the effects on an ileal fat infusion are more pronounced in the early postprandial period, we scheduled all infusions in this study at an earlier time point during the test day. It is known from animal studies that, apart from exposing the ileum to nutrients, increasing the small 
intestinal surface area exposed to nutrients also increases the anorectic effects. In the study described in Chapter 8, we compared oral fat ingestion to fat infusion in the ileum, and to infusions that resulted in a larger exposed area of small intestine.

Studies in which the fat was directly infused into the small intestine have demonstrated that lipids do induce satiety. It is, however, unclear to which extent gastric lipid processing influences satiety. In the study described in Chapter 9, we have tested whether the effects of intragastric lipid on fat absorption, gastric emptying CCK secretion and satiety scores can be modulated by controlling intragastric lipid distribution.

The results of the various studies described in this thesis have been summarized and discussed in Chapter 10. We will discuss our findings in relation to data from the recent literature. In addition, we will highlight several items for further research in this area. In Chapter $\mathbf{1 1}$ we will summarize the results in Dutch. 


\section{References}

1. Woods SC. Gastrointestinal satiety signals I. An overview of gastrointestinal signals that influence food intake. Am. J. Physiol Gastrointest. Liver Physiol 2004;286:G7-G13.

2. Sjolund K, Sanden G, Hakanson R, Sundler F. Endocrine cells in human intestine: an immunocytochemical study. Gastroenterology 1983;85:1120-1130.

3. Spiller, RC, Trotman IF, Higgins BE, Ghatei MA, Grimble GK, Lee YC, Bloom SR, Misiewicz JJ, Silk DB. The ileal brake--inhibition of jejunal motility after ileal fat perfusion in man. Gut 1984;25:365-374.

4. Spiller RC, Trotman IF, Adrian TE, Bloom SR, Misiewicz JJ, Silk DB. Further characterisation of the 'ileal brake' reflex in man--effect of ileal infusion of partial digests of fat, protein, and starch on jejunal motility and release of neurotensin, enteroglucagon, and peptide YY. Gut 1988;29:1042-1051.

5. Welch I, Saunders K, Read NW. Effect of ileal and intravenous infusions of fat emulsions on feeding and satiety in human volunteers. Gastroenterology 1985;89:1293-1297.

6. Welch IM, Sepple CP, Read NW. Comparisons of the effects on satiety and eating behaviour of infusion of lipid into the different regions of the small intestine. Gut 1988;29: 306-311.

7. French SJ, Conlon CA, Mutuma ST, Arnold M, Read NW, Meijer G, Francis J. The effects of intestinal infusion of long-chain fatty acids on food intake in humans. Gastroenterology 2000;119:943-948.

8. Feltrin KL, Little TJ, Meyer JH, Horowitz M, Smout AJ, Wishart J, Pilichiewicz AN, Rades T, Chapman IM, Feinle-Bisset C. Effects of intraduodenal fatty acids on appetite, antropyloroduodenal motility, and plasma CCK and GLP-1 in humans vary with their chain length. Am J Physiol Regul Integr Comp Physiol 2004;287:R524-R533.

9. Feltrin KL, Patterson M, Ghatei MA, Bloom SR, Meyer JH, Horowitz M, Feinle-Bisset C. Effect of fatty acid chain length on suppression of ghrelin and stimulation of PYY, GLP-2 and PP secretion in healthy men. Peptides 2006;27:1638-1643.

10. Armand M, Pasquier B, André M, Borel P, Senft M, Peyrot J, Salducci J, Portugal H, Jaussan V, Lairon D. Digestion and absorption of 2 fat emulsions with different droplet sizes in the human digestive tract. Am J Clin Nutr 1999;70:1096-1106.

11. Geliebter A. Gastric distension and gastric capacity in relation to food intake in humans. Physiol Behav 1988;44:665-668. 


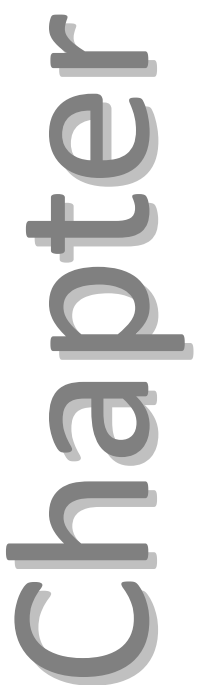

Review article: The gastrointestinal tract: neuroendocrine regulation of satiety and food intake

Maljaars J, Peters HPF, Masclee AAM

Aliment Pharmacol Ther 2007;26 Suppl 2:241-50 


\section{Abstract}

\section{Background}

The gastrointestinal tract elicits numerous signals regulating food intake and satiety, and recently many studies have been performed in order to elucidate the mechanisms regulating these signals.

\section{Aim}

To describe the effects of the gastrointestinal tract on satiety, satiation and food intake.

\section{Method}

A PubMed search was performed to identify and select relevant literature using search terms including 'gastric satiety, intestine + satiety, satiation, cholecystokinin, ghrelin, PYY, GLP-1, ileal brake'.

\section{Results}

Satiation, satiety and food intake result, among other factors, from signals originating in the stomach caused by distension and signals from the small intestine. These intestinal signals result from nutrient sensing in the gut and activate neural and humoral pathways.

Activation of the distal part of the gut, the so called ileal brake, leads to reduction in hunger and food intake, and models of chronic ileal brake activation lead to massive weight loss.

\section{Conclusion}

Gastrointestinal signals are crucial for the regulation of food intake, satiety and satiation. The ileal brake deserves special attention, as both ileal intubation studies and surgical studies demonstrate that activation of the ileal brake reduces food intake. In the surgical models weight loss occurs without adaptation to the anorectic effects of ileal brake activation. 


\section{Background/Aim}

The gastrointestinal tract elicits numerous signals regulating food intake and satiety ${ }^{1}$. Both in the stomach and in the small intestine, the presence of nutrients, through distension of the stomach or by chemical interactions between nutrients and the luminal wall induces the release of satiety signals ${ }^{2-4}$. These signals contribute to the inhibition of food intake. Distension of the stomach by a volume load is able to significantly reduce food intake ${ }^{2,3}$. Exposing the small intestine to nutrients leads to release of gut peptides and neurotransmitters that induce a reduction in hunger levels and food intake ${ }^{4-7}$.

During the process of meal ingestion, some nutrients will already have entered the small intestine and gastric and intestinal satiety signals interact in order to limit meal $\operatorname{size}^{5,8}$, to increase satiation and to increase satiety between meals.

In this review, we will discus the satiety signals from the stomach and the small intestine (with a special focus on the ileum), how both interact to satiation, satiety and food intake and the underlying neuro-endocrine regulation of these signals.

We use 'satiation' to refer to processes that act to reduce or terminate eating within a meal and the (acute) feeling state associated with this. 'Satiety' refers to processes that act to inhibit early post-prandially and/or redue intake at later meals, and the associated feeling state (hunger suppression).

\section{Methods}

Relevant studies were identified by a PubMed search using search terms including 'gastric satiety, intestine satiety, CCK, cholecystokinin, ghrelin, PYY, peptide YY, GLP-1, glucagon-like peptide 1, ileal brake'. Original articles and reviews were selected, and references in these papers were also examined for relevant papers. Where possible, emphasis was given to human studies, but when data was lacking, animal studies were used.

\section{Gastric satiety signals}

Instillation of a volume load in the stomach induces distension of the stomach wall. The satiating effect of distension of the stomach has repeatedly been demonstrated: Feinle et al. used an inflated barostat balloon to demonstrate that a gastric distension increases fullness ${ }^{9}$ and Rigaud et al. and Nieben et al. found that the presence of an inflated gastric balloon in the stomach, as a treatment for obesity, reduced food intake and hunger ${ }^{10,11}$. Geliebter et al. showed that the threshold volume for a gastric balloon to reduce food intake is around $400 \mathrm{ml}^{12}$. These results suggests that a 
volume load by itself is sufficient to induce a gastric satiety signal and reduce food intake and hunger $^{9-12}$. The role of nutrient composition of a gastric volume load in the reduction of food intake and hunger has been studied extensively in rats: Phillips et al. infused either saline or different nutrient solutions into the rat stomach and found that equivalent volumes produce equivalent reductions in food intake, without any effect of the nutritive value of the gastric load ${ }^{2,3}$. However, when this load was allowed to exit the stomach, the nutrient infusions inhibited food intake more potently than the saline infusions ${ }^{2}$. In humans, Goetze et al. found that postprandial hunger and satiety were correlated to postprandial gastric volumes, without significant effects of the nutrient composition of the meal ${ }^{13}$. From these studies one may conclude that gastric satiety is volume-dependent. Although the stomach is able to sense some aspects of the nutrient content of the stomach (for example, to regulate gastrin release), this does not seem to play a role in gastric satiety ${ }^{14}$. Up to $40 \%$ of a meal may have emptied from the stomach into the intestine before the end of meal ingestion occurs ${ }^{8}$ and interaction occurs between gastric and postgastric signals in physiological conditions. Many small intestinal satiety signals induce a delay in gastric emptying, and it is often thought that this inhibition is relevant for prolonging gastric distension ${ }^{15}$.

The role of the vagus nerve in gastric satiety has been studied in rats. Rats with pyloric cuffs underwent either sham vagotomy or total subdiaphragmatic vagotomy. After surgery, rats in both groups were fed 0,5 or $10 \mathrm{ml}$ meals, and the effect of these premeals on food intake was assessed. In the sham-operated group, the $5 \mathrm{ml}$ meal reduced food intake by $60 \%$ compared to the $0 \mathrm{ml}$ meal, and by $80 \%$ in the $10 \mathrm{ml}$ group. In the vagotomy-group, both $5 \mathrm{ml}$ and $10 \mathrm{ml}$ meals reduced food intake by $20 \%$ in either group, demonstrating a central role for the vagal nerve for gastric volumetric satiety $^{3}$. From this and other studies it follows that gastric satiety is predominantly mediated by neural pathways ${ }^{16-18}$.

\section{Intestinal satiety signals}

Exposure of the small intestine to nutrients increases satiety and limits food intake ${ }^{4,6,9}$. This increase in satiety occurs within seconds after the start of the intestinal nutrient infusion, suggesting that at least some of the intestinal satiety signals arise directly from the gut, rather than from post-absorptive nutrient processing ${ }^{14}$. French et al. demonstrated that infusion of certain long chain fat emulsions into the duodenum reduced food intake significantly compared to a saline infusion ${ }^{4}$ and this has also been demonstrated for carbohydrates and protein ${ }^{20}$. In the study by French et al., a 180 kcal infusion of intralipid reduced food intake by over $200 \mathrm{kcal}$, demonstrating that intestinal nutrient infusion is capable of releasing potent satiety signals ${ }^{4}$. 
Gastric emptying of already a small part of a meal will activate duodenal nutritive signals, and from there, gastric volumetric and intestinal nutritive signals cooperate. In rats, gastric infusions of saline reduced food intake, whereas an equal infusion in the duodenum had no effect on food intake ${ }^{3}$. An equivalent volume of $2.5-10 \%$ glucose did reduce food intake when infused into the duodenum, and this reduction in food intake could be enhanced by concomitant infusion of saline into the stomach, showing that combination of gastric and duodenal signals produced an additive inhibition of food intake ${ }^{3}$. In humans, Oesch et al. combined a $300 \mathrm{ml}$ gastric distension prior to a meal with a duodenal infusion of either fat or saline. The distension combined with the saline infusion did not affect hunger, maybe due to a sub threshold volume load ${ }^{12}$, but when this distension was combined with a duodenal fat infusion, a decrease in hunger was observed. Food intake is significantly reduced by fat infusion, independent of the presence or absence of a distension ${ }^{21}$. A gastric distension up to $600 \mathrm{ml}$ was necessary in order to reduce hunger without fat infusion, while the fat infusion lowered the distension threshold profoundly.

Similarly, Feinle et al. have shown that gastric distension-induced satiety scores were increased by a concomitant duodenal nutrient infusions ${ }^{9,22}$, and subjects stated that adding a $20 \%$ lipid or maltodextrose infusion to the distension made the satiety sensation more meal-like ${ }^{22}$. These studies are examples of how the stomach and the small intestine interact in order to limit food intake and reduce hunger feelings ${ }^{21}$.

While gastric satiety is of mechanical origin (volume-dependent), intestinal satiety is typically nutrient-dependent: the satiety signals are released upon interaction between the gut wall and nutrients ${ }^{3}$. Exposure of the small intestine to nutrients increases vagal afferent firing, and it is suggested that this is the case in intestinemediated satiety ${ }^{23-25}$. Intestinal nutrient exposure induces release of $5 \mathrm{HT}$, a neurotransmitter, and Ondansetron, a $5 \mathrm{HT}_{3}$ receptor antagonist, has been shown to attenuate the inhibitory effects of intraduodenal Intralipid on food intake in rats ${ }^{7}$. Direct vagal activation by intestinal nutrients may therefore be mediated by $5 \mathrm{HT}_{3}$.

Exposure of the intestinal mucosa to nutrients also induces release of many gut peptides and after release, these peptides either enter the bloodstream to function as a hormone, or they activate neural pathways ${ }^{14}$. Many of these gut peptides delay gastric emptying, thereby contributing to prolonged distension of the stomach, satiety and subsequently to meal termination. Regional differences exist in the release of gut peptides (Figure 2.1, Table 2.1): in the duodenum and jejunum, exposure of the gut wall to fat and protein results in the release of CCK, whereas in the distal small intestine, the presence of nutrients induces the release of GLP-1, oxyntomodulin and $\mathrm{PYY}^{14}$. 


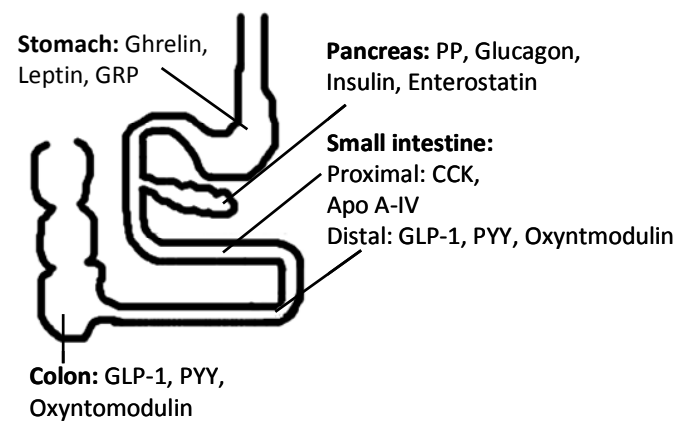

Figure 2.1 Principal site of secretion of gut peptides involved in regulation of eating behaviour.

Table 2.1 Gut peptides involved in satiety.

\begin{tabular}{llc}
\hline Peptide & Location of release & Food intake \\
\hline Cholecystokinin & Proximal intestine, I-cells & $\downarrow$ \\
Glucagon-like peptide 1 & Distal intestine, L-cells & $\downarrow$ \\
Peptide YY & Distal intestine, L-cells & $\downarrow$ \\
Oxyntomodulin & Distal intestine, L-cells & $\downarrow$ \\
Enterostatin & Exocrine pancreas & $\downarrow$ \\
Apolipoprotein A-IV & Intestinal epithelium & $\downarrow$ \\
Pancreatic peptide & Pancreatic F-cells & $\downarrow$ \\
Amylin & Pancreatic b-cells & $\downarrow$ \\
GRP, NMB & Gastric myenteric plexus & $\downarrow$ \\
Leptin & Gastric chief and P cells & $\downarrow$ \\
Ghrelin & Gastric X/A like cells & $\uparrow$ \\
\hline
\end{tabular}

GRP, gastrin-releasing peptide; NMB, neuromedin B.

\section{Proximal small intestine: Cholecystokinin (CCK)}

CCK has been widely studied as satiety signal ${ }^{1,26,27}$. CCK is released from intestinal Icells in the duodenal and jejunal mucosa in response to the intraluminal presence of digestion products of fat and protein in the small intestine. Various biological forms of CCK exist, classified according to the number of amino acids they contain ${ }^{28,29}$. In humans, the main circulating forms are CCK-8, CCK-22, CCK-33 and CCK-58 ${ }^{30}$. Two types of CCK receptors have been identified: The alimentary CCK-1 receptor (CCK1R) mediates gall bladder contraction, relaxation of the sphincter of Oddi, pancreatic growth and enzyme secretion, delay of gastric emptying and inhibition of gastric acid secretion $^{31}$. The CCK-2 receptor (CCK2R) is the predominant CCK receptor in the brain, although the CCK1R has also been demonstrated in the hindbrain and the hypothalamus ${ }^{31}$. 
Gibbs et al. demonstrated in rats that administration of CCK-8 induced a dosedependent reduction in both the size and duration of a meal ${ }^{27}$. In humans, Kissileff et al. were the first to demonstrate that intravenous administration of CCK- 8 reduces food intake and hunger in humans ${ }^{32}$. Following a $216 \mathrm{kcal}$ preload, intravenous infusion of CCK- 8 reduced ad libitum food intake by $19 \%$ when compared to a saline infusion $^{32}$. These results have been confirmed by several investigators ${ }^{33-36}$. Lieverse et al. demonstrated a decrease of $19 \%$ in food intake after intravenous infusion of CCK$33^{37}$. However, the effect of CCK-infusion on food intake is short-lasting: when the interval between the infusion and the start of the test meal is over 30 minutes, no anorexic effect will be observed ${ }^{14}$.

The role of endogenous CCK in the regulation of food intake has been studied with the specific CCK-1 receptor (CCK1R) antagonist loxiglumide. Intravenous infusion of loxiglumide attenuated the inhibitory effects of an intraduodenal fat infusion on subsequent energy intake ${ }^{38}$ and reduced satiety in humans ${ }^{39}$, whereas a CCK-2 receptor antagonist did not ${ }^{40}$.

After release, CCK activates CCK1R on gastric and duodenal vagal afferents. These vagal afferents transmit the signal to the nucleus of the solitary tract (NTS) and area postrema (AP) in the hindbrain, from where it is relayed to the hypothalamus ${ }^{31}$. Vagotomy has been shown to attenuate the anorexic effects of peripheral CCKadministration ${ }^{41}$, demonstrating a crucial vagal pathway for CCK-mediated satiation.

Gastric and intestinal satiety signals interact to reduce hunger. Regarding CCK, an intestinal satiety signal, it has been shown that the satiating effect of intravenous CCK infusion is enhanced by concomitant gastric distension. Intravenous CCK-infusion combined with a $300 \mathrm{ml}$ gastric balloon distension resulted in a stronger reduction in food intake compared to either CCK or distension alone ${ }^{36}$. Furthermore, the CCK induced dorsal vagal complex (DVC) activity was increased by concomitant gastric distension, indicating a stronger anorexic effect ${ }^{42,43}$.

\section{Proximal small intestine: Ghrelin}

Ghrelin, an acylated peptide hormone was first discovered by Kojima et al. $^{44}$. Two/thirds of circulating ghrelin is produced by X/A-like cells in the gastric oxyntic mucosa, and most of the remainder originates in X/A-like cells of the small intestine. Gastrectomy results in a decrease in plasma ghrelin concentrations of $75 \%{ }^{45}$. Ghrelin is also produced in other organs, such as pancreas, thyroid, adrenal, pituitary, hypothalamus, kidney, heart, lung and etc., but in much lower amounts than in the stomach $^{46}$.

In humans, energy intake was increased by $28 \%$, and hunger increased significantly in response to the ghrelin infusion ${ }^{47}$. Administration of ghrelin stimulates gastric emptying and small bowel transit. 
Ghrelin plasma concentrations peak before a meal and decrease postprandially, in response to nutrient ingestion ${ }^{48}$. The pre-meal increase in ghrelin-concentrations implicates a role for ghrelin in mealtime hunger and meal initiation, as a signal for energy depletion ${ }^{48}$. However, a recent study by Drazen et al. showed that when rats were forced to eat larger meals, this resulted in an increase in the pre-prandial ghrelin peak. These findings demonstrate that conditioning, and not just energy depletion, plays a role in pre-meal increases in ghrelin concentrations ${ }^{49}$. In line with other observations, during a $24 \mathrm{~h}$ fast, ghrelin concentrations increased before and decreased after the time points of customary meals, pointing to a conditioned pattern $^{50}$. It is therefore uncertain whether these pre-prandial increases reflect the need for food by the body, resulting in increased hunger and ingestion, or that these increases are not related to pre-meal hunger but reflect a preparatory response in order to facilitate the subsequent digestion, absorption and metabolism of the upcoming meal ${ }^{51}$.

At least two mechanisms have been proposed to explain the decrease in ghrelin concentrations. First, as mentioned above, when fasting, ghrelin concentrations decreased in the absence of a meal, and this is probably mediated by cephalic neural mechanisms ${ }^{52}$. Second, the postprandial decrease in ghrelin concentrations is related to the ingested caloric load ${ }^{53}$, with fat being less potent than either carbohydrates or proteins $^{51,54}$. However, the mechanism regulating this decrease in ghrelin concentrations is not fully understood. While the majority two/thirds of circulating ghrelin is produced in the stomach ${ }^{46}$, stomach content does not play a role in the regulation of ghrelin concentrations, since intestinal infusion of nutrients also results in a decrease in plasma ghrelin concentrations ${ }^{54}$, while inhibition of intestinal exposure by a pylorus-occluding cuff in rats did not affect ghrelin levels ${ }^{55}$. Whether small intestinal exposure to nutrients has a direct effect, as suggested by Caixas et al. $^{56}$, or influences ghrelin concentrations via insulin release ${ }^{57-59}$ remains to be determined.

Several gut peptides, such as PYY, GIP, GLP-1, Somatostatin, CCK but also the vagal nerve influence plasma ghrelin concentrations, and may therefore have a role in the physiological regulation of ghrelin concentrations ${ }^{52}$.

The orexogenic effect of ghrelin requires an intact vagal nerve: patients who underwent vagotomy did not demonstrate an increase in energy intake after intravenous administration of ghrelin ${ }^{60}$.

\section{Distal small intestine: GLP-1}

GLP-1 is released from enteroendocrine L-cells in the distal small intestine, in response to exposure of the gut wall to especially fat and carbohydrates ${ }^{61}$. Secretion not only occurs when nutrients are present in the lumen of the distal small intestine, 
but also from the duodenum by an indirect neurohumoral pathway involving the autonomous nervous system, Gastrin Releasing Peptide and acetylcholine ${ }^{62}$.

Infusion of GLP-1 results in a dose-dependent reduction in food intake and elicits satiety in normal weight, obese and diabetic humans ${ }^{63}$. Apart from the effects on food intake, GLP-1 increases glucose-dependent insulin-secretion, reduces glucagonsecretion and increases pancreatic $\beta$-cell growth ${ }^{61}$. GLP-1 mimetics are therefore being developed for the treatment of diabetes. Diabetic patients treated with GLP-1 or the GLP-1 receptor agonist exenatide experienced progressive weight loss in trials lasting up to two years ${ }^{14,64}$. A 14 week trial with a long-acting GLP-1 analogue resulted in significant weight loss compared to placebo $^{65}$, and this might be due to a decrease in appetite ${ }^{64}$. A recent meta-analysis showed that administration of GLP-1 resulted in a reduction of food intake by an average $11 \%{ }^{63}$.

Degen et al. demonstrated that the anorexic effect of GLP-1 could be increased by a $400 \mathrm{ml}(225 \mathrm{kcal})$ protein drink, but not by $400 \mathrm{ml}$ water administered 20 minutes prior to the test meal ${ }^{66}$. As the authors did not measure gastric distension or gastric emptying, it is impossible to determine whether this reduced appetite is due to a nutrient-specific effect of gastric distension or due to duodenal exposure to nutrients. Since gastric satiety signals are considered to be mechanical rather than nutritive, an additional duodenal signal is more likely to explain the additional anorectic effect. This study clearly demonstrated that GLP-1 interacts with gastric or duodenal satiety signals to increase satiety and reduce food intake ${ }^{66}$.

The mechanisms resulting in the anorexic effect of GLP-1 are not fully understood. A crucial ole for the vagus nerve was demonstrated in rodents, where vagotomy abolished the anorexic effect of peripheral GLP-1 administration ${ }^{67}$. Reduction of food intake by GLP-1 is mediated by the GLP-1 receptor (GLP1R), as a GLP1R knock-out mouse did not demonstrate a reduction in food intake ${ }^{68}$. This receptor can be found in the gut, pancreas, brainstem, hypothalamus and vagal-afferent nerves ${ }^{61}$.

As long-term administration of GLP-1 reduces food intake and hunger, and improves glucose control, increasing endogenous GLP-1-release by specific food products is therefore an interesting target.

\section{Distal small intestine:PYY}

PYY is co-secreted with GLP-1 by enteroendocrine L-cells in the distal small intestine. It is released postprandially in proportion to the amount of ingested calories, with fat being the most potent macronutrient, followed by carbohydrates, followed by proteins $^{69}$. Direct exposure of the distal small intestine to nutrients will release PYY, but an indirect neurohumoral pathway from the proximal small intestine to the distal small intestine also exists ${ }^{70,71}$. PYY is released as $\mathrm{PYY}_{1-36}$, and rapidly cleaved by DPP4 into the active form of PYY, PYY ${ }_{3-36}{ }^{69}$. 
Batterham et al. demonstrated that intravenous infusion of $\mathrm{PYY}_{3-36}$ significantly reduced energy intake by $33 \%$ over a $24 \mathrm{~h}_{\text {period }}{ }^{72}$. Degen et al. have questioned the role of PYY as a physiological mediator of satiety. These investigators found that during infusion, PYY $_{3-36}$ was able to reduce energy intake, but only at PYY-levels that were higher than they observed after a $1500 \mathrm{kcal}$ meal, and therefore should be considered as supraphysiological ${ }^{73}$. One study even failed to demonstrate any anorexic effect of PYY administration ${ }^{74}$. In humans, a significant reduction in food intake is observed only at supraphysiological plasma PYY concentrations, and adverse events that may influence food intake such as nausea and abdominal discomfort are frequently observed ${ }^{73,75}$. For instance, in a recent study, five of nine participants failed to complete the $\mathrm{PYY}_{3-36}$ infusion protocol, due to severe malaise ${ }^{75}$. These results have prompted some pharmaceutical companies to stop the clinical development of intranasal PYY3-36 because of insufficient efficacy ${ }^{14}$.

We have previously conducted a study in which we compared the effects of intestinal fat infusion to intravenous PYY infusion. At PYY-concentrations that were similar after intravenous infusion and after intestinal fat, the effects on satiety after the intestinal fat infusion were much more pronounced ${ }^{19}$.

Batterham et al. have demonstrated a reduction in energy intake and resulted weight loss in mice ${ }^{72}$. Although several investigators have not been able to reproduce and confirm these results ${ }^{74,76}$, the current consensus is that in rodents, PYY is a potent anorexic agent and long-term administration leads to significant weight loss ${ }^{77,78}$.

The anorectic effects of $\mathrm{PYY}_{3-36}$ are thought to be mediated by the Y2-receptor in the hypothalamic arcuate nucleus, and this receptor may be directly accessible via the bloodstream ${ }^{14}$. However, vagotomy abolished the anorectic effects of peripheral PYY administration, suggesting a role for the vagus nerve ${ }^{67,79}$.

\section{Ileal brake and satiety}

Studies in animals have clearly demonstrated that the reduction in food intake is larger when the distal in stead of the proximal half of the small intestine is exposed to nutrients ${ }^{80}$. In the ileum, exposure of the gut mucosa to especially fat and carbohydrates activates the ileal brake $e^{40,81,82}$. The ileal brake is a negative feedback mechanism that potently inhibits gastric emptying and small intestinal transit (Figure 2.2) ${ }^{83}$. Furthermore, activation of the ileal brake results in a reduction in gastric acidsecretion, pancreatic enzyme secretion, and bile acid secretion ${ }^{84-86}$.

Welch et al. were the first to demonstrate the potent anorexic effects of ileal brake activation in humans ${ }^{87,87-89}$. Perfusing the ileum with $370 \mathrm{kcal}$ corn oil emulsion resulted in a $575 \mathrm{kcal}$ reduction in energy intake, demonstrating a net reduction of $205 \mathrm{kcal}$ (88). In a subsequent study, they compared an ileal and a jejunal fat infusion 
to a control infusion, and found that the jejunal infusion induced the largest reduction in energy intake ${ }^{87}$. It should be noticed that these infusions were at high supraphysiological rates. During the jejunal infusion, fat may also have activated ileal receptors, thereby explaining the increased potency of the jejunal infusion to reduce food intake ${ }^{87}$. Our group recently conducted a study comparing the effects of duodenal and ileal infusion of fat on satiety levels, and found that the reduction in hunger levels was significantly larger after the ileal compared to the duodenal fat infusion $^{90}$.

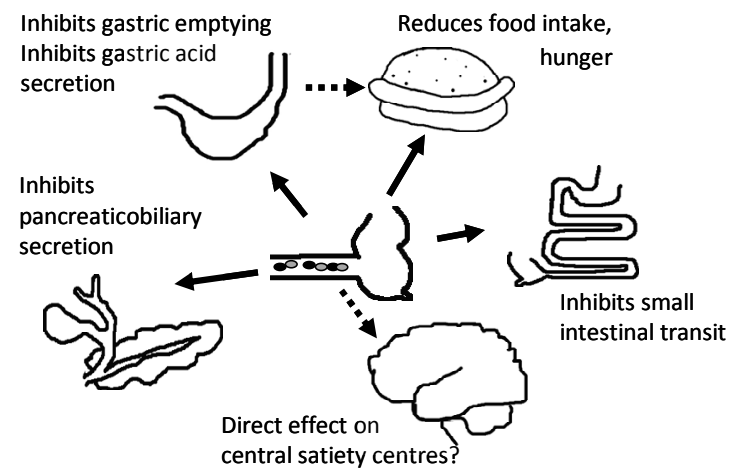

Figure 2.2 Effects of ileal brake activation.

These studies have employed ileal intubation techniques in order to expose the ileum to increased amounts of nutrients, resulting in ileal brake activation. However, surgical techniques provide excellent examples of the effects of chronic ileal brake activation on food intake and satiety. The jejuno-ileal bypass (JIB) is a procedure in which the proximal part of the jejunum is anastomosed to the distal part of the ileum $^{91}$. This surgical procedure has been introduced as a treatment for massive obesity $^{92}$. First, the mechanism resulting in weight loss was thought to be malabsorption. Condon et al. demonstrated that malabsorption could only account for $22 \%$ of weight loss, therefore other mechanisms must be involved ${ }^{93-95}$. Jejuno-ileal bypass results in rapid transit of nutrients to the distal intestine, with increased exposure of the ileum to nutrients ${ }^{96}$. Postoperatively, ad libitum food intake decreases ${ }^{94,95 ; 97}$. Bray et al. found that, compared to presurgical energy intake, energy intake was decreased with $80 \%$ at 1 month and with $45 \%$ at 12 months after jejunoileal bypass ${ }^{95}$. Naslund et al found a decrease of $13 \%$ nine months after jejuno-ileal bypass $^{97}$. As jejuno-ileal bypass can lead to diarrhoea, psychological factors have also 
been suggested as an additional cause for this reduction in food intake ${ }^{98}$, but more importantly, both GLP-1 and PYY levels are increased after jejuno-ileal bypass compared to pre- jejuno-ileal bypass levels ${ }^{99}$. The chronically increased PYY and GLP-1 concentration may account for the reduction in food intake and weight loss ${ }^{99}$.

Which neural or hormonal mechanisms mediate the ileal brake is not exactly known. As the effects of an ileal infusion on pancreatic enzyme secretion could be abolished by infusion of a specific GLP1R-antagonist, GLP-1 is thought to play an important role in the ileal brake ${ }^{100}$. Pironi et al. and Spiller et al. found that PYY correlated with changes in gastrointestinal motility, indicating a role for PYY in the ileal brake ${ }^{82,101}$. Therefore, PYY and GLP-1 are both considered mediatory peptides for ileal brakeactivation $^{61,102}$. Furthermore, Lin et al. have demonstrated that different neural mechanisms are involved in mediating the different effects of ileal brakeactivation $^{71,83,103,104}$.

The results from these surgical models demonstrate that no compensating behaviors on intake occur in response to the anorectic effects of chronic ileal brake activation. Therefore, we consider the ileal brake to be an excellent and promising target for the development of food products aimed a reducing food intake and hunger feelings.

\section{Conclusion}

The satiety signals that are derived from the stomach and the small intestine have been reviewed with special emphasis on their interaction in the reduction in hunger and food intake. Activation of the ileal brake significantly increases satiation and satiety, and reduces food intake. Surgical procedures that lead to increased exposure of the ileum to ingested nutrients confirm these results and indicate that adaptation to the anorectic effects of ileal brake activation does not occur, not even in the long term follow up..

The gastrointestinal tract is host to many signals that affect satiety and food intake. The ileal brake is considered an interesting target when designing products or procedures able to reduce food intake and produce weight loss. Not only studies using ileal delivery of nutrients via oro-ileal but also from studies on surgical models it has become apparent that activation of the ileal brake leads to a reduction in food intake, weight loss, without long term adaptation to these anorectic effects. 


\section{References}

1. Woods SC. Gastrointestinal satiety signals I. An overview of gastrointestinal signals that influence food intake. Am J Physiol Gastrointest Liver Physiol 2004;286:G7-13.

2. Phillips RJ, Powley TL. Gastric volume rather than nutrient content inhibits food intake. Am J Physiol 1996;271:R766-R769.

3. Powley TL, Phillips RJ. Gastric satiation is volumetric, intestinal satiation is nutritive. Physiol Behav 2004;82:69-74.

4. French SJ, Conlon CA, Mutuma ST, Arnold M, Read NW, Meijer G, Francis J. The effects of intestinal infusion of long-chain fatty acids on food intake in humans. Gastroenterology 2000;119:943-948.

5. Aja S. Serotonin-3 receptors in gastric mechanisms of cholecystokinin-induced satiety. Am J Physiol Regul Integr Comp Physiol 2006;291:R112-R114.

6. Lieverse RJ, Jansen JB, Masclee AA, Rovati LC, Lamers CB. Effect of a low dose of intraduodenal fat on satiety in humans: studies using the type $A$ cholecystokinin receptor antagonist loxiglumide. Gut 1994;35:501-505.

7. Savastano DM, Hayes MR, Covasa M. Serotonin-type 3 receptors mediate intestinal lipid-induced satiation and Fos-like immunoreactivity in the dorsal hindbrain. Am J Physiol Regul Integr Comp Physiol 2007;292:R1063-R1070.

8. Kaplan JM, Spector AC, Grill HJ. Dynamics of gastric emptying during and after stomach fill. Am J Physiol 1992;263:R813-R819.

9. Feinle C, Christen M, Grundy D, Faas H, Meier O, Otto B, Fried M. Effects of duodenal fat, protein or mixed-nutrient infusions on epigastric sensations during sustained gastric distension in healthy humans. Neurogastroenterol Motil 2002;14:205-213.

10. Rigaud D, Trostler N, Rozen R, Vallot T, Apfelbaum M. Gastric distension, hunger and energy intake after balloon implantation in severe obesity. Int J Obes Relat Metab Disord 1995;19:489-495.

11. Nieben OG, Harboe H. Intragastric balloon as an artificial bezoar for treatment of obesity. Lancet 1982;1:198-199.

12. Geliebter A. Gastric distension and gastric capacity in relation to food intake in humans. Physiol Behav 1988;44:665-668.

13. Goetze O, Steingoetter A, Menne D, van der Voort IR, Kwiatek MA, Boesiger P, Weishaupt D, Thumshirn M, Fried M, Schwizer W. The effect of macronutrients on gastric volume responses and gastric emptying in humans: A magnetic resonance imaging study. Am J Physiol Gastrointest Liver Physiol 2007;292:G11-G17.

14. Cummings DE, Overduin J. Gastrointestinal regulation of food intake. J Clin Invest 2007;117:13-23.

15. Clarkston WK, Pantano MM, Morley JE, Horowitz M, Littlefield JM, Burton FR. Evidence for the anorexia of aging: gastrointestinal transit and hunger in healthy elderly vs. young adults. Am J Physiol 1997;272:R243-R248.

16. Schwartz GJ, Salorio CF, Skoglund C, Moran TH. Gut vagal afferent lesions increase meal size but do not block gastric preload-induced feeding suppression. Am J Physiol 1999;276:R1623-R1629.

17. Schwartz GJ. The role of gastrointestinal vagal afferents in the control of food intake: current prospects. Nutrition 2000;16:866-873.

18. Ritter RC. Gastrointestinal mechanisms of satiation for food. Physiol Behav 2004;81:249-273.

19. Vu MK, Maljaars J.W., Biemond I, Mearadji B, Masclee AA. Role of Peptide YY in ileal brake induced satiety and proximal gastric function. Gastroenterology 2006;130(S2):A68.

20. French SJ. The effects of specific nutrients on the regulation of feeding behaviour in human subjects. Proc Nutr Soc 1999;58:533-539.

21. Oesch S, Ruegg C, Fischer B, Degen L, Beglinger C. Effect of gastric distension prior to eating on food intake and feelings of satiety in humans. Physiol Behav 2006;87:903-910.

22. Feinle C, Grundy D, Read NW. Effects of duodenal nutrients on sensory and motor responses of the human stomach to distension. Am J Physiol 1997;273:G721-G726. 
23. Cox JE, Kelm GR, Meller ST, Randich A. Suppression of food intake by GI fatty acid infusions: roles of celiac vagal afferents and cholecystokinin. Physiol Behav 2004;82:27-33.

24. Cox JE, Kelm GR, Meller ST, Spraggins DS, Randich A. Truncal and hepatic vagotomy reduce suppression of feeding by jejunal lipid infusions. Physiol Behav 2004;81:29-36.

25. Cox JE, Tyler WJ, Randich A, Kelm GR, Meller ST. Celiac vagotomy reduces suppression of feeding by jejunal fatty acid infusions. Neuroreport 2001;12:1093-1096.

26. Gibbs J, Young RC, Smith GP. Cholecystokinin elicits satiety in rats with open gastric fistulas. Nature 1973;245:323-325.

27. Gibbs J, Young RC, Smith GP. Cholecystokinin decreases food intake in rats. J Comp Physiol Psychol 1973;84:488-495.

28. Rehfeld JF. Four basic characteristics of the gastrin-cholecystokinin system. Am J Physiol 1981; 240:G255-G266.

29. Eberlein GA, Eysselein VE, Davis MT, Lee TD, Shively JE, Grandt D, Niebel W, Williams R, Moessner J, Zeeh J. Patterns of prohormone processing. Order revealed by a new procholecystokinin-derived peptide. J Biol Chem 1992;267: 1517-1521.

30. Rehfeld JF, Sun G, Christensen T, Hillingso JG. The predominant cholecystokinin in human plasma and intestine is cholecystokinin-33. J Clin Endocrinol Metab 2001;86:251-258.

31. Rehfeld JF. Clinical endocrinology and metabolism. Cholecystokinin. Best Pract Res Clin Endocrinol Metab 2004;18:569-586.

32. Kissileff HR, Pi-Sunyer FX, Thornton J, Smith GP. C-terminal octapeptide of cholecystokinin decreases food intake in man. Am J Clin Nutr 1981;34:154-160.

33. Lieverse RJ, Jansen JB, Masclee AM, Lamers CB. Satiety effects of cholecystokinin in humans. Gastroenterology 1994;106:1451-1454.

34. Pi-Sunyer X, Kissileff HR, Thornton J, Smith GP. C-terminal octapeptide of cholecystokinin decreases food intake in obese men. Physiol Behav 1982;29:627-630.

35. Muurahainen N, Kissileff HR, Derogatis AJ, Pi-Sunyer FX. Effects of cholecystokinin-octapeptide (CCK8) on food intake and gastric emptying in man. Physiol Behav 1988;44:645-649.

36. Kissileff HR, Carretta JC, Geliebter A, Pi-Sunyer FX. Cholecystokinin and stomach distension combine to reduce food intake in humans. Am J Physiol Regul Integr Comp Physiol 2003;285:R992-R998.

37. Lieverse RJ, Jansen JB, Masclee AA, Lamers CB. Satiety effects of a physiological dose of cholecystokinin in humans. Gut 1995;36:176-179.

38. Matzinger D, Gutzwiller JP, Drewe J, Orban A, Engel R, D'Amato M, Rovati L, Beglinger C. Inhibition of food intake in response to intestinal lipid is mediated by cholecystokinin in humans. Am J Physiol 1999;277:R1718-R1724.

39. Beglinger C, Degen L, Matzinger D, D'Amato M, Drewe J. Loxiglumide, a CCK-A receptor antagonist, stimulates calorie intake and hunger feelings in humans. Am J Physiol Regul Integr Comp Physiol 2001;280:R1149-R1154.

40. Spiller RC, Trotman IF, Higgins BE, Ghatei MA, Grimble GK, Lee YC, Bloom SR, Misiewicz JJ, Silk DB. The ileal brake--inhibition of jejunal motility after ileal fat perfusion in man. Gut 1984;25:365-374.

41. Joyner K, Smith GP, Gibbs J. Abdominal vagotomy decreases the satiating potency of CCK-8 in sham and real feeding. Am J Physiol 1993;264:R912-R916.

42. Hayes MR, Covasa M. Dorsal hindbrain 5-HT3 receptors participate in control of meal size and mediate CCK-induced satiation. Brain Res 2006;1103:99-107.

43. van de Wall EH, Duffy P, Ritter RC. CCK enhances response to gastric distension by acting on capsaicin-insensitive vagal afferents. Am J Physiol Regul Integr Comp Physiol 2005;289:R695-R703.

44. Kojima M, Hosoda H, Date Y, Nakazato M, Matsuo H, Kangawa K. Ghrelin is a growth-hormonereleasing acylated peptide from stomach. Nature 1999;402:656-660.

45. Jeon TY, Lee S, Kim HH, Kim YJ, Son HC, Kim DH, Sim MS. Changes in plasma ghrelin concentration immediately after gastrectomy in patients with early gastric cancer. J Clin Endocrinol Metab 2004; 89:5392-5396.

46. Leite-Moreira AF, Soares JB. Physiological, pathological and potential therapeutic roles of ghrelin. Drug Discov Today 2007;12:276-288. 
47. Wren AM, Seal LJ, Cohen MA, Brynes AE, Frost GS, Murphy KG, Dhillo WS, Ghatei MA, Bloom SR. Ghrelin enhances appetite and increases food intake in humans. J Clin Endocrinol Metab 2001;86:5992.

48. Cummings DE, Purnell JQ, Frayo RS, Schmidova K, Wisse BE, Weigle DS. A preprandial rise in plasma ghrelin levels suggests a role in meal initiation in humans. Diabetes 2001;50:1714-1719.

49. Drazen DL, Vahl TP, D'Alessio DA, Seeley RJ, Woods SC. Effects of a fixed meal pattern on ghrelin secretion: evidence for a learned response independent of nutrient status. Endocrinology 2006; 147:23-30.

50. Natalucci G, Riedl S, Gleiss A, Zidek T, Frisch H. Spontaneous 24-h ghrelin secretion pattern in fasting subjects: maintenance of a meal-related pattern. Eur J Endocrinol 2005;152:845-850.

51. Teff K. Learning hunger: conditioned anticipatory ghrelin responses in energy homeostasis. Endocrinology 2006;147:20-22.

52. Higgins SC, Gueorguiev M, Korbonits M. Ghrelin, the peripheral hunger hormone. Ann Med 2007; 39:116-136.

53. Callahan HS, Cummings DE, Pepe MS, Breen PA, Matthys CC, Weigle DS. Postprandial suppression of plasma ghrelin level is proportional to ingested caloric load but does not predict intermeal interval in humans. J Clin Endocrinol Metab 2004;89:1319-1324.

54. Overduin J, Frayo RS, Grill HJ, Kaplan JM, Cummings DE. Role of the duodenum and macronutrient type in ghrelin regulation. Endocrinology 2005;146:845-850.

55. Williams DL, Cummings DE, Grill HJ, Kaplan JM. Meal-related ghrelin suppression requires postgastric feedback. Endocrinology 2003;144:2765-2767.

56. Caixas A, Bashore C, Nash W, Pi-Sunyer F, Laferrere B. Insulin, unlike food intake, does not suppress ghrelin in human subjects. J Clin Endocrinol Metab 2002;87:1902.

57. Saad MF, Bernaba B, Hwu CM, Jinagouda S, Fahmi S, Kogosov E, Boyadjian R. Insulin regulates plasma ghrelin concentration. J Clin Endocrinol Metab 2002;87:3997-4000.

58. Murdolo G, Lucidi P, Di Loreto C, Parlanti N, De Cicco A, Fatone C, Fanelli CG, Bolli GB, Santeusanio F, De Feo P. Insulin is required for prandial ghrelin suppression in humans. Diabetes 2003;52:2923-2927.

59. Leonetti F, lacobellis G, Ribaudo MC, Zappaterreno A, Tiberti C, lannucci CV, Vecci E, Di Mario U. Acute insulin infusion decreases plasma ghrelin levels in uncomplicated obesity. Regul Pept 2004;122:179-183.

60. le Roux CW, Neary NM, Halsey TJ, Small CJ, Martinez-Isla AM, Ghatei MA, Theodorou NA, Bloom SR. Ghrelin does not stimulate food intake in patients with surgical procedures involving vagotomy. J Clin Endocrinol Metab 2005;90:4521-4524.

61. Schirra J, Goke B. The physiological role of GLP-1 in human: incretin, ileal brake or more? Regul Pept 2005;128:109-115.

62. Brubaker PL, Anini Y. Direct and indirect mechanisms regulating secretion of glucagon-like peptide-1 and glucagon-like peptide-2. Can J Physiol Pharmacol 2003;81:1005-1012.

63. Verdich C, Flint A, Gutzwiller JP, Näslund E, Beglinger C, Hellström PM, Long SJ, Morgan LM, Holst JJ, Astrup A. A meta-analysis of the effect of glucagon-like peptide-1 (7-36) amide on ad libitum energy intake in humans. J Clin Endocrinol Metab 2001;86:4382-4389.

64. Zander M, Madsbad S, Madsen JL, Holst JJ. Effect of 6-week course of glucagon-like peptide 1 on glycaemic control, insulin sensitivity, and beta-cell function in type 2 diabetes: a parallel-group study. Lancet 2002;359:824-830.

65. Vilsbøll T, Zdravkovic M, Le-Thi T, Krarup T, Schmitz O, Courrèges JP, Verhoeven R, Bugánová I, Madsbad S. Liraglutide, a long-acting human glucagon-like peptide-1 analog, given as monotherapy significantly improves glycemic control and lowers body weight without risk of hypoglycemia in patients with type 2 diabetes. Diabetes Care 2007;30:1608-1610.

66. Degen L, Oesch S, Matzinger D, Drewe J, Knupp M, Zimmerli F, Beglinger C. Effects of a preload on reduction of food intake by GLP-1 in healthy subjects. Digestion 2006;74:78-84. 
67. Abbott CR, Monteiro M, Small CJ, Sajedi A, Smith KL, Parkinson JR, Ghatei MA, Bloom SR. The inhibitory effects of peripheral administration of peptide $Y Y(3-36)$ and glucagon-like peptide-1 on food intake are attenuated by ablation of the vagal-brainstem-hypothalamic pathway. Brain Res 2005;1044:127-131.

68. Baggio LL, Huang Q, Brown TJ, Drucker DJ. Oxyntomodulin and glucagon-like peptide-1 differentially regulate murine food intake and energy expenditure. Gastroenterology 2004;127:546-558.

69. Onaga T, Zabielski R, Kato S. Multiple regulation of peptide $\mathrm{YY}$ secretion in the digestive tract. Peptides 2002;23:279-290.

70. Lin HC, Chey WY, Zhao X. Release of distal gut peptide YY (PYY) by fat in proximal gut depends on CCK. Peptides 2000;21:1561-1563.

71. Lin HC, Taylor IL. Release of peptide YY by fat in the proximal but not distal gut depends on an atropine-sensitive cholinergic pathway. Regul Pept 2004;117:73-76.

72. Batterham RL, Cowley MA, Small CJ, Herzog H, Cohen MA, Dakin CL, Wren AM, Brynes AE, Low MJ, Ghatei MA, Cone RD, Bloom SR. Gut hormone PYY(3-36) physiologically inhibits food intake. Nature 2002;418:650-654.

73. Degen L, Oesch S, Casanova M, Graf S, Ketterer S, Drewe J, Beglinger C. Effect of peptide YY3-36 on food intake in humans. Gastroenterology 2005;129:1430-1436.

74. Sloth B, Davidsen L, Holst JJ, Flint A, Astrup A. Effect of subcutaneous injections of PYY1-36 and PYY336 on appetite, ad libitum energy intake, and plasma free fatty acid concentration in obese males. Am J Physiol Endocrinol Metab. 2007;293:E604-9..

75. Sloth B, Holst JJ, Flint A, Gregersen NT, Astrup A. Effects of PYY1-36 and PYY3-36 on appetite, energy intake, energy expenditure, glucose and fat metabolism in obese and lean subjects. Am J Physiol Endocrinol Metab 2007;292:E1062-E1068.

76. Boggiano MM, Chandler PC, Oswald KD, Rodgers RJ, Blundell JE, Ishii Y, Beattie AH, Holch $P$, Allison DB, Schindler M, Arndt K, Rudolf K, Mark M, Schoelch C, Joost HG, Klaus S, Thöne-Reineke C, Benoit SC, Seeley RJ, Beck-Sickinger AG, Koglin N, Raun K, Madsen K, Wulff BS, Stidsen CE, Birringer M, Kreuzer OJ, Deng XY, Whitcomb DC, Halem H, Taylor J, Dong J, Datta R, Culler M, Ortmann S, Castañeda TR, Tschöp M. PYY3-36 as an anti-obesity drug target. Obes Rev 2005;6:307-322.

77. Chelikani PK, Haver AC, Reeve JR Jr, Keire DA, Reidelberger RD. Daily, Intermittent Intravenous Infusion of Peptide YY(3-36) Reduces Daily Food Intake and Adiposity in Rats. Am J Physiol Regul Integr Comp Physiol 2006;290:R298-305.

78. Abbott CR, Small CJ, Sajedi A, Smith KL, Parkinson JR, Broadhead LL, Ghatei MA, Bloom SR. The importance of acclimatisation and habituation to experimental conditions when investigating the anorectic effects of gastrointestinal hormones in the rat. Int J Obes (Lond) 2006;30:288-292.

79. Koda S, Date Y, Murakami N, Shimbara T, Hanada T, Toshinai K, Niijima A, Furuya M, Inomata N, Osuye K, Nakazato $M$. The role of the vagal nerve in peripheral PYY3-36-induced feeding reduction in rats. Endocrinology 2005;146:2369-2375.

80. Meyer JH, Elashoff JD, Doty JE, Gu YG. Disproportionate ileal digestion on canine food consumption. A possible model for satiety in pancreatic insufficiency. Dig Dis Sci 1994;39:1014-1024.

81. Read NW, McFarlane A, Kinsman RI, Bates TE, Blackhall NW, Farrar GB, Hall JC, Moss G, Morris AP, O'Neill B, Welch I, Lee $Y$, Bloom SR. Effect of infusion of nutrient solutions into the ileum on gastrointestinal transit and plasma levels of neurotensin and enteroglucagon. Gastroenterology 1984;86:274-280.

82. Spiller RC, Trotman IF, Adrian TE, Bloom SR, Misiewicz JJ, Silk DB. Further characterisation of the 'ileal brake' reflex in man--effect of ileal infusion of partial digests of fat, protein, and starch on jejunal motility and release of neurotensin, enteroglucagon, and peptide YY. Gut 1988;29:1042-1051.

83. Van Citters GW, Lin HC. Ileal brake: Neuropeptidergic control of intestinal transit. Curr Gastroenterol Rep 2006;8:367-373.

84. Layer P, Holst JJ, Grandt D, Goebell H. Ileal release of glucagon-like peptide-1 (GLP-1). Association with inhibition of gastric acid secretion in humans. Dig Dis Sci 1995;40:1074-1082.

85. Layer $\mathrm{P}$, Peschel S, Schlesinger $\mathrm{T}$, Goebell H. Human pancreatic secretion and intestinal motility: effects of ileal nutrient perfusion. Am J Physiol 1990;258:G196-G201. 
86. Keller J, Holst JJ, Layer P. Inhibition of human pancreatic and biliary output but not intestinal motility by physiological intraileal lipid loads. Am J Physiol Gastrointest Liver Physiol 2006;290:G704-G709.

87. Welch IM, Sepple CP, Read NW. Comparisons of the effects on satiety and eating behaviour of infusion of lipid into the different regions of the small intestine. Gut 1988;29:306-311.

88. Welch I, Saunders K, Read NW. Effect of ileal and intravenous infusions of fat emulsions on feeding and satiety in human volunteers. Gastroenterology 1985;89:1293-1297.

89. Welch IM, Davison PA, Worlding J, Read NW. Effect of ileal infusion of lipid on jejunal motor patterns after a nutrient and nonnutrient meal. Am J Physiol 1988;255:G800-G806.

90. Maljaars J, Haddeman E, Peters H., Masclee A. Comparison of Ileal and Duodenal brake mechanisms on satiety and gastrointestinal transport. Gastroenterology 2007;132:A207 Suppl.2.

91. Bray GA, Benfield JR. Intestinal bypass for obesity a summary and perspective. Am J Clin Nutr 1977; 30:121-127.

92. Payne JH, DeWind LT. Surgical treatment of obesity. Am J Surg 1969;118:141-147.

93. Condon SC, Janes NJ, Wise L, Alpers DH. Role of caloric intake in the weight loss after jejunoileal bypass for obesity. Gastroenterology 1978;74:34-37.

94. Pilkington TR, Gazet JC, Ang L, Kalucy RS, Crisp AH, Day S. Explanations for weight loss after ileojejunal bypass in gross obesity. Br Med J 1976;1:1504-1505.

95. Bray GA, Barry RE, Benfield JR, Castelnuovo-Tedesco P, Rodin J. Intestinal bypass surgery for obesity decreases food intake and taste preferences. Am J Clin Nutr 1976;29:779-783.

96. Backman L, Wiklund B, Svane B, Hallberg D. A roentgenological study of the small intestine after different intestinal bypass operations for treatment of morbid obesity. Int J Obes 1982;6:205-210.

97. Näslund E, Melin I, Grybäck P, Hägg A, Hellström PM, Jacobsson H, Theodorsson E, Rössner S, Backman L. Reduced food intake after jejunoileal bypass: a possible association with prolonged gastric emptying and altered gut hormone patterns. Am J Clin Nutr 1997;66:26-32.

98. Atkinson RL. Obesity surgery as a model for understanding the regulation of food intake and body weight. Am J Clin Nutr 1997;66:184-185.

99. Näslund E, Grybäck P, Backman L, Jacobsson H, Holst JJ, Theodorsson E, Hellström PM. Distal small bowel hormones: correlation with fasting antroduodenal motility and gastric emptying. Dig Dis Sci 1998; 43:945-952.

100. Schirra J, Shakir S, Nicolaus M, Woerle J, Goeke B. Glucagon-like Peptide 1 (GLP-1) mediated the 'ileal brake' in humans. Gastroenterology 2006;130:Suppl 2.; A544.

101. Pironi L, Stanghellini V, Miglioli M, Corinaldesi R, De Giorgio R, Ruggeri E, Tosetti C, Poggioli G, Morselli Labate AM, Monetti N, Gozzetti G, Barbara L, Go VLW. Fat-induced ileal brake in humans: a dose-dependent phenomenon correlated to the plasma levels of peptide YY. Gastroenterology 1993;105:733-739.

102. Wen J, Phillips SF, Sarr MG, Kost L, Holst JJ. PYY and GLP-1 contribute to feedback inhibition from the canine ileum and colon. Am J Physiol 1995;269:G945-G952.

103. Lin HC, Chen JH. Slowing of intestinal transit by fat depends on an ondansetron - sensitive, efferent serotonergic pathway. Neurogastroenterol Motil 2003;15:317-322.

104. Lin HC, Neevel C, Chen PS, Suh G, Chen JH. Slowing of intestinal transit by fat or peptide YY depends on beta-adrenergic pathway. Am J Physiol Gastrointest Liver Physiol 2003;285:G1310-G1316. 



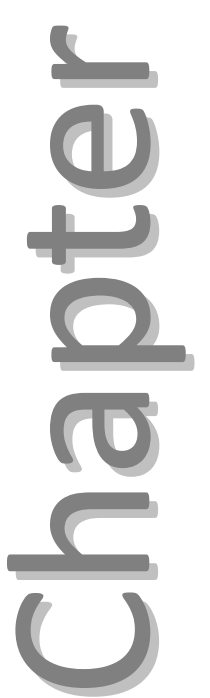

\section{Ileal brake: a sensible food target for} appetite control. A review

Maljaars PWJ, Peters HPF, Mela DJ, Masclee AAM

Physiol Behav. 2008;95:271-81 


\section{Abstract}

With the rising prevalence of obesity and related health problems, there is increased interest in the gastrointestinal system as a possible target for pharmacological or food-based approaches to weight management. Recent studies have shown that under normal physiological situations undigested nutrients can reach the ileum, and induce activation of the so-called "ileac brake", a combination of effects influencing digestive process and ingestive behaviour. The relevance of the ileal brake as a potential target for weight management is based on several findings: First, activation of the ileal brake has been shown to reduce food intake and increase satiety levels. Second, surgical procedures that increase exposure of the ileum to nutrients produce weight loss and improved glycaemic control. Third, the appetite-reducing effect of chronic ileal brake activation appears to be maintained over time. Together, this evidence suggests that activation of the ileal brake is an excellent long-term target to achieve sustainable reductions in food intake. This review addresses the role of the ileal brake in gut function, and considers the possible involvement of several peptide hormone mediators. Attention is given to the ability of macronutrients to activate the ileal brake, and particularly variation attributable to the physicochemical properties of fats. The emphasis is on implications of ileal brake stimulation on food intake and satiety, accompanied by evidence of effects on glycaemic control and weight loss. 


\section{Introduction}

Obesity is seen a growing world-wide threat to health and prosperity. Reduced-energy diets are a widely-recommended, non-invasive primary treatment strategy for overweight and obesity. However, it is difficult for obese individuals to maintain the desired regime of dietary control in part because of the associated effects including feelings of hunger and food cravings. Compliance with weight control diet programmes could be improved, or at least less burdensome, if the associated hunger feelings were less pronounced. Because the gastrointestinal tract is host to various signals that regulate hunger, food intake and satiety ${ }^{1}$, it is an obvious physiological target for developing food products and ingredients aimed at improving dietary compliance with a reduced energy intake. The relevant gastrointestinal signals are generated by various types of stimuli, such as distension of the luminal wall, presence of nutrients in the lumen or changes in $\mathrm{pH}$, and lead to the activation of vagal afferents or release of gut peptides ${ }^{2}$. For example, entry of nutrients, especially fat and proteins, into the duodenum and jejunum results in release of cholecystokinin (CCK), a peptide that induces satiety and inhibits food intake ${ }^{3,4}$.

The entry of nutrients into the duodenum and jejunum activates the so-called duodenal and jejunal "brakes": negative feedback mechanisms that influence the function of more proximal parts of the gastrointestinal tract. Activation of both of these feedback mechanisms results in reduction of food intake and inhibition of hunger, probably partly by inhibition of gastric emptying (thus contributing to enhanced and prolonged gastric distension) $)^{5-9}$. More distal in the GI tract, the ileal brake is a feedback mechanism that results in inhibition of proximal gastrointestinal motility and secretion. Animal and human studies show that activation of the ileal brake by local perfusion with nutrients increases feelings of satiety and reduces ad libitum food intake $\mathrm{i}^{10-12}$. These results all point to a potential role of the ileal brake in the regulation of digestion, with direct or indirect impact upon eating behaviour and satiety.

This review considers 1) the role of the ileal brake in the regulation of gut function, including its physiological role and comparison to other intestinal braking mechanisms; 2) the mechanisms and mediators involved in activation of the ileal brake; 3) the effects of dietary components on ileal brake; and 4) the effects of ileal brake stimulation on eating behaviour. The paper focuses on data from research in humans, with data from animal models discussed where adequate human data are lacking. 


\section{Ileal brake and gut function}

The ileal brake can be defined as a distal to proximal feedback mechanism to control transit of a meal through the gastrointestinal tract in order to optimise nutrient digestion and absorption ${ }^{13}$. While the original finding of ileal brake was confined to effects on jejunal motility and intestinal transit, since then the feedback concept was broadened to effects on gastric emptying, and pancreatic and biliary secretion. Spiller et al. ${ }^{14}$ and Read et al. ${ }^{15}$ were the first to describe such a transit control mechanism, and named it the "ileal brake". Spiller et al. ${ }^{14}$ demonstrated that ileal infusion of fat reduces jejunal motility, and this has since been confirmed by other studies ${ }^{16,17}$. Read et al., as well as others, demonstrated that gastrointestinal transit of a test meal is delayed when the distal part of the small intestine is perfused with a lipid emulsion (e.g. ${ }^{15,18,19}$ ). Activation of the ileal brake results in a dose-dependent delay in gastric emptying and small intestinal transit both for solid and liquid meals ${ }^{20-22}$.

lleal brake activation leads to a decrease in the frequency of antral and duodenal peristaltic pressure waves, a decrease in propagated antro-pyloro-duodenal pressure waves and induces an increase in pyloric sphincter pressure ${ }^{23}$ and these factors correlated with and contributed to the delay in gastric emptying ${ }^{23}$.

Activation of the ileal brake by nutrients in a meal also leads to a decrease in the frequency of jejunal contractions, the percentage of jejunal contractions involved in propagation, and the distance of propagation ${ }^{16}$, whereas ileal and ${ }^{16}$ duodenal $^{16}$ motility remain unchanged, although others have found changes in duodenal motility in response to ileal fat infusion ${ }^{23}$. Together, these effects result in an increased small intestinal transit time.

Apart from the inhibition of gastrointestinal motility leading to a delay in gastrointestinal transit, other processes contributing to nutrient digestion are also affected by activation of the ileal brake. First, activation of the ileal brake by ileal perfusion of nutrients has been shown to strongly reduce meal-stimulated secretion of pancreatic enzymes (over $80 \%$ reduction) ${ }^{24}$. Second, ileal fat perfusion reduces bile acid output in a dose-dependent fashion ${ }^{25}$. Third, activation of the ileal brake inhibits both basal and endogenously stimulated gastric acid secretion ${ }^{26,27}$. This clearly shows the distal to proximal negative feedback: infusion of nutrients into the ileum affects motility in the stomach, duodenum and jejunum and reduces gastric and pancreatic secretion. However, as there is very limited information on the actual nutrient concentrations in the ileum, studies using an ileal catheter to perfuse the ileum with nutrients may have used supraphysiological concentrations of nutrients in the ileum (postprandial concentrations between 3.6 and $10 \mathrm{mg} / \mathrm{ml}$ have been measured ${ }^{28-30}$, and meal conditions greatly affect these results ${ }^{31}$ ), although several studies (see below) show that relatively high nutrient concentrations do occur in the ileum. An additional problem is that, as demonstrated by Feltrin et al., effects of nutrients are 
not concentration, but load dependent ${ }^{32}$. This suggests that, when discussing whether nutrient infusions are (supra-) physiological, the concentration of nutrients found in the ileum may be less important than the total amount of nutrients entering the ileum.

\section{Physiological role of the ileal brake}

It is uncertain whether the ileal brake plays an important role in the regulation of gut function under physiological conditions. The percentage of nutrients reaching the ileum after meal ingestion is dependent on the caloric load of the meal, the meal composition and the rate of gastric emptying, i.e. entry into the duodenum. Lin et al., for instance, have demonstrated in dogs that $7 \%$ of a $15 \mathrm{~g}$ fat emulsion administered in the stomach reached the ileum (i.e., was not absorbed proximally) and of a 60-g fat emulsion, $30 \%$ reached the ileum ${ }^{31}$. The same group has demonstrated that after a protein load, $7-11 \%$ will reach the ileum in dogs, and $27-33 \%$ in rats, irrespective of the load given ${ }^{33,34}$. Meyer et al. demonstrated in rats that intragastric fatty acids would spread to the distal third of the small bowel, and the amount of fatty acids in the ileum was highest after the highest intragastric dose ${ }^{35}$.

In humans, small amounts of nutrients will reach the ileum in response to a normal size meal ${ }^{28,36}$ (Keller et al. ${ }^{36}$ found $50 \mathrm{j} / \mathrm{ml}$ of ileal content after a low-energy meal (300 kcal)). Layer and colleagues studied the effect of the entry of nutrients in the ileum on proximal intestinal motor and secretory function in healthy volunteers ${ }^{36,37}$. They demonstrated that increased nutrient concentrations in the ileum correlated to the transition from a fed to a fasted pattern of gastrointestinal motor and secretory function $^{36}$. Taken together, these studies provide convincing evidence that biologically relevant amounts of nutrients can reach the ileum and that the ileal brake mechanism contributes to the regulation of gastrointestinal motility and secretion under physiological conditions.

\section{Ileal brake versus other intestinal brakes}

Few studies have compared the inhibitory effects of duodenal and/or jejunal vs ileal infusion of nutrients on gastrointestinal motility. Our group has demonstrated that gastric emptying of a liquid meal was significantly delayed after ileal fat perfusion compared to an equicaloric duodenal infusion (gastric emptying half time: 207 vs. 138 min, small bowel transit time: 144 vs. $85 \mathrm{~min}$, both $p<0.05)^{19}$. In dogs, the inhibition of both gastric emptying and intestinal transit was found to be significantly stronger after ileal perfusion of a carbohydrate and a fat infusion compared to proximal intestinal perfusions ${ }^{18,38}$. In rats, Giralt et al. found no difference in inhibition of antral, duodenal or jejunal motility after an ileal or duodenal infusion of a protein hydrolysate ${ }^{39}$. However, inhibition of motility after duodenal infusion occurred only 
when the perfusate was allowed to pass to the rest of the intestine; blocking this passage abolished the inhibition in motility. This suggests that access to the distal intestine is necessary for the most potent inhibition of intestinal motility. In addition, the length of intestine exposed to nutrients influences the effect size of a given nutrient infusion ${ }^{40-42}$.

\section{Ileocolonic brake?}

Whether (signals arising from) the colon add to the ileal brake effect is uncertain. PYY and GLP-1 secreting cells are abundant in the colon, and colonic infusions of nutrients have been shown to release both peptides ${ }^{43,44}$. In animals, colonic nutrient infusion resulted in a prolongation of the cycle length of duodenal MMCs, an inhibition in ileal motility $^{43}$ and a reduction in pancreatic secretion ${ }^{45,46}$. In humans however, Read et

al. ${ }^{15}$ demonstrated that infusion of nutrients in the colon did not affect small bowel transit time at a dose that gave a significant reduction when infused into the ileum. However, colonic infusion of nutrients reduced biliary and pancreatic secretion ${ }^{47}$.

The effects of colonic nutrient infusion on food intake has never been studied in humans, but in rats, cecal nutrient infusion significantly reduced food intake, and this reduction in food intake was larger than the reduction observed after ileal infusion ${ }^{12}$. This suggests that in rats, the colon may very well contribute to the anorectic effect of ileal brake activation. As the colon is capable of secreting PYY and GLP-1, the weight loss, increased satiety and improvements in glucose homeostasis after bariatric surgery may, apart from the effects of increased ileal exposure to nutrients, also have a colonic component. However, in humans, this has never been specifically studied.

\section{Mediators of the ileal brake}

The satiety signals that are derived from the stomach and the small intestine have been reviewed with special emphasis on their interaction in the reduction in hunger and food intake. Activation of the ileal brake significantly increases satiation and satiety, and reduces food intake. Surgical procedures that lead to increased exposure of the ileum to ingested nutrients confirm these results and indicate that adaptation to the anorectic effects of ileal brake activation does not occur, not even in the long term follow up.

The gastrointestinal tract is host to many signals that affect satiety and food intake. The ileal brake is considered an interesting target when designing products or procedures able to reduce food intake and produce weight loss. Not only studies using ileal delivery of nutrients via oro-ileal but also from studies on surgical models it has 
become apparent that activation of the ileal brake leads to a reduction in food intake, weight loss, without long term adaptation to these anorectic effects.

There is not yet a clear consensus on the physiological factors mediating the actions of the ileal brake. In general, nutrients in the small intestine influence gut function as well as satiety and food intake via activation of neural afferents or the release of gut peptides ${ }^{3,48-51}$. Of the gut peptides, Proglucagon-derived peptides (PGDP) and neurotensin have initially been proposed as hormonal mediators of the ileal brake ${ }^{14,15,20}$. Indeed, intravenous (iv) administration of neurotensin has been shown to delay gastric emptying ${ }^{52}$, change antroduodenal motility to a post-prandial pattern ${ }^{53}$, reduce gastric acid secretion ${ }^{54,55}$ and reduce gall bladder emptying ${ }^{56}$. Neurotensin is secreted by $\mathrm{N}$-cells in response to oral ingestion of a mixed meal ${ }^{57}$. However, Pironi et al. and Read et al. found that ileal perfusions of oleic acid or Intralipid ${ }^{\circledR}$ caused a delay in gastric emptying or small intestinal transit without changes in plasma neurotensin levels ${ }^{15,20}$. This seemingly excluded a role for neurotensin as the circulating peptide primarily responsible for activation of the ileal brake, and little further attention has been given to neurotensin as a mediator of the ileal brake.

The following sections consider evidence for Peptide YY (PYY) and Glucagon-like peptide-1 (GLP-1) as the most likely putative mediators of the ileal brake, and for oxyntomodulin as a possible additional candidate for which more evidence is needed.

\section{Peptide YY}

Attention has recently focused on PYY ${ }^{13}$ and two products of the proglucagon gene, GLP-1 and oxyntomodulin ${ }^{58,59}$. PYY is a 36 amino-acid peptide, secreted by L-cells in the ileum and colon. It is released into the circulation following food intake, influenced by meal energy content and composition. Higher plasma concentrations are seen after fat-rich compared to protein- or carbohydrate-rich meals. An association between a delay in small intestinal transit and PYY release triggered by ileal fat perfusion has been repeatedly demonstrated ${ }^{17,20}$. Furthermore, in dogs, immunoneutralization of PYY was shown to abolish the delay in small intestinal transit caused by ileal fat ${ }^{60}$. The inhibitory effects of PYY on gastrointestinal motility have also been confirmed by intravenous infusion studies in humans and animals ${ }^{61}$.

From these observations it can be concluded that PYY is involved in distal-to-proximal intestinal feedback, and that PYY is a candidate mediator of the effects of the ileal brake. However, Vu et al. showed that intravenous perfusions of PYY equivalent to the levels reached during ileal fat perfusion was unable to reproduce the effects of intestinal fat-perfusion on satiety and gastric relaxation ${ }^{62}$.

The discrepancy between the associations of local ileal brake activity with endogenous PYY and the apparent lack of effect of exogenous PYY may be a consequence of the 
possibility that PYY acts more as a paracrine or neurocrine agent than as an endocrine agent, suggesting that plasma levels may not reflect the local effects of $P Y Y^{63,64}$. This follows from studies demonstrating that a reduction in food intake after peripheral administration of PYY (and GLP-1) could be abolished by vagotomy ${ }^{63,64}$. Similarly, it was demonstrated that vagotomy also abolished PYY-induced activation of feeding neurones in the hypothalamic arcuate nucleus ${ }^{64}$. These data suggest that the effect of PYY on food intake is paracrine, affecting local vagal afferents, rather than endocrine.

Furthermore, the inhibitory effect of PYY on food intake, as originally reported by Batterham et al. ${ }^{65,66}$ has been a subject of intense debate ${ }^{67,68}$. Batterham et al. demonstrated in humans that intravenous infusions replicating postprandial PYY PY $_{36}$ concentrations lessened hunger and decreased ad libitum food intake by 36\%, without causing nausea, affecting food palatability or altering fluid intake ${ }^{65,66}$. Several laboratories reported difficulties in reproducing these anorectic effect of PYYadministration in animals, despite using numerous different rodent models, experimental procedures and chemically validated $\mathrm{PYY}_{3-36}$ preparations ${ }^{67,69}$. However, recent studies have shown that stress, the habituation of the animals and the timing of the injections all influence the effects of the PYY-infusions ${ }^{69}$, and this might explain the discrepancies ${ }^{70}$.

Most recently, the anorectic effect of $\mathrm{PYY}_{3-36}$-infusion has been confirmed in humans, but only at supraphysiological concentrations ${ }^{68}$. Until these issues are resolved, the (physiological) role of PYY as primary humoral mediator of the ileal brake, or perhaps the particular conditions in which its effects dominate, remains unsettled.

\section{GLP-1}

Another candidate mediator of the ileal brake is GLP-1 ${ }^{58}$. GLP-1 is secreted by L-cells in the distal small intestine and colon, predominantly in response to carbohydrates and fat. GLP-1 inhibits gastroduodenal motility ${ }^{71}$, relaxes the proximal stomach ${ }^{72}$, stimulates phasic and tonic motility of the pylorus ${ }^{71}$ and inhibits gastric acid $^{73,74}$ and exocrine pancreatic secretion ${ }^{71}$. Furthermore, the averaged result from several studies of intravenous infusion of physiological amounts of GLP-1 in humans is an $11 \%$ reduction in food intake ${ }^{75}$. In rats, the GLP-1 receptor antagonist Exendin(9-39)amide was found to reduce the inhibitory effect of ileal nutrients on gastropancreatic secretion by $50 \%{ }^{76}$. In rats, the inhibition seen in antral, duodenal and jejunal motility in response to intraileal perfusion of a protein hydrolysate was abolished after infusion of a GLP-1 receptor antagonist ${ }^{39}$. Since effects of the ileal brake can be mimicked by intravenous perfusion of GLP-1, and these ileal brake effects can partially be blocked by a specific GLP-1 receptor antagonist, it is assumed that GLP-1 secretion is essential for activation of the ileal brake ${ }^{76}$. However, the potency of Exendin (9-39) 
amide to reduce the effects of ileal nutrients on gastrointestinal motility and food intake has not been evaluated in humans.

Both PYY and GLP-1 are therefore presently considered as key candidate mediators of the ileal brake. There is also evidence that the two peptides may act synergistically. They are co-secreted by intestinal L-cells, and the effects of simultaneous perfusion of both peptides on food intake and inhibition of gastric acid secretion in humans is larger than the sum of the individual contributions ${ }^{73,77}$. In addition, Keller et al. demonstrated that both GLP-1 and PYY were inversely correlated to the decreases in trypsin and bile acid secretions seen after intraileal perfusions of fat ${ }^{25}$.

\section{Oxyntomodulin}

Oxyntomodulin (OXM) is co-secreted with PYY and GLP-1 by L-cells. Intravenous infusion of oxyntomodulin has been shown to reduce gastric acid secretion and inhibit gastric emptying and duodenal postprandial motility in humans ${ }^{59}$. In rats, OXM reduces pancreatic exocrine secretions ${ }^{78}$ by a vagal-mediated indirect pathway ${ }^{79}$. The anorexic effects of OXM in normal weight humans were recently studied by Cohen et al., who reported a $19.3 \%$ decrease in energy intake from a buffet meal, and an $11 \%$ decrease in energy intake in the $12 \mathrm{~h}$ post-infusion period ${ }^{80}$. Given its effects on gastrointestinal motility, satiety and food intake, OXM should be considered a candidate mediator peptide for the ileal brake. However, to date there are no studies focusing specifically on the role of OXM in the ileal brake.

\section{Neural mediators}

Brown et al. demonstrated the involvement on neural pathways in the ileal brake when they showed that administration of $5 \mathrm{HT} 3-{ }^{81,82}$, adrenergic- ${ }^{83}$ or opioid receptor antagonists ${ }^{84}$ were able to abolish the inhibitory effect of ileal fat infusion on small bowel transit. This latter observation has been confirmed in humans ${ }^{85}$.

Lin and colleagues considered the ileal brake a reflex, in which nutrients were sensed in the distal small intestine (efferent $\operatorname{limb}$ ) and this induced inhibition of small intestinal transit in the proximal small intestine (afferent limb) ${ }^{86-89}$. Using a fistulated animal model that compartmentalized the distal and proximal small bowel, they and others demonstrated that that these neural pathways were located on the efferent limb of the ileal brake reflex ${ }^{86-90}$. Furthermore, by showing that immunoneutralization of PYY abolished the inhibition of small bowel transit after ileal fat infusion, they demonstrated that the afferent limb depended on $\mathrm{PYY}^{60}$, and furthermore, that the effects of PYY could be blocked by the same receptor antagonists ${ }^{87,88}$. Extrinsic denervation of the jejunoileum also abolished the inhibitory effects of ileal fat on gastric emptying ${ }^{91}$. This data demonstrates that neural pathways are involved in the inhibition of small bowel transit and gastric emptying after activation of the ileal 
brake. Similarly, vagotomy reduced or abolished the inhibitory effects of PYY on pancreatic secretion $^{92}$ and food intake ${ }^{63,64}$ and of GLP-1 on gastric acid secretion ${ }^{93}$ and food intake ${ }^{64}$. This suggests that neural and humoral mechanisms interact to produce the inhibitory effects of ileal brake activation.

\section{Effect of dietary components on ileal brake}

To date, studies in humans evaluating effects of ileal brake on food intake have employed only fat infusions. In order to asses the ability of different nutrient types to activate the ileal brake, it is necessary to refer to studies that used motility, transit and upper gut secretion as parameters.

Studies in animals indicate that all three macronutrients induce activation the ileal brake $^{94}$. In humans, studies comparing the relative effects of macronutrients are limited in number and scope. For instance, Spiller et al. ${ }^{17}$ compared isotonic infusions of $10 \mathrm{~g}$ fat, $7 \mathrm{~g}$ protein and $10 \mathrm{~g}$ carbohydrates. In this study, the fat infusion reduced jejunal motility, whereas the protein and carbohydrate infusion did not affect jejunal motility. As the intestine may recognize calories, studies using isotonic in stead of isocaloric infusion do not allow for direct comparison of the relative potencies of different macronutrients to activate the ileal brake. However, in this same study by Spiller et al. ${ }^{17}$, a higher dose of $15 \mathrm{~g}$ of carbohydrates did reduce jejunal motility, but this dosage was not pursued further due to nausea. Read et al. demonstrated that infusion of protein induced a significant delay in small intestinal transit ${ }^{15}$. From these studies, we can therefore conclude that both fat and carbohydrates, as measured by a reduction in jejunal motility, and protein, as measured by in increase in small intestinal transit time, activate the ileal brake (Table 3.1). However, as fat is the most extensively studied macronutrient for ileal brake activation, this review will primarily focus on fat as the stimulus.

Table 3.1 Effects of different nutrients on ileal brake activation and hormone release.

\begin{tabular}{|c|c|c|c|c|c|c|c|c|}
\hline $\begin{array}{l}\text { Infused } \\
\text { nutrient }\end{array}$ & $\begin{array}{l}\text { Gastric } \\
\text { emptying }\end{array}$ & $\begin{array}{l}\text { Intestinal } \\
\text { transit/motility }\end{array}$ & $\begin{array}{l}\text { Pancreatic } \\
\text { y secretion }\end{array}$ & $\begin{array}{l}\text { Bile acid } \\
\text { secretion }\end{array}$ & $\begin{array}{l}\text { Gastric acid } \\
\text { secretion }\end{array}$ & $\begin{array}{l}\text { Food } \\
\text { intake }\end{array}$ & PYY & GLP-1 \\
\hline Fat & $\downarrow(22,95)$ & $\begin{array}{l}\downarrow(15,17,22) \\
=(25)\end{array}$ & $\downarrow(24,25)$ & $\downarrow(25)$ & $\downarrow(27)$ & $\downarrow(10,11)$ & $\uparrow(20,25)$ & $\uparrow(25,27)$ \\
\hline $\mathrm{CH}$ & $\begin{array}{l}\downarrow(21) \\
=(95)\end{array}$ & $\downarrow(17)$ & $\begin{array}{l}\downarrow(24,116) \\
=(21)\end{array}$ & $=(21)$ & $\downarrow(27)$ & - & $\begin{array}{l}\uparrow(21) \\
=(27)\end{array}$ & $\uparrow(27)$ \\
\hline Protein & $=(95)$ & $\begin{array}{l}\downarrow(15) \\
=(17)\end{array}$ & - & - & $=(27)$ & - & $=(27)$ & $=(27)$ \\
\hline
\end{tabular}

Effects of different nutrients on ileal brake activation and hormone release. When characters are present in the second row per nutrient, this denotes that studies have yielded mixed results. = denotes that the perfusion did not induce a change in the given parameter, - denotes that this parameter has not been studied for this nutrient. 
Fat

Perfusion of fat into the ileum inhibits small intestinal transit, gastric emptying, pancreaticobiliary, gastric acid secretion and food intake in humans ${ }^{10,15,16,22,25,27}$. The subsequent sections therefore focus on the role of physicochemical properties of fat in the activation of the ileal brake.

\section{Fatty acids vs. triacylglycerols}

In food, fat is by large extent present in the form of triacylglycerols (TAG). The lipasemediated hydrolysis of TAG to monoacylglycerols and fatty acids (FA) is a necessary step for fat digestion and absorption. Spiller et al. investigated whether hydrolysis of TAG is required in order for fat to be able to activate the ileal brake ${ }^{17}$. These authors compared the effects of ileal perfusion of FA versus TAG or glycerol on jejunal motility. Thirty minutes after the perfusion, the inhibition of jejunal motility seen with FA was significantly greater than with TAG, and there was no effect of glycerol. Welch et al. found that $5 \mathrm{~g} F A$ and $12 \mathrm{~g}$ TAG had equivalent inhibitory effects on gastric emptying ${ }^{95}$. Although a direct comparison between these different doses is difficult to make, this study suggests a more potent effect of FA than TAG, possibly due to a relatively low lipase activity in the ileum. In rats, a difference between FA and TAG has been clearly demonstrated: vagal afferent activity, as measured by multi-unit recoding of the number of electronic discharges per second was much higher after perfusion of FFA vs. perfusion of TAG or Intralipid ${ }^{\circledR}$ emulsions ${ }^{96}$. Thus, it seems that hydrolysis of dietary TAG is important in activation of the ileal brake, as has been demonstrated for signals influencing satiety and gastrointestinal motility arising from the duodenum ${ }^{50,97,98}$. More definite are results from a study by Meyer et al. ${ }^{12}$ in rats, that demonstrated that the satiating effect of an oral corn oil load was completely abolished by addition of orlistat to the oil. In the same paper, they demonstrate that ingestion of this preload led to spreading of a large amount of FFA to the ileum. However, as orlistat almost completely blocked lipolysis, no or very little FFA, but large amounts of TAG will have entered the ileum ${ }^{12}$. These data demonstrated that FFA, and not TAG activate the ileal brake.

Furthermore, given that monolein (a MAG) was also able to inhibit gastric emptying, this suggests that both lipolytic products of TAG, but not TAG itself, are able to activate the ileal brake ${ }^{41}$.

Release of GLP-1 was nearly completely blocked by addition of orlistat to a duodenal fat load, suggesting the necessity of the presence of FFA for the L-cell to release GLP $-1^{99}$. One could argue that the low lipase activity in the ileum ${ }^{100}$ may limit hydrolysis of food TAG, favouring the use of (or even requirement for) FFA vs. TAG as the source material for lipid-derived ileal brake stimulation. Furthermore, Randich et al. suggest that the $\mathrm{pH}$ gradients in the distal small intestine may further inhibit 
enzymatic hydrolysis ${ }^{96}$. However, Holtman et al. found that, in the presence of nutrients (especially carbohydrates) lipase activity decreased $75 \%$ during duodenoileal transit, which leaves sufficient lipase activity for hydrolysis to FFA ${ }^{101}$. This has been confirmed in canine models, where Meyer et al. showed that as little as $2 \%$ of normal lipase secretion may suffice for normal fat hydrolysis and absorption when gastric emptying of fat is held below 5 grams per hour ${ }^{102}$. It is therefore unclear whether the enzymatic conditions favour the use of FFA over TAG as a food source for ileal brake stimulation.

\section{Chain length of fatty acids}

It is generally accepted that medium chain TAG (MCT) are hydrolyzed and absorbed more rapidly than long-chain TAG (LCT). FA with chain length under C10 diffuse from the enterocytes and pass predominantly into portal blood, bound to albumin, whereas FA with chain length above C10 proceed from the enterocyte via chylomicron formation into the lymphatic system ${ }^{103}$. When infused in the duodenum, lipids containing FA with chain length over $\mathrm{C} 10$ inhibit gastric emptying more than lipids containing FA with chain length below $\mathrm{C} 10^{104,105}$. Beyond chain length $\mathrm{C} 14$, no further increase in inhibition of transit is observed ${ }^{106}$. Feltrin et al. demonstrated that intraduodenal C12 but not C10 decreased appetite and energy intake ${ }^{107}$. Spiller et al. demonstrated that intraileal perfusion of MCT (trioctanoin (C8), tridecanoin (C10)) activated the ileal brake and increased plasma PYY concentrations ${ }^{17}$. No differences were seen with between MCT and LCT in their potency to inhibit jejunal motility. However, the inhibition was more rapid in response to the MCT perfusion, and the recovery of activity was also more rapid ${ }^{17}$. PYY concentrations were higher after triolein (C16) compared to $\mathrm{MCT}^{17}$. Brown et al. found no differences between fatty acids of different chain lengths ( $\mathrm{C} 14, \mathrm{C} 18$ and $\mathrm{C} 22)$ in their ability to delay transit time in rats ${ }^{106}$, and in pigs intraileal perfusion of short-chain FA (SCFA, e.g. C6 or smaller)) induced an inhibition in gastric motility ${ }^{108}$.

Overall, the evidence indicates that both MCT and LCT can both induce activation of the ileal brake in humans, and that activation of the ileal brake occurs more rapidly after $\mathrm{MCT}$ than $\mathrm{LCT}^{17}$. However, the comparative effects on satiety and food intake have not been studied, and when infused in the duodenum, fat with a chain length below $\mathrm{C} 12$ does not directly affect satiety and food intake ${ }^{107}$, although anorectic effects of MCT ingestion have been demonstrated (for a review, see ${ }^{109}$ ). As MCT are rapidly absorbed, their satiating effect may be due to conversion in the liver ${ }^{110}$. Fats with a chain length >C12 affect satiety and food intake by their action on the mucosa, as their effects occur before the entry into the systemic circulation, immediately upon application to the mucosa.

In animals, activation of the ileal brake has also been demonstrated after perfusion of SCFA in pigs ${ }^{108}$ and very long-chain TAG in rats ${ }^{106}$. Food intake was not assessed in 
these studies, but after mid-intestinal infusions in sham-feeding rats a reduction in food ingestion was observed only from fats with chain length $>\mathrm{C}_{10}{ }^{12}$.

\section{Degree of saturation of fatty acids}

Several studies have evaluated the effect of degree of FA saturation on food intake in humans. Findings from these studies suggest that differences in the degree of saturation of orally ingested fat usually only marginally affects satiety or food intake ${ }^{111}$. However, French et al. reported that when fat was infused directly into the duodenum (bypassing the mouth and stomach), di-unsaturated fats significantly inhibited food intake (but not satiety), whereas monounsaturated fat had no effect ${ }^{112}$. We have recently conducted a human study on the effects of degree of fat saturation on satiety when the fat was delivered directly into the ileum ${ }^{113}$. The satiating effects of mono- and di-unsaturated fats, but not a saturated fat source, were significantly larger than the saline control ${ }^{113}$. In rats, no differences were found between FA with different degrees of saturation perfused in the ileum in their ability to delay small intestinal transit ${ }^{106}$. Together this literature indicates that when infused directly in duodenum and ileum, the satiating effect of unsaturated fats is probably larger than saturated fatty acids, but the issue is not fully resolved.

\section{Quantity of fat}

Pironi et al. observed a significant delay in gastric emptying after just $480 \mathrm{mg}$ oleic acid when infused into the ileum ${ }^{20}$, and $1200 \mathrm{mg}$ of oleic acid delivered to the jejunum and/or ileum have been shown to slow both gastric emptying and small intestinal transit in humans ${ }^{114}$. A dose-dependent decrease in pancreatic and biliary secretion has been demonstrated in response to doses of fat of 0,50 or $100 \mathrm{mg} / \mathrm{min}$ perfused into the ileum ${ }^{25}$. In that study, however, no differences were seen in GLP-1 and PYY concentrations between the high and low dose of fat.

In general, it appears that relatively low doses are able to induce ileal brake effects on gut function. However, the effect on satiety of these low fat doses has been addressed in one study. We have shown that 3 or $9 \mathrm{~g}$ of fat infused in the ileum delayed small intestinal transit, and both amounts of fat induced reductions in hunger and food intake as compared to oral fat consumption ${ }^{115}$.

\section{Proteins}

Read et al. found that perfusion of protein into the ileum inhibited small bowel transit, indicating that protein induces activation of the ileal brake in humans ${ }^{15}$. However, other authors have reported no effect of intraileal protein-perfusion on jejunal motility ${ }^{17}$, gastric emptying ${ }^{95}$ or gastric acid secretion ${ }^{27}$. Although both Spiller et al. ${ }^{17}$ and Welch et al. ${ }^{95}$ used much lower doses of protein than of fat (to which they 
were compared), Layer et al. compared equicaloric (60 kcal) ileal perfusions of triolein + sodium-oleate to a protein hydrolysate perfusion, and found that fat, but not the protein hydrolysate, reduced spontaneous and stimulated gastric acid secretion ${ }^{27}$. In animals, an isocaloric dose-response study has been conducted, comparing the effects of amino acids, oleate, and glucose when infused in the ileum, while gastric emptying and proximal small intestinal motility were monitored ${ }^{94}$. In this study, it was demonstrated that protein and fat induce are equipotent activators of the ileal brake with regard to small intestinal transit, and gastric emptying ${ }^{94}$.

In a study addressing food intake, it was demonstrated that after administration in the duodenum, reductions in sham feeding differed between different types of proteins administered in the duodenum: L-tryptophane significantly reduced sham feeding, whereas L-Alanine had no effect ${ }^{12}$. However, food intake after ileal administration of proteins was not assessed in these dogs.

Together, the available evidence indicates that ileal protein infusions in both humans ${ }^{15}$ and animals ${ }^{94}$ activate the ileal brake, although differences may exist between different types of protein or amino acids ${ }^{12}$.

\section{Carbohydrates}

In humans, ileal perfusion of starch with maltose has been found to inhibit gastric emptying, reduce both stimulated and basal gastric acid secretion, small intestinal motility and cholinergic-stimulated pancreatic exocrine secretion ${ }^{24,27,37,116}$. From this, we can conclude that the ileal brake is activated by carbohydrates. Welch et al. ${ }^{95}$ failed to show an effect of carbohydrate infusions on gastric emptying, but, similarly to as discussed above, the dose of carbohydrates used in this study were lower than the doses of fat.

In contrast, Siegle et al. studied gastric emptying and small intestinal motility in dogs, and found that ileal glucose inhibited gastric emptying, also at doses lower than amino acids and oleate ${ }^{94}$. This was confirmed by Lin et al., who found a potent effect of ileal glucose and of digested starch on gastric emptying of solids in dogs ${ }^{38}$. Azpiroz et al. found that ileal infusion of maltose reduced gastric tone in dogs ${ }^{117}$.

Together, these data suggests that ileal administration of carbohydrates activates the ileal brake in humans $s^{24,27,37,116}$ and dogs $s^{38,94,117}$.

\section{Fibre}

Apart from the major dietary macronutrients, other food constituents such as fibres can influence activation of the ileal brake. Lin et al. showed in dogs that preventing access to the distal gut eliminated the delay in small intestinal transit due to addition of water-soluble fibres to an enteral feeding formula ${ }^{118}$. Soluble fibres may also delay the absorption of lipids by thickening the unstirred layer at the luminal surface, 
resulting in transport of larger amounts of nutrients to the ileum and/or spreading of nutrient absorption over a larger intestinal luminal surface area, leading to more pronounced inhibitory feedback from the distal gut ${ }^{118}$. Insoluble fibres may also activate a more distal braking mechanism, the colonic brake. Insoluble fibres (but also soluble fibres) in the colon are fermented by bacteria, producing significant quantities of short-chain FA, which are known to trigger the release of $P Y Y^{43}$. The potential role and applications of fibre in ileal brake activation in humans needs to be further elucidated.

\section{Satiety and food intake}

Evidence from effects of ileal brake activation on satiety and food intake come from studies of ileal perfusion of fat and bariatric surgical procedures that result in increased exposure of the ileum to nutrients. While the nutrient perfusions studies mainly focus on acute, short-term stimulation of the ileal brake, the surgical model reflects a more chronic and sustained activation.

\section{Nutrient perfusions}

\section{Animals}

The previous sections describe evidence for activation of ileal brake effects on gastrointestinal responses by carbohydrates, protein and fat. However, there are only a small number of human studies examining the effects of ileal brake activation on eating behaviour. Most of the relevant information is therefore derived from animal studies.

In rats, the inhibitory effect of ileal perfusion of nutrients on food intake has been clearly demonstrated in several studies ${ }^{119-121}$. Glick et al. showed that both duodenal and ileal perfusions of glucose resulted in a decreases in food intake approximately equal to the caloric content of the infusate ${ }^{121,122}$. A trend towards lower average food intake and reduction in number of meals during the ileal perfusion was observed, but did not reach statistical significance. Meyer et al. conducted a number of studies focusing on different aspects of intestinal satiety mechanisms ${ }^{12,35,40}$. They demonstrated that infusions of carbohydrates, certain amino acids and fatty acids in the mid-intestine reduced food ingestion during sham feeding ${ }^{12}$. Furthermore, they showed that the reduction in food intake was larger when the exposed surface of small intestine was larger ${ }^{35,40}$, confirming results on effects of carbohydrates ${ }^{42}$, fat ${ }^{41}$ and proteins $^{33}$ on gastrointestinal motility. Meyer et al. also demonstrated that infusions of dodecanoate, oleate-monolein, maltose and phenylalanine-tryptophane 
in the coecum reduced food intake significantly. Furthermore, in the same paper, they demonstrate that the anorectic effect of dodecanoate infusions increased from duodenum- to coecum: in the duodenum, intake was reduced by $11.3 \%$, in the ileum by $21.4 \%$ and in the coecum $40 \%{ }^{12}$. These data demonstrate that the colon in rats does reduce food intake, and contributes to the satiating effect of ileal brake activation $^{12}$.

Evidence for a normal physiologic role of the ileum in eating behaviour is derived from experiments assessing effects of resection of the ileum. Meyer et al. ${ }^{12}$ measured suppression of food intake in rats who underwent an ileum resection or sham surgery. intraduodenal infusion of nutrients. They found that suppression of food intake by an intra- duodenal nutrient infusion was larger in the sham-operated group compared to the ileum-resection group, although this was significant only for the oleate perfusion; in this group resection attenuated the reduction in food intake from $33 \%$ to $12.5 \%$ after the $0.48 \mathrm{mmoles} / \mathrm{h}$ perfusion, and from $80 \%$ to $57.25 \%$ in the $0.96 \mathrm{mmoles} / \mathrm{h}$ perfusion $^{12}$. These results show that the ileum and probably the colon contribute to the satiating effects of intestinal nutrients loads, and that this effect increases when the speed of absorption of a nutrient is lower.

Furthermore, Meyer et al. ${ }^{12}$ determined reduction ratios (reduction in energy consumed relative to the energy load perfused) of perfusions of different nutrients in different amounts in either duodenum or ileum. When the infusate was limited to the duodenum/jejunum or to the ileum/colon, reduction ratios were higher after ileal perfusions. This can taken to be a demonstration of the greater relative potency of ileal perfusions to reduce intake ${ }^{12}$.

Woltman et al. compared duodenal versus terminal ileal perfusions ( $14 \mathrm{~cm}$ from the ileocecal valve) of different amounts of glucose or oleic acid on meal size and number of meals in rats ${ }^{120}$. Ileal glucose was more potent than duodenal glucose for reducing cumulative food intake, whereas duodenal oleic acid had a stronger inhibitory effect on food intake than ileal oleic acid. The glucose experiments demonstrate that the anorectic effect of ileal glucose exposure is more potent than duodenal glucose exposure, confirming the higher potency of the ileal brake to reduce food intake. Furthermore, the colon may have added to the anorectic effect of the ileal infusion, as demonstrated by Meyer et al. ${ }^{12}$. The experiments with oleic acid seem to contradict this. Nevertheless, since absorption of glucose is about nine-fold faster than absorption of oleic acid ${ }^{40}$, oleic acid, but not glucose, will contact the entire small intestinal length during duodenal infusions of higher doses; whereas during these ileal perfusions, only $14 \mathrm{~cm}$ of ileum and colon were contacted, resulting in a shorter 
segment of intestine. This may explain the larger effect on food intake of oleic acid administration in the duodenum compared to the ileum.

The pattern by which food intake was reduced differed between the site of delivery and types of nutrient: In the duodenum, both glucose and oleic acid inhibited feeding by decreasing meal frequency, while delivery of nutrients to the ileum reduced both meal size and frequency. As the glucose and the oleic acid perfusions were not equicaloric, no direct conclusion can be made regarding their relative potency. The differing patterns of effects on feeding behaviour led the authors to suggest that ileal oleic acid and glucose inhibit food intake by different mechanisms ${ }^{120}$.

There is also evidence that the appetite suppression induced by nutrients delivered to the distal small intestine retains its effects over sustained periods. Cox et al. found that prolonged daily jejunal fat perfusion, 7 hours/day for 21 consecutive days, induced a net reduction in food intake, without compensation for the suppression of intake occurring during the perfusion ${ }^{123}$. Whether this also applies to the ileum is not known.

\section{Human studies}

Studies on the effect of ileal brake activation on food intake and satiety in humans are scarce. Welch et al. performed two studies in which they evaluated the effect of ileal fat on food intake and satiety ${ }^{10,11}$. They perfused a 50\% corn oil (370 kcal) emulsion (vs. saline control) into the ileum for $90 \mathrm{~min}$ and measured satiety-scores and food intake by an ad libitum meal 30 minutes after the start of the perfusion. In both studies, the ileal nutrients induced reductions (200 kcal and $279 \mathrm{kcal}$ ) in food intake above the infused amount of calories, when compared with control. No effect on satiety before the start of the ad libitum meal was observed in either study in response to the ileal perfusions. However, after the start of the ad libitum meal, fullness increased significantly during both ileal fat perfusions compared to saline. In a further series of experiments, ileal perfusion of corn oil emulsions delayed gastric emptying compared with ileal perfusions of albumen and saline ${ }^{10}$. When they compared ileal and jejunal perfusions of fat on satiety and food intake, the inhibition of food intake was larger after the jejunal perfusion ${ }^{11}$. However, because the rate of perfusion in the jejunum was supraphysiological, it is very likely that some of the fat infused into the jejunum spilled into the ileum. However, some of the fat infused in the ileum will have spilled over into the colon. This would result in a larger intestinal surface being exposed to fat after the jejunal experiment, which has been found to result in an enhanced reduction in food intake in rats ${ }^{40}$. Welch's observations after jejunal $v$ ileal infusions in humans parallel exactly the relative effects of jejunal v. ileal infusions of oleic acid later observed in rats ${ }^{35}$. 
In both of the experiments described above, ileal fat perfusions did not suppress appetite before the meal, but significantly increased fullness during the meal ${ }^{10,11}$. From this, the authors concluded that the effect of ileal brake activation on satiety might be explained by an indirect action, i.e. the earlier attainment of a critical level of gastric distension due to the delay in gastric emptying, as opposed to a direct action of ileal fat on the satiety centres in the brain. This would suggest that inhibition of food intake by ileal brake activation could be enhanced when it coincides with an intragastric volume load.

Our group has demonstrated a satiating effect of ileal fat perfusion without a preceding meal ${ }^{62}$. In this randomised crossover study, 14 healthy volunteers received either an intraileal perfusion of Intralipid $^{\circledR}$ (a $20 \%$ fat emulsion) at $2 \mathrm{kcal} / \mathrm{min}$, or a control saline perfusion. Satiety scores increased significantly in response to the ileal fat perfusion without a preceding meal, confirming the results of Meyer et al. ${ }^{12}$, who demonstrated similar reductions of food intakes after ileal infusions in rats with or without a gastric distension (sham vs natural feeding). These studies demonstrate that the satiating effect of the ileal brake is not exclusively mediated by the earlier attainment of a critical level of gastric distension, as suggested by Welch et al. ${ }^{10}$, but that a direct effect on satiety centres is very likely.

\section{Chronic ileal brake activation: surgical models}

Apart from ileal brake activation by perfusion of nutrients in the ileum, bariatric surgical procedures provide models in which (a part of) the ileum is exposed to an increased amount of nutrients: 1 ) the jejuno-ileal bypass (JIB), in which the proximal jejunum is anastomosed to the distal ileum, and 2) the ileal transposition (IT), in which a part of the ileum is transposed into the duodenum or jejunum.

The JIB was pioneered by Payne and De Wind in 1969, as treatment for gross obesity $^{124,125}$. The observed weight loss was at first thought to result from malabsorption, but as the loss in body weight was larger than could be accounted for by fecal losses, other mechanisms had to be involved ${ }^{125-127}$. Condon et al. demonstrated that only $21 \%$ of the weight loss observed was attributable to malabsorption $^{126}$, while both Naslund et al. and Bray et al. demonstrated that JIB induced an decrease in food intake ${ }^{127,128}$. Bray et al. reported that daily energy intakes at 1 and 12 months post-surgery were reduced to $20 \%$ and $45 \%$, respectively, of presurgery levels, thereby showing an impressive and sustained reduction in energy intake $^{128}$. Naslund et al. found that nine months after surgery, food intake was $13 \%$ lower during a test meal compared to the pre-surgery intake ${ }^{127}$. Psychological factors, such as the negative reinforcement of diarrhea after meals, have been considered explain these reductions in food intake, but they do not fully account for the sustained 
differences in intake and preferences because the malabsorption decreases with time after $\mathrm{JIB}^{129}$.

Roentgenological studies have demonstrated that JIB leads to a rapid exposure of the ileum to nutrients ${ }^{130}$. Furthermore, JIB leads to higher concentrations of distal intestinal hormones as PYY and GLP-1 compared to pre-surgical levels ${ }^{131}$. From this it follows that the increased exposure of the ileum to nutrients leads to an increased activation of the ileal brake, and this suggests that ileal brake-activation is involved in the decrease in food intake seen after JIB. However, due to severe complications, the JIB is no longer used in clinical practice, and these complications may also have influenced the food intake negatively ${ }^{132}$.

The surgical procedure of ileal transposition is another model to evaluate the effects of chronic ileal exposure to nutrients. In this procedure, a $10-20 \mathrm{~cm}$ segment of distal ileum is prepared and resected with preservation of vasculature and innervation. The segment is placed into the duodenum or proximal jejunum ${ }^{133}$, thereby eliciting early and enhanced activity of the ileal brake in response to regular feeding. Koopmans et al. compared rats with transpositions of $10 \mathrm{~cm}$ ( $8 \%$ of total length of ileum) and $20 \mathrm{~cm}$ of ileum into the duodenum to a JIB group and a control group in which the resected segment was reattached without transposition ${ }^{134}$. Relative to controls, food intake in the 10 and $20 \mathrm{~cm}$ transposition groups and the JIB group were reduced by $22 \%, 44 \%$ and $44 \%$ respectively. These reductions in food intake led to a loss in body weight relative to control at five days after surgery: $25 \%$ in the $10 \mathrm{~cm}$ transposition group, $33 \%$ in the $20 \mathrm{~cm}$ group, and by $45 \%$ in the JIB group. As food intake was similar between the $20 \mathrm{~cm}$ ileal transposition group and the JIB group, this difference in weight loss is probably due to malabsorption. The results for the ileal transposition have been confirmed in a study by Strader et al., where ileal transposition reduced food intake and body weight compared to control group, and was associated with increased secretion of PYY and GLP-1 ${ }^{133}$. Furthermore, this study indicates that adaptation to the reduction in food intake does not occur ${ }^{133}$. These results from animal studies provide evidence that greatly increased exposure of the ileum to nutrients induces a reduction in food intake with subsequent reduction in body weight $^{133,135}$. This has also been confirmed in humans.

De Paula et al. studied the effect of sleeve gastrectomy, a surgical procedure which results in a smaller gastric volume, in combination with ileal transposition (named the neuroendocrine brake) on weight loss in 19 obese patients ${ }^{136}$. All patients lost weight, a mean of $9.3 \%$ after 1 month, $23 \%$ after 6 months and $42.4 \%$ after 16 months. Together, these and other data suggest that chronic ileal brake activation results in weight loss in both animals and humans, with no (or at best incomplete) chronic adaptation to the anorexic effects. 
In the context of the current search for more effective preventive and treatment approaches for obesity, these data provide evidence for the potential value of ileal brake activation in the control of food intake and satiety. Different studies have shown that satiety scores correlate to ad libitum energy intake ${ }^{137,138}$, and changes satiety scores are associated with weight loss ${ }^{138}$.

Furthermore, perceived hunger has been shown to be a significant predictor of failure to lose weight in clinical trials ${ }^{139}$, and reduction of hunger is a mode of action of one of the major current drug treatments for obesity ${ }^{140}$. Our group has repeatedly demonstrated an increase in satiety-levels after activation of the ileal brake ${ }^{19,62,113}$, and the different surgical models both in humans ${ }^{127,128}$ and in animals ${ }^{119,135,141,142}$ have demonstrated a large anorectic effect, with concomitant weight loss ${ }^{142}$.

Obesity usually reflects a long-term accumulation of relatively small average daily excesses in energy intake relative to expenditure ${ }^{143}$. Technologies to help consumers make small but consistent reductions in energy intake, to bring it more closely into line with expenditure, should therefore help in obesity prevention. Given the powerful reduction observed after ileal brake activation, food products that trigger the ileal brake could contribute toward this goal.

\section{Glycaemic control}

Bariatric surgery can reduce a number of obesity-associated health risks, such as hyperglycaemia. For example, in the ileal transposition study of De Paula et al. ${ }^{136}$, all five type 2 diabetes patients (three taking oral hypoglycaemic agents, two using insulin) achieved normal blood glucose concentrations without medication within three weeks after surgery. Interestingly, the improvements in glucose regulation seen after bariatric surgery were achieved before any significant weight loss had occurred $^{144}$. Thus, mechanisms distinct from effects of weight loss itself are involved in the improvement of glucose regulation ${ }^{144,145}$. A recent study in which non-obese type 2 diabetes rats underwent an ileal transposition, demonstrated improved fasting plasma glucose levels, insulin and glucose tolerance compared to sham-operated rats, without alterations in food intake or body weight ${ }^{146}$. The ileal transposition also induced a significant increase in plasma GLP-1 concentrations.

The beneficial effect of GLP-1 on insulin sensitivity has been shown in humans and in animal studies ${ }^{147}$. GLP-1 is released after exposure of the distal small intestine to nutrients $^{27,148}$, especially carbohydrates and lipids ${ }^{27}$. Therefore, the improvement of glycaemic control after bariatric procedures, such as the ileal transposition and the Roux-en-Y gastric bypass is considered to be at least partly the consequence of increased distal small intestinal exposure to nutrients ${ }^{145,149,150}$. However, there are also other theories about the causes of improved glycaemic control after bariatric surgery ${ }^{144}$. 


\section{Conclusions}

Apart from the role the ileal brake plays in the regulation of gastrointestinal motor and secretory function, activation of the ileal brake leads to a reduction in hunger and in food intake. Activation occurs after exposure of the ileum to fat, carbohydrates and protein. Suggested mediators include PYY, GLP-1 and vagal nerve stimulation. The inhibitory effect of ileal brake activation on satiety has been repeatedly demonstrated, but it is uncertain whether this effect results from direct stimulation of central satiety centres in the brain, or if the ileal brake effect on hunger and satiety is achieved indirectly via the delay in gastric emptying. It is most likely that, after activation of the ileal brake, the enhanced gastric distension from delayed gastric emptying interacts with a direct stimulation of central satiety centres by hormonal and neural signals, to reduce hunger and energy intake. This reduction in food intake occurs when the ileum is exposed to infused nutrients, or when changes in gut anatomy after bariatric surgery induce greater exposure of the ileum to nutrients.

The chronically increased ileal brake activation seen after bariatric surgery demonstrates that an appetite-reducing effect of ileal brake activation is sustained. This suggests that activation of the ileal brake may serve as an excellent target to achieve long-term reductions in food intake. However, the idea of ileal stimulation to therapeutically control body weight is provocative but a long way from established.

The increased glycaemic control as demonstrated in ileal transposition studies provides an additional health benefit. The availability of a specific GLP-1 receptor antagonist enables new studies investigating the role of GLP-1 in ileal-brakedependent reductions in food intake, and functional MRI techniques showing brain activation may be applied to study possible direct effects of ileal brake activation on CNS satiety centres.

All in all, the ileal brake appears to be a sensible food target for appetite control that merits further research to explore its potential, understand the underlying mechanisms, and identify how it can be applied in practice. 


\section{References}

1. Woods SC. Gastrointestinal satiety signals I. An overview of gastrointestinal signals that influence food intake. Am. J. Physiol Gastrointest. Liver Physiol 2004;286:G7-13.

2. Badman MK, Flier JS. The Gut and Energy Balance: Visceral Allies in the Obesity Wars. Science 2005; 307:1909.

3. Lieverse RJ, Jansen JB, Masclee AA, Rovati LC, Lamers CB. Effect of a low dose of intraduodenal fat on satiety in humans: studies using the type $A$ cholecystokinin receptor antagonist loxiglumide. Gut 1994;35:501-505.

4. Lieverse RJ, Masclee AA, Jansen JB, Rovati LC, Lamers CB. Satiety effects of the type A CCK receptor antagonist loxiglumide in lean and obese women. Biol. Psychiatry 1995;37:331-335.

5. Clarkston WK, Pantano MM, Morley JE, Horowitz M, Littlefield JM, Burton FR. Evidence for the anorexia of aging: gastrointestinal transit and hunger in healthy elderly vs. young adults. Am J Physiol 1997;272:R243-R248.

6. Hveem K, Jones KL, Chatterton BE, Horowitz M. Scintigraphic measurement of gastric emptying and ultrasonographic assessment of antral area: relation to appetite. Gut 1996;38:816-821.

7. Jones KL, Doran SM, Hveem K, Bartholomeusz FD, Morley JE, Sun WM, Chatterton BE, Horowitz M. Relation between postprandial satiation and antral area in normal subjects. Am J Clin Nutr 1997; 66:127-132.

8. Geliebter A. Gastric distension and gastric capacity in relation to food intake in humans. Physiol Behav 1988;44:665-668.

9. Goetze O, Steingoetter A, Menne D, van der Voort IR, Kwiatek MA, Boesiger P, Weishaupt D, Thumshirn M, Fried M, Schwizer W. The effect of macronutrients on gastric volume responses and gastric emptying in humans: A magnetic resonance imaging study. Am J Physiol Gastrointest Liver Physiol 2007;292:G11-G17.

10. Welch I, Saunders K, Read NW. Effect of ileal and intravenous infusions of fat emulsions on feeding and satiety in human volunteers. Gastroenterology 1985;89:1293-1297.

11. Welch IM, Sepple CP, Read NW. Comparisons of the effects on satiety and eating behaviour of infusion of lipid into the different regions of the small intestine. Gut 1988;29:306-311.

12. Meyer JH, Hlinka M, Tabrizi Y, DiMaso N, Raybould HE. Chemical specificities and intestinal distributions of nutrient-driven satiety. Am J Physiol 1998;275:R1293-R1307.

13. Van Citters GW, Lin HC. The ileal brake: a fifteen-year progress report. Curr Gastroenterol Rep 1999; 1:404-409.

14. Spiller RC, Trotman IF, Higgins BE, Ghatei MA, Grimble GK, Lee YC, Bloom SR, Misiewicz JJ, Silk DB. The ileal brake--inhibition of jejunal motility after ileal fat perfusion in man. Gut 1984;25:365-374.

15. Read NW, McFarlane A, Kinsman RI, Bates TE, Blackhall NW, Farrar GB, Hall JC, Moss G, Morris AP, O'Neill B. Effect of infusion of nutrient solutions into the ileum on gastrointestinal transit and plasma levels of neurotensin and enteroglucagon. Gastroenterology 1984;86:274-280.

16. Welch IM, Davison PA, Worlding J, Read NW. Effect of ileal infusion of lipid on jejunal motor patterns after a nutrient and nonnutrient meal. Am J Physiol 1988;255:G800-G806.

17. Spiller RC, Trotman IF, Adrian TE, Bloom SR, Misiewicz JJ, Silk DB. Further characterisation of the 'ileal brake' reflex in man--effect of ileal infusion of partial digests of fat, protein, and starch on jejunal motility and release of neurotensin, enteroglucagon, and peptide YY. Gut 1988;29:1042-1051.

18. Lin HC, Zhao XT, Wang L. Intestinal transit is more potently inhibited by fat in the distal (ileal brake) than in the proximal (jejunal brake) gut. Dig Dis Sci 1997;42:19-25.

19. Maljaars J, Haddeman E, Peters H, Masclee A. Comparison of Ileal and Duodenal brake mechanisms on satiety and gastrointestinal transport. Gastroenterology 2007;132:A207 Suppl.2.

20. Pironi L, Stanghellini V, Miglioli M, Corinaldesi R, De Giorgio R, Ruggeri E, Tosetti C, Poggioli G, Morselli Labate AM, Monetti N. Fat-induced ileal brake in humans: a dose-dependent phenomenon correlated to the plasma levels of peptide YY. Gastroenterology 1993;105:733-739. 
21. Jain NK, Boivin M, Zinsmeister AR, DiMagno EP. The ileum and carbohydrate-mediated feedback regulation of postprandial pancreaticobiliary secretion in normal humans. Pancreas 1991;6:495-505.

22. Holgate AM, Read NW. Effect of ileal infusion of intralipid on gastrointestinal transit, ileal flow rate, and carbohydrate absorption in humans after ingestion of a liquid meal. Gastroenterology 1985; 88:1005-1011.

23. Fone DR, Horowitz M, Read NW, Dent J, Maddox A. The effect of terminal ileal triglyceride infusion on gastroduodenal motility and the intragastric distribution of a solid meal. Gastroenterology 1990; 98:568-575.

24. Layer $\mathrm{P}$, Peschel $\mathrm{S}$, Schlesinger $\mathrm{T}$, Goebell H. Human pancreatic secretion and intestinal motility: effects of ileal nutrient perfusion. Am. J. Physiol 1990;258:G196-G201.

25. Keller J, Holst JJ, Layer P. Inhibition of human pancreatic and biliary output but not intestinal motility by physiological intraileal lipid loads. Am. J. Physiol Gastrointest. Liver Physiol 2006;290:G704-G709.

26. Miller L, Malagelada JR, Taylor WF, Go VL. Intestinal control of human postprandial gastric function: the role of components of jejunoileal chyme in regulating gastric secretion and gastric emptying. Gastroenterology 1981;80:763-769.

27. Layer P, Holst JJ, Grandt D, Goebell H. Ileal release of glucagon-like peptide-1 (GLP-1). Association with inhibition of gastric acid secretion in humans. Dig Dis Sci 1995;40:1074-1082.

28. Borgstrom B, Dahlqvist A, Lundh G, Sjovall J. Studies of intestinal digestion and absorption in the human. J Clin Invest 1957;36:1521-1536.

29. Hofmann AF, Borgstrom B. The intraluminal phase of fat digestion in man: the lipid content of the micellar and oil phases of intestinal content obtained during fat digestion and absorption. J Clin Invest 1964;43:247-257.

30. Fields M, Duthie HL. Effect of vagotomy on intraluminal digestion of fat in man. Gut 1965;6:301-310.

31. Lin HC, Zhao XT, Wang L. Fat absorption is not complete by midgut but is dependent on load of fat. Am J Physiol 1996;271:G62-G67.

32. Feltrin KL, Little TJ, Meyer JH, Horowitz M, Rades T, Wishart J, Feinle-Bisset C. Effects of lauric acid on upper gut motility, plasma cholecystokinin and peptide $Y Y$, and energy intake are load, but not concentration, dependent in humans. J Physiol 2007;581:767-777.

33. Zhao XT, McCamish MA, Miller RH, Wang L, Lin HC. Intestinal transit and absorption of soy protein in dogs depend on load and degree of protein hydrolysis. J Nutr 1997;127:2350-2356.

34. Zhao XT, Miller RH, McCamish MA, Wang L, Lin HC. Protein absorption depends on load-dependent inhibition of intestinal transit in dogs. Am J Clin Nutr 1996;64:319-323.

35. Meyer JH, Hlinka M, Khatibi A, Raybould HE, Tso P. Role of small intestine in caloric compensations to oil premeals in rats. Am J Physiol 1998;275:R1320-R1333.

36. Keller J, Runzi M, Goebell H, Layer P. Duodenal and ileal nutrient deliveries regulate human intestinal motor and pancreatic responses to a meal. Am J Physiol 1997;272:G632-G637.

37. Layer P, Schlesinger T, Groger G, Goebell H. Modulation of human periodic interdigestive gastrointestinal motor and pancreatic function by the ileum. Pancreas 1993;8:426-432.

38. Lin HC, Kim BH, Elashoff JD, Doty JE, Gu YG, Meyer JH. Gastric emptying of solid food is most potently inhibited by carbohydrate in the canine distal ileum. Gastroenterology 1992;102:793-801.

39. Giralt M, Vergara P. Glucagonlike peptide-1 (GLP-1) participation in ileal brake induced by intraluminal peptones in rat. Dig Dis Sci 1999;44:322-329.

40. Meyer JH, Tabrizi Y, DiMaso N, Hlinka M, Raybould HE. Length of intestinal contact on nutrient-driven satiety. Am J Physiol 1998;275:R1308-R1319.

41. Lin HC, Doty JE, Reedy TJ, Meyer JH. Inhibition of gastric emptying by sodium oleate depends on length of intestine exposed to nutrient. Am J Physiol 1990;259:G1031-G1036.

42. Lin HC, Doty JE, Reedy TJ, Meyer JH. Inhibition of gastric emptying by glucose depends on length of intestine exposed to nutrient. Am J Physiol 1989;256:G404-G411.

43. Wen J, Phillips SF, Sarr MG, Kost $\amalg$, Holst JJ. PYY and GLP-1 contribute to feedback inhibition from the canine ileum and colon. Am J Physiol 1995;269:G945-G952. 
44. Izukura M, Hashimoto T, Gomez G, Uchida T, Greeley GH Jr, Thompson JC. Intracolonic infusion of bile salt stimulates release of peptide $\mathrm{YY}$ and inhibits cholecystokinin-stimulated pancreatic exocrine secretion in conscious dogs. Pancreas 1991;6:427-432.

45. Harper AA, Hood AJ, Mushens J, Smy JR. Inhibition of external pancreatic secretion by intracolonic and intraileal infusions in the cat. J Physiol 1979;292:445-454.

46. Hage G, Tiscornia O, Palasciano G, Sarles H. Inhibition of pancreatic exocrine secretion by intra-colonic oleic acid infusion in the dog. Biomedicine 1974;21:263-267.

47. Owyang C, Green L, Rader D. Colonic inhibition of pancreatic and biliary secretion. Gastroenterology 1983;84:470-475.

48. Powley TL, Phillips RJ. Gastric satiation is volumetric, intestinal satiation is nutritive. Physiol Behav 2004;82:69-74.

49. Matzinger D, Gutzwiller JP, Drewe J, Orban A, Engel R, D'Amato M, Rovati L, Beglinger C. Inhibition of food intake in response to intestinal lipid is mediated by cholecystokinin in humans. Am J Physiol 1999;277:R1718-R1724.

50. Matzinger D, Degen L, Drewe J, Meuli J, Duebendorfer R, Ruckstuhl N, D'Amato M, Rovati L, Beglinger $C$. The role of long chain fatty acids in regulating food intake and cholecystokinin release in humans. Gut 2000;46:688-693.

51. Peters $\mathrm{CT}$, Choi $\mathrm{YH}$, Brubaker PL, Anderson GH. A glucagon-like peptide-1 receptor agonist and an antagonist modify macronutrient selection by rats. J Nutr 2001;131:2164-2170.

52. Hellstrom PM, Nylander G, Rosell S. Effects of neurotensin on the transit of gastrointestinal contents in the rat. Acta Physiol Scand 1982;115:239-243.

53. Thor K, Rokaeus A. Antroduodenal motor response induced by (Gln4)-neurotensin in man. Acta Physiol Scand 1983;118:369-372.

54. Holst PJ, Skov OP, Kirkegaard P. Effect of neurotensin and neurotensin fragments on gastric acid secretion in man. Regul Pept 1986;15:77-86.

55. Skov OP, Holst PJ, Kirkegaard P, Stadil F, Fahrenkrug J, Christiansen J. Neurotensin inhibits mealstimulated gastric acid secretion in man. Scand J Gastroenterol 1983;18:1073-1076.

56. Walker JP, Khalil T, Wiener I, Fagan CJ, Townsend CM Jr, Greeley GH Jr, Thompson JC. The role of neurotensin in human gallbladder motility. Ann Surg 1985;201:678-683.

57. Dumoulin V, Moro F, Barcelo A, Dakka T, Cuber JC. Peptide YY, glucagon-like peptide-1, and neurotensin responses to luminal factors in the isolated vascularly perfused rat ileum. Endocrinology 1998;139:3780-3786.

58. Schirra J, Goke B. The physiological role of GLP-1 in human: incretin, ileal brake or more? Regul Pept 2005;128:109-115.

59. Schjoldager B, Mortensen PE, Myhre J, Christiansen J, Holst JJ. Oxyntomodulin from distal gut. Role in regulation of gastric and pancreatic functions. Dig. Dis. Sci. 1989, 34:1411-1419.

60. Lin HC, Zhao XT, Wang L, Wong H. Fat-induced ileal brake in the dog depends on peptide YY. Gastroenterology 1996;110:1491-1495.

61. Savage AP, Adrian TE, Carolan G, Chatterjee VK, Bloom SR. Effects of peptide YY (PYY) on mouth to caecum intestinal transit time and on the rate of gastric emptying in healthy volunteers. Gut 1987; 28:166-170.

62. Vu MK, Maljaars JW, Biemond I, Mearadji B, Masclee AA. Role of Peptide YY in ileal brake induced satiety and proximal gastric function. Gastroenterology 2006;130:Suppl2; A68.

63. Koda S, Date Y, Murakami N, Shimbara T, Hanada T, Toshinai K, Niijima A, Furuya M, Inomata N, Osuye K, Nakazato $\mathrm{M}$. The role of the vagal nerve in peripheral PYY3-36-induced feeding reduction in rats. Endocrinology 2005;146:2369-2375.

64. Abbott CR, Monteiro M, Small CJ, Sajedi A, Smith KL, Parkinson JR, Ghatei MA, Bloom SR. The inhibitory effects of peripheral administration of peptide $\mathrm{YY}(3-36)$ and glucagon-like peptide-1 on food intake are attenuated by ablation of the vagal-brainstem-hypothalamic pathway. Brain Res 2005;1044:127-131. 
65. Batterham RL, Cowley MA, Small CJ, Herzog H, Cohen MA, Dakin CL, Wren AM, Brynes AE, Low MJ, Ghatei MA, Cone RD, Bloom SR. Gut hormone PYY(3-36) physiologically inhibits food intake. Nature 2002;418:650-654.

66. Batterham RL, Cohen MA, Ellis SM, le Roux CW, Withers DJ, Frost GS, Ghatei MA, Bloom SR. Inhibition of food intake in obese subjects by peptide YY3-36. N Engl J Med 2003;349:941-948.

67. Boggiano MM, Chandler PC, Oswald KD, Rodgers RJ, Blundell JE, Ishii Y, Beattie AH, Holch P, Allison DB, Schindler M, Arndt K, Rudolf K, Mark M, Schoelch C, Joost HG, Klaus S, Thone-Reineke C, Benoit SC, Seeley RJ, Beck-Sickinger AG, Koglin N, Raun K, Madsen K, Wulff BS, Stidsen CE, Birringer M, Kreuzer OJ, Deng XY, Whitcomb DC, Halem H, Taylor J, Dong J, Datta R, Culler M, Ortmann S, Castaneda TR, Tschop M. PYY3-36 as an anti-obesity drug target. Obes Rev 2005;6:307-322.

68. Degen L, Oesch S, Casanova M, Graf S, Ketterer S, Drewe J, Beglinger C. Effect of peptide YY3-36 on food intake in humans. Gastroenterology 2005;129:1430-1436.

69. Cummings DE, Overduin J. Gastrointestinal regulation of food intake. J Clin Invest 2007;117:13-23.

70. Abbott CR, Small CJ, Sajedi A, Smith KL, Parkinson JR, Broadhead LL, Ghatei MA, Bloom SR. The importance of acclimatisation and habituation to experimental conditions when investigating the anorectic effects of gastrointestinal hormones in the rat. Int J Obes (Lond) 2006;30:288-292.

71. Schirra J, Nicolaus M, Roggel R, Katschinski M, Storr M, Woerle HJ, Goke B. Endogenous glucagon-like peptide 1 controls endocrine pancreatic secretion and antro-pyloro-duodenal motility in humans. Gut 2006;55:243-251.

72. Schirra J, Wank U, Arnold R, Goke B, Katschinski M. Effects of glucagon-like peptide-1(7-36)amide on motility and sensation of the proximal stomach in humans. Gut 2002;50:341-348.

73. Wettergren A, Maina P, Boesby S, Holst JJ. Glucagon-like peptide-1 7-36 amide and peptide YY have additive inhibitory effect on gastric acid secretion in man. Scand J Gastroenterol 1997;32:552-555.

74. Schjoldager BT, Mortensen PE, Christiansen J, Orskov C, Holst JJ. GLP-1 (glucagon-like peptide 1) and truncated GLP-1, fragments of human proglucagon, inhibit gastric acid secretion in humans. Dig Dis Sci 1989;34:703-708.

75. Verdich C, Flint A, Gutzwiller JP, Naslund E, Beglinger C, Hellstrom PM, Long SJ, Morgan LM, Holst JJ, Astrup A. A meta-analysis of the effect of glucagon-like peptide-1 (7-36) amide on ad libitum energy intake in humans. J Clin Endocrinol Metab 2001;86:4382-4389.

76. Schirra J, Shakir S, Nicolaus M, Woerle J, Goeke B. Glucagon-like Peptide 1 (GLP-1) mediated the 'ileal brake' in humans. Gastroenterology 2006;130:Suppl 2.; A544.

77. Neary NM, Small CJ, Druce MR, Park AJ, Ellis SM, Semjonous NM, Dakin CL, Filipsson K, Wang F, Kent AS, Frost GS, Ghatei MA, Bloom SR. Peptide YY3-36 and glucagon-like peptide-17-36 inhibit food intake additively. Endocrinology 2005;146:5120-5127.

78. Biedzinski TM, Bataille D, Devaux MA, Sarles H. The effect of oxyntomodulin (glucagon-37) and glucagon on exocrine pancreatic secretion in the conscious rat. Peptides 1987;8:967-972.

79. Anini Y, Jarrousse C, Chariot J, Nagain C, Yanaihara N, Sasaki K, Bernad N, Le Nguyen D, Bataille D, Rozé C. Oxyntomodulin inhibits pancreatic secretion through the nervous system in rats. Pancreas 2000;20:348-360.

80. Cohen MA, Ellis SM, le Roux CW, Batterham RL, Park A, Patterson M, Frost GS, Ghatei MA, Bloom SR. Oxyntomodulin suppresses appetite and reduces food intake in humans. J Clin. Endocrinol Metab 2003;88:4696-4701.

81. Brown NJ, French SJ, Rumsey RD, Read NW. The effect of a 5-HT3-antagonist on the ileal brake mechanism in the rat. J Pharm Pharmacol 1991;43:517-519.

82. Brown NJ, Horton A, Rumsey RD, Read NW. Granisetron and ondansetron: effects on the ileal brake mechanism in the rat. J Pharm Pharmacol 1993;45:521-524.

83. Brown NJ, Rumsey RD, Bogentoft C, Read NW. The effect of adrenoceptor antagonists on the ileal brake mechanism in the rat. Br J Pharmacol 1992;105:751-755.

84. Brown NJ, Rumsey RD, Bogentoft C, Read NW. The effect of an opiate receptor antagonist on the ileal brake mechanism in the rat. Pharmacology 1993;47:230-236.

85. Kinsman RI, Read NW. Effect of naloxone on feedback regulation of small bowel transit by fat. Gastroenterology 1984;87:335-337. 
86. Lin HC, Chen JH. Slowing of intestinal transit by fat depends on an ondansetron - sensitive, efferent serotonergic pathway. Neurogastroenterol. Motil 2003;15:317-322.

87. Lin HC, Neevel C, Chen PS, Suh G, Chen JH. Slowing of intestinal transit by fat or peptide YY depends on beta-adrenergic pathway. Am. J. Physiol Gastrointest. Liver Physiol 2003;285:G1310-G1316.

88. Lin HC, Neevel C, Chen JH. Slowing intestinal transit by PYY depends on serotonergic and opioid pathways. Am. J. Physiol Gastrointest. Liver Physiol 2004;286:G558-G563.

89. Zhao XT, Wang L, Lin HC. Slowing of intestinal transit by fat depends on naloxone-blockable efferent, opioid pathway. Am. J. Physiol Gastrointest. Liver Physiol 2000;278:G866-G870.

90. Adrian TE, Ballantyne GH, Longo WE, Bilchik AJ, Graham S, Basson MD, Tierney RP, Modlin IM. Deoxycholate is an important releaser of peptide $\mathrm{YY}$ and enteroglucagon from the human colon. Gut 1993;34:1219-1224.

91. Sarr MG, Foley MK, Winters RC, Duenes JA, DiMagno EP. Role of extrinsic innervation in carbohydrate-induced ileal modulation of pancreatic secretion and upper gut function. Pancreas 1997;14:166-173.

92. Masuda M, Tomita H, Okubo K, Miyasaka K. Vagal efferent nerve-dependent inhibitory action of pancreatic polypeptide and peptide $Y Y$ in conscious rats: comparison with somatostatin. J Auton Nerv Syst 1994;50:131-138.

93. Wettergren A, Wojdemann M, Meisner S, Stadil F, Holst JJ. The inhibitory effect of glucagon-like peptide-1 (GLP-1) 7-36 amide on gastric acid secretion in humans depends on an intact vagal innervation. Gut 1997; 40:597-601.

94. Siegle ML, Schmid HR, Ehrlein HJ. Effects of ileal infusions of nutrients on motor patterns of canine small intestine. Am J Physiol 1990;259:G78-G85.

95. Welch IM, Cunningham KM, Read NW. Regulation of gastric emptying by ileal nutrients in humans. Gastroenterology 1988;94:401-404.

96. Randich A, Tyler WJ, Cox JE, Meller ST, Kelm GR, Bharaj SS. Responses of celiac and cervical vagal afferents to infusions of lipids in the jejunum or ileum of the rat. Am J Physiol Regul Integr Comp Physiol 2000;278:R34-R43.

97. Degen L, Matzinger D, Drewe J, Nissle S, Maecke H, Lengsfeld H, Hadvary P, Beglinger C. Role of free Fatty acids in regulating gastric emptying and gallbladder contraction. Digestion 2006;74:131-139.

98. Borovicka J, Schwizer W, Guttmann G, Hartmann D, Kosinski M, Wastiel C, Bischof-Delaloye A, Fried $M$. Role of lipase in the regulation of postprandial gastric acid secretion and emptying of fat in humans: a study with orlistat, a highly specific lipase inhibitor. Gut 2000;46:774-781.

99. Feinle C, O'Donovan D, Doran S, Andrews JM, Wishart J, Chapman I, Horowitz M. Effects of fat digestion on appetite, APD motility, and gut hormones in response to duodenal fat infusion in humans. Am. J Physiol Gastrointest. Liver Physiol 2003;284:G798-G807.

100. Layer $P, G o$ VL, DiMagno EP. Fate of pancreatic enzymes during small intestinal aboral transit in humans. Am J Physiol 1986;251:G475-G480.

101. Holtmann G, Kelly DG, Sternby B, DiMagno EP. Survival of human pancreatic enzymes during small bowel transit: effect of nutrients, bile acids, and enzymes. Am J Physiol 1997;273:G553-G558.

102. Meyer JH, Gu YG, Jehn D, Doty JE. Factors that affect the performance of lipase on fat digestion and absorption in a canine model of pancreatic insufficiency. Pancreas 1994;9:613-623.

103. Raybould HE, Meyer JH, Tabrizi Y, Liddle RA, Tso P. Inhibition of gastric emptying in response to intestinal lipid is dependent on chylomicron formation. Am J Physiol 1998;274:R1834-R1838.

104. Hunt JN, Knox MT. A relation between the chain length of fatty acids and the slowing of gastric emptying. J Physiol 1968;194:327-336.

105. McLaughlin J, Grazia LM, Jones MN, D'Amato M, Dockray GJ, Thompson DG. Fatty acid chain length determines cholecystokinin secretion and effect on human gastric motility. Gastroenterology 1999; 116:46-53.

106. Brown NJ, Read NW, Richardson A, Rumsey RD, Bogentoft C. Characteristics of lipid substances activating the ileal brake in the rat. Gut 1990;31:1126-1129. 
107. Feltrin KL, Little TJ, Meyer JH, Horowitz M, Smout AJ, Wishart J, Pilichiewicz AN, Rades T, Chapman IM, Feinle-Bisset C. Effects of intraduodenal fatty acids on appetite, antropyloroduodenal motility, and plasma CCK and GLP-1 in humans vary with their chain length. Am J Physiol Regul Integr Comp Physiol 2004;287:R524-R533.

108. Cuche G, Cuber JC, Malbert $\mathrm{CH}$. Ileal short-chain fatty acids inhibit gastric motility by a humoral pathway. Am. J Physiol Gastrointest. Liver Physiol 2000;279:G925-G930.

109. St-Onge MP, Jones PJ. Physiological effects of medium-chain triglycerides: potential agents in the prevention of obesity. J Nutr 2002;132:329-332.

110. Van WV, Louis-Sylvestre J, Fantino M. Substrate oxidation and control of food intake in men after a fat-substitute meal compared with meals supplemented with an isoenergetic load of carbohydrate, long-chain triacylglycerols, or medium-chain triacylglycerols. Am J Clin Nutr 2001;74:620-630.

111. Alfenas RC, Mattes RD. Effect of fat sources on satiety. Obes Res 2003;11:183-187.

112. French SJ, Conlon CA, Mutuma ST, Arnold M, Read NW, Meijer G, Francis J. The effects of intestinal infusion of long-chain fatty acids on food intake in humans. Gastroenterology 2000;119:943-948.

113. Maljaars J, Haddeman E, Peters H, Masclee A. Effect of degree of saturation of triacylglycerols on ileal brake and satiety. Gastroenterology 2007;132:A-79 Suppl.1.

114. Dobson CL, Davis SS, Chauhan S, Sparrow RA, Wilding IR. The effect of oleic acid on the human ileal brake and its implications for small intestinal transit of tablet formulations. Pharm Res 1999;16:92-96.

115. Symersky T, Kee B, Haddeman E, Peters HP, Masclee AA. Low dose ileal oil perfusion increases satiety in humans. Gastroenterology 2004;126:A60 Suppl 2.

116. Groger G, Unger A, Holst JJ, Goebell H, Layer P. Ileal carbohydrates inhibit cholinergically stimulated exocrine pancreatic secretion in humans. Int J Pancreatol 1997;22:23-29.

117. Azpiroz F, Malagelada JR. Intestinal control of gastric tone. Am J Physiol 1985;249:G501-G509.

118. Lin HC, Zhao XT, Chu AW, Lin YP, Wang L. Fiber-supplemented enteral formula slows intestinal transit by intensifying inhibitory feedback from the distal gut. Am J Clin Nutr 1997;65:1840-1844.

119. Koopmans HS. The role of the ileum in the control of food intake and intestinal adaptation. Can J Physiol Pharmacol 1990;68:650-655.

120. Woltman T, Reidelberger R. Effects of duodenal and distal ileal infusions of glucose and oleic acid on meal patterns in rats. Am J Physiol 1995;269:R7-14.

121. Glick Z, Modan M. Behavioral compensatory responses to continuous duodenal and upper ileal glucose infusion in rats. Physiol Behav 1977;19:703-705.

122. Glick Z. Intestinal satiety with and without upper intestinal factors. Am J Physiol 1979;236:R142-R146.

123. Cox JE, Tyler WJ, Randich A, Kelm GR, Bharaj SS, Jandacek RJ, Meller ST. Suppression of food intake, body weight, and body fat by jejunal fatty acid infusions. Am J Physiol Regul Integr Comp Physiol 2000;278:R604-R610.

124. Payne JH, DeWind LT. Surgical treatment of obesity. Am J Surg 1969;118:141-147.

125. Pilkington TR, Gazet JC, Ang L, Kalucy RS, Crisp AH, Day S. Explanations for weight loss after ileojejunal bypass in gross obesity. BMJ 1976;1:1504-1505.

126. Condon SC, Janes NJ, Wise L, Alpers DH, Role of caloric intake in the weight loss after jejunoileal bypass for obesity. Gastroenterology 1978;74:34-37.

127. Naslund E,. Melin I, Gryback P, Hagg A, Hellstrom PM, Jacobsson H, Theodorsson E, Rossner S, Backman L. Reduced food intake after jejunoileal bypass: a possible association with prolonged gastric emptying and altered gut hormone patterns. Am J Clin. Nutr 1997;66:26-32.

128. Bray GA, Barry RE, Benfield JR, Castelnuovo-Tedesco P, Rodin J. Intestinal bypass surgery for obesity decreases food intake and taste preferences. Am J Clin Nutr 1976;29:779-783.

129. Atkinson RL. Obesity surgery as a model for understanding the regulation of food intake and body weight. Am J Clin Nutr 1997;66:184-185.

130. Backman L, Wiklund B, Svane B, Hallberg D. A roentgenological study of the small intestine after different intestinal bypass operations for treatment of morbid obesity. Int J Obes 1982;6:205-210.

131. Naslund E, Gryback P, Backman L, Jacobsson H, Holst JJ, Theodorsson E, Hellstrom PM. Distal small bowel hormones: correlation with fasting antroduodenal motility and gastric emptying. Dig Dis Sci 1998;43:945-952. 
132. Hocking MP, Davis GL, Franzini DA, Woodward ER. Long-term consequences after jejunoileal bypass for morbid obesity. Dig Dis Sci 1998;43:2493-2499.

133. Strader AD, Vahl TP, Jandacek RJ, Woods SC, D'Alessio DA, Seeley RJ. Weight loss through ileal transposition is accompanied by increased ileal hormone secretion and synthesis in rats. Am J Physiol Endocrinol Metab 2005;288:E447-E453.

134. Koopmans HS. An integrated organismic response to lower gut stimulation. Scand J Gastroenterol. Suppl 1983;82:143-153.

135. Koopmans HS, Ferri GL, Sarson DL, Polak JM, Bloom SR. The effects of ileal transposition and jejunoileal bypass on food intake and GI hormone levels in rats. Physiol Behav 1984;33:601-609.

136. de Paula AL, Macedo AL, Prudente AS, Queiroz L, Schraibman V, Pinus J. Laparoscopic sleeve gastrectomy with ileal interposition ("neuroendocrine brake")--pilot study of a new operation. Surg Obes Relat Dis 2006;2:464-467.

137. Parker BA, Sturm K, Maclntosh CG, Feinle C, Horowitz M, Chapman IM. Relation between food intake and visual analogue scale ratings of appetite and other sensations in healthy older and young subjects. Eur J Clin Nutr 2004;58:212-218.

138. Drapeau V, King N, Hetherington M, Doucet E, Blundell J, Tremblay A. Appetite sensations and satiety quotient: Predictors of energy intake and weight loss. Appetite 2007;48:159-166.

139. Womble LG, Williamson DA, Greenway FL, Redmann SM. Psychological and behavioral predictors of weight loss during drug treatment for obesity. Int J Obes Relat Metab Disord 2001;25:340-345.

140. Hansen DL, Toubro S, Stock MJ, Macdonald IA, Astrup A. The effect of sibutramine on energy expenditure and appetite during chronic treatment without dietary restriction. Int J Obes Relat Metab Disord 1999;23:1016-1024.

141. Doty JE, Gu YG, Meyer JH. The effect of bile diversion on satiety and fat absorption from liquid and solid dietary sources. J Surg Res 1988;45:537-543.

142. Meyer JH, Elashoff JD, Doty JE, Gu YG. Disproportionate ileal digestion on canine food consumption. A possible model for satiety in pancreatic insufficiency. Dig Dis Sci 1994;39:1014-1024.

143. Hill JO, Wyatt HR, Reed GW, Peters JC. Obesity and the environment: where do we go from here? Science 2003;299:853-855.

144. Rubino F. Bariatric surgery: effects on glucose homeostasis. Curr Opin Clin Nutr Metab Care 2006; 9:497-507.

145. Aylwin S. Gastrointestinal surgery and gut hormones. Curr Opin Endocrinol Diabetes 2005;12:89-98.

146. Patriti A, Facchiano E, Annetti C, Aisa MC, Galli F, Fanelli C, Donini A. Early improvement of glucose tolerance after ileal transposition in a non-obese type 2 diabetes rat model. Obes Surg 2005;15: 1258-1264.

147. Drucker DJ, Nauck MA. The incretin system: glucagon-like peptide-1 receptor agonists and dipeptidyl peptidase-4 inhibitors in type 2 diabetes. Lancet 2006;368:1696-1705.

148. Groger G, Cherian L, Goebell H, Layer P. Ileal inhibition and modulation of carbachol-stimulated proximal small intestinal motor functions in humans. Z Gastroenterol 1996;34:791-794.

149. Strader AD. Ileal transposition provides insight into the effectiveness of gastric bypass surgery. Physiol Behav 2006;88:277-282.

150. Patriti A, Aisa MC, Annetti C, Sidoni A, Galli F, Ferri I, Gulla N, Donini A. How the hindgut can cure type 2 diabetes. Ileal transposition improves glucose metabolism and beta-cell function in Goto-kakizaki rats through an enhanced Proglucagon gene expression and L-cell number. Surgery 2007;142:74-85. 


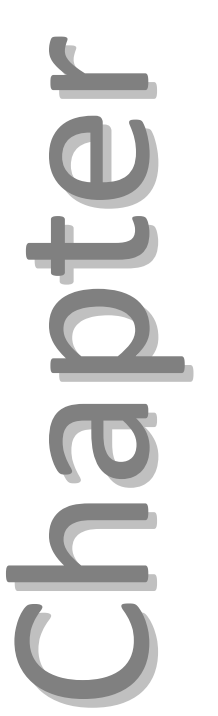

\section{Effect of ileal fat perfusion on satiety and} hormone release in healthy volunteers

Maljaars PWJ, Symersky T, Kee BC, Haddeman E, Peters HPF, Masclee AAM. Int J Obes (Lond) 2008;32:1633-1639 


\section{Abstract}

\section{Objective}

The ileal brake is a feedback mechanism activated by nutrients, especially fat, with marked effects on satiety. The effects of low doses of ileal fat on satiety are largely unknown. We therefore studied the effect of ileal vs. oral delivery of low doses of fat on satiety and gut peptide secretion.

\section{Design}

Randomized, single-blind crossover design

\section{Subjects}

Sixteen healthy, normal weight volunteers (6 male; mean age $26 \mathrm{yr}$, mean BMI 22.4).

\section{Intervention}

Subjects were intubated with a $290 \mathrm{~cm}$ long nasoileal tube and consumed, on three consecutive days, either a liquid breakfast with $3 \mathrm{~g}$ fat followed by an ileal placebo infusion at $\mathrm{t}=105-150$ min (treatment $\mathrm{C}$ ) or a fat-free liquid breakfast followed by an ileal infusion of either an emulsion of $3 \mathrm{~g}$ (treatment $13 \mathrm{~g}$ ) or $9 \mathrm{~g}$ (treatment 19g) safflower oil.

\section{Measurements}

Satiety parameters by visual analogue scales and plasma concentrations of CCK and PYY.

\section{Results}

C significantly increased satiety and CCK secretion compared to the fat-free breakfast. lleal fat perfusion of both $3 \mathrm{~g}$ and $9 \mathrm{~g}$ ( $13 \mathrm{~g}$ and $19 \mathrm{~g}$ ) significantly increased satiety during and after fat perfusion, without differences in satiety between $13 \mathrm{~g}$ and $19 \mathrm{~g}$. During ileal fat infusion, CCK increased dose-dependently, whereas PYY-concentrations increased significantly only after $9 \mathrm{~g}$ of fat. Secretion of CCK but not of PYY correlated to satiety levels.

\section{Conclusion}

Postprandial satiety following a liquid breakfast can be effectively and significantly increased by small amounts (as little as $3 \mathrm{~g}$ ) of fat perfused into the ileum. lleal fat dose-dependently increased CCK but not PYY secretion. The satiating effect of ileal fat may be partly mediated by CCK. 


\section{Introduction}

Satiety feelings on a meal-to-meal basis are to a large extent determined by gastrointestinal signals ${ }^{1}$. An option to prolong satiety and to reduce food intake is by delaying gastric emptying and/or small intestinal transit time $e^{2-4}$. This may be achieved by activation of the ileal brake $e^{5}$. The ileal brake is the primary inhibitory distal to proximal located feedback mechanism that controls meal transit through the gastrointestinal tract and is thought to regulate and optimize nutrient digestion and absorption $^{5}$. Several studies have shown that direct delivery of lipids into the ileum delays gastric emptying ${ }^{6}$, prolongs small intestinal transit time ${ }^{7}$ and induces satiety ${ }^{8}$. Long chain fatty acids (LCFA) are potent triggers of the ileal brake $\mathrm{e}^{5,7}$, and several studies have demonstrated that the ileal brake is already activated by small amounts of fat or free fatty acids ${ }^{9-11}$.

However, it is not known whether these small amounts of fat are able to induce satiety and influence food intake. Evidence for a direct effect of the ileal brake on satiety and food intake in humans is limited to two publications from the same research group ${ }^{8,12}$. An ileal infusion of $370 \mathrm{kcal}$ of lipids resulted in a significant reduction in hunger with a net decrease in caloric intake of $711 \mathrm{kcal}$. It should be noted that the amounts of fat used in these studies were high $(41 \mathrm{~g})$, and no studies have been performed on the satiating effect of ileal brake activation by very small amounts of fat.

Our aim was to explore whether delivery of small amounts of lipids into the ileum will further increase postprandial satiety and whether this effect is dose dependent. A second aim was to evaluate the effect of ileal lipid administration on gut peptide secretion, more specifically, on CCK, as a more proximal gut peptide with well known satiety effects ${ }^{13}$ and peptide $Y Y$, as a distal gut peptide and proposed biomarker for the activation of the ileal brake ${ }^{10}$.

We constructed the following hypotheses: Compared to oral ingestion of $3 \mathrm{~g}$ of lipid added to a liquid meal, delivery of the same amount of lipid through postprandial (after ingestion of the fat-free breakfast) perfusion into the ileum will 1) lead to an increase in postprandial satiety, 2) be dose-dependent ( $9 \mathrm{~g}$ vs. $3 \mathrm{~g}$ in the ileum) and 3) lead to distal gut hormone secretion.

\section{Method}

\section{Subjects}

Healthy volunteers were recruited by public advertisement. Sixteen volunteers were seen for screening. This included a questionnaire (Dutch Eating Behavior 
Questionnaire) to exclude restrained eaters, blood tests and physical examination. Signed informed consent was obtained from each individual. None had a history of gastro-intestinal disease or abdominal surgery, and none were using any medication. After providing their written informed consent, sixteen healthy individuals (mean age 26 yrs, range, $18-60$ yrs, mean BMI $22.4 \mathrm{~kg} / \mathrm{m}^{2}$ range $18.7-28.6 \mathrm{~kg} / \mathrm{m}^{2}$ ) participated in this study.

\section{Naso-ileal catheter}

Subjects were intubated with a 9-lumen $290 \mathrm{~cm}$ naso-ileal cathether ( 8 infusion ports, 1 balloon inflation channel, Dentsleeve International Ltd., Mississauga Canada). Through an anaesthetized nostril, the catheter was introduced into the stomach, and allowed to pass through the pylorus to the ileum by peristalsis. After passing the ligament of Treitz, a small balloon at the tip was inflated to facilitate passage of the catheter to the ileum. The tip was placed in the ileum (at least $120 \mathrm{~cm}$ catheter length distal from the pylorus-the catheters were fitted with radiopaque markers that enabled assessment of the length of catheter), so that three infusion ports were available in the ileum, and at least one infusion port in the duodenum. After this, the subjects were instructed to inflate and deflate the balloon during the evening, and inflate the balloon upon waking up, in order to advance further passage of the tube. During the positioning and before and directly after every test-day, the position of the catheter was checked fluoroscopically. The fluoroscopy techniques used do not enable assessment of the position of the tube compared to the ileocecal valve. However, on fluoroscopy, it was shown that the catheter made multiple loops within the small intestine. Furthermore, in two cases, contrast fluid was used to visualize the exact position of the catheter. After infusion of the contrast fluid, the contrast appeared in the colon within a few minutes, and a short segment of small bowel was visible $(30-60 \mathrm{~cm})$.

\section{Experimental design}

In this single-blind randomized controlled crossover design, each subject participated in three experiments on three consecutive days in random order. In treatment $C$ (oral fat, $3 \mathrm{~g}$ ), subjects received a liquid meal with $3 \mathrm{~g}$ of fat (breakfast $\mathrm{X}, \mathrm{BX}$ ) and an ileal placebo infusion (emulsion A). In treatment $13 \mathrm{~g}$ (ileal fat, $3 \mathrm{~g}$ ), subjects received a fatfree liquid meal (breakfast $\mathrm{Y}, \mathrm{BY}$ ) and an ileal infusion with an emulsion with $3 \mathrm{~g}$ of fat (emulsion B). In treatment $19 \mathrm{~g}$ (ileal fat, $9 \mathrm{~g}$ ), subjects received fat-free breakfast (BY) and an ileal infusion with an emulsion with $9 \mathrm{~g}$ of fat (emulsion $\mathrm{C}$ ).

On each study day (Figure 4.1), the subject arrived at the laboratory at 8:00 AM following an overnight fast. After checking the correct position of the catheter by 
fluoroscopy, a venous catheter was placed in a forearm-vein for collection of blood samples. At 9:00 a basal blood sample and a basal VAS score were taken. Immediately thereafter, the liquid meal was consumed. The ileal infusion was scheduled from $\mathrm{t}=105-150 \mathrm{~min}$ after meal ingestion, at a rate of $1 \mathrm{ml} / \mathrm{min}$. This resulted in an infusion rate of $0.6 \mathrm{kcal} / \mathrm{min}$ for the $13 \mathrm{~g}$ treatment, and $1.35 \mathrm{kcal} / \mathrm{min}$ for the $19 \mathrm{~g}$ treatment. For this experiment, the follow-up ended at $\mathrm{t}=240 \mathrm{~min}$.

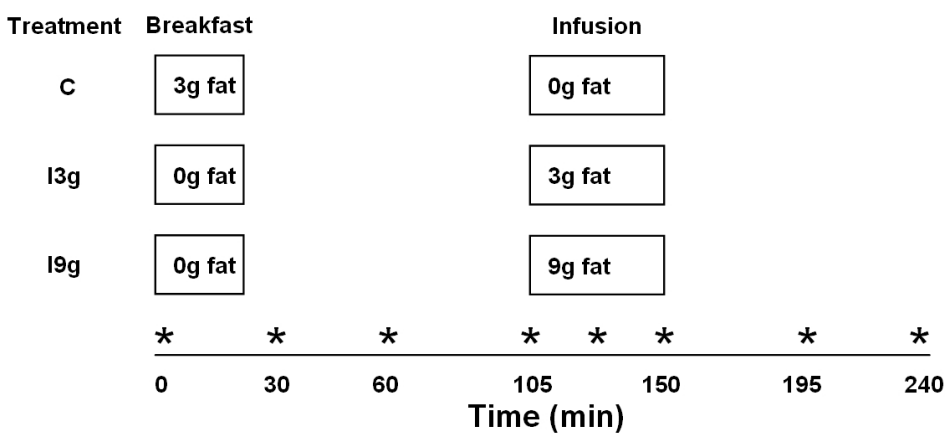

Figure 4.1 Study outline for the three experiments. Order of treatments was randomized. Each test day started with consumption of breakfast. Each subject consumed either a breakfast with $3 \mathrm{~g}$ fat followed by an ileal saline infusion at $\mathrm{t}=105-150 \mathrm{~min}$ (treatment $\mathrm{C}$ ) or a fat-free breakfast followed at $\mathrm{t}=105 \mathrm{~min}$ by an ileal infusion of either an emulsion of $3 \mathrm{~g}$ (treatment $\mathrm{I3g}$ ) or $9 \mathrm{~g}$ (treatment 19g) safflower oil. * denotes drawing blood sample \& satiety questionnaire.

This study was designed as a proof-of-principle study to evaluate dose-dependent effects of the ileal brake on satiety. The timing of the ileal fat perfusions is crucial and should represent the physiological postprandial conditions. We chose the infusion period at $\mathrm{t}=105-150 \mathrm{~min}$, as we thought this would best represent the physiological moment of arrival of the bulk of the fat ${ }^{14}$. Furthermore, Goebell et al. ${ }^{15}$ demonstrated that delivery of a meal marker to the ileum was the highest at 2-2.75 hours after ingestion of the meal. In this study, we tried to resemble to physiologic postprandial situation.

\section{Liquid meals and emulsions}

The liquid breakfasts and the fat emulsions (+ placebo) for ileal perfusion were produced by Unilever Research \& Development, Vlaardingen, the Netherlands. Two $325 \mathrm{ml}$ breakfast drinks were produced: BX (220 kcal) consisting of 99.1\% Slim.Fast French Vanilla US (fat-free) and $0.9 \%$ safflower oil, and BY (193 kcal) consisting of $100 \%$ Slim.Fast French Vanilla US (fat-free). Three emulsions were produced: placebo 
(named emulsion $\mathrm{A}$ - strictly speaking this is not an emulsion as it does not contain any oil) consisted of $1.0 \%$ sodium caseinate, $0.1 \%$ skim milk powder, $0.1 \%$ Guar gum, $0.9 \%$ sodium chloride in demineralized water. Oil emulsion B was composed of $1.0 \%$ sodium caseinate, $0.1 \%$ skim milk powder, $0.1 \%$ Guar gum, $0.9 \%$ sodium chloride and $6.0 \%$ safflower oil in demineralized water. Oil emulsion $\mathrm{C}$ was identical to emulsion $\mathrm{B}$ except that the oil concentration was $18 \%$ and $\mathrm{NaCl}$ was $0.66 \%$.

\section{Satiety scores}

The volunteers rated their feelings of hunger and satiety (and appetite for a meal, fullness, appetite for a snack and satiety) by means of a mark on 64-mm line scales using a EVAS (Electronic Visual Analogue Scale, iPAQ) ${ }^{16}$. This scale was anchored at the low end with the most negative or lowest intensity feelings (e.g., "extremely unpleasant", "not at all"), and with opposing terms at the high end (e.g., "extremely pleasant", "very high", "extreme") as described by Flint et al. ${ }^{17}$.

Measurements were taken during the test day every $30 \mathrm{~min}$ from $\mathrm{t}=0-240 \mathrm{~min}$, and every 15 min during infusion of emulsion ( $t=105-150 \mathrm{~min}$ ).

Gastrointestinal disturbances were scored using forms (4-point scale: "none", "a little", "some", "substantial") at regular intervals ( $t=-5,105,150,235,345,390,435$ min). The following gastrointestinal symptoms were scored: nausea, heartburn, belching, abdominal bloating, abdominal pain, borborygmi, flatulence, and urge to defecate. The following general symptoms were also scored: headache, malaise, dizziness, and fatigue.

\section{Hormone assays}

Blood samples were drawn at $\mathrm{t}=0$ (start meal ingestion), $\mathrm{t}=30, \mathrm{t}=60, \mathrm{t}=105$ (start ileal infusion), $t=125, t=150$ (end ileal infusion), $t=195, t=240$ min.

Total plasma PYY was measured by radioimmunoassay. PYY antiserum was generated in rabbits by intracutaneous injections of synthetic human PYY (BACHEM Biochemica $\mathrm{GmbH}$, Switzerland). PYY was labeled with ${ }^{125}$ lodine with chloramine T. The assay is highly specific. There is no cross-reactivity with PP or VIP. The detection limit is $10 \mathrm{pmol} / \mathrm{I}$. Both $\mathrm{PYY}_{(1-36)}$ and PYY(3-36) bind to the antibody in dilutions up to 250000. The intra-assay variation ranges from 1.8 to $15.6 \%$ and the inter-assay variation from 9.5 to $27.8 \%^{18}$.

Plasma CCK concentrations were measured by a RIA, as described previously ${ }^{19}$. The detection limit of the assay is $0.3 \mathrm{pM}$. The intra-assay variation ranges from 4.6 to $11.5 \%$ and the inter-assay variation from 11.3 to $26.1 \%{ }^{20}$. 


\section{Statistical analysis}

Results are expressed as least square means with standard error (SE), unless otherwise specified. Satiety and hunger measurements were calculated as absolute ratings.

Satiety scores were expressed as percentages of the maximal score $(0 \mathrm{~mm}$ equaled $0 \%$ and $64 \mathrm{~mm}$ equaled 100\%) and as incremental cumulative areas under the curve (iAUC). The AUC was calculated, using the trapezoid rule, for different periods and corrected for level at the start of that period (incremental AUC). All parameters were analyzed using analysis of variance with subjects as blocks and the three treatments as factor. Differences between treatment groups were established using Fisher's least significance difference (two-tailed). A p-value of 0.05 was considered significant. To establish possible relationships between plasma hormones and satiety ratings, Pearson's R correlations between plasma CCK and PYY levels and the corresponding VAS scores for satiety and hunger were calculated. For this correlation AUC for all time periods and changes in absolute levels in time were used.

Gastrointestinal disturbances were analysed using frequency of occurrence per time point and a standard ANOVA with the personal scores corrected for each subject's overall mean score.

\section{Statement of Ethics}

We certify that all applicable institutional and governmental regulations concerning the ethical use of human volunteers were followed during this research. The study protocol was approved by the Ethical Committee of the Leiden University Medical Centre.

\section{Results}

\section{Satiety scores}

Since all satiety parameters gave similar type results, we will only show scores for satiety and hunger. VAS scores for satiety are given in Figure $\mathbf{4 . 2}$ and for hunger in Figure 4.3. Fasting scores for hunger and satiety did not differ between the three treatments. Consumption of the meal increased satiety and decreased hunger feelings in all three treatments compared to baseline. At $t=30 \mathrm{~min}$, suppression of hunger levels was significantly more pronounced after the fat containing compared to the fat free breakfast, and scores remained lower till the start of the ileal infusion (sign. for hunger and satiety at $\mathrm{t}=105 \mathrm{~min})$. At $\mathrm{t}=150 \mathrm{~min}$, scores for satiety were significantly higher after treatments $13 \mathrm{~g}$ and $19 \mathrm{~g}$ compared to C. Incremental AUCs (iAUCs) for 
hunger and satiety for the different time periods are given in Table 4.1. From meal ingestion up to the start of the infusion, no significant differences were observed between the different treatments. However, from the start of the infusion till the end of the study day, iAUC for satiety was sign. higher after I3 g compared to C.

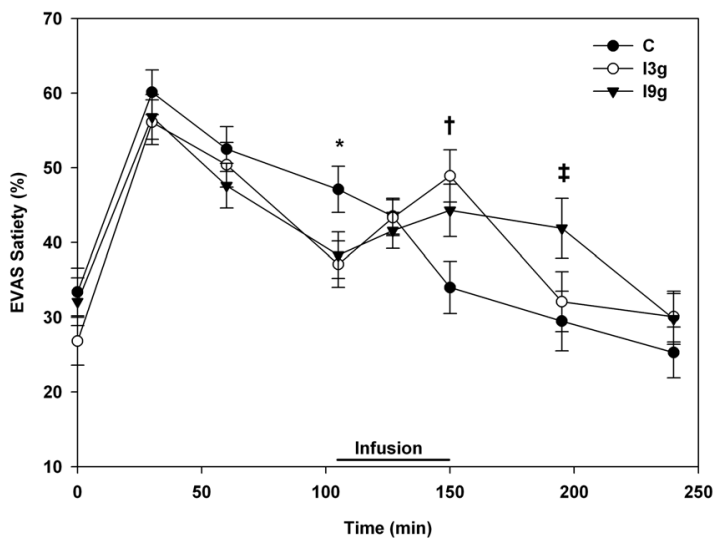

Figure 4.2 Subjective EVAS scores for satiety. * denotes $p<0.05$ for $\mathrm{C}$ vs. $13 \mathrm{~g}$ and $19 \mathrm{~g}$, + denotes $\mathrm{p}<0.05$ for $13 \mathrm{~g}$ and $19 \mathrm{~g}$ vs. $\mathrm{C}$ and $\ddagger$ denotes $\mathrm{p}<0.05$ for $19 \mathrm{~g}$ vs. $\mathrm{C}$.

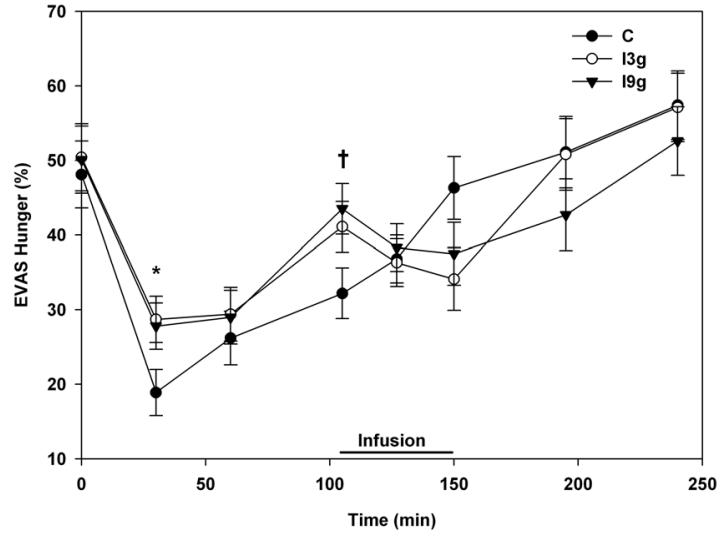

Figure 4.3 Subjective EVAS scores for hunger.

$*$ denotes $p<0.05$ for $C$ vs. I3g, + denotes $p<0.05$ for $C$ vs. 19g. 
Table 4.1 Incremental AUCs satiety scores

\begin{tabular}{|c|c|c|c|c|}
\hline Parameter & $\begin{array}{c}C \\
(\% \cdot \min )\end{array}$ & $\begin{array}{c}\text { I3g } \\
\text { (\%.min) }\end{array}$ & $\begin{array}{c}19 \mathrm{~g} \\
\text { (\%.min) }\end{array}$ & SE \\
\hline \multicolumn{5}{|l|}{ Satiety } \\
\hline 0-105 min & 17.4 & 19.0 & 13.9 & 2.5 \\
\hline $105-240 \mathrm{~min}$ & 0.6 & $11.8^{*}$ & 8.2 & 3.8 \\
\hline $0-240 \mathrm{~min}$ & 8.1 & 15.0 & 10.8 & 2.9 \\
\hline \multicolumn{5}{|l|}{ Hunger } \\
\hline 0-105 min & -19.6 & -15.7 & -15.3 & 3.0 \\
\hline $105-240 \mathrm{~min}$ & -1.4 & -6.3 & -7.9 & 4.0 \\
\hline $0-240 \mathrm{~min}$ & -9.5 & -10.5 & -11.2 & 1.7 \\
\hline
\end{tabular}

*denotes $p<0.05$ vs. C

\section{CCK}

Plasma CCK-concentrations are given in Figure 4.4. Baseline plasma CCK concentrations did not differ between study days. At $t=30$ and $t=60 \mathrm{~min}$, plasma CCKconcentrations were significantly higher after treatment $\mathrm{C}$ compared to $\mathrm{I3g}$ and $19 \mathrm{~g}$. The ileal infusions caused a rapid and significant increase in plasma CCK concentrations, resulting in significantly higher plasma concentrations for $19 \mathrm{~g}$ and for I3g compared to C. With regard to iAUCs (Table 4.2), CCK release was significantly larger after $\mathrm{C}$ compared to $\mathrm{I3g}$ and $19 \mathrm{~g}$ in the period from meal ingestion till the start of the infusion. IAUCs for $13 \mathrm{~g}$ and $19 \mathrm{~g}$ were significantly higher compared to $\mathrm{C}$ for the period between the start of the infusion period and the end of the test period.

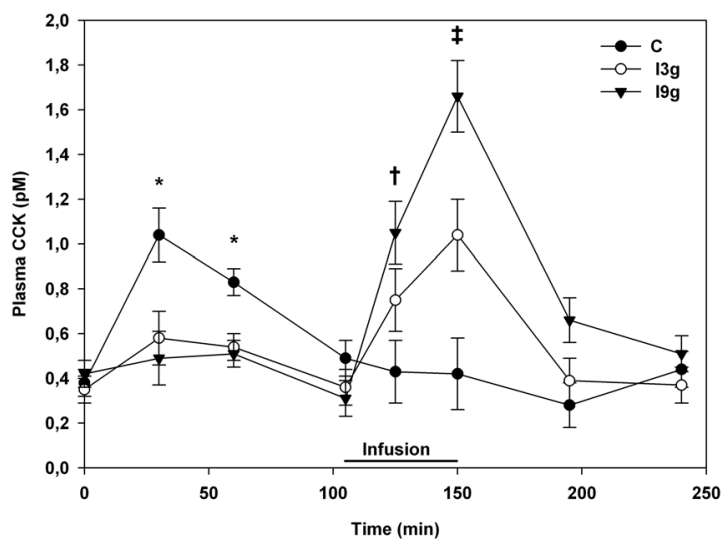

Figure 4.4 Plasma CCK concentrations. * denotes $p<0.05$ for $C$ vs. $13 g$ and $19 g$, + denotes $p<0.05$ for $19 g$ vs. $C$ and $\ddagger$ denotes $p<0.05$ for $19 \mathrm{~g}$ vs. $C$ and $\mathrm{I} 3 \mathrm{~g}$, and for $\mathrm{IBg}$ vs. $\mathrm{C}$. 
Table 4.2 Incremental AUCs gut peptides.

\begin{tabular}{lcccr}
\hline Parameter & $\begin{array}{c}\text { C } \\
\text { (pM.min) }\end{array}$ & $\begin{array}{c}\text { I3g } \\
\text { (pM.min) }\end{array}$ & $\begin{array}{c}\text { I9g } \\
\text { (pM.min) }\end{array}$ & SE \\
\hline CCK & & & & 6.2 \\
0-105 min & 37 & $15^{*}$ & $3 *$ & 10.9 \\
105-240 min & -1 & $35^{*}$ & $62^{*}$ & 13.8 \\
0-240 min & 37 & 50 & 65 & 91 \\
PYY & & & & 147 \\
0-105 min & 366 & $-6^{*}$ & $1171^{* *}$ & 170 \\
105-240 min & -50 & 74 & $1318^{* *}$ & 228 \\
$0-240$ min & 316 & 68 & & \\
\hline
\end{tabular}

*denotes $\mathrm{p}<0.05$ vs. $\mathrm{C} ;{ }^{* *}$ denotes $\mathrm{p}<0.05$ vs. $\mathrm{C}$ and $\mathrm{I3} \mathrm{g}$

\section{PYY}

Plasma PYY-concentrations are given in Figure 4.5. Baseline plasma PYY concentrations did not differ between study days. The fat containing liquid meal induced a significantly larger postprandial ( $t=0-105 \mathrm{~min}$ ) increase in PYY-concentration compared to I3g and I9g (Table 4.2).

The ileal infusion significantly increased plasma PYY-concentrations only after treatment 19g, whereas no effect on plasma PYY was seen in treatment 13g. After treatment 19g, plasma PYY remained significantly increased from $\mathrm{t}=150-240 \mathrm{~min}$ as compared to treatments $\mathrm{C}$ and $\mathrm{IBg}$.

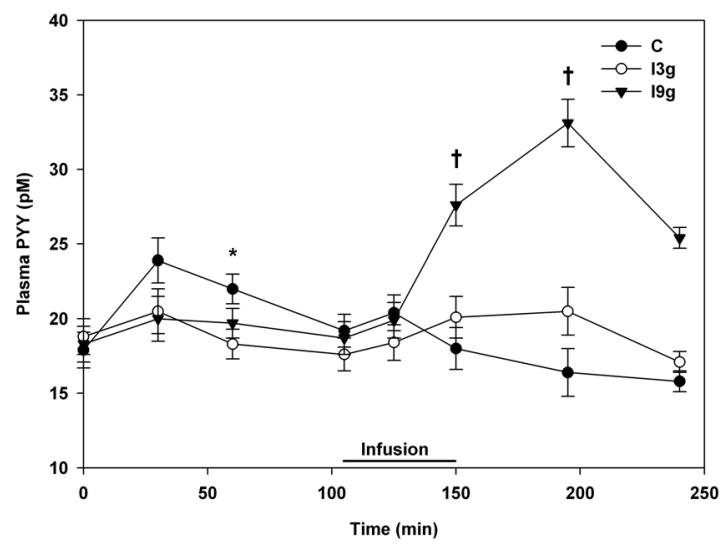

Figure 4.5 Plasma PYY concentrations. * denotes $p<0.05$ for $\mathrm{C}$ vs. $13 g$, + denotes $p<0.05$ for $19 \mathrm{~g}$ vs. C. 


\section{Correlations}

Plasma hormone levels and the corresponding VAS scores for satiety and hunger were plotted and correlations were calculated between CCK and PYY and satiety scores. For the period starting with the ileal perfusion until noon (105-240 min), significant positive correlations $(r=0.68, P<0.01)$ were found between the change in plasma CCK secretion and the increase in satiety (Figure 4.6.) No significant correlations between PYY concentrations and satiety scores were observed.

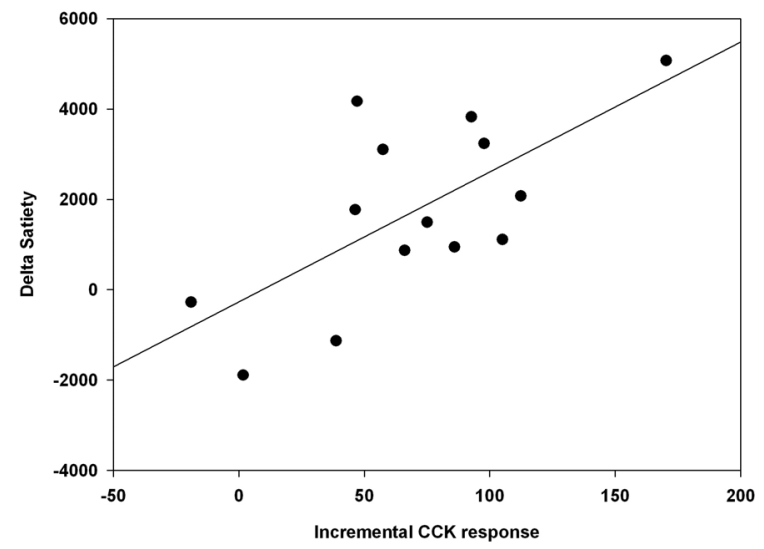

Figure 4.6 Correlation between incremental plasma CCK response and the delta of the satiety scores for the period starting with the ileal perfusion until the end of the test day (105-240 $\mathrm{min}) . \mathrm{R}=0.68$, $p<0.01$

\section{Discussion}

We are the first to demonstrate in humans that postprandial infusion of a small amount of fat into the ileum reduces hunger and increases satiety. This satiating effect was not different between 3 and $9 \mathrm{~g}$ ileal fat, and correlates with CCK secretion. Surprisingly, the release of PYY did not parallel the activation of the ileal brake triggered by ileal fat, as only the high dose $(9 \mathrm{~g})$ increased plasma PYY concentrations. Nutrients administered into the ileum inhibit gastric emptying ${ }^{6}$, slow intestinal motility and transit ${ }^{7,21}$, decrease exocrine pancreatic secretion ${ }^{9}$ and reduce food intake $^{8}$. These effects have been attributed to activation of the ileal brake mechanism ${ }^{5}$. Until recently, it was assumed that undigested nutrients reach the distal small intestine only under conditions of malabsorption or maldigestion. A more recent 
study in dogs has clearly shown that even under physiological circumstances unabsorbed fat reaches the distal small intestine and activates the ileal brakemechanism ${ }^{22}$. A role for the ileal brake in the physiologic regulation of gastrointestinal motility and secretion has been proposed ${ }^{23}$.

The effect of lipids administered into the small intestine on satiety and food intake in humans has been studied previously by Welch et al. ${ }^{8,12}$. These authors demonstrated that infusion of fat in the ileum caused a reduction in food intake in healthy volunteers.

In our experiments, we perfused the ileum with only small amounts of lipid ( 3 and $9 \mathrm{~g}$ of lipid in total, perfused over a $45 \mathrm{~min}$ period). This results in a delivery of calories to the ileum of $0.6 \mathrm{kcal} / \mathrm{min}$ and $1.8 \mathrm{kcal} / \mathrm{min}$ for the 3 and the $9 \mathrm{~g}$ of oil in total respectively, both being much lower than the $4.9 \mathrm{kcal} / \mathrm{min}$ in the studies by Welch et al. $^{8,12}$.

The $3 \mathrm{~g}$ ileal fat resulted in a reduction in appetite and an increase in satiety. This effect was comparable to that induced by the $9 \mathrm{~g}$ of ileal fat. Therefore, the satiating effect of ileal fat infusion was not dose-dependent. In humans, Pironi et al. were the first to show a significant correlation between the dose of lipids administered to the ileum and the ileal brake-effect on gastric emptying ${ }^{10}$. Similarly, Keller et al. ${ }^{9}$ demonstrated that the ileal brake induced a dose-dependent inhibition of pancreatic and biliary secretion. No dose-response studies with regard to the ileal brake and satiety have been performed in humans. With respect to the duodenum, a relation between fat load and satiating effect has previously been demonstrated ${ }^{24}$.

It is not apparent why no dose-dependent effects of ileal fat on satiety were observed. Several factors may be involved. First, triacylglycerols need to be hydrolyzed to fatty acids in order to be able to reduce satiety and food intake ${ }^{25}$. It is well known that the lipolytic capacity in the ileum is smaller compared to the duodenum ${ }^{26}$. A lack of lipase in the ileum may have limited the hydrolysis of the high fat dose. However, as plasma CCK-concentrations did increase dose-dependently, this is unlikely. Second, after the distal ileal perfusion, fat might directly spill over into the colon, from where no further satiety signals will arise. However, in humans, the satiety response to colonic lipids containing long chain fatty acids has not been studied in detail.

This study shows two important findings regarding gut peptides: (1) CCK, generally considered a "proximal" gut hormone was released in a dose-dependent fashion during distal small intestinal administration of the oil emulsion and CCK secretion correlated significantly with changes in satiety. (2) PYY, a distal gut peptide thought to represent activation of the ileal brake, did increase after ileal infusion of $9 \mathrm{~g}$ of fat, but not after $3 \mathrm{~g}$ of fat and did not correlate with the changes in satiety.

As the dose of ileal oil was increased to $9 \mathrm{~g}$, a significant increase in CCK secretion was observed and correlated significantly with the increase in satiety. We and other have previously reported on the satiating effects of $\mathrm{CCK}^{13,19,27-29}$. There is consensus that 
CCK suppresses food intake on the short term. Our study confirms the correlation between satiety scores and plasma CCK secretion.

It is remarkable that secretion of a so-called "proximal" gut peptide is activated upon ileal delivery of fat. However, Sjolund et al. ${ }^{30}$ demonstrated that CCK-producing cells are present in the ileum, confirming observations by Capella et al. ${ }^{31}$. The number of CCK-secreting cells in the distal ileum was lower compared to the duodenum or jejunum, but not absent, as in the large intestine ${ }^{30}$. The presence of these I-cells can explain the increase in plasma CCK concentrations observed after infusion of fat in the ileum.

To date, release of CCK by ileal fat infusion has previously been shown only by Lin et al. in dogs ${ }^{32}$. In this study by Lin et al., there was no difference in CCK-release between the proximal and distal small intestinal infusions ${ }^{32}$, whereas Konturek et al. ${ }^{33}$ did not find an increase in plasma CCK concentrations. However, in the study by Konturek et al. $^{33}$, all intrinsic enteric nerves between the proximal and distal segments were severed whereas in the Lin study, neural fibres remained intact. Thus, a neural mechanism connecting the distal and proximal small bowel may be responsible for the increase in plasma CCK-concentrations after ileal fat infusion ${ }^{32}$. Such a mechanism has been shown in animals for the release of Apolipoprotein A-IV (Apo A-IV), a peptide secreted after intestinal lipid absorption ${ }^{34,35}$. However, such a neural distal-toproximal mechanism involved in the secretion of CCK has never been demonstrated in humans.

Pironi et al. ${ }^{10}$ found an increase in PYY release after ileal infusion of a small amount of $480 \mathrm{mg}$ of fat (given as FFA). In this study, the amounts of lipids administered correlated with release of PYY. Our results are not in line with these findings, as PYY release did not increase during the $3 \mathrm{~g}$ fat experiment but only during the $9 \mathrm{~g}$ infusion. Recently, Pilichiewicz et al. ${ }^{24}$ demonstrated that, after duodenal infusion of lipid, a threshold infusion rate exists for fat in order to be able to induce PYY-release. They demonstrated that a load of $0.25 \mathrm{kcal} / \mathrm{min}$ did not increase PYY plasma levels, whereas $1.5 \mathrm{kcal} / \mathrm{min} \mathrm{did}^{24}$. In our study with $3 \mathrm{~g}$ of fat, we infused $0.6 \mathrm{kcal} / \mathrm{min}$ through three infusion ports, each separated from the other by $15 \mathrm{~cm}$, thus $0.2 \mathrm{kcal} / \mathrm{min}$ per infusion port. Although covering a larger area of the ileum, this infusion rate may result in a fat load that is below the sensing-threshold in order to induce PYY-release. Furthermore, the combination of a small amount of fat with a relatively low lipase activity in the ileum may also have limited the release of PYY after the low dose.

Infusion of PYY has been shown to affect eating behavior in various animal models. A recent study by Batterham et al. showed an impressive reduction in food intake after infusion of PYY in both lean and obese human subjects ${ }^{36}$. The anorectic effect of PYY has been confirmed by Degen et al. ${ }^{37}$. However, in that study, the anorectic effect of 
exogenous PYY infusion was observed only at pharmacological but not at physiological plasma concentrations ${ }^{37}$.

While both 3 and $9 \mathrm{~g}$ of ileal fat increased satiety, PYY secretion was increased only during and after the high dose.

Previous studies have suggested that the activation of the ileal brake is accompanied by release of the distal gut hormone $\mathrm{PYY}^{9,10,38}$. PYY is released from L-endocrine cells of which the high concentrations in humans are found in the distal small intestine, colon and rectum, with progressively more PYY producing cells when going distally in the gut. The most powerful stimulants for PYY release is fat, especially (triglycerides consisting of) long chain fatty acids, although amino acids and even carbohydrates have been shown to be effective. Our results therefore do not fully support the hypothesis that PYY is the mediator of the 'ileal brake'. There is evidence that PYY acts as a paracrine agent after release by the L-cell ${ }^{39}$,a nd this may suggest that plasma levels do not reflect the local effects of PYY.

In summary, we have shown that postprandial satiety following a liquid breakfast can be effectively and significantly increased by small amounts (as little as $3 \mathrm{~g}$ ) of oil perfused into the ileum. This effect correlated with CCK release, but not with PYY release. This satiety effect deserves further evaluation in clinical setting as a factor that may contribute to a reduction in caloric intake and weight loss. 


\section{References}

1. Woods SC. Gastrointestinal satiety signals I. An overview of gastrointestinal signals that influence food intake. Am J Physiol Gastrointest Liver Physiol 2004;286:G7-13.

2. Geliebter A. Gastric distension and gastric capacity in relation to food intake in humans. Physiol Behav 1988;44:665-668.

3. Jones KL, Doran SM, Hveem K, Bartholomeusz FD, Morley JE, Sun WM, Chatterton BE, Horowitz M. Relation between postprandial satiation and antral area in normal subjects. Am J Clin Nutr 1997;66:127-132.

4. Hveem K, Jones KL, Chatterton BE, Horowitz M. Scintigraphic measurement of gastric emptying and ultrasonographic assessment of antral area: relation to appetite. Gut 1996;38:816-821.

5. Van Citters GW, Lin HC. The ileal brake: a fifteen-year progress report. Curr Gastroenterol Rep 1999;1:404-409.

6. Welch IM, Cunningham KM, Read NW. Regulation of gastric emptying by ileal nutrients in humans. Gastroenterology 1988;94:401-404.

7. Read NW, McFarlane A, Kinsman RI, Bates TE, Blackhall NW, Farrar GB, Hall JC, Moss G, Morris AP, O'Neill B, Welch I, Lee $Y$, Bloom SR. Effect of infusion of nutrient solutions into the ileum on gastrointestinal transit and plasma levels of neurotensin and enteroglucagon. Gastroenterology 1984;86:274-280.

8. Welch I, Saunders K, Read NW. Effect of ileal and intravenous infusions of fat emulsions on feeding and satiety in human volunteers. Gastroenterology 1985;89:1293-1297.

9. Keller J, Holst JJ, Layer P. Inhibition of human pancreatic and biliary output but not intestinal motility by physiological intraileal lipid loads. Am J Physiol Gastrointest Liver Physiol 2006;290: G704-G709.

10. Pironi L, Stanghellini V, Miglioli M, Corinaldesi R, De Giorgio R, Ruggeri E, Tosetti C, Poggioli G, Morselli Labate AM, Monetti N, Gozzetti G, Barbara L, Go VLW. Fat-induced ileal brake in humans: a dose-dependent phenomenon correlated to the plasma levels of peptide YY. Gastroenterology 1993;105:733-739.

11. Dobson CL, Davis SS, Chauhan S, Sparrow RA, Wilding IR. The effect of oleic acid on the human ileal brake and its implications for small intestinal transit of tablet formulations. Pharm Res 1999;16:92-96.

12. Welch IM, Sepple CP, Read NW. Comparisons of the effects on satiety and eating behaviour of infusion of lipid into the different regions of the small intestine. Gut 1988;29:306-311.

13. Lieverse RJ, Jansen JB, Masclee AA, Lamers CB. Satiety effects of a physiological dose of cholecystokinin in humans. Gut 1995;36:176-179.

14. Klein S, Stein J, Dressman J. Site-specific delivery of anti-inflammatory drugs in the gastrointestinal tract: an in-vitro release model. J Pharm Pharmacol 2005;57:709-719.

15. Goebell H, Klotz U, Nehlsen B, Layer P. Oroileal transit of slow release 5-aminosalicylic acid. Gut 1993;34:669-675.

16. Stratton RJ, Stubbs RJ, Hughes D, King N, Blundell JE, Elia M. Comparison of the traditional paper visual analogue scale questionnaire with an Apple Newton electronic appetite rating system (EARS) in free living subjects feeding ad libitum. Eur J Clin. Nutr. 1998;52:737-741.

17. Flint A, Raben A, Blundell JE, Astrup A. Reproducibility, power and validity of visual analogue scales in assessment of appetite sensations in single test meal studies. Int J Obes Relat Metab Disord 2000;24:38-48.

18. Symersky T, Biemond I, Frolich M, Masclee AA. Effect of peptide YY on pancreatico-biliary secretion in humans. Scand J Gastroenterol 2005;40:944-949.

19. Lieverse RJ, Jansen JB, Masclee AM, Lamers CB. Satiety effects of cholecystokinin in humans. Gastroenterology 1994;106:1451-1454.

20. Symersky T, Vu MK, Frolich M, Biemond I, Masclee AA. The effect of equicaloric medium-chain and long-chain triglycerides on pancreas enzyme secretion. Clin Physiol Funct Imaging 2002;22:307-311.

21. Spiller RC, Trotman IF, Higgins BE, Ghatei MA, Grimble GK, Lee YC, Bloom SR, Misiewicz JJ, Silk DB. The ileal brake--inhibition of jejunal motility after ileal fat perfusion in man. Gut 1984;25:365-374. 
22. Lin HC, Zhao XT, Wang L. Fat absorption is not complete by midgut but is dependent on load of fat. Am J Physiol 1996;271:G62-G67.

23. Layer P, Schlesinger T, Groger G, Goebell H. Modulation of human periodic interdigestive gastrointestinal motor and pancreatic function by the ileum. Pancreas 1993;8:426-432.

24. Pilichiewicz AN, Papadopoulos P, Brennan IM, Little TJ, Meyer JH, Wishart JM, Horowitz M, FeinleBisset C. Load-dependent effects of duodenal lipid on antropyloroduodenal motility, plasma CCK and PYY, and energy intake in healthy men. Am J Physiol Regul Integr Comp Physiol 2007;293:R2170R2178.

25. Feinle C, O'Donovan D, Doran S, Andrews JM, Wishart J, Chapman I, Horowitz M. Effects of fat digestion on appetite, APD motility, and gut hormones in response to duodenal fat infusion in humans. Am J Physiol Gastrointest Liver Physiol 2003;284:G798-G807.

26. Layer $P$, Groger $G$. Fate of pancreatic enzymes in the human intestinal lumen in health and pancreatic insufficiency. Digestion 1993;54 Suppl 2:10-14.

27. Lieverse RJ, Jansen JB, Masclee AA, Rovati LC, Lamers CB. Effect of a low dose of intraduodenal fat on satiety in humans: studies using the type $A$ cholecystokinin receptor antagonist loxiglumide. Gut 1994;35:501-505.

28. Lieverse RJ, Jansen JB, van de Zwan A, Samson L, Masclee AA, Lamers CB. Effects of a physiological dose of cholecystokinin on food intake and postprandial satiation in man. Regul Pept 1993;43:83-89.

29. Lieverse RJ, Masclee AA, Jansen JB, Rovati LC, Lamers CB. Satiety effects of the type A CCK receptor antagonist loxiglumide in lean and obese women. Biol Psychiatry 1995;37:331-335.

30. Sjolund K, Sanden G, Hakanson R, Sundler F. Endocrine cells in human intestine: an immunocytochemical study. Gastroenterology 1983;85:1120-1130.

31. Capella C, Solcia E, Frigerio B, Buffa R. Endocrine gut and pancreas. Fujita T (ed.). Elsevier Biomedical, Amsterdam 1976:43-59.

32. Lin HC, Chey WY. Cholecystokinin and peptide YY are released by fat in either proximal or distal small intestine in dogs. Regul Pept 2003;114:131-135.

33. Konturek SJ, Tasler J, Bilski J, de Jong AJ, Jansen JB, Lamers CB. Physiological role and localization of cholecystokinin release in dogs. Am J Physiol 1986;250:G391-G397.

34. Kalogeris TJ, Rodriguez MD, Tso P. Control of synthesis and secretion of intestinal apolipoprotein A-IV by lipid. J Nutr 1997;127:537S-543S.

35. Tso P, Liu M. Apolipoprotein A-IV, food intake, and obesity. Physiol Behav 2004;83:631-643.

36. Batterham RL, Cohen MA, Ellis SM, Le Roux CW, Withers DJ, Frost GS, Ghatei MA, Bloom SR. Inhibition of food intake in obese subjects by peptide YY3-36. N Engl J Med 2003;349:941-948.

37. Degen L, Oesch S, Casanova M, Graf S, Ketterer S, Drewe J, Beglinger C. Effect of peptide YY3-36 on food intake in humans. Gastroenterology 2005;129:1430-1436.

38. Van Citters GW, Lin HC. Ileal brake: Neuropeptidergic control of intestinal transit. Curr Gastroenterol. Rep 2006;8:367-373.

39. Koda S, Date $Y$, Murakami N, Shimbara T, Hanada T, Toshinai K, Niijima A, Furuya M, Inomata N, Osuye K, Nakazato $M$. The role of the vagal nerve in peripheral PYY3-36-induced feeding reduction in rats. Endocrinology 2005;146:2369-2375. 


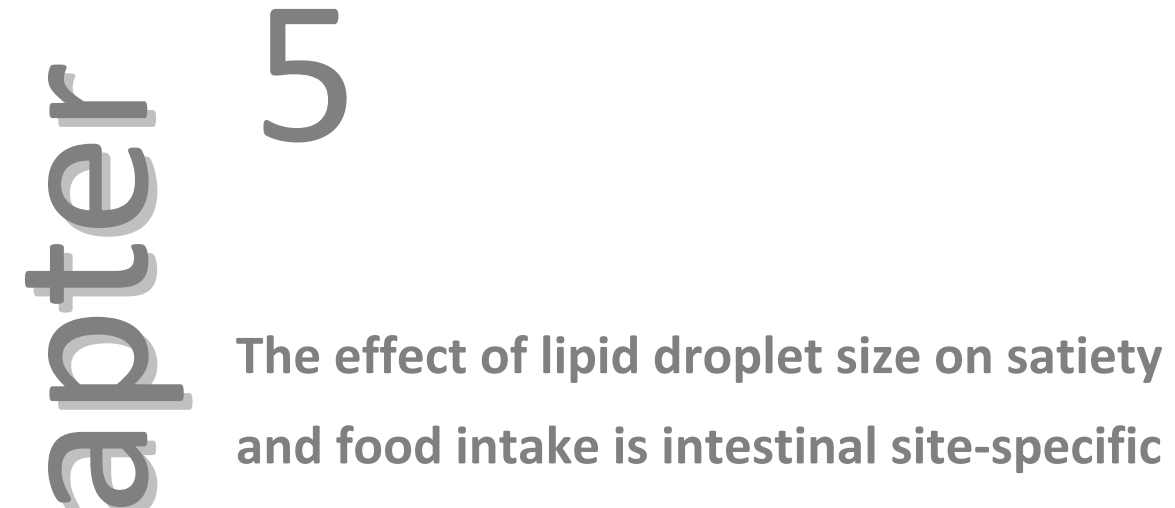

Maljaars PWJ, van der Wal RJP, Wiersma T, Peters HPF, Haddeman E, Masclee AAM Submitted 


\section{Abstract}

\section{Introduction}

Fat induces satiety. A reduction in droplet size results in accelerated fat digestion but the effect on appetite, especially after ileal fat infusion, is not known.

\section{Objective}

To compare the effects of fat emulsions differing in droplet size (fine versus coarse) infused in either duodenum or ileum, on satiety, food intake, gastrointestinal transit and peptide (CCK, PYY) secretion.

Design

Randomized single-blind crossover study with 15 healthy volunteers (mean age 23 yrs, mean BMI $21.6 \mathrm{~kg} / \mathrm{m}^{2}$ ) who received, after intubation with a nasoileal tube, 4 different treatments on 4 consecutive days. After consumption of a liquid meal at $\mathrm{t}=0 \mathrm{~min}, 6 \mathrm{~g}$ of Fine or Coarse fat emulsion was infused into duodenum ( $\mathrm{t}=30-90 \mathrm{~min}$ ) or ileum ( $\mathrm{t}=105-165 \mathrm{~min}$ ). Study parameters were food intake (ad libitum lunch), satiety (line scales), gastrointestinal transit (breath tests), gut peptides (RIA) and statistically evaluated using ANCOVA with subjects as blocks and location (Duodenum, lleum) and size (Fine,Coarse) as factors.

\section{Results}

In the duodenum, Fine emulsion significantly reduced hunger and increased fullness versus Coarse, whereas in the ileum no such effect was observed. After duodenal infusion, Fine emulsions significantly delayed gastric emptying compared to Coarse. Droplet size did not affect gut peptide secretion after duodenal infusion, but after ileal infusion, Fine emulsions increased both CCK and PYY significantly versus Coarse. Droplet size did not affect food intake $(p=0.06)$.

\section{Conclusions}

Compared to larger fat droplets, smaller fat droplets significantly affect satiety, gastric emptying and gut peptide release, with the effect dependent on the intestinal location of fat delivery. 


\section{Introduction}

The gastrointestinal tract provides various signals that affect satiety and food intake ${ }^{1}$. These signals are released in response to both mechanical (distension) ${ }^{2,3}$ and chemical (nutrients) stimuli ${ }^{1}$. The presence of nutrients in the small intestine is sensed by receptors in the intestinal mucosa, and activation of these receptors induces activation of neural afferents or the release of gut peptides, such as cholecystokinin (CCK) and peptide YY (PYY). These neural and hormonal stimuli lead to an increase in satiety, a reduction in food intake and multiple effects on gastrointestinal (GI) function.

Upon entry into the small intestine, fat has potent effects on hunger and food intake. Recent studies have demonstrated that addition of orlistat, a lipase inhibitor, abolishes the effects of fat infusion, indicating that digestion of triacylglycerols (TAG) to fatty acids is a crucial step for fat in order to be sensed by the small intestine and to influence satiety ${ }^{4-6}$. Sensing of nutrients results in satiety, reduces food intake, affects gut peptide secretion and also gut physiology. An increase in the sensing of fatty acids will affect the magnitude of these effects. Evidence for the hypothesis of dose dependent satiety effects by fatty acids is provided by a recent study by Armand et al. ${ }^{7}$, who compared the effects of an intragastric fat emulsion with different droplet sizes on gastric emptying. Lipase is active on the surface of a fat droplet, and smaller droplet size will increase total emulsion surface area, thereby allowing the rate of fat hydrolysis to increase (as in a state of lipase abundance in the duodenum surface area will become the rate-limiting step) . Indeed, Armand et al. observed that inhibition of gastric emptying is more pronounced after smaller droplets compared to larger fat droplets, suggesting an increase in fatty acid sensing. Additional evidence is provided by Ledeboer et al. $^{8}$, who showed that reducing emulsion droplet size significantly increased secretion of CCK. Taken together, these studies suggest that a reduction in fat droplet size may increase the satiating and anorectic effects of a fat load.

This was recently confirmed by Seimon et al. ${ }^{9}$, who demonstrated that, after duodenal infusion, fat droplet size affects satiety, peptide secretion and motility. In their study, these authors compared a small droplet $(0.26 \mu \mathrm{m})$ soy bean emulsion (intralipid), consisting mainly of di-unsaturated fatty acids, to 2 canola oil emulsions with larger droplets $(30 \mu \mathrm{m}, 170 \mu \mathrm{m})$ consisting mainly of mono-unsaturated fatty acids. After duodenal infusion, the smaller droplet-emulsion had larger effects on satiety, motility and peptide ecretion compared to the larger droplet-emulsions.

The duodenum is the most extensively studied location with regard to small intestinal satiety mechanisms in response to nutrients. Welch et al. have demonstrated that entry of nutrients into the ileum also has potent effects on satiety and food intake through activation of the ileal brake $\mathrm{e}^{10,11}$. We have previously demonstrated that the effects of ileal fat infusion on satiety are larger than these of fat infused into the 
duodenum $^{12}$. Furthermore, a satiating effect was already demonstrated after infusion of a small amount of $\mathrm{fat}^{13}$.

The effect of fat droplet size during ileal fat infusion on satiety and food intake and on peptide secretion has never been investigated. Therefore, the present study was designed to compare the effect of emulsions differing in droplet size on 1.) satiety and food intake and on 2.) GI peptide release and motility when the emulsions are infused into the duodenum or ileum. We hypothesize that reducing lipid droplet size will lead to 1 . an increase in the inhibitory effect on food intake and hunger and 2. an increase in gut peptide secretion and gastrointestinal transit, through increased fatty acid sensing.

\section{Materials and methods}

\section{Subjects}

Healthy volunteers aged between 18 and 55 yrs with a BMI between 18 and $32 \mathrm{~kg} / \mathrm{m}^{2}$ were recruited by advertisement. Restrained eaters (as assessed by the Dutch Eating Behaviour Questionnaire ${ }^{14}$ ) and subjects who reported that they were following either a weight-reduction diet or a medically-prescribed diet were excluded from participation. Subjects who were taking medication that may have influenced appetite and sensory function or who reported metabolic or endocrine disease, gastrointestinal disorders or a history of medical or surgical events that may have affected study outcome were also excluded. Informed consent was obtained from each individual, and the study protocol was approved by the local Medical Ethics Committee. Seventeen subjects met the inclusion criteria. Two volunteers dropped out during the study: one due to discomfort during catheter positioning and one due to failure to position the tip of the catheter beyond the ligament of Treitz (flexura duodenojejunalis). Fifteen healthy volunteers ( 12 female, mean age 23 yrs, mean BMI $21.6 \mathrm{~kg} / \mathrm{m}^{2}$ ) participated in the study and completed the protocol.

\section{Study design}

In this single-blind randomized controlled crossover design, $6 \mathrm{~g}$ of fine or coarse oil emulsion was administrated into the duodenum or into the ileum. The study design is shown in Figure 5.1.

\section{Protocol}

The study protocol consisted of five consecutive days. On Monday, subjects arrived at 12:00 hr for catheter placement. The catheter for ileal intubation was a $290 \mathrm{~cm}$ long 
rubber silicon 9-channel (8-lumen, 1 balloon inflation channel, diameter $3.5 \mathrm{~mm}$ ) catheter custom-made by Dentsleeve International Ltd (Mississauga, Ontario, Canada). The functional length of the catheter was $240 \mathrm{~cm}$, with a additional $50 \mathrm{~cm}$ connection segment. The catheters contained side-holes at $0,10,20,30,115,130$, 145 and $160 \mathrm{~cm}$ from the tip and had an inflatable balloon (maximum inflation capacity $10 \mathrm{ml}$ ) at the distal tip. At least one of the four proximal side-holes (usually at 145 or $160 \mathrm{~cm}$ ) was positioned in the duodenum, and was used for the duodenal infusion. The three distal side-holes $(0,10,20 \mathrm{~cm})$ reaching into the ileum were used to administer placebo or fat emulsion in the ileum. Through an anaesthetized nostril, the catheter was introduced into the stomach, and allowed to pass trough the pylorus to the ileum by peristalsis. After passing the ligament of Treitz, a small balloon at the tip was inflated to facilitate passage of the catheter to the ileum. During the day, the subject was offered sugared tea or coffee to stimulate peristalsis. The tip was placed in the ileum (at least $120 \mathrm{~cm}$ distal from Treitz). During the positioning and before every test-day, the position of the catheter was checked by fluoroscopy.

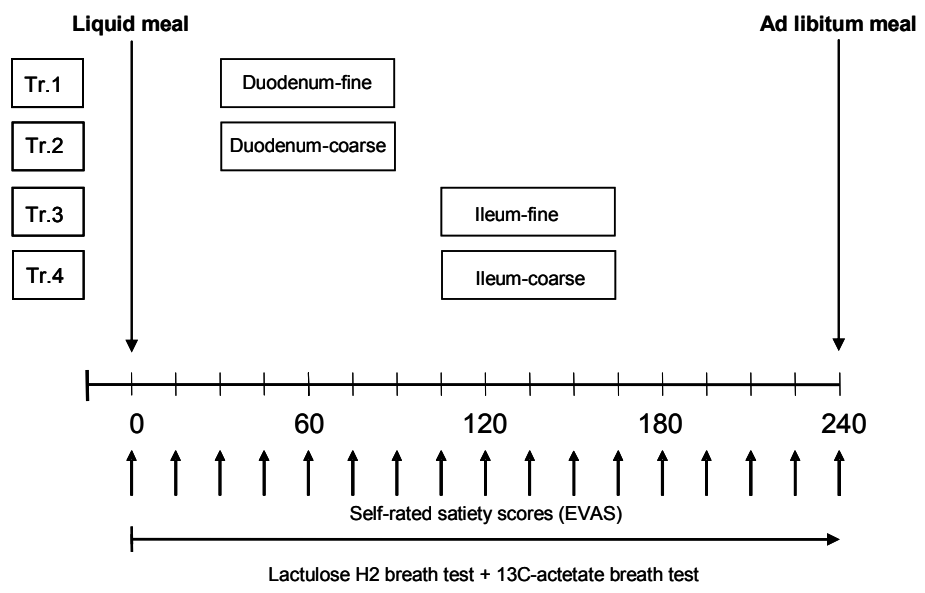

Figure 5.1 Study outline for the experiment.

The study consisted of four treatments. Order of treatments was randomized. Each subject started each test day by consuming a $145 \mathrm{kcal}$ fat-free liquid meal. On two of the test days, a duodenal fat infusion was scheduled from $t=30-90 \mathrm{~min}$, and on the other two test days, an ileal fat infusion was scheduled from $t=105-165 \mathrm{~min}$. Each fat infusion consisted of $6 \mathrm{~g}$ of fat, and either of small droplets (fine emulsion: 0.65 micron) or large droplets (5.40 micron). Throughout the test day, blood was sampled for gut peptide analysis and satiety was measured by VAS questionnaires. Gastric emptying was measured during the duodenal infusion experiments by the $13 \mathrm{C}$ breath test. Small bowel transit time was measured by $\mathrm{H}_{2}$ breath test. On all test days, an ad libitum meal was consumed at $\mathrm{t}=\mathbf{2 4 0}$ minutes 


\section{Test day (Figure.1)}

On each of the four consecutive test days, the subject arrived at the laboratory at 8:00 $\mathrm{hr}$ following an overnight fast. First, correct position of the catheter was verified by fluoroscopy. Then, a venous catheter was placed in a forearm-vein for collection of blood samples. At 8:45 hr ( $\mathrm{t}=-15 \mathrm{~min})$, a basal VAS score was taken, and at 9:00 hr a basal blood sample. Immediately after this (at $\mathrm{t}=0 \mathrm{~min}$ ), the breakfast (fat free Slim.Fast Optima Ready To Drink (RTD): $325 \mathrm{ml}, 145 \mathrm{Kcal}$, Unilever, Covington, TN, USA) was consumed within fifteen minutes. To this breakfast, $150 \mathrm{mg}$ Sodium $\left[1-\mathrm{C}^{13}\right]$ acetate was added in order to measure gastric emptying half time (T1/2).

The duodenal infusion started $30 \mathrm{~min}$ after the start of the breakfast, and lasted for 60 minutes till $t=90 \mathrm{~min}$. This infusion was given through the infusion port which was located just distal from the pylorus. The ileal infusion, which was perfused through the most distal infusion ports, started at $\mathrm{t}=105 \mathrm{~min}$, and lasted till $\mathrm{t}=165 \mathrm{~min}$. Infusion rate in both cases was $1 \mathrm{ml} / \mathrm{min}$ or $0.9 \mathrm{kcal} / \mathrm{min}$. Each day either the ileum or the duodenum was perfused with an emulsion, consisting either of fine or coarse droplets. When the duodenum was perfused with emulsion, the ileum was perfused with saline and vice versa. Subjects were unaware of the timing and the nature of the infusion.

Ten min before each fat infusion (at $\mathrm{t}=\mathbf{2 0} \mathrm{min}$ for the duodenal fat infusion; at $\mathrm{t}=\mathbf{9 5}$ min for the ileal fat infusion), $6 \mathrm{~g}$ of lactulose (Legendal, Inpharzam, Amersfoort) dissolved in 20-30 $\mathrm{ml}$ tap water was administered by syringe through the duodenal infusion port closest to (but located distally from) the pylorus, to enable measurement of the small bowel transit time.

At 13:00 hr, $\mathrm{t}=240 \mathrm{~min}$, the ad libitum-lunch was served. At 14:45 hr, the intravenous canula was removed, and subjects were allowed to go home. They received an evening meal from which they were allowed to consume freely till 22:00 hr.

The infusion periods ( $t=30-90 \mathrm{~min}, \mathrm{t}=105-165 \mathrm{~min}$ ) were chosen to represent the physiologic postprandial period of maximum exposure of respectively the duodenum and ileum to fat ${ }^{15,16}$. Goebell et al. demonstrated that delivery of a meal marker to the ileum was at it maximum at 120-165 min after the meal ${ }^{16}$. We performed an explorative study on the timing of arrival of the low energy liquid meal (Slim.Fast) in the cecum and found a mean arrival time of 110 min after ingestion (data not published).

\section{Satiety}

The volunteers rated their feelings of hunger, satiety, appetite for a meal, fullness, appetite for a snack by means of a mark on 64-mm line scales using a EVAS (Electronic Visual Analogue Scale, iPAQ) ${ }^{17}$. This scale was anchored at the low end with the most negative or lowest intensity feelings (e.g., "extremely unpleasant", "not at all"), and 
with opposing terms at the high end (e.g., "extremely pleasant", "very high", "extreme") as described by Flint et al. $^{18}$. Measurements were taken at regular intervals during the test day.

Gastrointestinal disturbances (nausea, abdominal pain, bloating, heartburn, abdominal cramps) and general symptoms (headache, malaise, dizziness, and fatigue) were analysed using frequency of occurrence per time point and a standard ANOVA with the personal scores corrected for each subject's overall mean score.

\section{Food intake}

Each test day, an ad libitum-lunch was served to measure food intake. Each lunch was offered in excess, and consisted of 15 slices of brown bread with mature cheese. Each sandwich was cut in different-sized pieces, so the subject would not be able to assess the number of sandwiches eaten. During the ad libitum-lunch, subjects were not allowed to watch television, listen to the radio or read, as this could have influenced the amount eaten.

\section{Gastric emptying}

Gastric emptying was measured by ${ }^{13} \mathrm{C}$ stable isotope breath test. The parameters used were gastric emptying half time $\left(T_{1 / 2}\right)$ which is the moment at which half of the marker has been emptied from the stomach. For this purpose, $150 \mathrm{mg}$ of sodium $\left[1-{ }^{13} \mathrm{C}\right]$-acetate (99\%; Cambridge Isotope laboratories/ ARC Laboratories, Amsterdam) was added to the RTD ingested at $\mathrm{t}=0$. One basal breath sample was taken at $\mathrm{t}=0$ before consuming the RTD, and subsequent samples were taken at $15 \mathrm{~min}$ intervals for the first two hours, and at $30 \mathrm{~min}$ intervals thereafter until $\mathrm{t}=\mathbf{2 4 0} \mathrm{min}$. Breath samples were collected using plasticized aluminium bags, and analysed by InfraRed ISotope analysis (IRIS, Wagner Analisen Technik, Bremen, Germany). Half time of gastric emptying was calculated after curve fitting using methods described by Braden et al. ${ }^{19}$.

\section{Small Bowel Transit Time}

Small bowel transit time (SBTT) measurement was performed by lactulose hydrogen breath analysis as described by Ledeboer et al. ${ }^{20}$. Samples of end-expiratory breath were taken just before administration of $6 \mathrm{~g}$ of lactulose and at regular intervals during the test day afternoon. The samples were directly analyzed using a handheld hydrogen breath test unit (Gastrolyzer, HoekLoos, The Netherlands). SBTT is defined as the time between the administration of lactulose and the onset of a sustained (in three consecutive readings) rise in breath $\mathrm{H}_{2}$ concentration of at least 10 parts per 
million (ppm) above basal level. At our department the mean coefficient of variation for SBTT using the lactulose hydrogen breath test with $6 \mathrm{~g}$ lactulose is $12 \%$.

\section{Hormone assays}

Blood samples were drawn at regular intervals throughout the test day. Total plasma PYY was measured by radioimmunoassay as described previously ${ }^{21}$. The detection limit is $10 \mathrm{pmol} / \mathrm{l}$. The intra-assay variation ranges from 1.8 to $15.6 \%$ and the inter-assay variation from 9.5 to $27.8 \%{ }^{21}$.

Plasma CCK concentrations were measured by a RIA, as described previously ${ }^{22}$. The detection limit of the assay is $0.3 \mathrm{pM}$. The intra-assay variation ranges from 4.6 to $11.5 \%$ and the inter-assay variation from 11.3 to $26.1 \%{ }^{13}$.

\section{Emulsions}

The emulsions consisted of $10 \%$ Canola oil (high oleic rapeseed oil) in water. As emulsifier $2.5 \% \mathrm{~K}$-caseinate was used. A very small amount of xanthan gum (0.1\%) and guar gum (0.1\%) was used as stabiliser. Sodium chloride was added to obtain isoosmotic solutions $(0.8 \% \mathrm{NaCl})$. The emulsions were standardized on a fixed oil/water ratio and a fixed amount of emulsifier. The variation in droplet size was obtained using high-shear mixers. The volume-weighted mean diameter was 0.88 micrometer for the fine emulsion and 15.5 micrometer for the coarse emulsion. The surfaceweighted mean diameter was 0.65 and 5.40, respectively, implying that droplet surface was $5.4 / 0.65=8.3$ times larger for the fine emulsion as compared to the coarse one. When droplet sizes were measured after two months of storage, no change in droplet size was observed. Also osmolarity (262 mOsm/kg), $\mathrm{pH}(6.8)$ and viscosity ( $50 \mathrm{cP}$ at $60 \mathrm{rpm}$ at a Brookfield DVII Viscometer) were similar for both emulsions and this did not change after two month of storage.

\section{Statistical analysis}

Results are presented as least squares means with standard error (SE), unless otherwise specified. Satiety VAS scores were expressed as percentages of the maximal score $(0 \mathrm{~cm}$ equaled $0 \%$ and $64 \mathrm{~mm}$ equaled $100 \%)$ and as cumulative areas under the curve (AUC). The AUC was calculated using the trapezoid rule.

Where possible, parameters were analyzed using analysis of variance (ANCOVA) with subjects as blocks and location (duodenum/ileum) and size (fine/coarse) as factors. A p-value of 0.05 was considered significant.

The timing for the duodenal ( $t=30-90$ min after liquid meal) and ileal infusions (105165 min after liquid meal) was chosen as being in the physiologic range of postprandial exposure to intraluminal nutrients ${ }^{16}$. However, as the timing of the 
duodenal and ileal infusions was different, this precludes a direct comparison between the duodenal and ileal infusion.

\section{Results}

The results are presented per site of fat infusion: first, results from duodenal infusions, then results from ileal infusions.

\section{Duodenum: Food intake}

In the duodenum droplet size did not significantly influence food intake (Fine vs. Coarse, 185 vs. $199 \mathrm{~g}, \mathrm{SE}=7, \mathrm{p}>0.05)$.

\section{Duodenum: Appetite}

Since the appetite parameters gave similar results, only scores for fullness and hunger are shown. Fullness and hunger scores for the duodenal infusions are shown in Figure 5.2, starting from the onset of the duodenal infusions. Fasting scores of fullness and hunger did not differ between the two treatments (data not shown).

During the duo-fine infusion, EVAS scores remained at the same level until at least the end of the infusion ( $t=90 \mathrm{~min}$ ), whereas during the duo-coarse infusion, fullness scores started to decrease and hunger scores started to increase already during the infusion, and became significantly different compared to the duodenum-fine at the end of the infusion period (fullness $t=75,90$ min; hunger: $t=105$ min, $p<0.05$ ).

As shown in Figure 5.3C-D, the AUC for fullness was significantly increased for duofine vs duo-coarse, whereas the difference for hunger was not statistically significant.

\section{Duodenum: Gastric emptying}

In the duodenum, a significant difference in gastric emptying half time (Figure 5.3) was HP observed between the Fine and Coarse treatment (148 vs. 129 min, SE=5, $\mathrm{p}<0.05)$.

\section{Duodenum: SBTT}

In the duodenum (Fine vs. Coarse, 83 vs. $84 \mathrm{~min}, \mathrm{SE}=15, \mathrm{p}>0.05$ ) droplet size did not influence small bowel transit time. 
A

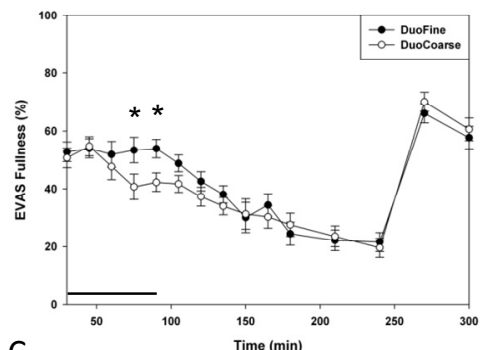

C

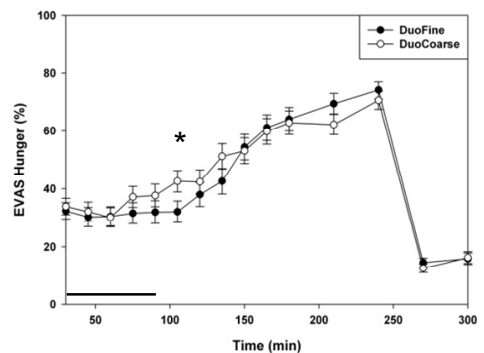

B

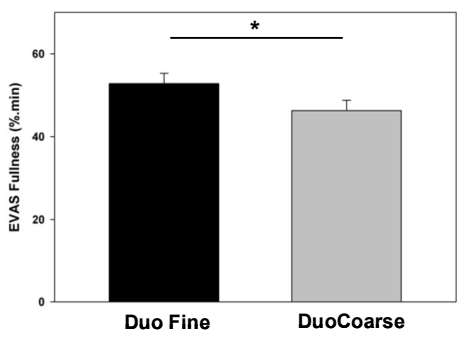

D

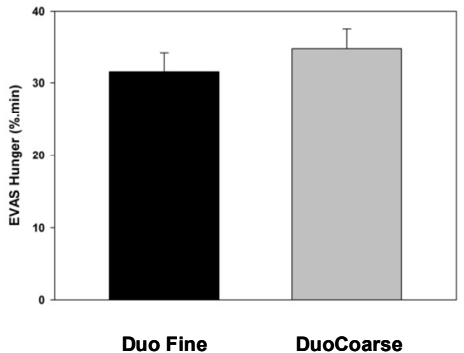

Figure 5.2 Results for Fullness and Hunger after duodenal fat infusions. Duodenal infusion of either the fine or the coarse emulsion was scheduled from $t=30-90$ min. Fullness and Hunger were measured by EVAS (Electronic Visual Analogue Scales) and were expressed as percentages of the maximal score $(0 \mathrm{~cm}$ equaled $0 \%$ and $64 \mathrm{~mm}$ equaled $100 \%)$. Data are LSmeans ( \pm SEM), $\mathrm{n}=15, *$ denotes $\mathrm{p}<0.05$, based on analysis by ANCOVA.

A. Results for fullness after the duodenal fat infusions. B. Results for fullness AUC after duodenal fat infusions. AUC was calculated by trapezoid rule over $t=30-240$ min period. C. Results for hunger after the duodenal fat infusions. D. Results for hunger AUC after duodenal fat infusions. AUC was calculated by trapezoid rule over $\mathrm{t}=30-240 \mathrm{~min}$ period.

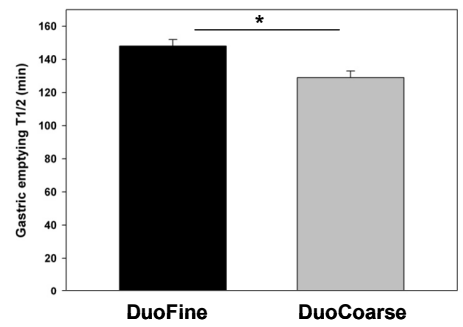

Figure 5.3 Gastric emptying $\mathrm{T} 1 / 2$ in response to the duodenal infusion of either the fine or the coarse emulsion (30-90min). Gastric emptying was measured by the ${ }^{13} \mathrm{C}$ acetate breath test. $150 \mathrm{mg}$ of Sodium $\left[1-{ }^{13} \mathrm{C}\right]$-acetate was added to the liquid meal ingested at $\mathrm{t}=0$, and throughout the test day, breath samples were collected.

Data are LSmeans $\left( \pm\right.$ SEM), $n=15,{ }^{*}$ denotes $p<0.001$, based on analysis by ANCOVA. 


\section{Duodenum: Gut peptides}

Plasma concentrations and AUC of CCK and PYY are given in Figure 5.4. Fasting concentrations of CCK and PYY did not differ between the two treatments (data not shown). Both infusions significantly increased plasma concentrations of CCK and PYY, but secretion of these peptides was not affected by the droplet size of the emulsions.

A

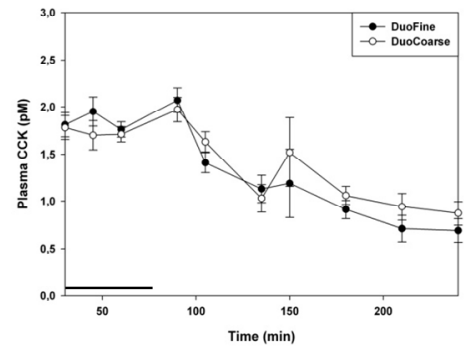

C

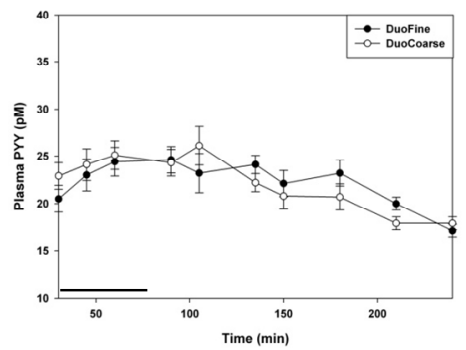

B

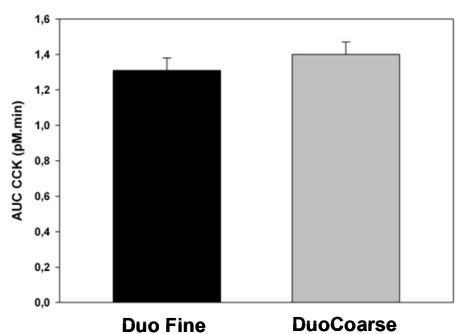

D

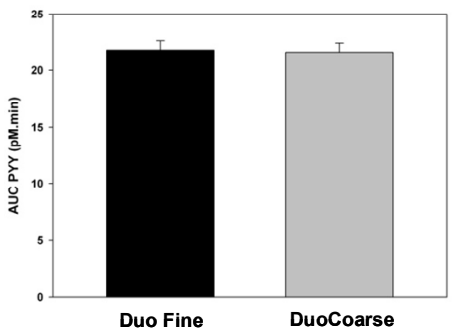

Figure 5.4 Results for Cholecystokinin (CCK) and peptide YY (PYY) plasma concentrations after duodenal fat infusion. Duodenal fat infusion of either the fine or the coarse emulsion was scheduled from $t=30-90 \mathrm{~min}$. Blood samples were collected at regular intervals throughout the test day, and kept on ice. CCK and PYY were measured by RIA. Data are LSmeans ( \pm SEM), $n=15$.

A. Results for plasma CCK concentrations after the duodenal fat infusions. B. Results for CCK AUC after duodenal fat infusions. AUC was calculated by trapezoid rule over $t=30-240$ min period. C. Results for plasma PYY concentrations after the duodenal fat infusions. D. Results for PYY AUC after duodenal fat infusions. AUC was calculated by trapezoid rule over $\mathrm{t}=30-240$ min period.

\section{Ileum: Food intake}

In the ileum, droplet size did not significantly influence food intake (Fine vs. Coarse, 163 vs. $174 \mathrm{~g}, \mathrm{SE}=7, \mathrm{p}>0.05$ ). 


\section{Ileum: Appetite}

Results for hunger and fullness are given in Figure 5.5. For the ileal infusions, no significant differences between the two emulsions were seen for hunger and fullness.

A

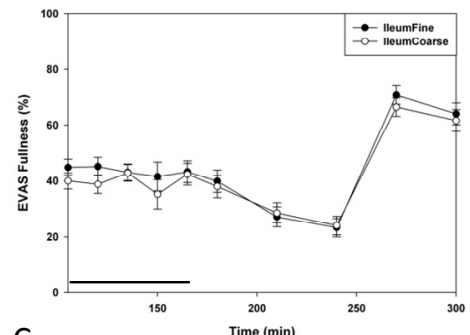

C

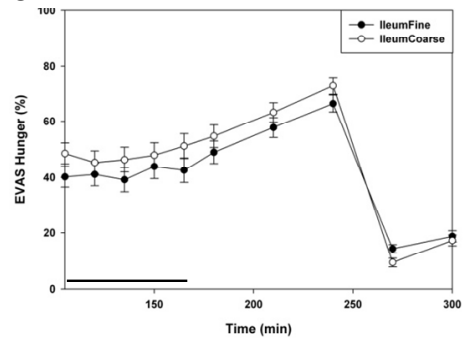

B
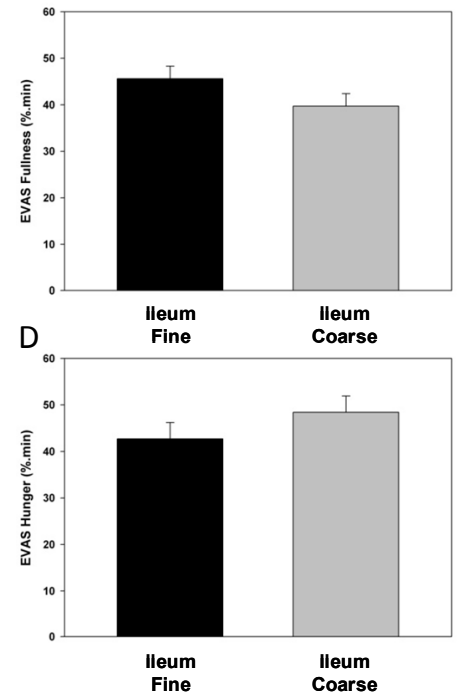

Figure 5.5 Results for Fullness and Hunger after ileal fat infusions. Ileal infusion of either the fine or the coarse emulsion was scheduled from $\mathrm{t}=105-165 \mathrm{~min}$. Fullness and Hunger were measured by EVAS (Electronic Visual Analogue Scales) and were expressed as percentages of the maximal score $(0 \mathrm{~cm}$ equaled $0 \%$ and $64 \mathrm{~mm}$ equaled $100 \%)$. Data are LSmeans ( \pm SEM), $\mathrm{n}=15$.

A. Results for fullness after the ileal fat infusions. B. Results for fullness AUC after ileal fat infusions. AUC was calculated by trapezoid rule over $t=105-240$ min period. C. Results for hunger after the ileal fat infusions. D. Results for hunger AUC after ileal fat infusions. AUC was calculated by trapezoid rule over $\mathrm{t}=105-240 \mathrm{~min}$ period.

\section{Ileum: SBTT}

In the ileum, droplet size did not influence small bowel transit time (Fine vs. Coarse, 133 vs. $126 \min , S E=15, p>0.05)$.

\section{Ileum: Gut peptide secretion}

Plasma concentrations and AUCs for CCK and PYY are given in Figure 5.6. Fasting concentrations and concentrations at $\mathrm{t}=105 \mathrm{~min}$ (the start of infusion period) of CCK and PYY did not differ between the two treatments (data not shown). In the ileum, both CCK and PYY plasma concentrations were significantly increased during the fine 
compared to the coarse infusion experiments. This resulted in a significantly higher AUC 105-240 min for CCK, whereas no significant difference were observed with regard to the AUC for PYY.

A

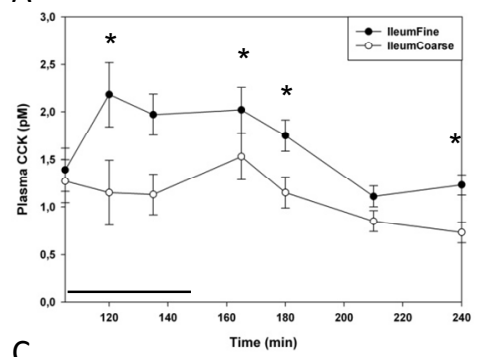

C

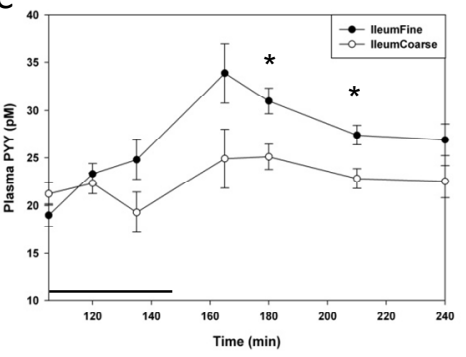

B
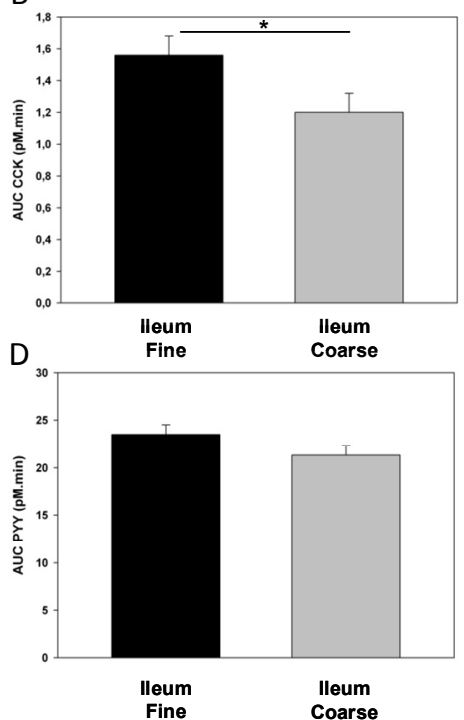

Figure 5.6 Results for Cholecystokinin (CCK) and peptide YY (PYY) plasma concentrations after ileal fat infusion of fine and coarse emulsions. from $\mathrm{t}=105-165 \mathrm{~min}$. Blood samples were collected at regular intervals throughout the test day, and kept on ice. CCK and PYY were measured by RIA. Data are LSmeans ( \pm SEM), $n=15,{ }^{*}$ denotes $p<0.005$, based on analysis by ANCOVA.

A. Results for plasma CCK concentrations after the ileal fat infusions. B. Results for CCK AUC after ileal fat infusions. AUC was calculated by trapezoid rule over $\mathrm{t}=105-240 \mathrm{~min}$ period. C. Results for plasma PYY concentrations after the ileal fat infusions. D. Results for PYY AUC after ileal fat infusions. AUC was calculated by trapezoid rule over $t=105-240$ min period.

\section{Food intake- Overall effects}

When the data from both locations were pooled, droplet size did not significantly influence food intake (Fine vs. Coarse: 174 vs. 187g, $S E=7, p=0.061$ ).

\section{Small Bowel Transit Time- Overall effects}

Combining the data per location or per droplet size, droplet size did not affect SBTT (Fine vs. Coarse: 109 vs. 105 min, SE=15). 


\section{Gl symptoms}

Droplet size did not affect gastrointestinal symptoms.

\section{Discussion}

In order for fat to influence satiety and food intake, gut function and gut peptide secretion, degradation of TAG to fatty acids and subsequent sensing of these fatty acids by the intestinal mucosa is required ${ }^{4,5}$. We hypothesized that reducing fat droplet size would increase fatty acid sensing, leading to a reduction in hunger and food intake.

Duodenal infusion of fat reduces hunger and increases satiety, and the physicochemical properties of the fat present in the emulsion influence the magnitude of these effects ${ }^{23}$. We hypothesized that the fine emulsion would increase satiety and reduce hunger compared to the coarse emulsion. Indeed, the effects of duodenal fat infusion on satiety scores were significantly more pronounced after the fine compared to the coarse emulsion. The fine emulsion postponed the increase in hunger and the reduction in fullness observed during the coarse treatment. In the ileum, hunger was also reduced and fullness increased after the fine vs. coarse emulsion, but these differences were not statistically significant.

Perceived hunger is a significant predictor of failure to lose weight ${ }^{24}$, which may suggest that hunger negatively influences compliance to a dieting strategy. Therefore, a reduction in hunger could be helpful in increasing adherence to dieting plans.

Reducing fat droplet size increases the effective surface area available for hydrolysis, and this may lead to higher amounts of fatty acids present in the small intestine ${ }^{7}$. Droplet size may also influence other physicochemical properties, such as formation of mixed micelles or diffusion of lipids through the unstirred water layer. This may in turn affect exposure of epithelial receptors (such as GPR120) to fatty acids ${ }^{7}$.

Neither during the duodenal nor during the ileal infusions was food intake influenced by the droplet size of the infused emulsion. We did observe an overall reduction in food intake of $7 \%$ after the fine vs. the coarse emulsion, but this difference was not statistically significant $(p=0.061)$. It is well known that infusion of fat reduces food intake ${ }^{11,23}$, and this effect is influenced by a number of physicochemical properties of fat, such as fatty acid chain length ${ }^{25}$ and degree of saturation ${ }^{23}$. The lack of a significant effect of droplet size on food intake may be related to the interval between 
the infusion and the meal (135 min for the duodenal infusions, $75 \mathrm{~min}$ for the ileal infusions $)^{26}$. Rolls et al. demonstrated that increasing the interval between a preload and the ad libitum test meal by 90 min reduced the effect of a preload on intake of the ad libitum meal by $14 \%$. In our study, the longer time interval will have decreased the effects of the fat infusions on food intake ${ }^{26}$. One should realise that the timing of the infusion was aimed to represent the physiologic postprandial period of maximum exposure of the ileum to meal components. Several studies have demonstrated that exposure of the ileum to digestive products of nutrients peaks at 120-165 min. after meal ingestion ${ }^{15,16}$.

Duodenal infusion of fat increases plasma concentrations of both CCK and PYY. We did not observe an effect of droplet size on CCK release in our study when fat was infused in the duodenum. This may be due to the fact that at the start of the infusion, plasma CCK concentrations were already elevated by ingestion of the breakfast meal. However, when infused into the ileum, the fine emulsion significantly increased plasma CCK concentrations. An identical pattern was observed for PYY, although the integrated PYY secretion did not differ significantly between the fine and coarse emulsion. As CCK is considered a proximal gut peptide, release of CCK in response to ileal fat might not be expected to occur. However, CCK release after ileal fat infusion has previously been shown in humans ${ }^{13}$ and animals ${ }^{27}$. Previous work from Sjolund et al. $^{28}$, demonstrating the presence of CCK-secreting cells in the terminal ileum supports these findings.

Smaller fat droplet size will result in readier hydrolysis with an increased generation of fatty acids. In the duodenum, the amount of intraluminal lipase is abundant relative to the ileum. Generation of fatty acids with subsequent release of peptides is not limited by lipase activity, in contrast to the ileum. The observed effects after ileal infusions, expressed in plasma CCK-response, do suggest that not the total amount of FFA, but rather the rate of release of FFA is important.

A discrepancy seems to exist between the results obtained from the duodenum and the ileum infusions. In the duodenum experiments, the fine emulsion increased satiety, but did not affect CCK or PYY secretion, whereas in the ileum experiments, no differences existed in satiety scores but the fine emulsion significantly increased secretion of both CCK and PYY. Opposing results in peptide secretion and satiety scores have been described previously ${ }^{29,30}$. Gut peptides act local as paracrine or neurocrine agents, and not only as hormones ${ }^{31,32}$. Plasma concentrations of peptides may therefore not truly reflect the local effects of these peptides ${ }^{1}$. Moreover, nutrients in the small intestine also have a direct, non-peptide-mediated effect on neural afferent contributing to satiety ${ }^{33}$. These intestinal signals interweave with signals from the stomach, and are integrated in the satiety centres in the brain ${ }^{34,35}$. 
Gastric emptying after duodenal fat infusion was significantly affected by emulsion droplet size. The fine emulsion significantly delayed gastric emptying half time compared to the coarse emulsion, confirming the results of Armand et al. ${ }^{7}$.

At the start of the duodenal infusions ( $\mathrm{t}=30 \mathrm{~min}$ ), most of the meal still is present in the stomach, whereas, at the start of the ileal infusions ( $t=105 \mathrm{~min}$ ), the meal will have largely emptied from the stomach. A link between gastric emptying and gastric distension on the one hand and satiety and eating behaviour on the other has repeatedly been demonstrated ${ }^{1,2,30,36}$. Kissileff et al. have demonstrated that, in the presence of elevated plasma CCK-concentrations, additional distension of the stomach further reduces food intake ${ }^{3}$. During the duodenal infusions, gastric emptying was more delayed in the fine vs. the coarse infusion, resulting in a more pronounced and prolonged gastric distension. We therefore hypothesise that these differences have contributed to the observed differences in satiety levels.

We studied the effect of reducing fat droplet size on satiety by direct infusion of emulsions into the small intestine. It is, however, uncertain whether these effects will remain when the emulsions are added to food products and then ingested orally. The gastric environment can affect the stability of emulsions. Marciani et al. ${ }^{37}$ for instance, showed that gastric stable emulsions behave differently than gastric unstable emulsions, and this, in turn, can influence the effects on peptide secretion and satiety scores $^{38}$. However, in vitro and in vivo data suggest that the emulsions used in the current study are acid stable ${ }^{39}$, implying that the effects observed after intestinal infusion would mimick effects after oral or gastric infusion. However, when these emulsions are ingested orally, data from Armand et al. suggest that passage through the stomach may influence droplet size. Armand et al. observed an increase in the average emulsion droplet size after intragastric administration of an emulsion consisting of small droplets. This, however, may be a measurement artifact as it may very well be the result of rapid hydrolysis of the smaller fat droplets (and thus measurement of the remaining bigger droplets).

In conclusion, we have demonstrated that, compared to larger fat droplets, smaller fat droplets significantly affect satiety, gastric emptying and gut peptide release, with the effect dependent on the intestinal site of fat delivery. Thus, fat droplet size, through influencing fatty acid sensing, is relevant for satiety signalling and regulation of GI function and secretion. 


\section{References}

1. Maljaars J, Peters HP, Masclee AM. Review article: The gastrointestinal tract: neuroendocrine regulation of satiety and food intake. Aliment Pharmacol Ther 2007;26 Suppl 2: 241-250.

2. Geliebter A. Gastric distension and gastric capacity in relation to food intake in humans. Physiol Behav 1988;44: 665-668.

3. Kissileff HR, Carretta JC, Geliebter A, Pi-Sunyer FX. Cholecystokinin and stomach distension combine to reduce food intake in humans. Am. J. Physiol Regul. Integr. Comp Physiol 2003;285: R992-R998.

4. Matzinger D, Degen L, Drewe J, Meuli J, Duebendorfer R, Ruckstuhl N, D'Amato M, Rovati L, Beglinger $C$. The role of long chain fatty acids in regulating food intake and cholecystokinin release in humans. Gut 2000;46: 688-693.

5. Feinle C, O'Donovan D, Doran S, Andrews JM, Wishart J, Chapman I, Horowitz M. Effects of fat digestion on appetite, APD motility, and gut hormones in response to duodenal fat infusion in humans. Am. J. Physiol Gastrointest. Liver Physiol 2003;284: G798-G807.

6. Feinle-Bisset C, Patterson M, Ghatei MA, Bloom SR, Horowitz M. Fat digestion is required for the suppression of ghrelin and stimulation of peptide $Y Y$ and pancreatic polypeptide secretion by intraduodenal lipid. Am J Physiol Endocrinol Metab 2005; 289:E948-53

7. Armand M, Pasquier B, Andre M, Borel P, Senft M, Peyrot J, Salducci J, Portugal H, Jaussan V, Lairon D. Digestion and absorption of 2 fat emulsions with different droplet sizes in the human digestive tract. Am J Clin Nutr 1999;70: 1096-1106.

8. Ledeboer M, Masclee AA, Biemond I, Lamers CB. Differences in cholecystokinin release and gallbladder contraction between emulsified and nonemulsified long-chain triglycerides. $J$ Parenter Enteral Nutr 1999;23: 203-206.

9. Seimon RV, Wooster T, Otto B, Golding M, Day L, Little TJ, Horowitz M, Clifton PM, Feinle-Bisset C. The droplet size of intraduodenal fat emulsions influences antropyloro-duodenal motility, hormone release, and appetite in healthy males. Am J Clin Nutr 2009;89: 1729-1736.

10. Maljaars PW, Peters HP, Mela DJ, Masclee AA. lleal brake: a sensible food target for appetite control. A review. Physiol Behav 2008;95:271-281.

11. Welch I, Saunders K, Read NW. Effect of ileal and intravenous infusions of fat emulsions on feeding and satiety in human volunteers. Gastroenterology 1985;89: 1293-1297.

12. Maljaars J, Haddeman E, Peters H, Masclee A. Comparison of Ileal and Duodenal brake mechanisms on satiety and gastrointestinal transport. Gastroenterology 2007;132: A207 Suppl.2.

13. Maljaars PW, Symersky T, Kee BC, Haddeman E, Peters HP, Masclee AA. Effect of ileal fat perfusion on satiety and hormone release in healthy volunteers. Int J Obes (Lond) 2008; 32:1633-1639.

14. Van Strien T, Frijters JER, Bergers GPA, Defares PB. The Dutch Eating Behavior Questionnaire (DEBQ) for assessment of restrained, emotional, and external eating behavior. Int J Eat Disord 2008;5: 295.

15. Klein S, Stein J, Dressman J. Site-specific delivery of anti-inflammatory drugs in the gastrointestinal tract: an in-vitro release model. J Pharm Pharmacol 2006;57: 709-719.

16. Goebell H, Klotz U, Nehlsen B, Layer P. Oroileal transit of slow release 5-aminosalicylic acid. Gut 1993;34: 669-675.

17. Stratton RJ, Stubbs RJ, Hughes D, King N, Blundell JE, Elia M. Comparison of the traditional paper visual analogue scale questionnaire with an Apple Newton electronic appetite rating system (EARS) in free living subjects feeding ad libitum. Eur J Clin Nutr 1998;52: 737-741.

18. Flint A, Raben A, Blundell JE, Astrup A. Reproducibility, power and validity of visual analogue scales in assessment of appetite sensations in single test meal studies. Int J Obes Relat Metab Disord 2000; 24: 38-48.

19. Braden B, Adams S, Duan LP, Orth KH, Maul FD, Lembcke B, Hor G, Caspary WF. The [13C]acetate breath test accurately reflects gastric emptying of liquids in both liquid and semisolid test meals. Gastroenterology 1995;108: 1048-1055. 
20. Ledeboer $M$, Masclee AA, Jansen JB, Lamers CB. Effect of equimolar amounts of long-chain triglycerides and medium-chain triglycerides on small-bowel transit time in humans. J Parenter Enteral Nutr 1995;19: 5-8.

21. Symersky T, Biemond I, Frolich M, Masclee AA. Effect of peptide YY on pancreatico-biliary secretion in humans. Scand J Gastroenterol 2005;40: 944-949.

22. Lieverse RJ, Jansen JB, Masclee AM, Lamers CB. Satiety effects of cholecystokinin in humans. Gastroenterology 1994;106: 1451-1454.

23. French SJ, Conlon CA, Mutuma ST, Arnold M, Read NW, Meijer G, Francis J. The effects of intestinal infusion of long-chain fatty acids on food intake in humans. Gastroenterology 2000;119: 943-948.

24. Womble LG, Williamson DA, Greenway FL, Redmann SM. Psychological and behavioral predictors of weight loss during drug treatment for obesity. Int J Obes Relat Metab Disord 2001;25: 340-345.

25. Feltrin KL, Little TJ, Meyer JH, Horowitz M, Smout AJ, Wishart J, Pilichiewicz AN, Rades T, Chapman IM, Feinle-Bisset C. Effects of intraduodenal fatty acids on appetite, antropyloroduodenal motility, and plasma CCK and GLP-1 in humans vary with their chain length. Am J Physiol Regul Integr Comp Physiol 2004;287: R524-R533.

26. Rolls BJ, Kim S, McNelis AL, Fischman MW, Foltin RW, Moran TH. Time course of effects of preloads high in fat or carbohydrate on food intake and hunger ratings in humans. Am J Physiol 1991;260: R756-R763.

27. Lin HC, Chey WY. Cholecystokinin and peptide YY are released by fat in either proximal or distal small intestine in dogs. Regul Pept 2003;114: 131-135.

28. Sjolund K, Sanden G, Hakanson R, Sundler F. Endocrine cells in human intestine: an immunocytochemical study. Gastroenterology 1983;85: 1120-1130.

29. Feltrin KL, Little TJ, Meyer JH, Horowitz M, Rades T, Wishart J, Feinle-Bisset C. Comparative effects of intraduodenal infusions of lauric and oleic acids on antropyloroduodenal motility, plasma cholecystokinin and peptide YY, appetite, and energy intake in healthy men. Am J Clin Nutr 2008;87: 1181-1187.

30. Wang GJ, Tomasi D, Backus W, Wang R, Telang F, Geliebter A, Korner J, Bauman A, Fowler JS, Thanos PK, Volkow ND. (2008) Gastric distention activates satiety circuitry in the human brain. Neuroimage 2008;39: 1824-1831.

31. Koda S, Date $Y$, Murakami N, Shimbara T, Hanada T, Toshinai K, Niijima A, Furuya M, Inomata N, Osuye K, Nakazato M. (2005) The role of the vagal nerve in peripheral PYY3-36-induced feeding reduction in rats. Endocrinology 2005;146: 2369-2375.

32. Abbott CR, Monteiro M, Small CJ, Sajedi A, Smith KL, Parkinson JR, Ghatei MA, Bloom SR. The inhibitory effects of peripheral administration of peptide $Y Y(3-36)$ and glucagon-like peptide-1 on food intake are attenuated by ablation of the vagal-brainstem-hypothalamic pathway. Brain Res 2005;1044: 127-131.

33. Savastano DM, Hayes MR, Covasa M. Serotonin-type 3 receptors mediate intestinal lipid-induced satiation and Fos-like immunoreactivity in the dorsal hindbrain. Am J Physiol Regul Integr Comp Physiol 2007;292: R1063-R1070.

34. Walls EK, Phillips RJ, Wang FB, Holst MC, Powley TL. Suppression of meal size by intestinal nutrients is eliminated by celiac vagal deafferentation. Am J Physiol 1995;269: R1410-R1419.

35. Randich A, Chandler PC, Mebane HC, Turnbach ME, Meller ST, Kelm GR, Cox JE. Jejunal administration of linoleic acid increases activity of neurons in the paraventricular nucleus of the hypothalamus. Am J Physiol Regul Integr Comp Physiol 2004;286: R166-R173.

36. Jones KL, Doran SM, Hveem K, Bartholomeusz FD, Morley JE, Sun WM, Chatterton BE, Horowitz M. Relation between postprandial satiation and antral area in normal subjects. Am J Clin Nutr 1997;66: 127-132.

37. Marciani L, Faulks R, Wickham MS, Bush D, Pick B, Wright J, Cox EF, Fillery-Travis A, Gowland PA, Spiller RC. Effect of intragastric acid stability of fat emulsions on gastric emptying, plasma lipid profile and postprandial satiety. Br J Nutr 2009;101: 919-928. 
38. Foltz M, Maljaars J, Schuring EA, van der Wal RJ, Boer T, Duchateau GS, Peters HP, Stellaard F, Masclee AA. Intragastric layering of lipids delays lipid absorption and increases plasma CCK but has minor effects on gastric emptying and appetite. Am J Physiol Gastrointest Liver Physiol 2009;296: G982-G991.

39. Hoad CL, Rayment P, Spiller RC, Marciani L, Alonso BC, Traynor C, Mela DJ, Peters HP, Gowland PA. In vivo imaging of intragastric gelation and its effect on satiety in humans. J Nutr 2004;134: 2293-2300. 



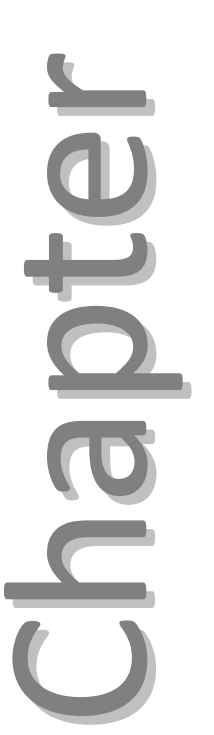

\section{Effect of fat saturation on satiety,} hormone release and food intake

Maljaars J, Romeyn EA, Haddema E, Peters HPF, Stellaard F, Masclee AAM Am J Clin Nutr. 2009;89:1019-1024 


\section{Abstract}

\section{Background}

Background: lleal delivery of fat reduces hunger and food intake through activation of the ileal brake. Physicochemical properties of fat have been shown to affect satiety and food intake.

\section{Objective}

The objective of this study was to assess the effect of ileal fat emulsions with differing degrees of fatty acid saturation on satiety, food intake and gut peptides (CCK, PYY). We hypothesized that long-chain triacylglycerols (LCT) with diunsaturated fatty acids would increase satiety and reduce energy intake compared to LCT with monounsaturated or saturated fatty acids.

\section{Design}

We performed a double-blind randomized cross-over study in which fifteen healthy subjects (mean age: 24 yrs, mean BMI $22 \mathrm{~kg} / \mathrm{m}^{2}$ ) were intubated with a naso-ileal catheter and participated in four experiments performed in random order on four consecutive days. After consumption of a liquid meal, subjects received fat or control infusion in the ileum. Fat emulsions consisted of 6 gram of either C18:0 (Shea oil; mainly C18:0), C18:1 (Canola oil; mainly C18:1) or C18:2 oil (Safflower oil; mainly C18:2). Food intake was measured during an ad-libitum lunch. Satiety questionnaires (VAS) and blood samples were collected at regular intervals.

\section{Results}

Compared to control, only C18:2 and C18:1 significantly increased fullness and reduced hunger. No effect on food intake was observed. C18:1 and C18:2 increased CCK secretion significantly compared to control. Fatty acid saturation did not affect PYY secretion.

\section{Conclusions}

When infused into the ileum, TAG with unsaturated fatty acids increases satiety compared to control, whereas TAG with saturated fatty acids does not. 


\section{Introduction}

Fat in the gastrointestinal tract reduces hunger and impairs food intake by eliciting satiety signals ${ }^{1}$. These signals are evoked by entry of triacylglycerols (TAG; after hydrolysation to fatty acids) or fatty acids (FA) into the small intestine. Duodenal fat induces release of CCK and other gastrointestinal peptides, involved in the regulation of satiety and food intake ${ }^{1}$. When infused into the ileum, fat also increases satiety and reduces food intake ${ }^{2}$. Studies in both animals ${ }^{3,4}$ and humans ${ }^{1,5}$ suggest that the satiating effect of fat from the ileum is even larger compared to the effect of fat from the duodenum. Infusion of fat into the ileum activates the ileal brake mechanism ${ }^{6}$, an inhibitory distal to proximal feedback mechanism that regulates the transit and handling of a meal through the digestive tract in order to optimize nutrient digestion and absorption ${ }^{7}$.

The satiating effect of fat is dependent on its physicochemical properties ${ }^{8,9}$. For instance, reduction of hunger and food intake increases with increasing fatty acid chain length ${ }^{8}$. Feltrin et al. ${ }^{8}$ demonstrated that reduction in energy intake and in hunger was stronger after isocaloric infusion of Lauric acid (C12) versus Decanoic acid (C10).

Apart from FA chain length, another physicochemical property of fat that may affect hunger and food intake is the degree of fatty acid saturation. The effect of fatty acid saturation on ileal brake mediated satiety is not known, but data are available on oral and duodenal administration of fats differing in fatty acid saturation. Lawton et al. ${ }^{10}$ demonstrated that oral ingestion of TAG with unsaturated FAs induced a greater reduction in food intake than TAG with saturated FAs. However, Flint et al. ${ }^{11}$ and Alfenas and Mattes ${ }^{12}$ did not find such a difference on food intake or satiety.

French et al. ${ }^{9}$ measured food intake and satiety following various intraduodenally infused fat emulsions. Emulsions enriched with linoleic acid (c18:2) reduced food intake more than oleic (c18:1) or stearic (c18:0) acid without affecting satiety.

Entry of fat into the small intestine induces release of gut peptides (CCK, PYY), and secretion of these peptides is (partly) responsible for the effects of fat on satiety and food intake ${ }^{1}$.

Aim of the present study was to assess the effect of ileal fat emulsions with differing degrees of saturation of fatty acid chains on 1 . satiety and food intake and 2 . secretion of peptides known to affect satiety (CCK, PYY). We hypothesized that long-chain triglyceride (LCT) emulsions with di-unsaturated fatty acids will enhance postprandial satiety and reduce energy intake compared to LCT emulsions with mono-unsaturated or saturated fatty acids. 


\section{Materials and method}

\section{Subjects}

Healthy volunteers aged between 18 and 55 yrs with a BMI between 18 and $32 \mathrm{~kg} / \mathrm{m}^{2}$ were recruited by advertisement. Restrained eaters (as assessed by the Dutch eating behaviour questionnaire) and subjects who reported that they were following either a weight-reduction diet or a medically-prescribed diet were excluded from participation. Subjects who were taking medication that may have influenced appetite and sensory function or who reported metabolic or endocrine disease, gastrointestinal disorders or a history of medical or surgical events that may have affected study outcome were also excluded. Informed consent was obtained from each individual. The study protocol had been approved by the Medical Ethics Committee of the Leiden University Medical Centre, and procedures followed were in accordance with the ethical standards of the institution on human experimentation. This study has been registered (ISRCTN51742545), and subject recruitment started in September 2005.

Eighteen subjects met the inclusion criteria. Three volunteers dropped out during the study: one due to discomfort during catheter positioning and two due to failure to position the tip of the catheter beyond the ligament of Treitz (flexura duodenojejunalis). Fifteen healthy volunteers ( 13 female, mean age 24 yrs, mean BMI $22 \mathrm{~kg} / \mathrm{m}^{2}$ ) participated in the study and completed the protocol.

\section{Catheters}

The catheter for ileal intubation was a $290 \mathrm{~cm}$ long rubber silicon 9-channel (8-lumen, 1 balloon inflation channel, diameter $3.5 \mathrm{~mm}$ ) catheter custom-made by Dentsleeve International Ltd (Mississauga, Ontario, Canada). The functional length of the catheter was $240 \mathrm{~cm}$; there was a $50 \mathrm{~cm}$ connection segment. The catheters contained sideholes at $80,95,110,125,210,220,230$ and $240 \mathrm{~cm}$ from the proximal junction and had an inflatable balloon (maximum inflation capacity $10 \mathrm{ml}$ ) at the distal tip. The three distal side-holes $(220,230,240 \mathrm{~cm})$ reaching into the ileum were used to administer placebo or fat emulsion.

\section{Experimental protocol}

In this double blind placebo controlled crossover design, four different perfusions were scheduled: 1 . saline (control) or a $6 \mathrm{~g}$ fat emulsion consisting either of 2 . mainly unsaturated fats (C18:0), 3. mainly mono-unsaturated fat (C18:1) or 4. mainly diunsaturated fat (C18:2) was administered into the ileum. (See Table 6.1. for details on fatty acid composition of the different emulsions.) 
Table 6.1 Fatty acid composition of the emulsions.

\begin{tabular}{lrrrrrr}
\hline & \multicolumn{3}{c}{ Overall fatty acid comp. } & \multicolumn{3}{c}{ sn-1,3 fatty acid comp. } \\
& C18:0 & C18:1 & C18:2 & C18:0 & C18:1 & C18:2 \\
\hline Shea & $\mathbf{5 9 \%}$ & $32 \%$ & $4 \%$ & $\mathbf{8 3} \%$ & $7 \%$ & $5 \%$ \\
Canola & $2 \%$ & $\mathbf{7 6 \%}$ & $12 \%$ & $2 \%$ & $\mathbf{7 7 \%}$ & $\mathbf{7 \%}$ \\
Safflower & $2 \%$ & $12 \%$ & $\mathbf{7 6 \%}$ & $3 \%$ & $12 \%$ & $\mathbf{7 2 \%}$ \\
\hline
\end{tabular}

Percentage fatty acid composition for the different emulsions used in this study, specified for all three fatty acid positions, and for the sn-1, 3 positions.

\section{Catheter positioning}

On Monday, subjects arrived at 12:00 hr after a light breakfast (ingested before 09:00 AM). Through an anaesthetized nostril, the catheter was introduced into the stomach, and allowed to pass through the pylorus to the ileum by peristalsis. After passing the ligament of Treitz, a small balloon at the tip was inflated to facilitate passage of the catheter to the ileum. During the day, the subject was offered small snacks and sugared tea or coffee to stimulate peristalsis. The tip was placed in the ileum (at least $120 \mathrm{~cm}$ distal from the pylorus ${ }^{13}$ ), so 3 infusion ports were available in the ileum. In our study, we perfused the ileum at at least $175-195 \mathrm{~cm}$ from the nose. During the positioning and before every test-day, the position of the catheter was checked fluoroscopically.

\section{Test day}

On each study day, the subject arrived at the GI unit at 8:00 AM following an overnight fast. After checking the position of the catheter, a venous catheter was placed in a forearm-vein for collection of blood samples. At 8:45 hr, a basal VAS score and a basal blood sample were taken. After this, the experiment was started. At 9:00 hr ( $t=0 \mathrm{~min})$, a fat-free liquid meal was ingested.

The ileal infusion started at $\mathrm{t}=105 \mathrm{~min}$. Infusion rate was $1 \mathrm{ml} / \mathrm{min}(0.9 \mathrm{kcal} / \mathrm{min})$ for $60 \mathrm{~min}$. Each day the ileum was perfused with a fat emulsion or the fat-free emulsion. The three most distal catheter ports were used for this perfusion, so the emulsion was spread out over a length of $30 \mathrm{~cm}$.

At 13:00 hr ( $\mathrm{t}=240 \mathrm{~min})$ the ad libitum lunch was served. At 14:45 hr, the intravenous canula was removed, and subjects were allowed to go home. They received an evening meal and snackbox from which they were allowed to consume freely till 22:00 hr.

\section{Satiety}

Scores for satiety feelings (fullness, hunger, prospective feeding, desire to eat a meal, desire to eat a snack) was measured using electronic Visual Analogue Scales (EVAS) 
anchored at the low end with the most negative or lowest intensity feelings (e.g., extremely unpleasant, not at all), and with opposing terms at the high end (e.g., extremely pleasant, very high, extreme $)^{14}$. Volunteers were asked to indicate on a line which place on the scale best reflects their feeling at that moment. Measurements were taken during the test day every $30 \mathrm{~min}$, and every $15 \mathrm{~min}$ during infusion of emulsion.

\section{Food intake}

Each test day, an ad libitum-lunch was served to measure food intake. Each lunch was offered in excess, and consisted of 15 equal slices of brown bread with mature cheese ( $48 \%$ fat). Each sandwich was cut in different-sized pieces, so the subject would not be able to assess to number of sandwiches eaten. During the ad libitum-lunch, subjects were not allowed to watch television, listen to the radio or read books as this could have influenced the amount eaten.

\section{Liquid meal}

As breakfast, subjects received a fat-free Slim Fast Optima drink (Slim-Fast Foods, West Palm Beach, FL; 325 ml, 145 kcal). These are vitamin- and mineral-fortified meal replacement products, used by consumers primarily in order to aid in weight loss and/or prevention of weight gain.

\section{Emulsions}

The emulsions consisted of $10 \%$ oil in water. As an emulsifier $2.5 \% \mathrm{~K}$-caseinate was used. A very small amount of xanthan gum $(0.1 \%)$ and guar gum $(0.1 \%)$ was used as a stabiliser. Sodium chloride was added to obtain iso-osmotic solutions $(0.8 \% \mathrm{NaCl})$. See Table 6.1. for fatty acid composition of the emulsions. Total infused volume was $60 \mathrm{ml}$, containing $6 \mathrm{~g}$ fat. Caloric load was $54 \mathrm{kcal}$. The $\mathrm{pH}$ of the emulsions ranged from 6.7 till 6.8 .

\section{Hormone assays}

Blood samples were drawn at regular intervals throughout the test day. After collection, the blood was kept on ice. PYY (total) and CCK were measured by sensitive and specific radioimmunoassays, as described previously ${ }^{15,16}$.

\section{Statistical analysis}

Results are presented as least squares means with standard error of the mean (SEM), unless otherwise specified. Satiety VAS scores were expressed as percentages of the 
maximal score $(0 \mathrm{~cm}$ equaled $0 \%$ and $6,4 \mathrm{~cm}$ equaled $100 \%)$ and as incremental cumulative areas under the curve, with the value at $\mathrm{t}=105 \mathrm{~min}$, the starting point of the infusion, as a covariate. The incremental AUC was calculated, using the trapezoid rule, with the beginning of the infusion period, $\mathrm{t}=105 \mathrm{~min}$, as a covariate.

All parameters were analyzed using analysis of variance with subjects as blocks and treatment as factor. Differences of the treatment groups from the control were established using Dunnett least significant difference test (two-tailed). A p-value of 0.05 was considered significant. When a significant time $\mathrm{x}$ treatment interaction was present, differences at individual time points are reported.

\section{Results}

\section{Satiety parameters}

As results from all satiety parameters are similar and consistent, we will only show scores for fullness and hunger. Mean VAS scores for hunger are given in Figure 6.1A and for fullness in Figure 6.2A. Fasting scores for hunger and fullness did not differ between the four treatments. Consumption of the liquid meal led to a decrease in hunger feelings and an increase in fullness in all four treatments.

The AUCs for hunger for the $t=105-240$ min period for both canola and safflower differed significantly from control (Figure 6.1B). Over the test day (0-240 $\mathrm{min})$, both canola and safflower resulted in lower AUCs for hunger compared to control. The AUCs for fullness for the $t=105-240$ min period for both canola and safflower differ significantly from control (Figure 6.2B).

\section{Food intake}

Food intake did not differ significantly between treatments (control $180 \mathrm{~g}$, shea $173 \mathrm{~g}$, canola $167 \mathrm{~g}$, and safflower $189 \mathrm{~g}$, SE=10).

CCK

Plasma CCK-concentrations are shown in Figure 6.3A. Baseline plasma CCK concentrations did not differ between study days. The liquid meal induced an increase in CCK-concentrations in all four treatments. The infusion significantly increased plasma CCK concentrations after canola oil ( $t=135, t=150 \mathrm{~min}$ ) and safflower oil $(t=150, t=165 \mathrm{~min}$ ) compared to control. For the period $t=105-t=240 \mathrm{~min}$, the AUCs (Figure 6.3B) for canola and safflower were significantly greater as compared to control, whereas no overall difference in CCK AUCs for the entire period ( $t=0-240 \mathrm{~min}$ ) was observed between treatments. 
A

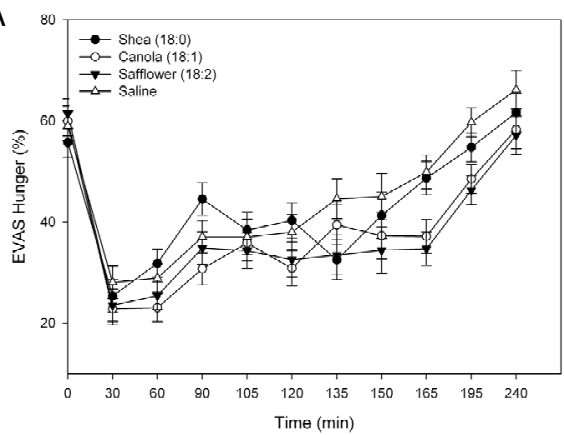

B

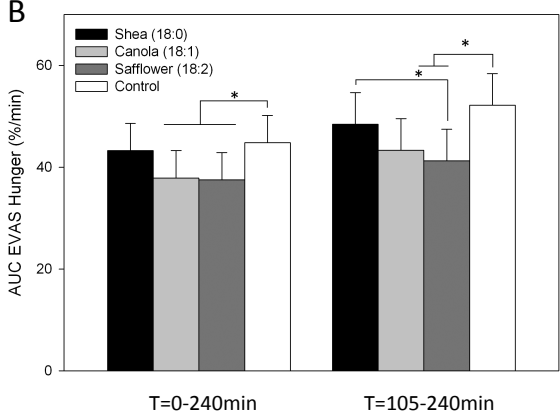

Figure 6.1 Results for hunger in response to the liquid meal and ileal infusion of shea oil (18:0), canola oil (18:1) safllower oil (C18:2) or control. The infusion period was scheduled from $t=105-165$ min. Fullness and Hunger was measured by EVAS (Electronic Visual Analogue Scales) and was expressed as percentage of the maximal score $(0 \mathrm{~cm}$ equaled $0 \%$ and $64 \mathrm{~mm}$ equaled $100 \%)$.

A. EVAS scores for hunger. $\uparrow$ denotes $p<0.05$ for shea vs. saline, $¥$ denotes $p<0.05$ canola and safflower vs.saline. Data are means $( \pm$ SEM), $n=15$, based on analysis by Dunnett. B. Area under the curve (AUC) for hunger. AUC was calculated by trapezoid rule over $t=105-240 \mathrm{~min}$ period. Data are means ( \pm SEM), $n=15,{ }^{*}$ denotes $p<0.05$ based on analysis by Dunnett.

A

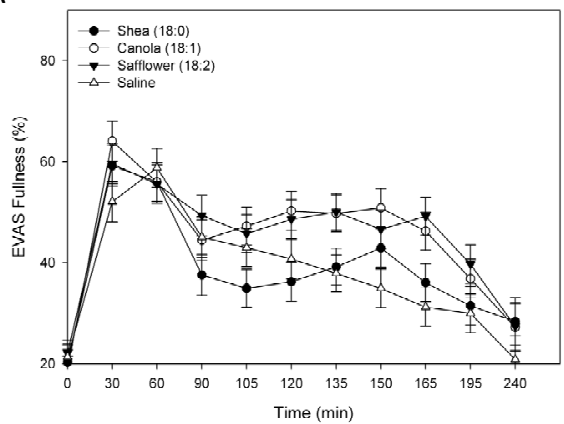

B

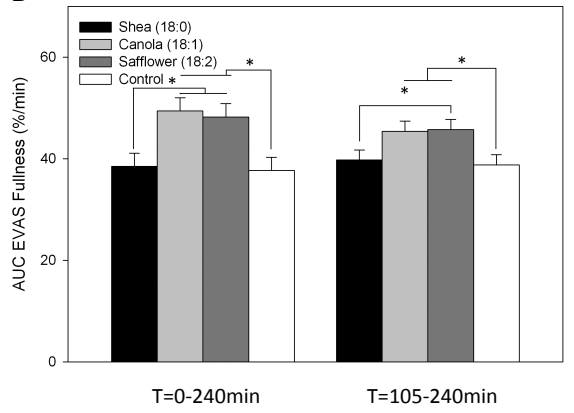

Figure 6.2 Results for fullness in response to the liquid meal and ileal infusion of shea oil (18:0), canola oil (18:1) safllower oil (C18:2) or control. The infusion period was scheduled from $t=105-165$ min. Fullness and Hunger was measured by EVAS (Electronic Visual Analogue Scales) and was expressed as percentage of the maximal score $(0 \mathrm{~cm}$ equaled $0 \%$ and $64 \mathrm{~mm}$ equaled $100 \%)$.

A. EVAS scores for fullness. $\ddagger$ denotes $p<0.05$ canola and safflower vs. saline. Data are means ( \pm SEM), $n=15$, based on analysis by Dunnett.B. Area under the curve (AUC) for fullness. AUC was calculated by trapezoid rule over $t=105-240$ min period. Data are means ( \pm SEM), $n=15$, * denotes $p<0.05$ based on analysis by Dunnett.

Plasma PYY-concentrations are given in Figure 6.4A. Baseline plasma PYY concentrations did not differ between study days. The liquid meal induced a slight increase in PYY-concentrations in all 4 treatments. The start of the infusion induced an 
increase in plasma PYY concentrations after all fat emulsions compared to control. For the $t=105-t=240 \mathrm{~min}$ and $t=0-240$ min period, AUCs (Figure 6.4B) were statistically increased for all fat emulsions compared to control.

A

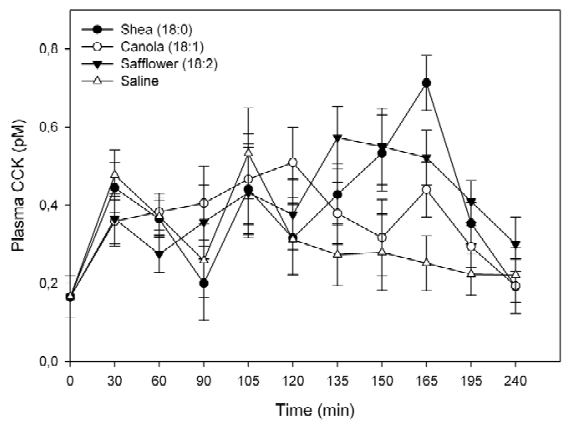

B

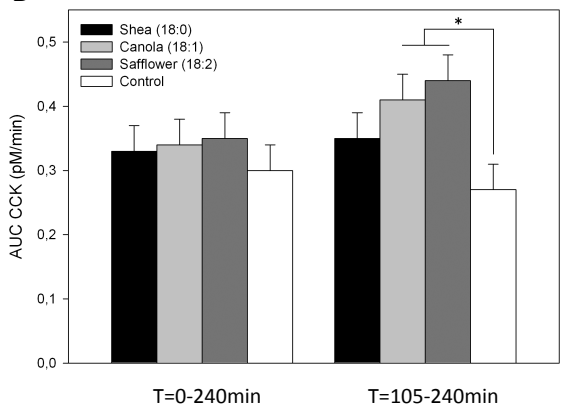

Figure 6.3 Plasma concentrations and AUC of Cholecystokinin (CCK) in response to the liquid meal and ileal infusion of shea oil (18:0), canola oil (18:1) safllower oil (C18:2) or control. The infusion period was scheduled from $\mathrm{t}=105-165 \mathrm{~min}$. Blood samples were collected at regular intervals throughout the test day, and kept on ice. CCK was measured by RIA. A. Plasma concentrations of CCK. Data are means $( \pm$ SEM), $n=15, \ddagger$ denotes $p<0.05$ canola and safflower vs. saline, based on analysis by Dunnett. B. Area under the curve (AUC) of CCK. AUC was calculated by trapezoid rule over $t=105-240$ min period. Data are means ( \pm SEM), $n=15,{ }^{*}$ denotes $p<0.05$ based on analysis by Dunnett.
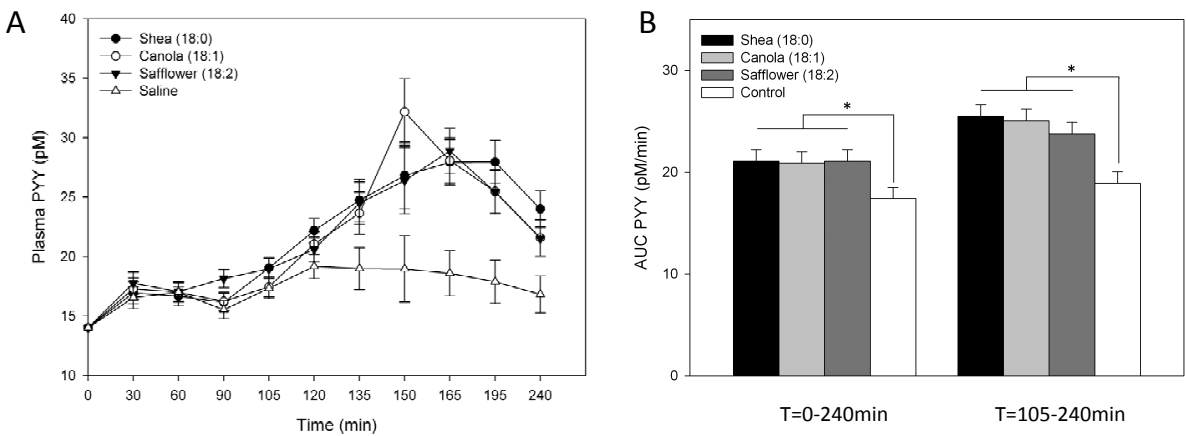

Figure 6.4 Plasma concentrations and AUC of Peptide YY (PYY) in response to the liquid meal and ileal infusion of shea oil (18:0), canola oil (18:1) safllower oil (C18:2) or control. The infusion period was scheduled from $\mathrm{t}=105-165 \mathrm{~min}$. Blood samples were collected at regular intervals throughout the test day, and kept on ice. PYY was measured by RIA. A. Plasma concentrations of PYY. Data are means ( \pm SEM), $n=15,+$ denotes $p<0.05$ for shea vs. saline, $\ddagger$ denotes $p<0.05$ canola vs. saline, a denotes $p<0.05$ for safflower vs. saline, based on analysis by Dunnett.

B. Area under the curve (AUC) of PYY. AUC was calculated by trapezoid rule over $t=105-240$ min period. Data are means $( \pm S E M), n=15, *$ denotes $p<0.05$ based on analysis by Dunnett. 


\section{Discussion}

We have demonstrated that the degree of fatty acid saturation of triacylglycerols infused into the ileum affects satiety levels and release of CCK but not food intake. Neither did the degree of fatty acid saturation affect PYY release.

Intraduodenal infusion of fat reduces hunger and increases satiety ${ }^{17}$, and physicochemical properties of fat (such as chain length) affect its satiating potency ${ }^{8,9}$. Evidence exists that the degree of fatty acid saturation affects the satiating effect of fat $^{10}$, but this has not been consistently demonstrated ${ }^{9,11,12}$. While it has been shown that ileal infusion of fat reduced hunger and food intake ${ }^{2}$, the effect of differences in fatty acid saturation on ileal fat induced satiety has never been tested. In the present study, both TAGs with unsaturated fatty acids reduced hunger and increased fullness significantly compared to the saline control infusion, whereas shea oil, consisting of saturated fatty acids, did not. This clearly demonstrates that ileal brake-mediated satiety is most potently stimulated by oils containing high amounts of unsaturated fatty acids.

The anorectic effect of intestinal fat when infused in the duodenum and in the ileum has been demonstrated repeatedly and consistently ${ }^{2,9,18}$. French et al. observed an effect of fatty acid saturation on food intake after duodenal fat infusion ${ }^{9}$. We observed that the different fat emulsions affected satiety, but did not affect food intake. In the study by French et al. ${ }^{9}$ and Welch et al. ${ }^{2}$ the ad libitum meal was provided already during the infusion. In our study, the interval between the end of the infusion and the start of the ad libitum lunch was 75 minutes. Rolls et al. demonstrated that the time-interval between a caloric load and an ad libitum meal affects meal intake ${ }^{19}$. We hypothesise that the longer interval between infusion and lunch $(75 \mathrm{~min}$ ) may have affected the results and may explain the lack of effect of the treatments (fat infusion) on food intake, and a significant effect on food intake may have been present if we had measured food intake at an earlier point in the test day. The finding that at $\mathrm{t}=\mathbf{2 4 0}$ min the significant differences between the treatments in satiety scores had disappeared provides evidence to support this hypothesis. When studying eating behaviour and satiety scores, a distinction should be made between satiation, the processes that lead to the termination of a meal, and satiety, which refers to postprandial events that affect the time interval to the next meal. Satiety regulates meal frequency and food intake during a next meal, in which learned habits also play a role ${ }^{1}$. In the studies by French et al. ${ }^{9}$ and by Welch et al. ${ }^{2,18}$, food intake was measured during the infusion and the parameter studied therefore was satiation. During our study, we studied the effects between meals, and have focused on satiety. 
Entry of fat into the small intestine induces release of $\mathrm{CCK}^{1}$. Beardshall et al. ${ }^{20}$ found that ingestion of a meal high in monounsaturated fat resulted in significantly higher plasma CCK concentrations compared to a saturated fat meal. In our study, both canola and safflower oil significantly increased plasma CCK concentrations compared to the saline infusion, whereas shea oil had no significant effect. Release of CCK after ileal fat infusion was not anticipated. However, release of CCK in response to ileal fat infusions has been described ${ }^{21}$. In general, secretion of CCK is thought to be confined to the duodenum and jejunum. Sjolund et al. $^{22}$, as well as others ${ }^{23}$ have demonstrated the presence of CCK-secreting I-cells in the (terminal) ileum. However, the number of CCK cells was smaller in the ileum compared to the duodenum or jejunum ${ }^{22}$. In a previous study ${ }^{5}$, we compared secretion of CCK after isocaloric infusion of fat into the duodenum and ileum, and found that both infusions increased secretion of CCK, although CCK secretion was more potently stimulated after duodenal compared to ileal fat infusion.

We can exclude that incorrect positioning of the catheter has affected CCK-release. Both during the positioning of the catheter and each test day at the start and end of the procedure, the position of the catheter was checked fluoroscopically to ascertain placement of the tip of the catheter in the ileum. A full 22 hours period was used for positioning of the catheter. Subjects were routinely instructed to assist passage and aboral progression of the catheter at home. Furthermore, in 3 cases, contrast fluid was used to ascertain position of the catheter. After infusion of the contrast fluid, the contrast appeared in the colon within a few minutes.

TAGs are hydrolyzed in the proximal GI tract to fatty acids and monoacylglycerols ${ }^{24}$. Hydrolysis is necessary in order to induce the effects of fat on gastrointestinal function, hormone release and satiety ${ }^{25,26}$. Fatty acids are incorporated in micelles, and transported to the surface of epithelial cells ${ }^{24}$, where sensing and subsequent absorption of fatty acids occurs ${ }^{27}$. As the ease of micelle formation increases with the degree of fat unsaturation ${ }^{28}$, unsaturated fatty acids are more readily available for sensing and absorption, leading to increased satiety and hormone release $\mathrm{e}^{27}$. Jones et al. ${ }^{29}$ demonstrated that after oral ingestion of labelled fatty acids, significantly more stearic acid (saturated) was found in stool as compared to oleic acid (unsaturated). This is probably due to an increased ability of saturated fatty acids to interact with calcium, resulting in the formation of insoluble calcium-fatty acid soaps and increased faecal excretion ${ }^{30}$. Both mechanisms (micelle formation, calcium binding) may be involved in the differences in satiety and CCK-release observed in our study. However, Recent studies demonstrate that the 'metabolisation' of saturated and unsaturated fats occurs roughly at the same rate, and differences in plasma peaks are caused more by the sn-structure, and not by the degree of saturation/unsaturation $\{486\}$. 
In the present study, all fat emulsions induced a significant increase in PYY-secretion compared to the saline infusion, without differences between the fat emulsions. With respect to GI peptides, both CCK and PYY are considered satiety signals. Infusion of CCK reduces food intake during a meal ${ }^{17}$. The reduction in hunger observed after fat infusion can be abolished by a CCK receptor antagonist ${ }^{17}$, pointing to a role for CCK in the physiologic regulation of eating behaviour. Batterham et al. ${ }^{31,32}$ demonstrated that infusion of PYY reduced food intake in both animals and humans. Whether PYY is involved in the physiological regulation of food intake is still object of debate ${ }^{33}$. In animals, this debate has been resolved: although many studies failed to confirm the results of Batterham et al. ${ }^{33}$, adequate habituation and acclimatisation of animals proved to be essential in these studies, and PYY is considered to be a physiologic satiety signal ${ }^{34}$.

We have previously performed a study in human subjects in order to examine whether the satiating effect of ileal brake activation was mediated by PYY. At plasma PYY-concentrations that were similar after intravenous PYY infusion and after ileal fat infusion, the effects on satiety after the intestinal fat infusion were much more pronounced $^{35}$. From that study, we concluded that the satiating effect of the ileal brake is not solely mediated by PYY. From the current study, as from previous studies $^{36}$, we hypothesise that a role for CCK in ileal brake-mediated satiety should be considered. However, other peptides may also be involved. Release of GLP-1, a gut peptide released from L-cells that predominate in the distal small intestine and colon has been shown to increase after a monounsaturated fat-rich compared to saturated fat-rich meal $^{37}$, and a reduction in both hunger and food intake has been demonstrated after GLP-1 infusion ${ }^{1}$. In animals, Kalogeris et al. ${ }^{38}$ have demonstrated that, compared to saturated fatty acids, unsaturated fatty acids increased lymphatic outflow of Apo A-IV, a chylomicron particle that has been shown to reduce food intake in rats ${ }^{39}$, significantly.

In conclusion, when infused into the ileum, TAG with unsaturated fatty acids increases satiety compared to control whereas TAG with saturated fatty acids does not 


\section{References}

1. Maljaars J, Peters HP, Masclee AM. Review article: The gastrointestinal tract: neuroendocrine regulation of satiety and food intake. Aliment Pharmacol Ther 2007;26 Suppl 2:241-250.

2. Welch I, Saunders K, Read NW. Effect of ileal and intravenous infusions of fat emulsions on feeding and satiety in human volunteers. Gastroenterology 1985;89:1293-1297.

3. Meyer JH, Hlinka M, Tabrizi Y, DiMaso N, Raybould HE. Chemical specificities and intestinal distributions of nutrient-driven satiety. Am J Physiol 1998;275:R1293-R1307.

4. Koopmans HS. The role of the ileum in the control of food intake and intestinal adaptation. Can J Physiol Pharmacol 1990;68:650-655.

5. Maljaars J, Haddeman E, Peters H, Masclee A. Comparison of Ileal and Duodenal brake mechanisms on satiety and gastrointestinal transport. Gastroenterology 2007;132:A207 Suppl.2.

6. Van Citters GW, Lin HC. Ileal brake: Neuropeptidergic control of intestinal transit. Curr Gastroenterol Rep 2006;8:367-373.

7. Maljaars PW, Peters HP, Mela DJ, Masclee AA. Ileal brake: a sensible food target for appetite control. A review. Physiol Behav 2008;doi:10.1016/j.physbeh.2008.07.018.

8. Feltrin KL, Little TJ, Meyer JH, Horowitz M, Smout AJ, Wishart J, Pilichiewicz AN, Rades T, Chapman IM, Feinle-Bisset C. Effects of intraduodenal fatty acids on appetite, antropyloroduodenal motility, and plasma CCK and GLP-1 in humans vary with their chain length. Am J Physiol Regul Integr Comp Physiol 2004;287:R524-R533.

9. French SJ, Conlon CA, Mutuma ST, Arnold M, Read NW, Meijer G, Francis J. The effects of intestinal infusion of long-chain fatty acids on food intake in humans. Gastroenterology 2000;119:943-948.

10. Lawton CL, Delargy HJ, Brockman J, Smith FC, Blundell JE. The degree of saturation of fatty acids influences post-ingestive satiety. Br J Nutr 2000;83:473-482.

11. Flint A, Helt B, Raben A, Toubro S, Astrup A. Effects of different dietary fat types on postprandial appetite and energy expenditure. Obes Res 2003;11:1449-1455.

12. Alfenas RC, Mattes RD. Effect of fat sources on satiety. Obes Res 2003;11:183-187.

13. Spiller RC, Trotman IF, Higgins BE, Ghatei MA, Grimble GK, Lee YC, Bloom SR, Misiewicz JJ, Silk DB. The ileal brake--inhibition of jejunal motility after ileal fat perfusion in man. Gut 1984;25:365-374.

14. Flint A, Raben A, Blundell JE, Astrup A. Reproducibility, power and validity of visual analogue scales in assessment of appetite sensations in single test meal studies. Int J Obes Relat Metab Disord 2000; 24:38-48.

15. Jansen JB, Lamers CB. Radioimmunoassay of cholecystokinin in human tissue and plasma. Clin Chim Acta 1983;131:305-316.

16. Symersky T, Vu MK, Frolich M, Biemond I, Masclee AA. The effect of equicaloric medium-chain and long-chain triglycerides on pancreas enzyme secretion. Clin Physiol Funct Imaging 2002;22:307-311.

17. Lieverse RJ, Jansen JB, Masclee AA, Rovati LC, Lamers CB. Effect of a low dose of intraduodenal fat on satiety in humans: studies using the type $A$ cholecystokinin receptor antagonist loxiglumide. Gut 1994;35:501-505.

18. Welch IM, Sepple CP, Read NW. Comparisons of the effects on satiety and eating behaviour of infusion of lipid into the different regions of the small intestine. Gut 1988;29:306-311.

19. Rolls BJ, Kim S, McNelis AL, Fischman MW, Foltin RW, Moran TH. Time course of effects of preloads high in fat or carbohydrate on food intake and hunger ratings in humans. Am J Physiol 1991;260: R756-R763.

20. Beardshall K, Frost G, Morarji Y, Domin J, Bloom SR, Calam J. Saturation of fat and cholecystokinin release: implications for pancreatic carcinogenesis. Lancet 1989;2:1008-1010.

21. Lin HC, Chey WY. Cholecystokinin and peptide YY are released by fat in either proximal or distal small intestine in dogs. Regul Pept 2003;114:131-135.

22. Sjolund K, Sanden G, Hakanson R, Sundler F. Endocrine cells in human intestine: an immunocytochemical study. Gastroenterology 1983;85:1120-1130. 
23. Capella C., Solcia E., Frigerio B., Buffa R. Endocrine cells of the human intestine. An ultrastructural study. In: Fujita T, ed. Endocrine gut and pancreas. Amsterdam: Elsevier Biomedical 1976:43-59.

24. Armand M, Pasquier B, André M, Borel P, Senft M, Peyrot J, Salducci J, Portugal H, Jaussan V, Lairon D. Digestion and absorption of 2 fat emulsions with different droplet sizes in the human digestive tract. Am J Clin Nutr 1999;70:1096-1106.

25. Feinle-Bisset C, Patterson M, Ghatei MA, Bloom SR, Horowitz M. Fat digestion is required for the suppression of ghrelin and stimulation of peptide $Y Y$ and pancreatic polypeptide secretion by intraduodenal lipid. Am J Physiol Endocrinol Metab 2005;289:E948

26. O'Donovan D, Feinle-Bisset $\mathrm{C}$, Wishart J, Horowitz M. Lipase inhibition attenuates the acute inhibitory effects of oral fat on food intake in healthy subjects. Br J Nutr 2003;90:849-852.

27. Raybould HE, Glatzle J, Freeman SL, Whited K, Darcel N, Liou A, Bohan D. Detection of macronutrients in the intestinal wall. Auton Neurosci 2006;125:28-33.

28. Wu Z, Ohajuruka OA, Palmquist DL. Ruminal synthesis, biohydrogenation, and digestibility of fatty acids by dairy cows. J Dairy Sci 1991;74:3025-3034.

29. Jones AE, Stolinski M, Smith RD, Murphy JL, Wootton SA. Effect of fatty acid chain length and saturation on the gastrointestinal handling and metabolic disposal of dietary fatty acids in women. $\mathrm{Br}$ J Nutr 1999;81:37-43.

30. Shahkhalili Y, Murset C, Meirim I, Duruz E, Guinchard S, Cavadini C, Acheson K. Calcium supplementation of chocolate: effect on cocoa butter digestibility and blood lipids in humans. Am J Clin Nutr 2001;73:246-252.

31. Batterham RL, Cowley MA, Small CJ, Herzog H, Cohen MA, Dakin CL, Wren AM, Brynes AE, Low MJ, Ghatei MA, Cone RD, Bloom SR. Gut hormone PYY(3-36) physiologically inhibits food intake. Nature 2002;418:650-654.

32. Batterham RL, Cohen MA, Ellis SM, Le Roux CW, Withers DJ, Frost GS, Ghatei MA, Bloom SR. Inhibition of food intake in obese subjects by peptide YY3-36. N Engl J Med 2003;349:941-948.

33. Boggiano MM, Chandler PC, Oswald KD, Rodgers RJ, Blundell JE, Ishii $Y$, Beattie AH, Holch $P$, Allison DB, Schindler M, Arndt K, Rudolf K, Mark M, Schoelch C, Joost HG, Klaus S, Thöne-Reineke C, Benoit SC, Seeley RJ, Beck-Sickinger AG, Koglin N, Raun K, Madsen K, Wulff BS, Stidsen CE, Birringer M, Kreuzer OJ, Deng XY, Whitcomb DC, Halem H, Taylor J, Dong J, Datta R, Culler M, Ortmann S, Castañeda TR, Tschöp M. PYY3-36 as an anti-obesity drug target. Obes Rev 2005;6:307-322.

34. Abbott CR, Small CJ, Sajedi A, Smith KL, Parkinson JR, Broadhead LL, Ghatei MA, Bloom SR. The importance of acclimatisation and habituation to experimental conditions when investigating the anorectic effects of gastrointestinal hormones in the rat. Int J Obes (Lond) 2006;30:288-292.

35. Vu MK, Maljaars J.W., Biemond I, Mearadji B, Masclee AA. Role of Peptide YY in ileal brake induced satiety and proximal gastric function. Gastroenterology 2006;130:Suppl2; A68.

36. Maljaars PW, Symersky T, Kee BC, Haddeman E, Peters HP, Masclee AA. Effect of ileal fat perfusion on satiety and hormone release in healthy volunteers. Int J Obes (Lond) 2008.

37. Thomsen C, Storm H, Holst JJ, Hermansen K. Differential effects of saturated and monounsaturated fats on postprandial lipemia and glucagon-like peptide 1 responses in patients with type 2 diabetes. Am J Clin Nutr 2003;77:605-611.

38. Kalogeris TJ, Monroe F, Demichele SJ, Tso P. Intestinal synthesis and lymphatic secretion of apolipoprotein A-IV vary with chain length of intestinally infused fatty acids in rats. J Nutr 1996; 126:2720-2729.

39. Tso P, Liu M. Apolipoprotein A-IV, food intake, and obesity. Physiol Behav 2004;83:631-643. 


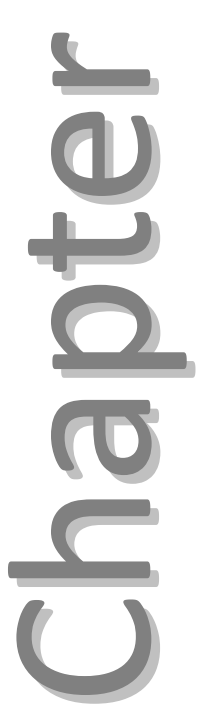

\section{Both intestinal site and timing of fat} delivery affect appetite in humans

Maljaars J, van der Marel S, Peters HPF, Haddema EH,Stellaard F, Masclee AAM Submitted 


\section{Abstract}

\section{Objective}

In both the duodenum and ileum, exposure of the luminal wall to nutrients activates a negative feedback mechanism. This duodenal and ileal brake are known to reduce appetite and food intake, and to inhibit gastric emptying and small bowel transit. In this study we compared the effects of duodenal vs. ileal fat infusion on satiety, food intake, gastrointestinal transit and peptide release. Furthermore, we studied whether the timing of the infusions relative to a previous meal influences these effects.

\section{Design}

Randomized single-blind cross over study.

\section{Subjects}

15 healthy female volunteers (mean age 23 yrs, mean BMI $22 \mathrm{~kg} / \mathrm{m}^{2}$ ).

\section{Intervention}

Subjects were intubated with a $290 \mathrm{~cm}$ long nasoileal tube. Through this tube, subjects received an infusion of $6 \mathrm{~g}$ fat either in the Duodenum or in the lleum. This infusion was given in the Early (30-90 min after ingestion of breakfast) or in the Late (105-165 min after breakfast) postprandial phase.

\section{Measurements}

Appetite parameters, food intake, gastric emptying, small bowel transit time and plasma concentrations of CCK and PYY.

\section{Results}

Compared to Duo-Early, lleum-Early significantly reduced appetite and increased fullness, and delayed gastric emptying and small bowel transit. Food intake did not differ between treatments. CCK-secretion was higher after Duo-Early vs Ileum-Early, whereas PYY was increased after Ileum-Early vs. Duo-Early at one time point.

In the Late postprandial phase, no differences existed between these parameters.

The effects of ileal fat on appetite were larger in the Early vs. the Late postprandial phase.

\section{Conclusions}

The effects of fat infusion are more potent in the distal compared to the proximal small intestine, particularly in the early postprandial phase. 


\section{Introduction}

The gastrointestinal tract is an importance source for signals that influence appetite and food intake ${ }^{1,2}$. Traditionally, appetite signals arising from the stomach are triggered by mechanical stimuli ${ }^{3-5}$, whereas signals from the intestine are evoked by chemical or nutritional stimuli ${ }^{5}$. After ingestion of a meal, these gastric and intestinal signals interact to terminate food intake (satiation) and influence between-meal satiety $^{2}$. This interaction was demonstrated by Oesch et al., who showed that infusion of nutrients into the duodenum lowered the threshold at which a gastric distension reduces hunger ${ }^{6}$, confirming earlier results by Matzinger et al. ${ }^{7}$. In animals, a synergistic effect of gastric and intestinal stimuli on food intake has also been reported ${ }^{5}$.

It has been suggested that within the small intestine, differences may exist in the relative potency of segments of the small intestine to reduce food intake and hunger ${ }^{8}$. Most human studies have focused on the effects of duodenal nutrient infusions on satiety and food intake. Evidence for the effects of infusion of nutrients into the ileum on satiety and food intake comes from two types of studies. First, studies with ileal perfusion of fat using catheters and second, studies on surgical procedures that result in increased exposure of the ileum to nutrients.

Welch et al. were the first to demonstrate a reduction in food intake after ileal fat infusion ${ }^{9}$. More recent, we compared ileal fat infusion to oral fat ingestion, and demonstrated that ileal fat infusion reduced hunger significantly compared to oral fat $^{10}$. In animals, several studies have been performed comparing the effects of duodenal and ileal nutrient infusions on food intake. From these studies it can be concluded that 1 ) infusion of nutrients into the ileum does reduce food intake, 2). the surface area over which nutrients are spread plays an important role in the magnitude of food intake reduction, and 3). when comparing nutrients that are absorbed rapidly (and spread over only a small intestinal segment) the inhibitory effect of ileal nutrients is at least equal and presumably larger than the effect of the same nutrients infused into the duodenum ${ }^{11-14}$.

An interesting model for increased ileal exposure to nutrients is ileal transposition. In this surgical procedure, a segment of ileum is resected with preservation of vascular and neuronal innervations, and anastomosed to the duodenum or proximal jejunum. In rats, Koopmans et al. compared an ileal transposition group to a group of rats in which a segment of ileum was resected and reattached in the same location ${ }^{15-17}$. In regular feeding conditions, the ileal transposition group reduced food intake by 20 and $40 \%$, dependent of the length of the transposed segment. 
These studies clearly demonstrate that, at least in animals, increased exposure of the ileum to nutrients reduces food intake. However, in humans, the relative potency of the duodenum and the ileum to reduce food intake has never been compared.

Therefore, the aims of this study were 1. to compare the effects of small amounts of fat infused either in the duodenum vs. the ileum on postprandial satiety and on food intake, gastrointestinal transit and hormone release, and 2. to test whether timing of the infusions relative to a previous meal (early or late) influences these effects. Cholecystokinin (CCK) and peptide YY (PYY) were measured as proximal and distal regulatory peptides.

\section{Materials and method}

\section{Subjects}

Healthy volunteers aged between 18 and 55 yrs with a BMI between 18 and $32 \mathrm{~kg} / \mathrm{m}^{2}$ were recruited by advertisement. Restrained eaters (as assessed by the Dutch Eating Behaviour Questionnaire ${ }^{18}$ ) and subjects who reported that they were following either a weight-reduction diet or a medically-prescribed diet were excluded from participation. Subjects who were taking medication that may have influenced appetite and sensory function or who reported metabolic or endocrine disease, gastrointestinal disorders or a history of medical or surgical events that may have affected study outcome were also excluded. Informed consent was obtained from each individual, and the study protocol was approved by the Medical Ethics Committee of the Leiden University Medical Centre. Seventeen subjects met the inclusion criteria. Two volunteers dropped out during the study: one due to discomfort during catheter positioning and one due to failure to position the tip of the catheter beyond the ligament of Treitz (flexura duodenojejunalis). Fifteen healthy females (mean age 23yrs, mean BMI $22 \mathrm{~kg} / \mathrm{m}^{2}$ ) participated in the study and completed the protocol.

\section{Study design}

In this single-blind randomized controlled crossover design, $6 \mathrm{~g}$ fat was administered into the duodenum or into the ileum either in the early or late postprandial phase after breakfast. The study design is shown in Figure 7.1. 


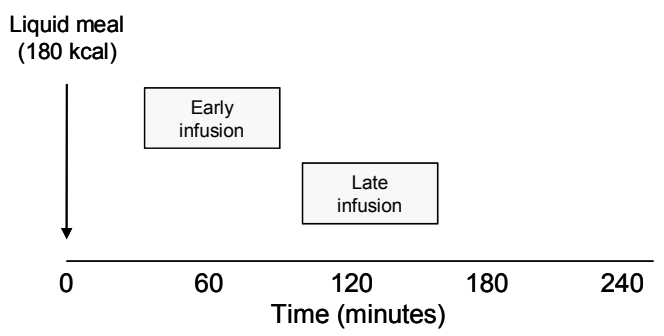

Figure 7.1 Study outline for the four experiments. Order of treatments was randomized. Each subject consumed a liquid breakfast at $\mathrm{t}=0 \mathrm{~min}$. Infusion of $6 \mathrm{~g}$ of fat was scheduled in the early postprandial phase $(t=30-90 \mathrm{~min})$ or in the late postprandial phase $(t=105-165)$. The location of the infusion was either in the duodenum or in the ileum. Satiety questionnaires and blood samples were collected at regular intervals.

\section{Protocol}

The study protocol consisted of five consecutive days. On Monday, subjects arrived at the laboratory at $12: 00 \mathrm{hr}$ for catheter placement. The catheter for duodeno-ileal intubation was a $290 \mathrm{~cm}$ long rubber silicon 9-channel (8-lumen, 1 balloon inflation channel, diameter $3.5 \mathrm{~mm}$ ) catheter custom-made by Dentsleeve International Ltd (Mississauga, Ontario, Canada). Through an anaesthetized nostril, the catheter was introduced into the stomach and allowed to pass through the pylorus to the ileum by peristalsis. After passing the ligament of Treitz, a small balloon at the tip was inflated to facilitate passage of the catheter to the ileum. During the day, the subject was offered small snacks to stimulate peristalsis. The tip was placed in the ileum (at least $120 \mathrm{~cm}$ distal from the pylorus). The catheter was fitted with radiopaque markers, which allowed for assessing the position of the catheter during and after the positioning procedure by fluoroscopy. Before every test-day, the position of the catheter was checked by fluoroscopy.

\section{Test day (Figure 7.1)}

On each of the four consecutive test days, the subject arrived at the laboratory of the Gastroenterology department at 8:00 hr following an overnight fast. First, correct position of the catheter was verified by fluoroscopy. Then, a venous catheter was placed in a forearm-vein for collection of blood samples. At 8:45 hr ( $t=-15 \mathrm{~min}$ ), appetite ratings were scored, and at 9:00 hr a basal blood sample was taken. Immediately after this (at $\mathrm{t}=0 \mathrm{~min}$ ), a breakfast (fat free Slim.Fast Optima Ready To Drink meal replacer; Unilever, Vlaardingen, The Netherlands: $325 \mathrm{ml}, 145 \mathrm{Kcal}$ ) was consumed within fifteen minutes. To this breakfast, $150 \mathrm{mg}$ Sodium [1-C13]-acetate was added in order to measure gastric emptying half time (T1/2). 
The early infusion started at $\mathrm{t}=30 \mathrm{~min}$, and lasted for 60 minutes. The late infusion started at $\mathrm{t}=105 \mathrm{~min}$, and lasted till $\mathrm{t}=165 \mathrm{~min}$. These periods of infusion were chosen as they mimic the physiological period of maximum postprandial duodenal and ileal nutrient exposure, respectively ${ }^{19,20}$. Infusion rate in all cases was $1 \mathrm{ml} / \mathrm{min}$ or $0.9 \mathrm{kcal} / \mathrm{min}$. Each day either the ileum (through the most distal infusion port) or the duodenum (through the infusion port which was located just distal from the pylorus) was perfused with an emulsion. Subjects were unaware of the timing and the location of the infusion.

Ten min before each fat infusion (at $t=20$ min for the early fat infusion; at $t=95$ min for the late fat infusion), $6 \mathrm{~g}$ of lactulose was administered to enable measurement of the small bowel transit time.

At $\mathrm{t}=240 \mathrm{~min}$, an ad libitum lunch was served. At $\mathrm{t}=345 \mathrm{~min}$, the intravenous canula was removed, and subjects were allowed to go home. They received an evening meal from which they were allowed to consume freely till 22:00 hr.

\section{Fat emulsion}

The emulsions consisted of $10 \%$ high oleic rapeseed oil in water. As an emulsifier $2.5 \%$ $\mathrm{K}$-caseinate was used. A very small amount of xanthan gum $(0.1 \%)$ and guar gum $(0.1 \%)$ was used as a stabiliser. Sodium chloride $(0.8 \% \mathrm{NaCl})$ was added to obtain isoosmotic solutions. Total emulsion volume infused per test day was $60 \mathrm{ml}$.

\section{Appetite ratings}

The volunteers rated their appetite feelings (appetite for a snack, appetite for a meal, fullness, hunger, how much do you want to eat) by means of a mark on 64-mm line scales using an Electronic Visual Analogue Scale (EVAS) on a hand-held computer $\left(\mathrm{iPAQ}{ }^{21}\right)$. This scale was anchored at the low end with the most negative or lowest intensity feelings (e.g., "not at all"), and with opposing terms at the high end (e.g.,"very high") as described by Flint et al. ${ }^{22}$. EVAS scores were collected at $\mathrm{t}=-15,0$, $30,60,75,90,105,120,135,150,165,180,210$ and 240 minutes.

Gastrointestinal symptoms (nausea, abdominal pain, bloating, heartburn, abdominal cramps, headache, fatigue) were scored every two hours. The questions were related to symptoms that the volunteers possibly experienced during the last hour. Ratings were made on 4 -point scale $(0=$ not, $1=$ mild, $2=$ moderate, $3=$ severe) on the handheld computer.

\section{Food intake}

Each test day, an ad libitum-lunch was served to measure food intake. The lunch was scheduled at $\mathrm{t}=\mathbf{2 4 0} \mathrm{min}$. The maximum lunch time was set at 30 minutes. Each lunch 
was offered in excess, and consisted of $1500 \mathrm{~g}$ macaroni pasta (per $100 \mathrm{~g}: 430 \mathrm{~kJ}$, $5 \mathrm{~g}$ protein, $2 \mathrm{~g}$ fat, $16 \mathrm{~g}$ carbohydrates). During lunch, subjects were alone and were not allowed to watch television, listen to the radio or read.

\section{Gastric emptying}

Gastric emptying half time $\left(\mathrm{T}_{1 / 2}\right)$ was measured by ${ }^{13} \mathrm{C}$ stable isotope breath test. For this purpose, $150 \mathrm{mg}$ of sodium $\left[1-{ }^{13} \mathrm{C}\right]$-acetate (99\%; Cambridge Isotope laboratories/ ARC Laboratories, Amsterdam) was added to the breakfast ingested at $\mathrm{t}=0$. Breath samples were taken at regular intervals over a 240 min period according to a standard protocol and analysed by InfraRed ISotope analysis (IRIS, Wagner Analisen Technik, Bremen, Germany). Gastric emptying $T_{1 / 2}$ was calculated after curve fitting using methods described by Braden et al. ${ }^{23}$. Gastric emptying $T_{1 / 2}$ was assessed only for the early infusions, as the late infusions were scheduled too late to influence $T_{1 / 2}$.

\section{Small Bowel Transit Time}

Small bowel transit time (SBTT) measurement was performed by lactulose hydrogen breath analysis as described by Ledeboer et al. ${ }^{24}$. Six grams of lactulose (Legendal, Inpharzam, Amersfoort) was dissolved in 20-30 $\mathrm{ml}$ tap water. This solution was administered by syringe through the duodenal infusion port closest to (but located distally from) the pylorus.

Expiratory breath samples were taken at regular intervals over a 240 min period and directly analyzed using a handheld hydrogen breath test unit (Gastrolyzer, Hoekloos, The Netherlands). SBTT is defined as the time between the administration of lactulose and the onset of a sustained (in three consecutive readings) rise in breath $\mathrm{H}_{2}$ concentration of at least 10 parts per million (ppm) above basal level. At our department the mean coefficient of variation for SBTT using the lactulose hydrogen breath test with $6 \mathrm{~g}$ lactulose is $12 \%$.

\section{Hormone assays}

Blood samples were drawn at $t=0,30,45,75,90,105,120,150,165,180,210$ and 240 min. Total plasma PYY concentrations were measured by a Radio Immuno Assay (RIA), as described previously ${ }^{10}$. There is no cross-reactivity with PP or VIP. The detection limit is $10 \mathrm{pmol} / \mathrm{l}$. Both $\mathrm{PYY}_{(1-36)}$ and $\mathrm{PYY}_{(3-36)}$ bind to the antibody in dilutions up to 250000. The intra-assay variation ranges from 1.8 to $15.6 \%$ and the inter-assay variation from 9.5 to $27.8 \%{ }^{25}$. Plasma CCK concentrations were measured by a RIA, as described previously ${ }^{26}$. The detection limit of the assay was $0.2 \mathrm{pmol}_{\bullet} \mathrm{I}^{-1}$. The intraassay variation ranges from 3.9 to $9.1 \%$ and the inter-assay variation from 10.4 to $19.9 \%{ }^{26}$. 


\section{Statistical analysis}

Data was analysed using ANOVA with time and location and test day as factors and subjects as blocks. In the hormone and EVAS scores analyses, baseline values were used as a covariate. As location and time showed a significant interaction, time $x$ location combinations were calculated and time differences within both locations and location differences within both times were tested. Bonferroni correction was applied by dividing the calculated probability by a factor 4 . A p-value of 0.05 was considered significant.

Results are presented as least squares means with standard error (SE), unless otherwise specified. EVAS scores were expressed as percentages of the maximal score $(0 \mathrm{~cm}$ equaled $0 \%$ and $6.4 \mathrm{~cm}$ equaled $100 \%)$ and as cumulative areas under the curve (AUC). The AUC was calculated using the trapezoid rule.

Gastrointestinal symptoms were analysed using frequency of occurrence per time point and a standard ANOVA with the personal scores corrected for each subject's overall mean score.

\section{Results}

Results will be presented in order of timing of the intestinal infusions: Early infusion (30-90 min after breakfast) and Late infusion (105-165 min after breakfast).

There was no day-effect observed for any of the parameters measured.

Although there were occasional Gl symptoms, most of them were rated "mild" and some were rated "moderate" (data not shown). gastrointestinal symptoms did not differ significantly between treatments.

\section{Early infusions: Appetite}

Since the effects of the various treatments showed similar trends for all appetite scores, only the data for fullness and appetite will be given. Appetite for a snack scores were significantly lower after the Ileum-Early vs. Duo-Early treatment for several time points (Figure 7.2A). This difference occurred mainly in the later time period, which resulted in a significantly lower AUC for $\mathrm{t}=30-240 \mathrm{~min}$, but not for $\mathrm{t}=30$ 90 min (Figure 7.2B). Fullness was significant larger after lleum-Early vs. Duo-Early at later time points (Figure $\mathbf{7 . 2 C}$ ), although this difference was not reflected in a significantly larger AUC (Figure 7.2D). 

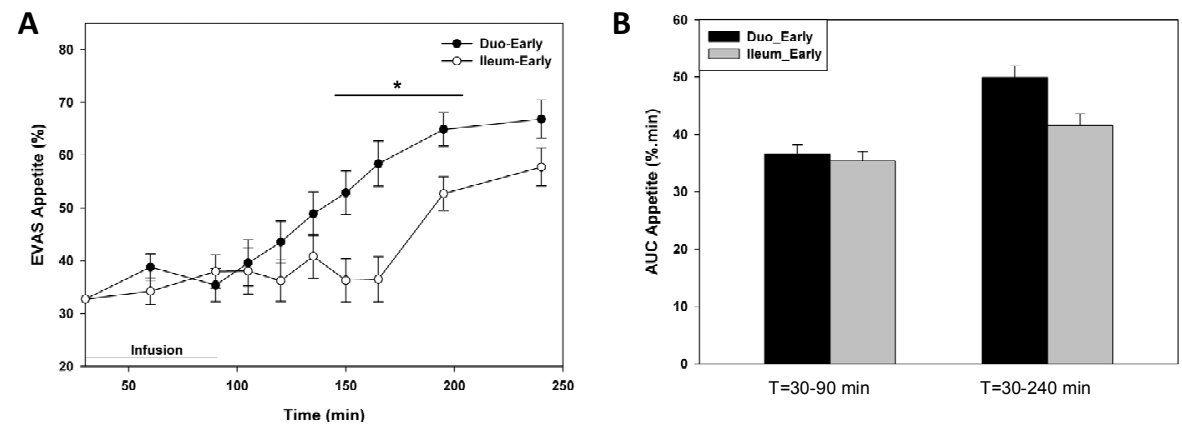

C

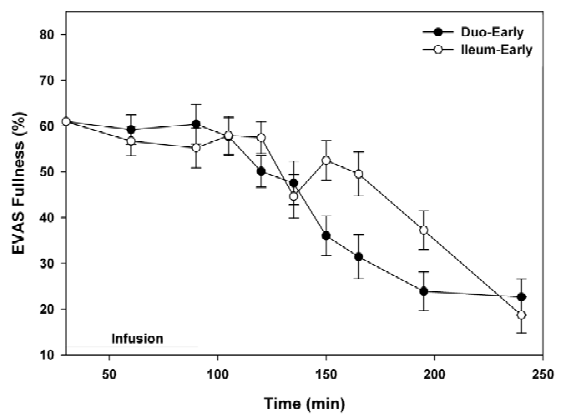

D

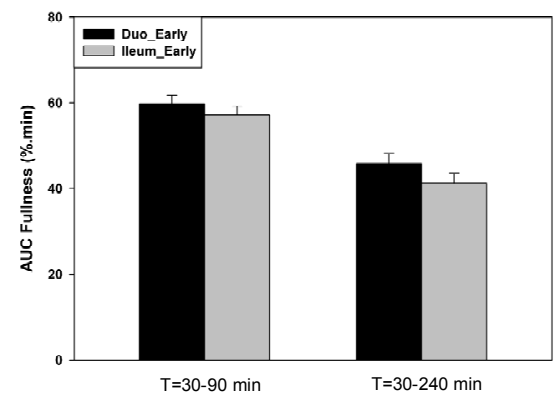

Figure 7.2 Subjective EVAS scores (LSmeans $\pm S E, n=15$, in \%) and AUCs (LSmeans $\pm S E, n=15$, in \%.min) for Appetite and Fullness after infusion of $6 \mathrm{~g}$ fat in duodenum or ileum in the early postprandial phase $(\mathrm{t}=30-90 \mathrm{~min}) .{ }^{*}$ denotes $\mathrm{p}<0.05$ for Duo-Early vs. Ileum-Early.

\section{Early infusions: Food intake}

Food intake was not affected by the location of fat infusion (408 vs. $422 \mathrm{~g}$ for DuoEarly vs. Ileum-Early, SE=17; N.S.).

\section{Early infusions: Peptide secretion}

For the early infusions CCK concentrations were significantly increased after Duo-Early vs. Ileum-Early (Figure 7.3A), resulting in a significantly higher AUC ( $t=30-90$ min; Figure 7.3B).

Except for one significant time point PYY secretion was, overall, not significantly different between Duo-Early and Ileum-Early (Figure 7.3C and 7.3D).

\section{Early infusions: Gastrointestinal transit}

The Ileum-Early infusion significantly delayed gastric emptying $T_{1 / 2}$ and significantly prolonged SBTT compared to the Duo-Early infusion, as shown in Table 7.1. 
A

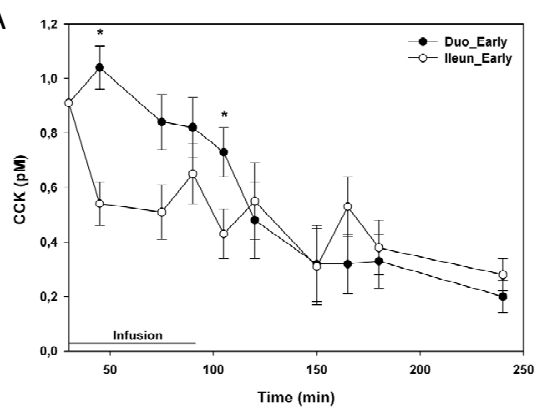

A

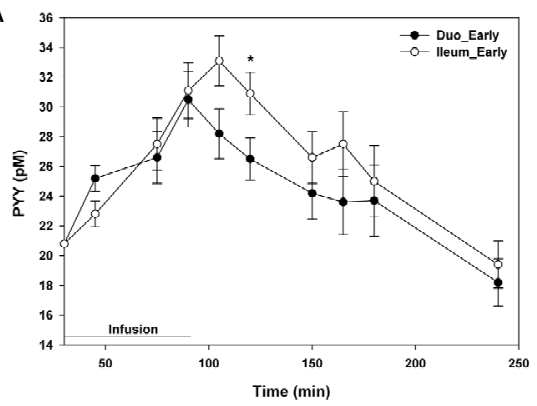

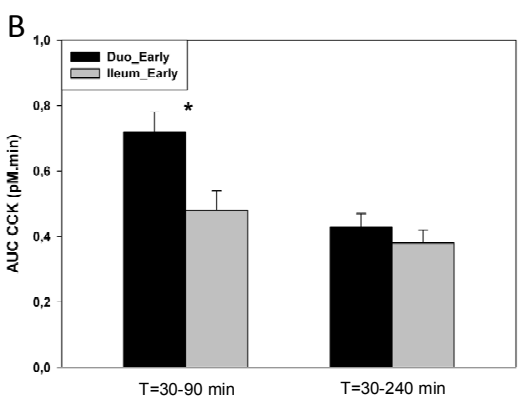

B

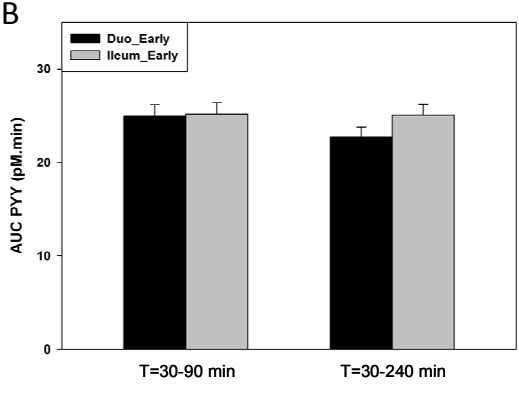

Figure 7.3 Plasma concentrations of CCK and PYY after infusion of $6 \mathrm{~g}$ fat in duodenum or ileum in the early postprandial phase ( $\mathrm{t}=30-90 \mathrm{~min}) .{ }^{*}$ denotes $\mathrm{p}<0.05$ for Duo-Early vs. lleum-Early.

Table 7.1 Gastrointestinal transit after infusion of $6 \mathrm{~g}$ of fat either in the early $(\mathrm{t}=30-90 \mathrm{~min})$ or in the late postprandial phase ( $t=105-165)$ in either duodenum or ileum.

\begin{tabular}{lccccc}
\hline $\begin{array}{l}\text { Gastric emptying } \\
\left(\mathrm{T}_{1 / 2} ; \mathrm{min}\right)\end{array}$ & Duo-Early & Duo-Late & lleum-Early & lleum-Late & SE \\
SBTT (min) & $138^{\mathrm{b}}$ & & $206^{\mathrm{a}}$ & & 10.3 \\
& $85^{\mathrm{a}}$ & $108^{\mathrm{c}}$ & $144^{\mathrm{b}, \mathrm{d}}$ & $151^{\mathrm{b}, \mathrm{d}}$ & 13.7 \\
\hline
\end{tabular}

$P<0.05$ for a vs. $b$, and for $c$ vs. $d$

\section{Late infusions: Satiety}

Results for fullness and appetite after the Late infusions are given in Figure 7.4. No significant differences were observed for both appetite and fullness between the lleum-Late and Duo-Late treatment.

\section{Late infusions: Food intake}

During the late infusions, food intake was not affected by the location of fat infusion (407 vs. $425 \mathrm{~g}$ for Duo-Late vs. Ileum-Late, SE=17). 

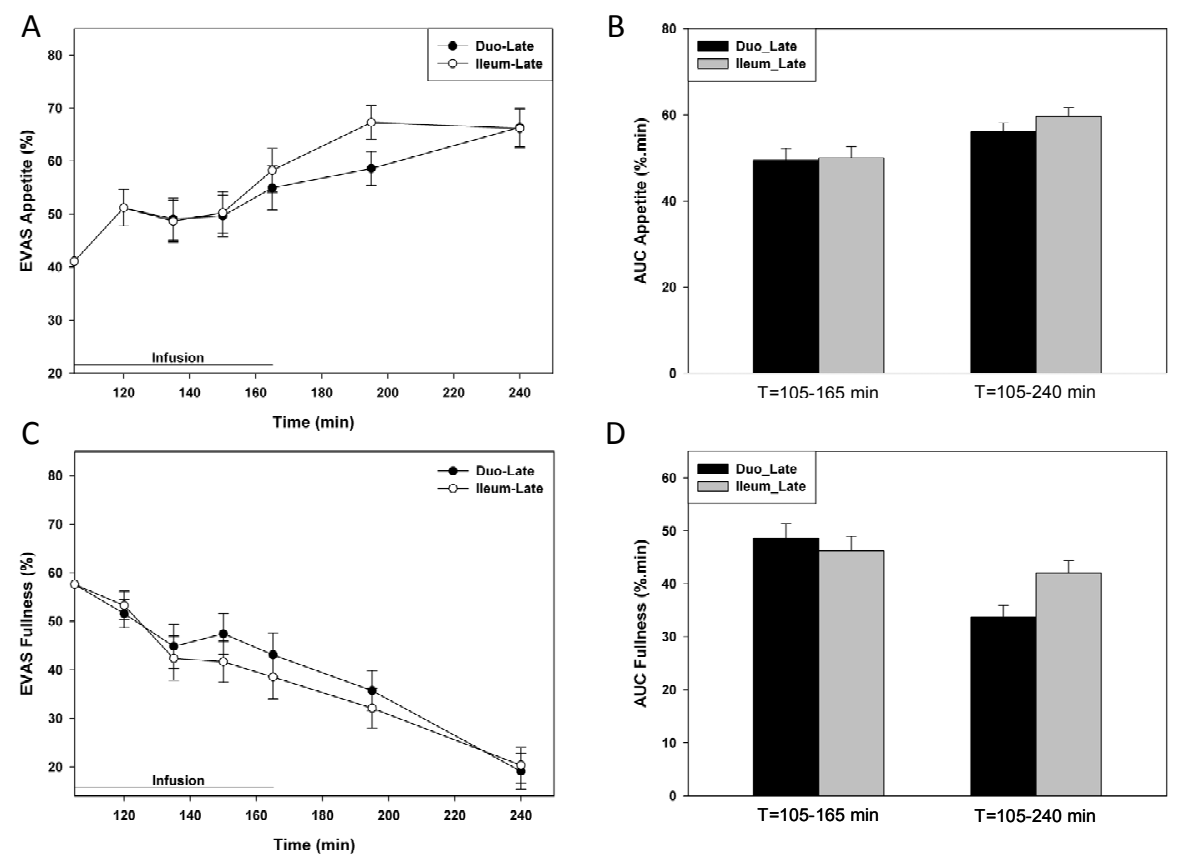

D

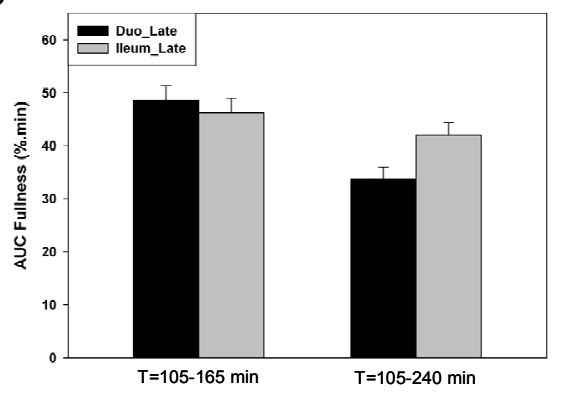

Figure7.4 Subjective EVAS scores and AUCs for Appetite and Fullness after infusion of $6 \mathrm{~g}$ fat in duodenum or ileum in the late postprandial phase ( $t=105-165 \mathrm{~min})$.

\section{Late infusions: Peptide secretion}

Results for CCK and PYY secretion are given in Figure 7.5 for the late infusions. Neither secretion of CCK nor of PYY did significantly differ between Ileum-Late and Duo-Late.

\section{Late infusions: Gastrointestinal transit}

The lleum-Late infusion significantly delayed SBTT compared to the Duo-Late infusion, as shown in Table 7.1.

\section{Satiety: Effect of timing}

For satiety, the overall AUCs are displayed in Table 7.2.

When the overall AUCs ( $t=30-240 \mathrm{~min}$ ) for both appetite and fullness are compared, no differences are observed between the duodenal early and late infusions. However, appetite was significantly lower after Ileum-Early compared to lleum-Late. 

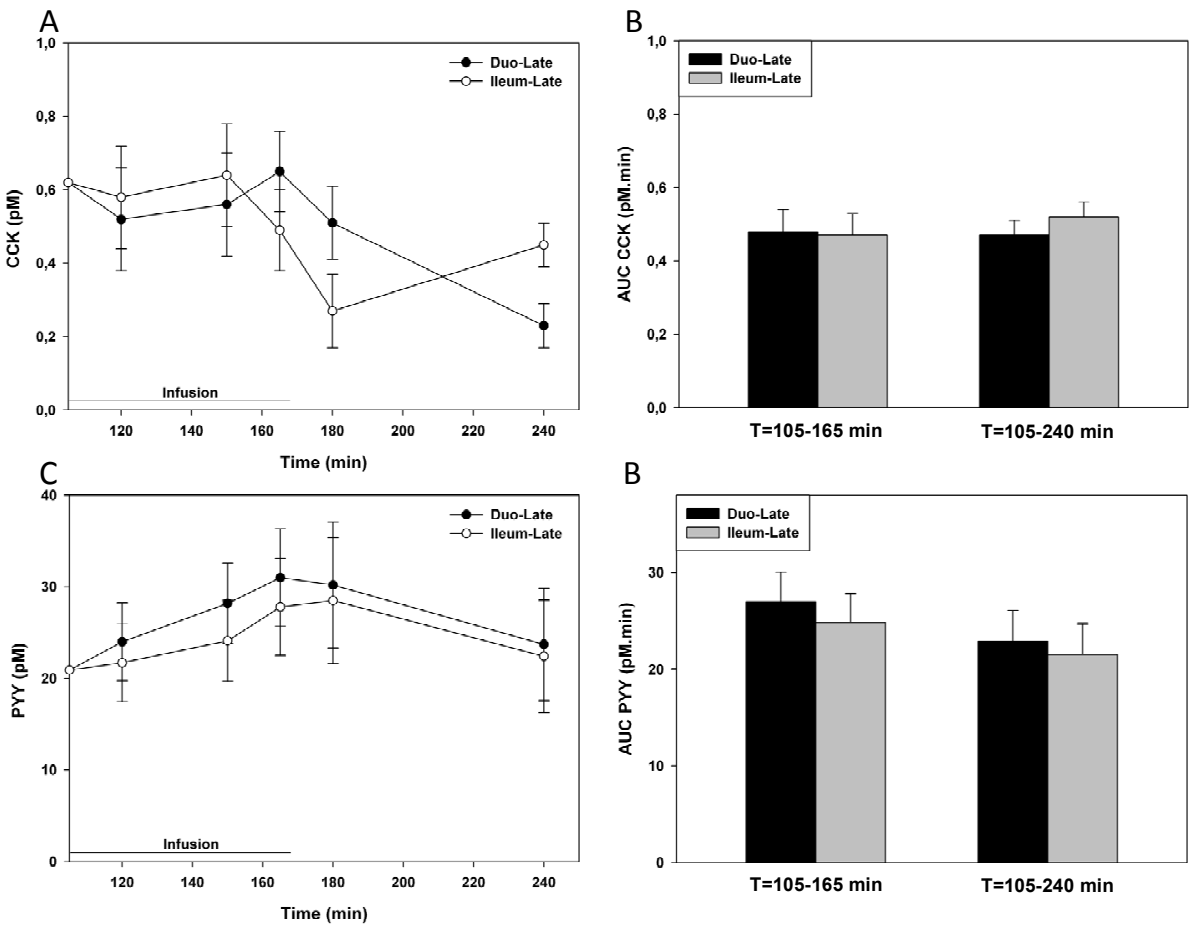

Figure 7.5 Plasma concentrations of CCK and PYY after infusion of $6 \mathrm{~g}$ fat in duodenum or ileum in the late postprandial phase ( $\mathrm{t}=105-165 \mathrm{~min})$.

Table 7.2 Area Under the curve for Appetite after infusion of $6 \mathrm{~g}$ of fat either in the early $(t=30-90 \mathrm{~min})$ or in the late postprandial phase $(t=105-165)$ in either duodenum or ileum.

\begin{tabular}{lccccc}
\hline & Duo-Early & Duo-Late & lleum-Early & lleum-Late & SE \\
\hline $\begin{array}{l}\text { Appetite }(\mathrm{mm} . \mathrm{min}) \\
30-240 \mathrm{~min}\end{array}$ & $49.9^{\mathrm{a}}$ & $50.1^{\mathrm{a}}$ & $41.6^{\mathrm{b}}$ & $53.0^{\mathrm{a}}$ & 2.0 \\
$\begin{array}{l}\text { Fullness }(\mathrm{mm} . \mathrm{min}) \\
30-240 \mathrm{~min}\end{array}$ & 43.0 & 45.9 & 47.5 & 41.3 & 2.3 \\
\hline
\end{tabular}

$\mathrm{P}<0.05$ for $a$ vs. $b$

\section{Food intake: Effect of timing}

The timing of the infusions did not affect food intake (408 vs. 407 vs. 422 vs. $425 \mathrm{~g}$ for Duo-Early vs. Duo-Late vs. Ileum-Early vs. Ileum-Late, SE=17).

\section{Gastrointestinal transit: Effect of timing}

As shown in Table 7.1, the timing of the infusions did not affect SBTT. 


\section{Peptide secretion: Effect of timing}

As shown in Table $\mathbf{7 . 3}$ no differences were present between Duo-Early and Duo-Late and Ileum-Early and Ileum-Late with regard to secretion of CCK and PYY.

Table 7.3 Area under the curve for peptide secretion after infusion of $6 \mathrm{~g}$ of fat either in the early ( $\mathrm{t}=30$ $90 \mathrm{~min})$ or in the late postprandial phase $(\mathrm{t}=105-165)$ in either duodenum or ileum.

\begin{tabular}{lccccc}
\hline & Duo-Early & Duo-Late & lleum-Early & lleum-Late & SE \\
\hline CCK (pM.min) & 0.54 & 0.59 & 0.45 & 0.51 & 0.06 \\
$\begin{array}{l}30-240 \text { min } \\
\text { PYY (pM.min) }\end{array}$ & 23.8 & 23.9 & 24.4 & 22.9 & 0.96 \\
$30-240$ min & & & & & \\
\hline
\end{tabular}

\section{Discussion}

Regional differences are thought to exist between the proximal and the distal small intestine with respect to the magnitude of the effects of nutrients on appetite and food intake ${ }^{8}$.

In the present study, we have demonstrated that, when given in the early postprandial phase, ileal infusion of fat significantly increased satiety compared to duodenal fat infusion. On the other hand, during the late postprandial infusions, no significant differences in satiety parameters were observed between the duodenal and ileal infusions.

Few studies in humans have focussed on a comparison of the effects of nutrient infusion into different parts of the small intestine on satiety. Recently, Chaikomin et al. have compared duodenal to mid-jejunal glucose infusions ${ }^{27}$. These authors found that satiety was more pronounced when glucose was infused into the duodenum compared to the jejunum ${ }^{27}$. Welch et al. infused a large amount of $40 \mathrm{~g}$ of fat into ileum and jejunum and found that both infusions reduced food intake, but only the jejunal infusion reduced hunger ${ }^{28}$. However, from this large amount of fat, a significant part of fat will have spilled over into the ileum during the jejunal infusion ${ }^{28,29}$ which may have resulted in an increased small intestinal surface area exposed to fat and accordingly to a more pronounced reduction in hunger and food intake ${ }^{12,13}$.

In our study, no differences in food intake were observed between any of the treatments. Our study design was based on a breakfast meal early in the morning (at 9:00) with a lunch scheduled at $13.00(t=240 \mathrm{~min})$. This resulted in a time schedule 
that compares to a regular morning, allowing us to assess whether ileal brake activation by fat reduces hunger during the morning and would then be able to reduce food intake during a subsequent lunch meal. Rolls et al. demonstrated that prolonging the time interval between a preload and the ad libitum test meal by 90 min reduced the effect of a preload on intake of the ad libitum meal by $14 \%$ (30). This observation suggests that, in our study, the meal may have been scheduled too late to be significantly affected by the intestinal fat infusions. Therefore, we cannot not rule out an effect of fat infusion on food intake would have been present when food intake had been evaluated at an earlier moment in the protocol .

Duodenal infusion of fat dose-dependently delays gastric emptying ${ }^{31}$. Inhibition of gastric emptying by ileal fat has also been described previously ${ }^{32}$. However, the magnitude of these effects had not been compared previously in humans.

Compared to the duodenal infusion, the ileal infusion significantly and profoundly delayed gastric empting (half time 206 vs $138 \mathrm{~min}, \mathrm{p}<0.05$ ). A link between gastric distension and gastric emptying on the one hand and postprandial satiety on the other has been demonstrated previously ${ }^{3,33-35}$. Geliebter et al. demonstrated that a gastric volume load by itself can reduce food intake in humans ${ }^{3}$. Delaying gastric emptying results in prolongation of postprandial gastric distension, and may therefore affect satiety. Others have shown that intestinal fat infusion lowers the threshold at which a gastric volume load affects satiety scores and food intake ${ }^{6}$.

This may explain the larger effect of the Ileum-Early infusion on appetite, when compared with the Duo-Early infusion. The Ileum-Early infusions significantly delayed gastric emptying compared to the Duo-Early, which resulted in a larger and more prolonged gastric distension. When this larger and more prolonged distension is combined with an equally or even more satiating intestinal fat infusion, this will probably result in a more pronounced effect on appetite. The absence of a difference in satiating effect between duodenum and ileum in the late-postprandial phase is possibly related to the absence of an effect of the lleum-Late perfusion on gastric emptying, since these infusions will have been scheduled too late to effectively delay gastric emptying.

The ileal brake has initially been described as the inhibition of jejunal motility in response to ileal fat infusion ${ }^{36}$, resulting in an increase in transit time ${ }^{37}$. In animals, Lin et al. have demonstrated that small intestinal transit was more potently inhibited by infusions of nutrients in the distal vs. the proximal small intestine ${ }^{38}$. In our study, ileal infusion of fat, both in the early and in the late postprandial phase delayed small bowel transit time. The timing of the infusions did not affect SBTT. 
In the early postprandial period, secretion of CCK was significantly higher after the duodenal compared to the ileal infusions. As CCK is considered a peptide predominantly originating from the proximal gut ${ }^{1}$, this result was anticipated. CCK is involved primarily in satiation, or meal termination, and to a lesser extent in betweenmeal satiety. It is therefore not surprising that the higher plasma concentrations observed after the Duo-Early do not translate into reductions in appetite or increases in fullness.

On the other hand, PYY is thought to play a role in between-meal hunger, and has a longer-lasting effect on satiety and food intake ${ }^{39,40}$. PYY is secreted by enteroendocrine L-cells, and the concentration of PYY -secreting cells increases aborally.

Although previous studies have demonstrated that secretion of PYY occurs after both distal $^{10}$ and proximal ${ }^{41}$ fat infusions, we expected the ileal infusions to increase PYY secretion more compared to duodenal fat infusions. However, in our study the location of the fat infusion did not affect PYY secretion.

A number of recent studies indicate that mechanisms other than direct sensing of gut content by L-cells may be involved in secretion of PYY. For instance, infusion of fat into the human duodenum increased PYY concentrations before the distal gastrointestinal tract was reached by the fat ${ }^{42}$. This suggests the presence of neural or humoral mechanisms in modulation of PYY release ${ }^{42}$. Also, vagal stimulation ${ }^{43}$ or secretion of other gut peptides, such as vasoactive intestinal polypeptide (VIP), gastrin or CCK may play a role in the secretion of PYY. This may explain the lack of any difference in PYY secretion between the duodenal and ileal fat infusions.

In conclusion, the effects of intestinal fat infusion on satiety and gastrointestinal transit are more pronounced and potent when fat is administered in the distal compared to the proximal small intestine, when given in the early postprandial phase. 


\section{References}

1. Woods SC. Gastrointestinal satiety signals I. An overview of gastrointestinal signals that influence food intake. Am J Physiol Gastrointest Liver Physiol 2004;286:G7-13.

2. Maljaars J, Peters HP, Masclee AM. Review article: The gastrointestinal tract: neuroendocrine regulation of satiety and food intake. Aliment Pharmacol Ther 2007;26 Suppl 2:241-250.

3. Geliebter A. Gastric distension and gastric capacity in relation to food intake in humans. Physiol Behav 1988;44:665-668.

4. Phillips RJ, Powley TL. Gastric volume rather than nutrient content inhibits food intake. Am J Physiol 1996;271:R766-R769.

5. Powley TL, Phillips RJ. Gastric satiation is volumetric, intestinal satiation is nutritive. Physiol Behav 2004;82:69-74.

6. Oesch S, Ruegg C, Fischer B, Degen L, Beglinger C. Effect of gastric distension prior to eating on food intake and feelings of satiety in humans. Physiol Behav 2006;87:903-910.

7. Matzinger D, Gutzwiller JP, Drewe J, Orban A, Engel R, D'Amato M, Rovati L, Beglinger C. Inhibition of food intake in response to intestinal lipid is mediated by cholecystokinin in humans. Am J Physiol 1999;277:R1718-R1724.

8. Maljaars PW, Peters HP, Mela DJ, Masclee AA. Ileal brake: a sensible food target for appetite control. A review. Physiol Behav 2008;doi:10.1016/j.physbeh.2008.07.018.

9. Welch I, Saunders K, Read NW. Effect of ileal and intravenous infusions of fat emulsions on feeding and satiety in human volunteers. Gastroenterology 1985;89:1293-1297.

10. Maljaars PW, Symersky T, Kee BC, Haddeman E, Peters HP, Masclee AA. Effect of ileal fat perfusion on satiety and hormone release in healthy volunteers. Int J Obes (Lond) 2008.

11. Meyer JH, Hlinka M, Tabrizi Y, DiMaso N, Raybould HE. Chemical specificities and intestinal distributions of nutrient-driven satiety. Am J Physiol 1998;275:R1293-R1307.

12. Meyer JH, Tabrizi Y, DiMaso N, Hlinka M, Raybould HE. Length of intestinal contact on nutrient-driven satiety. Am J Physiol 1998;275:R1308-R1319.

13. Meyer JH, Hlinka M, Khatibi A, Raybould HE, Tso P. Role of small intestine in caloric compensations to oil premeals in rats. Am J Physiol 1998;275:R1320-R1333.

14. Meyer JH, Elashoff JD, Doty JE, Gu YG. Disproportionate ileal digestion on canine food consumption. A possible model for satiety in pancreatic insufficiency. Dig Dis Sci 1994;39:1014-1024.

15. Koopmans HS. An integrated organismic response to lower gut stimulation. Scand J Gastroenterol Suppl 1983;82:143-153.

16. Koopmans HS. The role of the ileum in the control of food intake and intestinal adaptation. Can J Physiol Pharmacol 1990;68:650-655.

17. Koopmans HS, Ferri GL, Sarson DL, Polak JM, Bloom SR. The effects of ileal transposition and jejunoileal bypass on food intake and GI hormone levels in rats. Physiol Behav 1984;33:601-609.

18. Van Strien T, Frijters JER, Bergers GPA, Defares PB. The Dutch Eating Behavior Questionnaire (DEBQ) for assessment of restrained, emotional, and external eating behavior. Int J Eat Disord 2008;5:295.

19. Goebell H, Klotz U, Nehlsen B, Layer P. Oroileal transit of slow release 5-aminosalicylic acid. Gut 1993;34:669-675.

20. Klein S, Stein J, Dressman J. Site-specific delivery of anti-inflammatory drugs in the gastrointestinal tract: an in-vitro release model. J Pharm Pharmacol 2005;57:709-719.

21. Stratton RJ, Stubbs RJ, Hughes D, King N, Blundell JE, Elia M. Comparison of the traditional paper visual analogue scale questionnaire with an Apple Newton electronic appetite rating system (EARS) in free living subjects feeding ad libitum. Eur J Clin Nutr 1998;52:737-741.

22. Flint A, Raben A, Blundell JE, Astrup A. Reproducibility, power and validity of visual analogue scales in assessment of appetite sensations in single test meal studies. Int J Obes Relat Metab Disord 2000;24:38-48. 
23. Braden B, Adams S, Duan LP, Orth KH, Maul FD, Lembcke B, Hör G, Caspary WF. The [13C]acetate breath test accurately reflects gastric emptying of liquids in both liquid and semisolid test meals. Gastroenterology 1995;108:1048-1055.

24. Sakata Y, Fujimoto K, Ogata S, Koyama T, Fukagawa K, Sakai T, Tso P. Postabsorptive factors are important for satiation in rats after a lipid meal. Am J Physiol 1996;271:G438-G442.

25. Symersky T, Biemond I, Frolich M, Masclee AA. Effect of peptide YY on pancreatico-biliary secretion in humans. Scand J Gastroenterol 2005;40:944-949.

26. Foltz M, Maljaars J, Schuring EA, van der Wal RJ, Boer T, Duchateau GS, Peters HP, Stellaard F, Masclee AA. Intragastric layering of lipids delays lipid absorption and increases plasma CCK but has minor effects on gastric emptying and appetite. Am J Physiol Gastrointest Liver Physiol 2009;296:G982-G991.

27. Chaikomin R, Wu KL, Doran S, Meyer JH, Jones KL, Feinle-Bisset C, Horowitz M, Rayner CK. Effects of mid-jejunal compared to duodenal glucose infusion on peptide hormone release and appetite in healthy men. Regul Pept. 2008;150:38-42.

28. Welch IM, Sepple CP, Read NW. Comparisons of the effects on satiety and eating behaviour of infusion of lipid into the different regions of the small intestine. Gut 1988;29:306-311.

29. Lin HC, Zhao XT, Wang L. Fat absorption is not complete by midgut but is dependent on load of fat. Am J Physiol 1996;271:G62-G67.

30. Rolls BJ, Kim S, McNelis AL, Fischman MW, Foltin RW, Moran TH. Time course of effects of preloads high in fat or carbohydrate on food intake and hunger ratings in humans. Am J Physiol 1991;260:R756-R763.

31. Hunt JN, Knox MT. A relation between the chain length of fatty acids and the slowing of gastric emptying. J Physiol 1968;194:327-336.

32. Welch IM, Cunningham KM, Read NW. Regulation of gastric emptying by ileal nutrients in humans. Gastroenterology 1988;94:401-404.

33. Goetze O, Steingoetter A, Menne D, van der Voort IR, Kwiatek MA, Boesiger P, Weishaupt D, Thumshirn M, Fried M, Schwizer W. The effect of macronutrients on gastric volume responses and gastric emptying in humans: A magnetic resonance imaging study. Am J Physiol Gastrointest Liver Physiol 2007;292:G11-G17.

34. Hveem K, Jones KL, Chatterton BE, Horowitz M. Scintigraphic measurement of gastric emptying and ultrasonographic assessment of antral area: relation to appetite. Gut 1996;38:816-821.

35. Jones KL, Doran SM, Hveem K, Bartholomeusz FD, Morley JE, Sun WM, Chatterton BE, Horowitz M. Relation between postprandial satiation and antral area in normal subjects. Am J Clin Nutr 1997;66:127-132.

36. Spiller RC, Trotman IF, Higgins BE, Ghatei MA, Grimble GK, Lee YC, Bloom SR, Misiewicz JJ, Silk DB. The ileal brake--inhibition of jejunal motility after ileal fat perfusion in man. Gut 1984;25:365-374.

37. Read NW, McFarlane A, Kinsman RI, Bates TE, Blackhall NW, Farrar GB, Hall JC, Moss G, Morris AP, O'Neill B, Welch I, Lee $Y$, Bloom SR. Effect of infusion of nutrient solutions into the ileum on gastrointestinal transit and plasma levels of neurotensin and enteroglucagon. Gastroenterology 1984;86:274-280.

38. Lin HC, Zhao XT, Wang L. Intestinal transit is more potently inhibited by fat in the distal (ileal brake) than in the proximal (jejunal brake) gut. Dig Dis Sci 1997;42:19-25.

39. Batterham RL, Cowley MA, Small CJ, Herzog H, Cohen MA, Dakin CL, Wren AM, Brynes AE, Low MJ, Ghatei MA, Cone RD, Bloom SR. Gut hormone PYY(3-36) physiologically inhibits food intake. Nature 2002;418:650-654.

40. Batterham RL, Cohen MA, Ellis SM, Le Roux CW, Withers DJ, Frost GS, Ghatei MA, Bloom SR. Inhibition of food intake in obese subjects by peptide YY3-36. N Engl J Med 2003;349:941-948.

41. Feltrin KL, Little TJ, Meyer JH, Horowitz M, Rades T, Wishart J, Feinle-Bisset C. Effects of lauric acid on upper gut motility, plasma cholecystokinin and peptide $\mathrm{YY}$, and energy intake are load, but not concentration, dependent in humans. J Physiol 2007;581:767-777. 
42. Pilichiewicz AN, Little TJ, Brennan IM, Meyer JH, Wishart JM, Otto B, Horowitz M, Feinle-Bisset C. Effects of load, and duration, of duodenal lipid on antropyloroduodenal motility, plasma CCK and PYY, and energy intake in healthy men. Am J Physiol Regul Integr Comp Physiol. 2006;290:R668-677.

43. Fu-Cheng X, Anini Y, Chariot J, Castex N, Galmiche JP, Roze C. Mechanisms of peptide YY release induced by an intraduodenal meal in rats: neural regulation by proximal gut. Pflugers Arch 1997;433:571-579. 


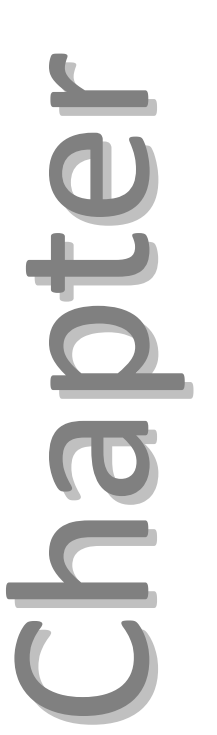

\section{Small intestinal fat distribution influences} hunger and food intake

Maljaars J, Peters HPF, Kodde A, Geraedts M, Troost FJ, Haddeman E, Masclee AAM Submitted 


\section{Abstract}

The site of intestinal fat delivery affects satiety and may affect food intake in humans. Animal data suggest that the length of small intestine exposed to fat is also relevant.

Aim of our study was to investigate whether increasing the areas of intestinal fat exposure would affect satiety parameters and food intake.

In this single-blind randomized crossover study, 15 volunteers, each intubated with a nasoileal tube, received 4 treatments on consecutive days.

The oral (Control) control was a liquid meal (LM) containing $6 \mathrm{~g}$ of fat ingested at $\mathrm{t}=0 \mathrm{~min}$, with saline infusion at t=30-120 min. Experimental treatments were a fat-free $L M$ at $t=0 \mathrm{~min}$, with either $6 \mathrm{~g}$ oil delivered sequentially ( $2 \mathrm{~g}$ duodenal $t=30-60,2 \mathrm{~g}$ jejunal $t=60-90,2 \mathrm{~g}$ ileal $t=90-120 \mathrm{~min}$ ), simultaneously ( $2 \mathrm{~g}$ each to all sites $t=30-120 \mathrm{~min}$ ), or ileal only (lleum: $6 \mathrm{~g} \mathrm{t}=30-120 \mathrm{~min}$ ). Satiety parameters (hunger, fullness) and CCK, GLP-1, PYY secretion were measured until t=180 $\mathrm{min}$, when ad libitum food intake was assessed.

Only lleum reduced food intake significantly over Control. lleum and Simultaneous significantly reduced hunger compared to Control. Compared to control, no differences were observed with regard to PYY, CCK and GLP-1 integrated 180 min secretion.

lleal fat infusion had the most pronounced effect on food intake and satiety. Increasing the areas of intestinal fat exposure only affected hunger when fat was delivered simultaneously to the exposed areas, not sequentially. These results demonstrate that ileal brake activation offers an interesting target for regulation of ingestive behavior. 


\section{Introduction}

The rapidly increasing prevalence of obesity necessitates the development of strategies for weight management and control. As the gastrointestinal (GI) tract elicits various signals that influences hunger and food intake ${ }^{1}$, the gut is considered a strategic target organ.

The use of reduced energy-diets, such as low-calorie meal replacers, may result in body weight reduction ${ }^{2}$. However, compliance to these diets is difficult to achieve, partly due to hunger pangs, thereby seriously limiting its success. Food-based approaches that employ GI mechanisms for an enhanced and prolonged reduction in hunger and food intake may be very helpful in this respect.

It is well known that the satiating effect of nutrients varies between the different segments of the intestine where nutrients are delivered ${ }^{3-13}$. For instance, in animal studies, surgical transposition of an ileal segment to a proximal site, results in an increase in ileal nutrient exposure and a significant reduction in food intake.

This has been confirmed in human studies. Infusion of fat in the ileum more potently reduces hunger feelings compared to infusion of the same dose of fat in the duodenum ${ }^{14}$. Welch et al. ${ }^{9}$ compared infusion of a high dose of fat in ileum versus jejunum. The reduction in food intake was larger after jejunal compared to ileal fat infusion ${ }^{9}$. It should be noticed that the doses of fat employed in that study were supra-physiological (370 Kcal). Therefore, fat will have spilled over into the ileum after the jejunal infusion, expanding the intestinal area exposed to fat in the jejunal experiment. These human data appear to confirm results from animal studies that increasing the small intestinal surface area exposed to nutrients increases the impact on food intake ${ }^{5}$.

In previous studies we have shown in humans that fat delivery to the ileum via an ileal tube results in a significant reduction in hunger score. Targeted delivery of nutrients to the ileum is difficult to achieve in daily life non-invasively. However, development of substances or capsules that slowly release fat during intestinal transport appears technically feasible (e.g. Knutson et al.). The present study was undertaken to explore alternative strategies of intestinal fat delivery, in order to compare and eventually optimise their effects on hunger and food intake.

In the present design, oral fat ingestion was taken as the control, and the effects of ileal fat infusion were tested in the lleum- treatment. Gradual fat delivery was mimicked by a sequential release of fat (duodenum first, then jejunum, followed by ileum). As animal studies have shown that simultaneous exposure of different small intestinal segments increases the effects on food intake, a fourth study arm was 
added where the identical total amount of fat was simultaneously distributed over duodenum, jejunum and ileum.

We hypothesized that increasing the intestinal area exposed to a standard dose of fat may reproduce effects on hunger and food intake comparable to those observed when the same amount of fat is administered to the ileum only.

\section{Experimental method}

\section{Subjects}

Healthy volunteers aged between 18 and 55 yrs with a BMI between 18 and $29 \mathrm{~kg} / \mathrm{m}^{2}$ were recruited by advertisement. Restrained eaters (as assessed by the Dutch Eating Behavior Questionnaire) and subjects on a weight-reduction diet or a medicallyprescribed diet were excluded. Medication influencing appetite or sensory function was not allowed. Subjects with metabolic or endocrine disease, gastrointestinal disorders or after abdominal surgery were excluded. Informed consent was obtained from each individual. The study protocol had been approved by the Medical Ethics Committee of the University Hospital Maastricht, and procedures followed were in accordance with the ethical standards of the institution on human experimentation. Seventeen subjects met the inclusion criteria. Two volunteers dropped out during the study: one due to discomfort during catheter positioning and one due to failure to position the tip of the catheter beyond the ligament of Treitz (flexura duodenojejunalis). Fifteen healthy volunteers completed the protocol.

\section{Catheter}

The catheter for small intestinal intubation was a $290 \mathrm{~cm}$ long rubber silicon 9-channel (8-lumen, 1 balloon inflation channel, diameter $3.5 \mathrm{~mm}$ ) catheter custom-made by Dentsleeve International Ltd (Mississauga, Ontario, Canada). The functional length was $240 \mathrm{~cm}$ with a $50 \mathrm{~cm}$ connection segment. The catheter contains side-holes at 80 , $95,110,125,210,220,230$ and $240 \mathrm{~cm}$ from the proximal junction and had an inflatable balloon (maximum inflation capacity $10 \mathrm{ml}$ ) at the distal tip.

\section{Experimental protocol}

The meal replacer we used contains $6 \mathrm{~g}$ of fat. This meal replacer is expected to reduce hunger for a 3-4 hour period, until the next meal. Reducing hunger in the betweenmeal period and reducing food intake were specific goals in our design. The 60 minutes period between the end of the infusion and the ad-libitum lunch was 
scheduled to assess how the study treatments affect between-meal hunger compared to a regular meal replacer. As these meal replacers contain $6 \mathrm{~g}$ of fat, this is the amount we tested in this study. Amounts as low as $3 \mathrm{~g}$ have been shown to affect ingestive behaviour when delivered to the ileum ${ }^{15}$.

The experimental protocol is shown in Figure 8.1. In this single blind placebocontrolled crossover study, four treatments were scheduled. Each test day, a liquid meal replacer (for details see below) was ingested at $t=0 \mathrm{~min}$, followed by an intestinal infusion from $t=30$ to $t=120 \mathrm{~min}$ in all treatments. During the control treatment, a liquid meal replacer containing $6 \mathrm{~g}$ of fat was ingested at $\mathrm{t}=0 \mathrm{~min}$, followed by a saline infusion. In the other three treatments, a fat-free liquid meal replacer was ingested at $\mathrm{t}=0 \mathrm{~min}$, followed by intestinal infusions with variations in location, but all with delivery of $6 \mathrm{~g}$ fat. As positive control, $6 \mathrm{~g}$ of fat was given in the ileum : "lleum". In the sequential treatment, representing slow release intestinal delivery , $2 \mathrm{~g}$ of fat was given in the duodenum ( $\mathrm{t}=30-60 \mathrm{~min}$ ), followed by $2 \mathrm{~g}$ in the jejunum ( $t=60-90 \mathrm{~min}$ ), followed by $2 \mathrm{~g}$ in the ileum ( $\mathrm{t}=90-120 \mathrm{~min}$ ): 'Sequential'. The "Simultaneous" treatment was given to optimize the surface area exposed to nutrients Here, $2 \mathrm{~g}$ of fat was given in the duodenum, $2 \mathrm{~g}$ in the jejunum and $2 \mathrm{~g}$ in the ileum continuously, for 90 minutes, that is from 30 to $120 \mathrm{~min}$. .

\section{Catheter positioning}

On Monday, subjects arrived at 12:00 hr after a light breakfast (ingested before 09:00 $\mathrm{hr})$. Through an anaesthetized nostril, the catheter was introduced into the stomach, and allowed to pass through the pylorus to the ileum by peristalsis. After passing the ligament of Treitz, a small balloon at the tip was inflated to facilitate passage of the catheter to the ileum. During the day, the subject was offered small snacks and sugared tea or coffee to stimulate peristalsis. The tip was placed in the ileum (at least $120 \mathrm{~cm}$ distal from the pylorus ${ }^{16}$ ), so three infusion ports were available in the ileum. The most distal port was used for infusion. In this study, we perfused the ileum at at least $175-195 \mathrm{~cm}$ from the nose. During the positioning and before every test-day, the position of the catheter was checked fluoroscopically. 


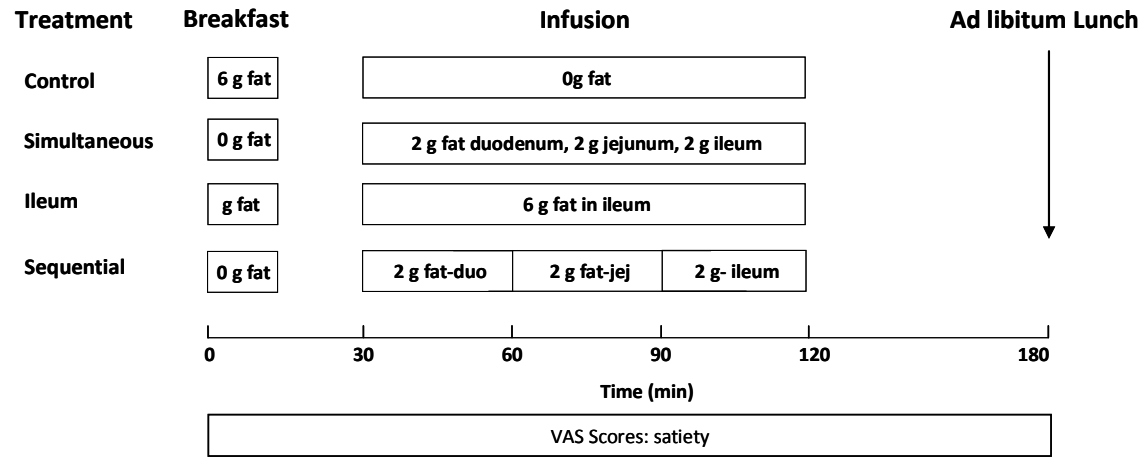

Figure 8.1 Study outline for the experiment.

The study consisted of four treatments. Order of treatments was randomized. Each subject started each test day by consuming a breakfast at $\mathrm{t}=0 \mathrm{~min}$. In the Control treatment, this was a fat-containing drink (199 kcal). This breakfast meal was then followed by a saline infusion from $\mathrm{t}=30-120 \mathrm{~min}$.

On the treatment days, a fat-free breakfast ( $145 \mathrm{kcal}$ ) was ingested at $\mathrm{t}=0 \mathrm{~min}$, followed by an intestinal infusion of $6 \mathrm{~g}$ of fat from $\mathrm{t}=30-120 \mathrm{~min}$. In the Simultaneous treatment, $2 \mathrm{~g}$ of fat was given in the duodenum, $2 \mathrm{~g}$ in the jejunum and $2 \mathrm{~g}$ in the ileum continuously for 90 minutes. During the lleum treatment, $6 \mathrm{~g}$ of fat was given in the ileum only. Finally, in the Sequential treatment, $2 \mathrm{~g}$ of fat was given in the duodenum ( $\mathrm{t}=30-60 \mathrm{~min})$, followed by $2 \mathrm{~g}$ in the jejunum ( $t=60-90 \mathrm{~min}$ ), followed by $2 \mathrm{~g}$ in the ileum ( $\mathrm{t}-90-120 \mathrm{~min}$ ).

Throughout the test day, blood was sampled for gut peptide analysis and satiety was measured by VAS questionnaires. Gastric emptying was measured by the $13 \mathrm{C}$ stable isotope breath test. On all test days, an ad libitum meal was consumed at $\mathrm{t}=180$ minutes.

\section{Test day}

On each study day (Tuesday till Friday), the subject arrived at the gastrointestinal research laboratory unit at 8:00 hr following an overnight fast. After checking the position of the ileal catheter, a venous catheter was placed in a forearm-vein for collection of blood samples. At 8:45 hr, a basal VAS scores for hunger feelings and a basal blood sample were collected. After this, the experiment was started. At 9:00 hr ( $\mathrm{t}=0 \mathrm{~min}$ ), the liquid meal was ingested. The infusions started at $\mathrm{t}=30 \mathrm{~min}$. Infusion rate was $0.67 \mathrm{ml} / \mathrm{min}(0.6 \mathrm{kcal} / \mathrm{min})$ for $90 \mathrm{~min}$ for all treatments. At $12: 00 \mathrm{hr}$ ( $\mathrm{t}=180$ $\mathrm{min}$ ) the ad libitum lunch was served. At $12: 30 \mathrm{hr}$, the intravenous canula was removed, and subjects were allowed to go home. They received an evening meal and snackbox from which they were allowed to consume freely till 22:00 hr. 


\section{Hunger}

Scores for hunger feelings (fullness, hunger, desire to eat a meal, desire to eat a snack) was measured using electronic Visual Analogue Scales (EVAS) anchored the low end with the most negative or lowest intensity feelings (e.g., extremely, not at all), and with opposing terms at the high end (e.g., not at all, very high) ${ }^{17}$. Volunteers were asked to indicate on a $64 \mathrm{~mm}$ line on the IPAQ which place on the scale best reflects their feeling at that moment. Measurements were taken during the test day every $30 \mathrm{~min}$, and every 15 min during infusion of emulsion.

\section{Food intake}

Each test day, an ad libitum-lunch was served to measure food intake. Each lunch was offered in excess, and consisted of a pasta meal (per $100 \mathrm{~g}: 430 \mathrm{~kJ}, 5 \mathrm{~g}$ protein, $2 \mathrm{~g}$ fat, $16 \mathrm{~g}$ carbohydrates). During the ad libitum-lunch, subjects were not allowed to watch television, listen to the radio or read as this could have influenced the amount eaten.

\section{Liquid meal}

A liquid meal replacer with or without fat was administered. The regular, fatcontaining drink, which was given during the control treatment, was a liquid meal replacer (Slim·Fast Optima, Unilever, Vlaardingen, Netherlands; $325 \mathrm{ml}, 199 \mathrm{kcal}$ ) containing $6 \mathrm{~g}$ of high-oleic rapeseed oil. The fat-free version of the same drink $(325 \mathrm{ml}, 145 \mathrm{kcal})$ was given during the other treatments. These are vitamin- and mineral-fortified meal replacement products, used by consumers primarily in order to aid in weight loss and/or prevention of weight gain.

\section{Emulsions}

The emulsions consisted of $10 \%$ oil in water. As an emulsifier $2.5 \% \mathrm{~K}$-caseinate was used. A very small amount of xanthan gum $(0.1 \%)$ and guar gum $(0.1 \%)$ was used as a stabiliser. Sodium chloride was added to obtain iso-osmotic solutions $(0.8 \% \mathrm{NaCl})$. Total infused volume was $60 \mathrm{ml}$, containing $6 \mathrm{~g}$ fat. Caloric load was $54 \mathrm{kcal}$. The $\mathrm{pH}$ of the emulsions ranged from 6.7 till 6.8. As a control infusion, saline was administrated to the ileum.

\section{Chemical analyses}

Blood samples were drawn at regular intervals throughout the test day. After collection, the blood was kept on ice. Total PYY (PYYT-66HK, Linco Research, St. Charles, Missouri, US), CCK (RB302, Lucron Bioproducts), and GLP-1 (GLP1A-35HK, Linco Research, St. Charles, Missouri, US) were measured by sensitive and specific 
commercially available radioimmunoassays. Blood for GLP-1 analysis was collected in ice-chilled tubes, to which DPP-IV inhibitor was added (DPP4, Linco Research St. Charles, Missouri, US). All gut peptides were measured in a subset of 9 subjects.

\section{Statistical analysis}

Results are presented as least squares means with standard error of the mean (SE), unless otherwise specified. Satiety VAS scores were expressed as percentages of the maximal score $(0 \mathrm{~cm}$ equaled $0 \%$ and $6.4 \mathrm{~cm}$ equaled $100 \%)$ and as incremental cumulative areas under the curve, with the value at $t=0$ min as a covariate. The incremental AUC was calculated using the trapezoid rule.

An $n=9$ subject subset was used for evaluation of gut peptide secretion. This group size ( $n$ ) of nine was based on a power calculation with a predicted difference in peptide release of at least $20 \%$, a power of 0.8 , and an overall $\alpha$ of 0.05 (taking into account multiple comparisons, 2-sided), this resulted in a group size ( $\mathrm{n}$ ) of 9.

All parameters were analyzed using analysis of variance with subjects as blocks and treatment as factor. A Dunnett test was used to compare each treatment to control. A p-value of 0.05 was considered significant.

\section{Results}

\section{Food intake}

Food intake (Figure 8.2) was significantly reduced after lleum vs. Control (422g vs. 499g, $S E=40, p<0.01$ ), whereas no significant differences were observed after Simultaneous and Sequential (458g for Simultaneous and $480 \mathrm{~g}$ for Sequential, SE=40).

\section{Hunger}

We measured Hunger, Fullness, Appetite for a meal and Appetite for a snack. As hunger, appetite for a meal and appetite for a snack produced identical results, we only show hunger scores.

Over the period $\mathrm{t}=-\mathbf{1 5 - 1 8 0} \mathrm{min}$, hunger AUC (Figure 8.3a) was significantly reduced after both Simultaneous and Ileum vs. Control, but not after sequential. No significant differences between the four experiments were observed for AUC fullness (Figure 8.3c).

At the start of each test day, hunger (Figure 8.3b) and fullness (Figure 8.3d) scores did not differ between the treatments. Hunger was significantly reduced after lleum vs. Control at $150 \mathrm{~min}$. No differences were observed for fullness. 


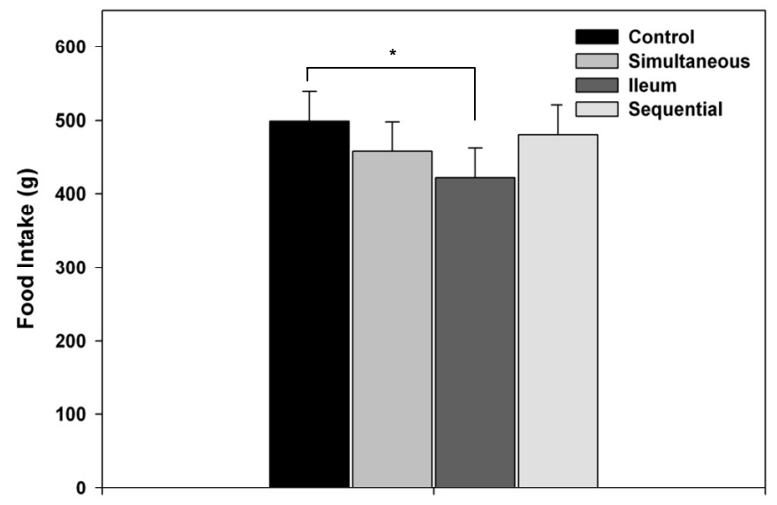

Figure 8.2 Results for food intake. * denotes $p<0.05$.

A
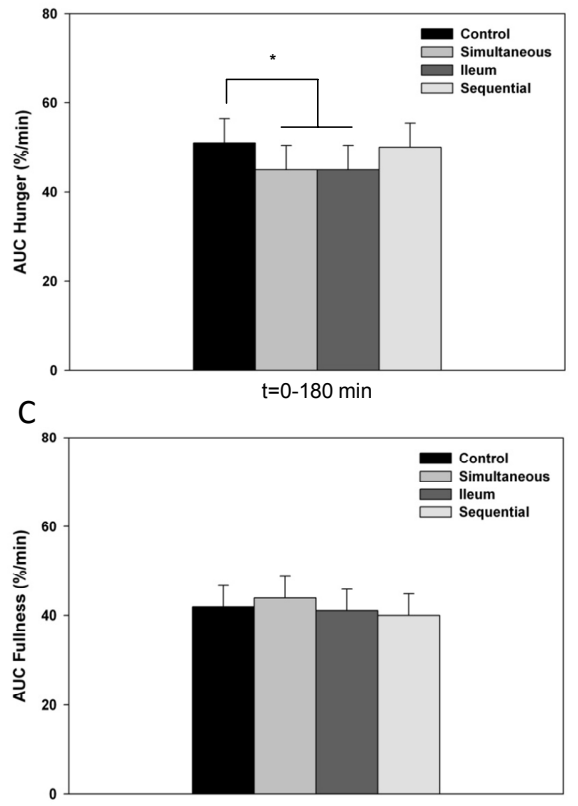

B

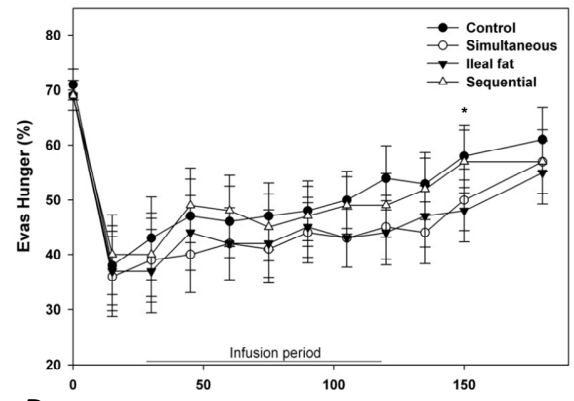

D

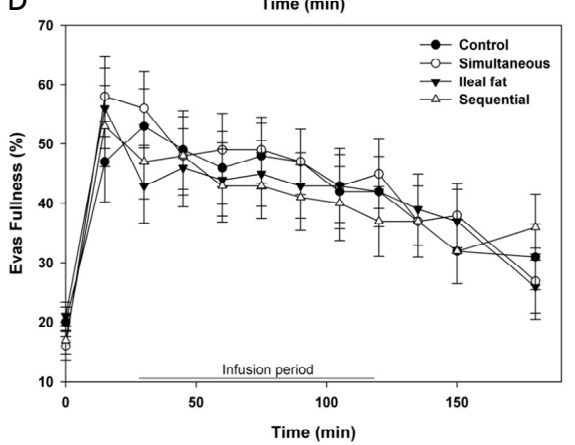

Figure 8.3 Results for Fullness and Hunger.

A. Results for hunger AUC. * denotes $p<0.05$. B. Results for hunger scores. * denotes $p<0.05$.

C. Results for fullness AUC. D. Results for fullness scores. 


\section{Gut peptide secretion}

Fasting plasma concentrations of CCK, GLP-1 and PYY did not differ between the treatments. With regard to the 0-180 min AUC integrated secretion (AUC 0-180 min), neither for CCK, nor for PYY or GLP-1 were significant differences observed between the four treatments (Table 8.1).

Table 8.1 Secretion of gut peptides in response to the different treatments, as measured as AUC ( $t=0$ $180 \mathrm{~min})$

\begin{tabular}{lcccccc}
\hline Treatment: & CCK $(\mathrm{pM} / \mathrm{min})$ & $\mathrm{SE}$ & $\mathrm{PYY}(\mathrm{pM} / \mathrm{min})$ & $\mathrm{SE}$ & $\mathrm{GLP}-1(\mathrm{pM} / \mathrm{min})$ & SE \\
\hline Oral & 162 & 55 & 96 & 55 & 3842 & 462 \\
Simultaneous & 187 & 55 & 101 & 55 & 5176 & 462 \\
Ileum & 142 & 55 & 91 & 55 & 4243 & 462 \\
Sequential & 204 & 55 & 86 & 55 & 4496 & 462 \\
\hline
\end{tabular}

CCK (cholecystokinin), PYY (peptide YY), GLP-1 (glucagon-like peptide-1)

Values are LSmeans. No significant differences were observed.

\section{Discussion}

In the present study, we have shown that infusion of a low, physiological dose of fat into the ileum resulted in a significant and clinically relevant reduction in food intake when compared to oral ingestion of the same dose of fat.

When an equicaloric fat dose was spread sequentially over the small intestine, mimicking slow release of fat during intestinal transit, neither hunger scores nor food intake were significantly affected. On the other hand, optimalisation of the exposed intestinal area to fat with the simultaneous delivery of fat along the whole length of small intestine resulted in a significant reduction in hunger scores compared to oral fat but had no effect on food intake. The observed differences in satiety and food intake were not reflected by changes in serum gut peptide levels.

The concept of the ileal brake has been introduced by Spiller et al. ${ }^{16}$ and Read was initially described as a reduction in small intestinal transit in response to ileal nutrient infusions $^{16,18}$. Additionally, ileal brake effects on satiety and food intake have since been demonstrated ${ }^{3}$.

Welch et al. were the first to show that ileal infusion of large doses of fat reduced food intake when compared to a control saline infusion or to intravenous infusion of fat $^{9,19}$. In a previous study, we compared infusion of fat into the ileum vs duodenum on hunger levels and food intake ${ }^{14}$. The ileal fat infusions significantly increased satiety and reduced hunger scores compared to duodenal fat infusion. With respect to food intake no differences were observed between the two treatments. We 
hypothesize that the timing of the ad-libitum meal relative to the end of the infusion in that study (150 min vs. $60 \mathrm{~min}$ in the present study) may have affected the outcome. Rolls et al. demonstrated that the effects of a preload on food intake during a subsequent meal diminished as the time between preload administration and meal ingestion increased ${ }^{20}$.

Ileal fat infusion reduced food intake by about $15 \%$, which at first sight may seem to be a rather small effect. However, obesity usually reflects a long-term accumulation of relatively small daily 'energy gaps ${ }^{\prime 21}$. Hill et al. describe that by reducing caloric intake by $50 \mathrm{kcal}$ per day, weight gain could be prevented in $90 \%$ of the population ${ }^{21}$. This suggests that the $15 \%$ reduction in food intake we observed represents a meaningful and significant contribution to treating and preventing obesity and overweight.

The ileal brake as a target for food-based strategies to reduce hunger and food intake has been proposed previously ${ }^{3,22}$. However, under physiological conditions, only a small percentage of nutrients will reach the (terminal) ileum after intake of a normal sized meal.. The percentage reaching the ileum may however increase to almost $30 \%$ after ingestion of a very large volume, high caloric meal ${ }^{23}$. Targeted delivery of fat to the ileum through ileal intubation is feasible for research purposes but not for clinical purposes. Therefore, the question arises whether designing emulsions or encapsulates that result in a higher amount of fat delivery to the ileum, is feasible. This may be achieved by increasing the resistance of the emulsion to lipolysis in the proximal GI tract. This may lead either to a larger surface area exposed to nutrients and/or to a higher concentration of fat or fatty acids in the distal small intestine. Targeted delivery of nutrients to the ileum is difficult to achieve in daily life noninvasively. However, development of substances or capsules that slowly release fat during intestinal transport and do not necessarily need to reach the ileum solely, appears much more feasible $22,24,25$.

Animals studies have clearly shown that the effect of a small intestinal nutrient load on food intake and small intestinal transit increases when the small intestinal surface area exposed to these nutrients increases ${ }^{5,26}$. Two mechanisms appear to be involved. First, as the exposed luminal surface increases, the total number of activated receptors involved in satiety signalling increases as well. Second, exposure of the distal surface area with fat infusion will lead to activation of distal receptors, which may be more potent in their effects on satiety ${ }^{14}$.

In the present study, two treatments resulted in an increase in the small intestinal surface area that was exposed to fat: the sequential and simultaneous fat delivery. In the sequential treatment, a slow-release delivery of fat was mimicked, but without any significant effect on food intake or hunger scores. As fourth arm we included the condition with optimalisation of intestinal area exposed to the $6 \mathrm{~g}$ fat. Here we 
observed a significant reduction in hunger scores. This finding is in line with those of Meyer et al., who stated that simultaneous exposure of the different segments of small intestine would potentiate the effects on food intake ${ }^{5}$. This suggests that simultaneous feedback from the different small intestinal segments is pivotal in the increased effects on eating behaviour and transit that are observed after increased small intestinal exposure.

In the small intestine, the secretion of several gut peptide varies dependent on the intestinal segments that are activated ${ }^{27}$. CCK is predominantly released from the proximal small intestine, although CCK-secreting cells have also been demonstrated in the terminal ileum ${ }^{28}$. Peptide YY (PYY)-and glucagon-like peptide-1 (GLP-1) secreting L-cells reside predominantly in the distal small intestine and colon ${ }^{27}$. We hypothesized that modulating the distribution of fat over the small intestine would affect peptide secretion in line with effects on satiety scores and food intake. However, no differences were observed in peptide secretion. It should be taken into consideration that only small amounts of fat were administered and that peptides may exert their effect by paracrine or neurocrine routes vs. endocrine routes (secretion into bloodstream) ${ }^{27}$.

In conclusion, we confirm that ileal fat infusion significantly reduces food intake compared to oral fat ingestion. Further optimising the exposure of the small intestine to fat through simultaneous fat delivery did result in a reduction of hunger scores, but no effects on food intake were observed. These results point to the ileal brake as most potent small intestinal control mechanism for hunger and food intake. The ileal brake is therefore an interesting target for food-based strategies in weight management. 


\section{References}

1. Badman MK, Flier JS. The Gut and Energy Balance: Visceral Allies in the Obesity Wars. Science 2005;307:1909.

2. Truby H, Baic S, deLooy A, Fox KR, Livingstone MB, Logan CM, Macdonald IA, Morgan LM, Taylor MA, Millward DJ. Randomised controlled trial of four commercial weight loss programmes in the UK: initial findings from the BBC "diet trials". BMJ 2006;332:1309-1314.

3. Maljaars P.W., Peters H.P., Mela DJ, Masclee A.A. lleal brake: a sensible food target for appetite control. A review. Physiol Behav 2008;95:271-81

4. Meyer JH, Hlinka M, Tabrizi Y, DiMaso N, Raybould HE. Chemical specificities and intestinal distributions of nutrient-driven satiety. Am J Physiol 1998;275:R1293-R1307.

5. Meyer JH, Tabrizi Y, DiMaso N, Hlinka M, Raybould HE. Length of intestinal contact on nutrient-driven satiety. Am J Physiol 1998;275:R1308-R1319.

6. Meyer JH, Hlinka M, Khatibi A, Raybould HE, Tso P. Role of small intestine in caloric compensations to oil premeals in rats. Am J Physiol 1998;275:R1320-R1333.

7. Meyer JH, Elashoff JD, Doty JE, Gu YG. Disproportionate ileal digestion on canine food consumption. A possible model for satiety in pancreatic insufficiency. Dig Dis Sci 1994;39:1014-1024.

8. Welch IM, Davison PA, Worlding J, Read NW. Effect of ileal infusion of lipid on jejunal motor patterns after a nutrient and nonnutrient meal. Am J Physiol 1988;255:G800-G806.

9. Welch IM, Sepple CP, Read NW. Comparisons of the effects on satiety and eating behaviour of infusion of lipid into the different regions of the small intestine. Gut 1988;29:306-311.

10. Koopmans HS. An integrated organismic response to lower gut stimulation. Scand J Gastroenterol Suppl 1983;82:143-153.

11. Koopmans HS. The role of the ileum in the control of food intake and intestinal adaptation. Can J Physiol Pharmacol 1990;68:650-655.

12. Koopmans HS, Ferri GL, Sarson DL, Polak JM, Bloom SR. The effects of ileal transposition and jejunoileal bypass on food intake and GI hormone levels in rats. Physiol Behav 1984;33:601-609.

13. Strader AD, Vahl TP, Jandacek RJ, Woods SC, D'Alessio DA, Seeley RJ. Weight loss through ileal transposition is accompanied by increased ileal hormone secretion and synthesis in rats. Am J Physiol Endocrinol Metab 2005;288:E447-E453.

14. Maljaars J, Haddeman E, Peters H., Masclee A. Comparison of Ileal and Duodenal brake mechanisms on satiety and gastrointestinal transport. Gastroenterology 2007;132:A207 Suppl.2.

15. Maljaars PW, Symersky T, Kee BC, Haddeman E, Peters HP, Masclee AA. Effect of ileal fat perfusion on satiety and hormone release in healthy volunteers. Int J Obes (Lond) 2008;32:1633-1639

16. Spiller RC, Trotman IF, Higgins BE, Ghatei MA, Grimble GK, Lee YC, Bloom SR, Misiewicz JJ, Silk DB. The ileal brake--inhibition of jejunal motility after ileal fat perfusion in man. Gut 1984;25:365-374.

17. Flint A, Raben A, Blundell JE, Astrup A. Reproducibility, power and validity of visual analogue scales in assessment of appetite sensations in single test meal studies. Int J Obes Relat Metab Disord 2000; 24:38-48.

18. Read NW, McFarlane A, Kinsman RI, Bates TE, Blackhall NW, Farrar GB, Hall JC, Moss G, Morris AP, $\mathrm{O}^{\prime} \mathrm{Neill} B$, et al. Effect of infusion of nutrient solutions into the ileum on gastrointestinal transit and plasma levels of neurotensin and enteroglucagon. Gastroenterology 1984;86:274-280.

19. Welch I, Saunders K, Read NW. Effect of ileal and intravenous infusions of fat emulsions on feeding and satiety in human volunteers. Gastroenterology 1985;89:1293-1297.

20. Rolls BJ, Kim S, McNelis AL, Fischman MW, Foltin RW, Moran TH. Time course of effects of preloads high in fat or carbohydrate on food intake and hunger ratings in humans. Am J Physiol 1991;260: R756-R763.

21. Hill JO, Wyatt HR, Reed GW, Peters JC. Obesity and the environment: where do we go from here? Science 2003;299:853-855.

22. Golding $\mathrm{M}$, Wooster TJ. The influence of emulsion structure and stability on lipid digestion. Current Opinion in Colloid \& Interface Science 2010;15:90-101. 
23. Lin HC, Zhao XT, Wang L. Fat absorption is not complete by midgut but is dependent on load of fat. Am J Physiol 1996;271:G62-G67.

24. Knutson L, Koenders DJ, Fridblom H, Viberg A, Sein A, Lennernas H. Gastrointestinal metabolism of a vegetable-oil emulsion in healthy subjects. Am J Clin Nutr. 2010;92:515-524.

25. Maljaars PJ, Keszthelyi D, Masclee AA. An ileal brake-through? Am J Clin Nutr. 2010;92:467-468.

26. Lin HC, Doty JE, Reedy TJ, Meyer JH. Inhibition of gastric emptying by sodium oleate depends on length of intestine exposed to nutrient. Am J Physiol 1990;259:G1031-G1036.

27. Maljaars J, Peters HP, Masclee AM. Review article: The gastrointestinal tract: neuroendocrine regulation of satiety and food intake. Aliment Pharmacol Ther 2007;26 Suppl 2:241-250.

28. Buffa R, Solcia E, Go VL. Immunohistochemical identification of the cholecystokinin cell in the intestinal mucosa. Gastroenterology 1976;70:528-532. 


\section{Intragastric layering of lipids delays lipid} absorption and increases plasma CCK but has minor effects on gastric emptying and appetite

Foltz M, Maljaars J, Schuring EAH, van der Wal RJP, Boer T, Duchateau GSM, Peters HPF, Stellaard F, Masclee AAM

Am J Physiol Gastrointest Liver Physiol 2009;295:G982-991 


\section{Abstract}

Intestinal intubation studies have demonstrated that lipids induce satiety, but the contribution of lipid processing by the stomach on satiety remains poorly understood. In this explorative, randomized, placebocontrolled, crossover study we tested whether delayed lipid absorption, increased cholecystokinin (CCK), decelerated gastric emptying (GE) and increased satiety can be achieved by controlling lipid distribution in the stomach. Six healthy males were intubated nasogastrically. Two treatments were performed and repeated in duplicate. Subjects received in the on top treatment (OT) a fat-free liquid meal (LM, $325 \mathrm{ml}$, $145 \mathrm{kcal})$ followed by intragastric infusion of $4 \mathrm{~g}$ high oleic acid rapeseed oil $(4.6 \mathrm{ml}, 36 \mathrm{kcal})$ labeled with $77 \mathrm{mg}$ glyceryl- ${ }^{13} \mathrm{C}$-trioleate. In the emulsion treatment (EM, control) $4 \mathrm{~g}$ labeled rapeseed oil was incorporated into the $\mathrm{LM}(325 \mathrm{ml}, 181 \mathrm{kcal}) ; 4.6 \mathrm{ml}$ saline was infused as a control. In OT and EM a $2^{\text {nd }} \mathrm{LM}$ was consumed at $\mathrm{t}=270 \mathrm{~min}$. Plasma ${ }^{13} \mathrm{C}-\mathrm{C} 18: 1, \mathrm{CCK}$ and satiety were measured over $480 \mathrm{~min}$. GE was determined using the paracetamol absorption test. OT delayed oleic acid absorption shown by an increased lag time of absorption (EM: $37 \pm 7 \mathrm{~min}$; OT: $75 \pm 10 \mathrm{~min}$; P<0.01) and $T_{\max }$ (EM: $162 \pm 18 \mathrm{~min}$; OT: $280 \pm 33 \mathrm{~min}$; $\mathrm{p}=0.01)$. OT released more CCK than EM $(P=0.03)$ including increased CCK after the $2^{\text {nd }}$ meal. OT accelerated initial GE until 30 min postprandial. OT showed a tendency $(P=0.06)$ to suppress hunger and increase satiety and fullness 120-270 min postprandially. The results demonstrate that low amounts of lipids, when separated from the aqueous phase of a meal, delay lipid absorption and increase CCK. An escalating dose study should determine whether this could have implications for the development of weight control foods. 


\section{Introduction}

Long-term dietary interventions using low energy liquid meals (LM) have clearly demonstrated effectiveness in achieving and maintaining weight loss in addition to improving metabolic biomarkers of comorbid diseases in clinical trials ${ }^{1,2}$. Despite the proven success of LM in clinical trials, it remains a challenge to achieve and maintain weight loss in all users because of perceived hunger, which is a significant predictor of failure to lose weight ${ }^{3}$. This suggests that delaying the return of hunger and increasing satiety following consumption of LM would help to improve compliance, and would aid in achieving weight loss and weight control ${ }^{4}$.

Food stimulates satiety and inhibits food intake by complex and interdependent mechanisms in which signals arising from the gastrointestinal tract play an important role5. Gastrointestinal satiety consists of two interacting components: distention of the stomach (mechanical) and release of gastrointestinal peptides by the small intestine (nutritive) ${ }^{5}$. In the intestine, lipids are sensed in the wall of the intestine by specialized receptors, induce inter alia release of cholecystokinin (CCK) from enteroendocrine cells and activate extrinsic vagal afferent nerve terminals. Together, this leads to a multitude of physiological processes amongst which an inhibition of gastric emptying (GE) and finally to a reduction in hunger and food intake ${ }^{6,7}$.

Underlying mechanisms of satiety signaling are often investigated by using small intestinal intubation studies. In these studies, nutrients are infused at constant rates into specific small intestinal regions. In general, infusion rates $(0.1-2 \mathrm{kcal} / \mathrm{min})$ and concentrations $(14-80 \mathrm{mmol})$ which are suggested to mimic the postprandial physiological concentrations entering the small intestine after consumption of a meal $^{8-10}$ were used. It has been proven that these mechanism are associated with satiety, food intake and satiety-related physiological parameters such as $\mathrm{GE}^{11-14}$

However, such mechanistic studies neglect that after intake of complex meals, nutrients may arrive in non-uniform patterns to the duodenal and jejunal region ${ }^{15}$ and not at constant rates. Furthermore, effects on satiety and physiological parameters related to satiety (GE and gut hormone secretion) that are observed after infusion of low-lipid doses may be overruled in complex meals by the effects of other meal components (proteins and / or carbohydrates) ${ }^{16,17}$. Therefore, in our view, when compared to "real meal"-situations, small intestinal infusion studies neglect the effects of $A$ ) intragastric distribution of lipids and the subsequent effects on lipid delivery to the small intestine and $B$ ) complex and interacting effects of macronutrients on satiety inducing mechanisms under fed conditions. Support for the former hypothesis, i.e. sequential lipid delivery from the gastric lumen to the gut originates from early studies using gamma scintigraphy. These studies show that fat empties with the meal from the stomach when it is an integral part of the food ${ }^{18}$. However, when the fat is free and liquid, phase separation occurs, i.e. the fat forms a 
layer on top of the meal ("creaming"), resulting in slower gastric emptying ${ }^{18,19}$. Recent magnetic-resonance imaging (MRI) studies including echo-planar imaging have demonstrated that the rate of emptying of lipids from the gastric lumen influences emptying rates of the total meal and is dependent on the physical state of the lipid (whether the lipid is part of the meal or free), the ingestion order and posture of the subject $^{20-26}$.

Most processed foods contain lipids in the form of emulsions. By varying the emulsifier type and emulsification process these emulsions can be tailored towards their stability under gastric conditions; i.e. emulsions which stay intact at low $\mathrm{pH}$ (gastric-stable) or emulsions which release free lipid due to emulsifier breakdown under gastric conditions (gastric-unstable). Lipids in gastric-stable emulsions have been shown to empty with the aqueous phase. Compared to gastric-unstable emulsions, where the oil forms a layer on top of the aqueous phase, they increased the forward and backward antral flow in the stomach, increased CCK secretion and increased gallbladder contraction ${ }^{21,25,26}$. However, in these studies, pure oil in water emulsions at very high lipid doses (75-100 g) were used. It is unclear whether gastricunstable emulsions will continue to yield the same results when these emulsions, at physiological concentrations, are incorporated into a real food matrix.

Based on previous work on intragastric lipid distribution in the stomach, intraduodenal lipid sensing and triggering of mediators of satiety, we questioned whether a modulation is also possible under more physiological conditions. The aim of this explorative, randomized, placebo-controlled, crossover study was to investigate whether it would be possible to modulate release of lipids from the stomach, plasma CCK levels and GE in healthy volunteers by using low lipid loads layered in the stomach on an orally consumed LM. Possible translation of these changes, if present, into concomitant changes in perceptive satiety was measured as additional outcome. In healthy males we infused nasogastrically $4 \mathrm{~g}$ of high oleic acid rapeseed oil labeled with ${ }^{13} \mathrm{C}$-C18:1 (oleic acid given in the form of a triacylglyceride) on top of an orally consumed LM. In the control treatment $4 \mathrm{~g}$ labeled rapeseed oil was emulsified in the LM, saline was infused as a control. The effect of emptying of lipids from the stomach measured by plasma ${ }^{13} \mathrm{C}-\mathrm{C} 18: 1$ appearance and CCK profiles (primary outcomes) as well as GE of the aqueous phase of the LM and satiety perception (secondary outcomes) were determined. 


\section{Materials and method}

\section{Subjects}

Male subjects aged 18-45 y were recruited from the campus population of the Leiden University Medical Center. Subjects were screened to be generally healthy as assessed by means of a screening questionnaire, BMl assessment $\left(19-25 \mathrm{~kg} / \mathrm{m}^{2}\right)$ and standard hematology. Smokers, restrained eaters (assessed with the Dutch Eating Behavior Questionnaire $^{27}$ with a score of restriction $>2.5$ ), subjects with hemoglobin concentrations $<8.4 \mathrm{mmol} / \mathrm{l}$ or had donated blood in the last 4 weeks and subjects who reported dieting or who were on a medically prescribed diet in the last 6 months before the start of the study were excluded from participation. Subjects on medication that may influence appetite and sensory functioning or subjects who reported a metabolic or endocrine disease, gastrointestinal disorders were not included. Six subjects (age 22.0 \pm 1.4 y; BMI $23.8 \pm 1.1 \mathrm{~kg} / \mathrm{m}^{2}$ ) were included in the study and all subjects finished the study. Participants were informed about the study and all subjects signed an informed consent form before participation. The Medical Ethics Committee of the Leiden University Medical Center (Leiden, The Netherlands) approved the study.

\section{Study design}

The study was an explorative, randomized, double-blind, placebo-controlled, crossover study performed at the University of Leiden Medical Center and was conducted following GCP guidelines. The study design is presented in Figure 9.1. The study used a within and between subject design with two treatments (OT and EM) which each subject underwent twice leading to four interventions per subjects. Thus, the study consisted of four intervention days separated by washout periods lasting one week each. This study design led to six possible sequences in receiving the treatments. Each subject was randomly allocated to one of the six possible treatment sequences. The study had a staggered start, with two subjects starting per day. The study hypothesis was that intragastric lipid layering leads to delayed lipid absorption compared to emulsified lipids when incorporated into a LM. The delayed lipid absorption in turn enhances postprandial CCK concentrations and modulates GE. Primary outcomes of the study were changes in plasma ${ }^{13} \mathrm{C}-\mathrm{C} 18: 1$ concentrations $\left(C_{\max }, T_{\max }\right.$ and $\mathrm{T}_{\text {lag }}$ ) and $\mathrm{CCK}$ concentrations (area under the time-plasma concentration curve). Secondary outcomes were changes in GE (gastric emptying half time, $T_{50}$ ) as well as satiety and hunger perception (area under the time-appetite curve). 


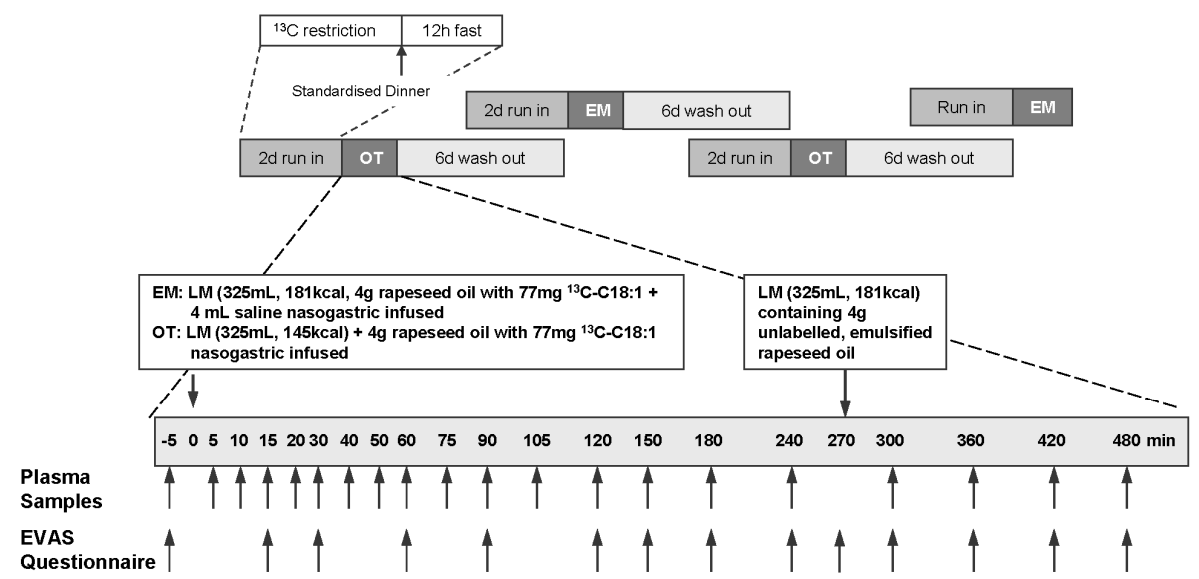

Figure 9.1 Study design and sampling scheme. Subjects underwent two treatments (OT, oil on top; EM, emulsion) which each subject underwent twice resulting in four interventions per subject. The treatment order is shown exemplarily, as each subject was randomly allocated to one of the six possible treatment orders to avoid a treatment order effect. All treatments were preceded by a $2 d$ run in period in which subjects refrained from ${ }^{13} \mathrm{C}$-rich foods and consumed a standardised dinner before the test day. Plasma samples were taken for quantification of paracetamol ( $\mathrm{t}=-5-240 \mathrm{~min}),{ }^{13} \mathrm{C}-\mathrm{C} 18: 1$ and $\mathrm{CCK}(\mathrm{t}=-5-480 \mathrm{~min})$. Electronic visual analogue scales (EVAS) were used at intervals to register satiety, hunger, fullness, and appetite for a meal. Nausea was registered at the same time intervals.

\section{Sample Size Estimate}

The current study was designed as an explorative study as no data on either the variance of the difference between treatments nor on the variance within subjects for the primary outcome parameters (oleic acid kinetics) was available. Previous studies showed significant differences in fat absorption kinetics with $6-9$ subjects $^{28}$. Our own studies showed a within subject variance in the incremental AUC of CCK of $0.64 \mathrm{pmol} / \mathrm{l} / \mathrm{min}$. Based on an estimated physiological meaningful effect of at least $10 \%$ needed for CCK, ten observations would be sufficient for CCK (2-sided test, power $0.8, \alpha 0.05)$. For satiety, we found in earlier studies a within subject variance of about 85 (area-under-the curve). Based on a 2-sided test, power of 0.8 and $\alpha$ of 0.05 , twelve observations would be sufficient to detect significant differences in satiety of at least $12 \%$. Based on the above mentioned, we decided to use in this crossover study six subjects, but to repeat each treatment twice in each subject. By repetition of both treatments in each individual, the treatment effect could be estimated with the same precision as compared to a trial with 12 individuals and 1 observation per treatment. The advantage of this design is that it allows for a statistical analysis in which both 
inter-individual as well as between individual variations are estimated. In crossover trials the within individual variation is the most important variation because the treatment difference is estimated within each person. Thus, the current design improves the precision of the determination of the within subject variation. The model used in the ANCOVA analysis (see Data and Statistical Analysis) took the repetition of the treatments per individual into account.

\section{Treatments}

Two treatments were tested. In the "on top" treatment (OT) subjects received orally a fat-free LM (325 ml, $145 \mathrm{kcal}, 0.4 \%$ intrinsic fat) followed by a nasogastric infusion of $4.06 \mathrm{~g}$ high oleic rapeseed oil $\left(4.6 \mathrm{ml}, 36 \mathrm{kcal}\right.$ ) labeled with $77 \mathrm{mg}{ }^{13} \mathrm{C}$-Triolein (glyceryltrioleate with a uniformly labeled ${ }^{13} \mathrm{C}-\mathrm{C} 18: 1$ on the sn-1 position, isotopic enrichment 99\%; Buchem BV, The Netherlands). In the second treatment, "emulsion" (EM), subjects received orally a LM $(325 \mathrm{ml}, 181 \mathrm{kcal}, 1.6 \% \mathrm{fat})$ containing $4.06 \mathrm{~g}$ high oleic rapeseed oil $\left(4.6 \mathrm{ml}\right.$ ) labeled with $77 \mathrm{mg}{ }^{13} \mathrm{C}$-Triolein as a fine emulsion; $4.6 \mathrm{ml}$ saline was infused via the nasogastric tube as a control. All nasogastric infusions were given as bolus infusion within $1 \mathrm{~min}$. In both conditions, $1.5 \mathrm{~g}$ paracetamol was dissolved in the LM immediately and not later than 10 min prior to consumption.

\section{Experimental Protocol}

Two days prior to the intervention subjects were asked to refrain from foods rich in ${ }^{13} \mathrm{C}$ (list provided to participants). In every period the day prior to the intervention the subjects received the same standardized dinner. After dinner, subjects stayed absent from food and caloric beverages and came on each intervention day to the study facility in a fasted state. Subjects arrived at the study facility at least $1.5 \mathrm{~h}$ before their scheduled intervention. Prior to all interventions the subjects were taken to a room equipped with a hospital bed, where a nasogastric tube (Flocare Bengmark, Nutricia, Zoetermeer, The Netherlands) was inserted. To avoid detection of differences between the two types of treatments by the subject as well as investigator the tube was obscured with opaque tape. A cannula was inserted into the antecubital vein of each subjects forearm, and a fasting blood sample was taken ( $t=-15 \mathrm{~min}$ ). Subjects then completed a validated electronic visual analog scale (EVAS) questionnaire to assess satiety related parameters and nausea (see "Measurements"). Subsequently subjects consumed the LM using a straw and were asked to finish the beverage in 5 min. The moment in which the last gulp was swallowed, was considered to be $t=0$ min. Immediately after consumption of the LM, the intragastric infusion (bolus infusion within $1 \mathrm{~min}$ ) of rapeseed oil (condition OT) or saline (condition EM) was performed manually using an obscured syringe taking into account the void volume of the nasogastric tube. At $\mathrm{t}=\mathbf{2 7 0}$ min subjects consumed within $5 \mathrm{~min}$ a standardized, commercially available LM (325 ml, $176 \mathrm{kcal})$. Blood sampling and EVAS 
measurements schedules were as outlined in Figure 9.1. At $\mathrm{t}=480 \mathrm{~min}$, the nasogastric tube and the cannula were removed and subjects departed from the clinic after receiving a macaroni meal.

\section{Preparation of test products}

For this study two LM formulations were produced as referred here to in the following as "fat-free" and "fat emulsion-containing" LM. Both formulations were processed in the pilot plant of Unilever R\&D (Vlaardingen, The Netherlands) by Ultra High Temperature using a 2-stage homogenization process (100 and 40 bar) on a sterilization line connected to an isolator (La Calhene Inc., France) for aseptic filling. All ingredients used were food grade. The ${ }^{13} \mathrm{C}$-labeled high oleic rapeseed oil was prepared by homogenously mixing $6 \mathrm{~g}^{13} \mathrm{C}$-Triolein (glyceryl-trioleate, with uniformly labeled ${ }^{13} \mathrm{C}-\mathrm{C} 18: 1$ on sn-1 position) with $317.5 \mathrm{~g}$ high oleic rapeseed oil (Clear Valley 75 High Oleic Canola Oil, Cargill, USA) using a high shear mixer (Silverson L4RT, UK). Fifteen aliquots of $10 \mathrm{ml}$ were filled into syringes for later administration via the nasogastric tube. The remaining amount was used to produce the fat emulsioncontaining LM. Emulsification of the ${ }^{13} \mathrm{C}$-labeled oil was achieved during processing. The fat-free formulation was processed on the same line in an identical process, but without adding high oleic rapeseed oil to the premix. Oleic acid content of both LM was confirmed using gas chromatography (GC) coupled to a flame ionization detector (FID, see "Analytical measurements". Both LM formulations were filled into $330 \mathrm{ml}$ polyethylene terephthalate (PET) bottles (Amcor PET Packaging N.V; The Netherlands). The fat-free and fat emulsion-containing LM were spiked with paracetamol (acetaminophen, European pharmaceutical grade, Pharmachemie, Haarlem, The Netherlands) at the intervention day by manually dissolving $1.5 \mathrm{~g}$ paracetamol into $325 \mathrm{ml}$ of LM until homogeneity. The nutritional composition of both LM is given in Table 9.1.

Table 9.1 Nutritional composition of the liquid meal (LM)*.

\begin{tabular}{lcc}
\hline Nutritional Facts & $E M$ & $O T$ \\
\hline Serving size - 1 bottle (325 ml) & & \\
Amount per serving & 181 & 145 \\
Energy, $k c a l^{1}$ & 5.4 & 1.35 \\
Fat, $g$ & 4.06 & - \\
- Rapeseed Oil, $g$ & 77 & - \\
- Glyceryl-trioleate $\left({ }^{13}\right.$ C-C18:1 in sn-1), $m g$ & 15.2 & 15.2 \\
Carbohydrates, $g$ & 8.1 & 8.1 \\
- Fructose & 7.1 & 7.1 \\
- Sucrose & 5.0 & 5.0 \\
- Fibre & 15.6 & 15.6 \\
Protein, $g^{1}$ &
\end{tabular}

* Values are calculated based on weighted ingredients 


\section{Analytical Measurements}

\section{Blood sampling}

Venous blood samples $(10 \mathrm{ml})$ were collected into ice-chilled EDTA-treated tubes containing $400 \mathrm{kU}$ aprotinin $\bullet \mathrm{ml}^{-1}$ (Trasylol, Bayer, Germany). Plasma was separated by centrifugation at $3200 \mathrm{rpm}$ for $15 \mathrm{~min}$ at $4{ }^{\circ} \mathrm{C}$ within $30 \mathrm{~min}$ after collection and stored in aliquots at -70 ㅇ C until analyzed.

\section{Paracetamol absorption test for determining GE of the aqueous phase of the meal}

Postprandial plasma paracetamol concentrations were used as an indirect marker for the rate of gastric emptying of the aqueous phase of the $\mathrm{LM}^{29}$. Plasma paracetamol (acetaminophen) concentrations were analyzed with a clinical chemistry analyzer (Roche Hitachi 911 Chemistry Analyzer, Hitachi, Japan) using a clinical chemistry paracetamol test kit (Product No. 03255379, Roche Diagnostics GmbH, Mannheim, Germany) according to the suppliers instructions. The limit of quantification was $1.2 \mu \mathrm{g} \bullet \mathrm{ml}^{-1}$ and the assay was linear up to a concentration of $600 \mu \mathrm{g} \bullet \mathrm{ml}^{-1}$ (7.9-3972 $\mu \mathrm{mol} \bullet \mathrm{I}^{1}$ ) as determined with a commercially available linearity set (Roche Diagnostics $\mathrm{GmbH}$, Mannheim, Germany).

\section{Plasma CCK concentrations}

Plasma CCK concentrations $\left(\mathrm{pmol}^{-1} \mathrm{l}^{-1}\right)$ were determined using an established radioimmunoassay as described previously ${ }^{30}$ with the following modifications. A rabbit antibody binding to all circulating CCK peptides, including sulphated cholecystokinin octapeptide, but not with gastrin was used. ${ }^{125}$ lodine labeling was performed using Bolton-Hunter reagent (PerkinElmer Life Sciences, Inc., Wellesley, MA 02481-4078, USA) and human sulphated CCK-33 (Bachem Holding AG, Bubendorf, Switzerland). Measurement of CCK in plasma requires extraction with ethanol. Separation of bound and unbound label was done using decanting suspension anti-rabbit IgG Sac-Cel@ (IDS Ltd., Boldon, UK). The detection limit of the assay was $0.2 \mathrm{pmol}^{\circ} \mathrm{I}^{-1}$. The intra-assay variation ranges from 3.9 to $9.1 \%$ and the inter-assay variation from 10.4 to $19.9 \%$.

\section{Plasma oleic acid analysis}

Oleic acid plasma concentrations were performed by applying routine techniques using GC analysis (Agilent HP6890 GC equipped with a HP7683 autosampler) coupled to a FID (Agilent, Amstelveen, The Netherlands). The method used was a modification of the boron-trifluoride procedure originally described by Morrison et al. ${ }^{31}$. Data processing was performed using the Totalchrom multi client data system (Perkin Elmer, Norwalk, USA). 
The ${ }^{13} \mathrm{C} /{ }^{12} \mathrm{C}$ ratio of oleic acid (C18:1) in plasma was determined using GC-combustion isotope ratio mass spectrometry (GC-C-IRMS) with a Delta plus/Agilent 6890 instrument (Thermo Fisher Scientific, Bremen, Germany) as described previously ${ }^{32}$ with the exception that a $60 \mathrm{~m} \times 0.32 \mathrm{~mm}$ DB-23 with a film thickness of $0.25 \mu \mathrm{m}$ (J\&W Scientific Inc, Folsom, CA, USA) column was used. The GC temperature programming conditions were optimized to obtain baseline separation between oleic acid methyl ester and other fatty acid methyl esters. C17:0 was added as an internal standard for fatty acid quantification and was used to check the variation of measurements. Calibration samples consisting of mixtures of ${ }^{13} \mathrm{C}-\mathrm{C} 18: 1$ and unlabeled C18:1 were used to convert measured enrichment values to molar enrichments. The molar enrichment was expressed as concentration of ${ }^{13} \mathrm{C}-\mathrm{C} 18: 1$ by multiplying molar percent ${ }^{13} \mathrm{C}-\mathrm{C} 18: 1$ enrichment by the endogenous $\mathrm{C} 18: 1$ plasma concentration $\left(\mu \mathrm{mol} \bullet \mathrm{I}^{-1}\right)$ determined by GC-FID. This resulted in the actual ${ }^{13} \mathrm{C}-\mathrm{C} 18: 1$ concentration expressed in $\left.\mu \mathrm{mol} \bullet\right|^{-1}$.

\section{Appetite perception}

Self-assessed ratings of appetite were monitored using a validated questionnaire on satiety feelings (appetite for a meal, prospective food consumption, fullness, hunger, appetite for a snack, thirst, satiety) immediately prior to and every 30 min after start of the intervention till 480 min. Ratings were made on a hand held computer (iPAQ, Hewlett Packard), using EVAS ${ }^{33}$ anchored at the low end with the most negative or lowest intensity feelings (e.g., extremely unpleasant, not at all), and with opposing terms at the high end (e.g., extremely pleasant, very high, extreme). Volunteers were asked to indicate on a line scale what score on the scale best reflects their feeling at that moment.

\section{Data and Statistical Analysis}

Results are graphically and numerically presented for six subjects with the duplicate measures per treatment included for paracetamol, CCK and appetite perception data. Plasma samples for ${ }^{13} \mathrm{C}-\mathrm{C} 18: 1$ were analyzed per individual for the first intervention per treatment only, i.e. replicate measures per treatment were not available. Thus, data for ${ }^{13} \mathrm{C}-\mathrm{C} 18: 1$ are graphically and numerically presented for six subjects for the first intervention per treatment.

\section{Kinetic analysis}

Individual plasma concentrations versus time data for ${ }^{13} \mathrm{C}-\mathrm{C} 18: 1$ and paracetamol were analyzed in WinNonlin version 5.1 (Pharsight, Mountain View, CA, USA) using non compartmental analysis with lag-time included. The following parameters were derived from this analysis: lag time $\left(T_{\text {lag }}\right)$, maximum concentration $\left(C_{\max }\right)$, time at $C_{\max }$ 
$\left(T_{\max }\right)$, area under the time concentration curve $(A \cup C)$ and mean residence time $(M R T)$. Modeling of the paracetamol data using a one or two compartmental model was not possible in two of the six subjects, since a high variability was observed for the absorption phase of paracetamol. Therefore, in order to determine the half-life of absorption ( $T_{1 / 2}$ absorption $)$ a population based pharmacokinetic analysis using a mixedeffects model was performed using the software R with the package "nlme" (R core team, 2007).

CCK plasma concentrations were plotted against time and the AUC was calculated using the trapezoidal equation. $C_{\max }$ and $T_{\max }$ of CCK were directly derived from the non-modeled data set.

\section{Statistical Analysis}

The statistical analysis was performed using SAS (version 9.1, SAS Institute, Cary, USA). Descriptive analysis consisting of distribution statistics (number of available observations, mean, standard error of the mean and $95 \%$ confidence intervals) is presented for continuous data. The data were further analyzed using analysis of covariance (ANCOVA) with subjects and treatments as main effect. Baseline measurements were used as covariate to correct for individual CCK and satiety levels. The statistical model used took the repetition of the treatments per individual into account. Differences between the treatment group (OT) and the control group (EM) were established on the basis of adjusted means using Fisher's least significance difference (two-tailed). We did not adjust for multiplicity due to testing multiple (secondary) variables. We expected the secondary analyses to support the primary results. A p-value of less than or equal to 0.05 was considered to be statistically significant. Descriptive data are expressed as mean \pm SEM and group analysis data of

${ }^{13} \mathrm{C}-\mathrm{C} 18: 1, \mathrm{CCK}$, satiety, and paracetamol are expressed as adjusted means (LSmeans) \pm SEM.

\section{Results}

\section{Experimental procedures}

The study protocol was well tolerated and completed by all 6 subjects. None of the subjects enrolled withdrew from the study. The nasogastric tube was well positioned in the proximal stomach as controlled by length and auscultation. 


\section{Plasma ${ }^{13} \mathrm{C}-\mathrm{C} 18: 1$ concentration}

${ }^{13} \mathrm{C}-\mathrm{C} 18: 1$ was quantified in total plasma using GC-C-IRMS. The measured maximum enrichments obtained were all $<0.1$ atom $\%$ excess. Time versus ${ }^{13} \mathrm{C}-\mathrm{C} 18: 1$ plasma concentrations for OT and EM are shown in Figure 9.2A (individual data available in supplemental Figure 9.1 in the online supporting material). Baseline ${ }^{13} \mathrm{C}-\mathrm{C} 18: 1$ concentration in plasma did not differ from zero in both treatments. The lag time ( $T_{\text {lag }}$, time between ${ }^{13} \mathrm{C}-\mathrm{C} 18: 1$ administration and the time point where ${ }^{13} \mathrm{C} 18: 1$ concentrations significantly increased above baseline concentration) differed $37 \pm 12$ min between EM and OT and was significantly longer $(p=0.01)$ in OT (Figure 9.2B and Table 9.2). $T_{\max }$ was delayed in OT with a mean difference of $118 \pm 38 \mathrm{~min}$ between EM and OT $(p=0.01)$. No significant differences in $C_{\max }$ and $A U C_{0-480}$ values were detected between EM and OT. The mean residence time (MRT) was increased by approximately $40 \mathrm{~min}$ after OT $\left(\mathrm{p}=0.003\right.$ ) (Table 9.2). Plasma concentrations of ${ }^{13} \mathrm{C}$ C18:1 did not return to baseline in both treatments $8 \mathrm{~h}$ after the label was ingested (Figure 9.2A).
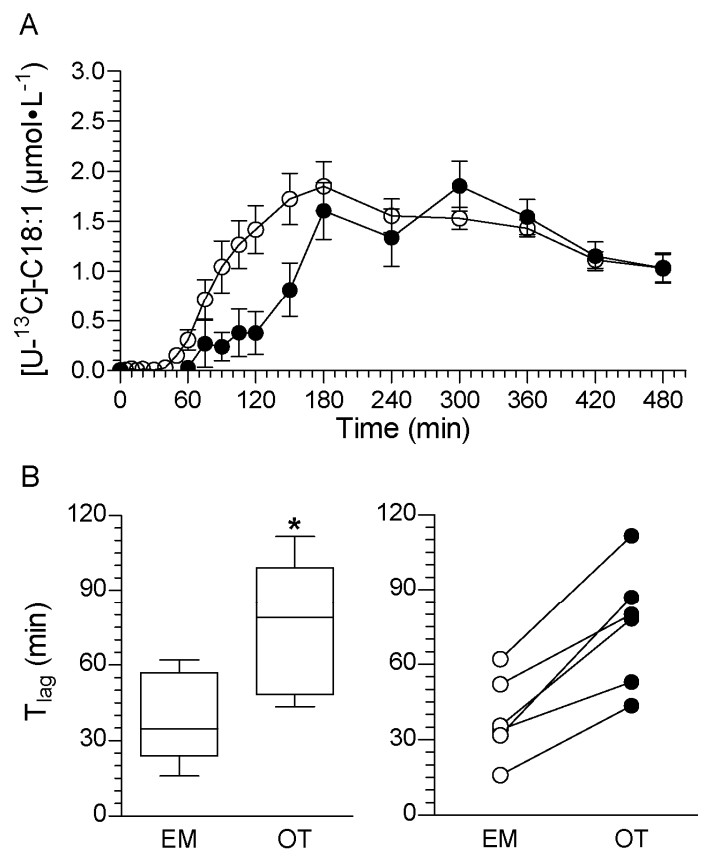

Figure 9.2 Plasma ${ }^{13} \mathrm{C}-\mathrm{C} 18: 1$ kinetics in 6 healthy subjects. (A) Time versus plasma ${ }^{13} \mathrm{C}-\mathrm{C} 18: 1$ concentration after nasogastric application of $4 \mathrm{~g}{ }^{13} \mathrm{C}$-labelled rapeseed oil on top of $325 \mathrm{ml}$ of a liquid meal (OT, filled circles) and after consumption of the same meal containing the labeled rapeseed as an emulsion (EM, open circles). Values are expressed as mean \pm SEM. (B) Mean and individual shift in lag time $\left(T_{\text {lag }}\right)$ in OT (filled circles) and EM (open circles) of absorption of ${ }^{13} \mathrm{C}-\mathrm{C} 18: 1$. 
Table 9.2 ${ }^{13} \mathrm{C}$-C18:1 kinetic parameters in healthy male subjects after consumption of a liquid meal (LM) containing $4 \mathrm{~g}$ rapeseed oil as an emulsion (EM) and after consumption of a fat-free LM and nasogastric application of $4 \mathrm{~g}$ rapeseed oil (OT).*

\begin{tabular}{|c|c|c|c|}
\hline & \multicolumn{3}{|c|}{ Treatment } \\
\hline & $E M$ & OT & $P$ value \\
\hline$T_{\text {Lag }}, \min$ & $37 \pm 7(16-62)$ & $75 \pm 10(53-112)$ & 0.01 \\
\hline$T_{\max }, \min$ & $163 \pm 18(105-240)$ & $280 \pm 34(180-360$ & 0.01 \\
\hline$C_{\max }, \mathrm{pmol} \cdot \Gamma^{1}$ & $1.97 \pm 24(1.34-2.81)$ & $2.12 \pm 0.20(1.51-2.88$ & 0.5 \\
\hline $\boldsymbol{A U C}_{0-480}, \mu \mathrm{mol} \cdot \mathrm{min} \cdot \Gamma^{1}$ & $572 \pm 53(431-697)$ & $494 \pm 65(304-703)$ & 0.2 \\
\hline MRT, $\min$ & $266 \pm 9(244-298)$ & $304 \pm 13(261-349)$ & 0.003 \\
\hline
\end{tabular}

* Values are expressed as means \pm SEM (range)

\section{Plasma CCK concentrations}

Baseline plasma CCK concentrations were not significantly different between both treatments (EM: $0.25 \pm 0.08 \mathrm{pmol} \bullet^{-1}$, OT: $0.40 \pm 0.13 \mathrm{pmol} \bullet \mathrm{L}^{-1} ; \mathrm{p}>0.05$ ). Baseline concentrations had no significant effect on the AUC for plasma CCK concentrations ( $p>0.05$ ). CCK concentrations increased very rapidly and peaked $15 \mathrm{~min}$ after intake of the LM (Figure 9.3A) with no difference in $C_{\text {max-1 }}$ and $T_{\max }$ between EM and OT (Table 9.3). CCK plasma concentrations were numerically higher in OT in comparison to $E M$ between $t=50$ and 480 min after ingestion of the $L M$ and were significantly $(p<0.05)$ elevated at the time points $t=50$ and $t=300 \mathrm{~min}$. The total integrated area under the CCK curve $\left(A \cup C_{0-480}\right)$ was significantly higher for OT than for EM ( $\left.P=0.03\right)$, in particular this effect was more pronounced when integrated for the area $A \cup C_{240-480}$ ( $p=0.01$ ) (Table 9.3). Plasma CCK levels returned to baseline within 60 to 90 min after consumption of the LM. CCK concentrations increased after intake of the $2^{\text {nd }}$ LM with a significant difference in $C_{\text {max-2 }}$ between EM and OT (Figure 9.3A and Table 9.3).

Table 9.3 CCK plasma concentrations in healthy male subjects after consumption of a liquid meal (LM) containing $4 \mathrm{~g}$ rapeseed oil as an emulsion (EM) and after consumption of a fat-free LM and nasogastric application of $4 \mathrm{~g}$ rapeseed oil (OT).*

\begin{tabular}{|c|c|c|c|}
\hline & & tment & \\
\hline & $E M$ & OT & $P$ value \\
\hline $\mathrm{C}_{\max -1}, \mathrm{pmol} \cdot \Gamma^{-1}$ & $1.56 \pm 0.40(0.5-3.2)$ & $1.35 \pm 0.32(0.6-2.6)$ & 0.5 \\
\hline $\mathbf{T}_{\max -1}, \min$ & $12 \pm 2(5-20)$ & $11 \pm 2(5-15)$ & 0.7 \\
\hline $\mathrm{C}_{\max -2}, \mathrm{pmol} \cdot \Gamma^{1}$ & $0.87 \pm 0.16(0.5-1.4)$ & $1.28 \pm 0.26(0.6-2.3)$ & 0.03 \\
\hline $\mathrm{AUC}_{0-480}, \mathrm{pmol} \cdot \min \cdot \Gamma^{-1}$ & $402 \pm 114$ & $519 \pm 114$ & 0.03 \\
\hline $\mathrm{AUC}_{240-480}, \mathrm{pmol} \cdot \mathrm{min} \cdot \digamma^{-1}$ & $232 \pm 61$ & $314 \pm 61$ & 0.01 \\
\hline $\mathrm{AUC}_{0-240}, \mathrm{pmol} \cdot \min \cdot I^{-1}$ & $173 \pm 51$ & $203 \pm 51$ & 0.3 \\
\hline $\mathrm{AUC}_{0-120}, \mathrm{pmol} \cdot \min \cdot \Gamma^{-1}$ & $136 \pm 35$ & $143 \pm 35$ & 0.6 \\
\hline $\mathrm{AUC}_{0-45}, \mathrm{pmol} \cdot \min \cdot l^{-1}$ & $84 \pm 17$ & $67 \pm 17$ & 0.07 \\
\hline
\end{tabular}

* Values are expressed as means $\pm \mathrm{SEM}$ (range) for $C_{\max }$ and $T_{\max }$; AUC values are given as LSmeans $\pm \mathrm{SEM}$. 

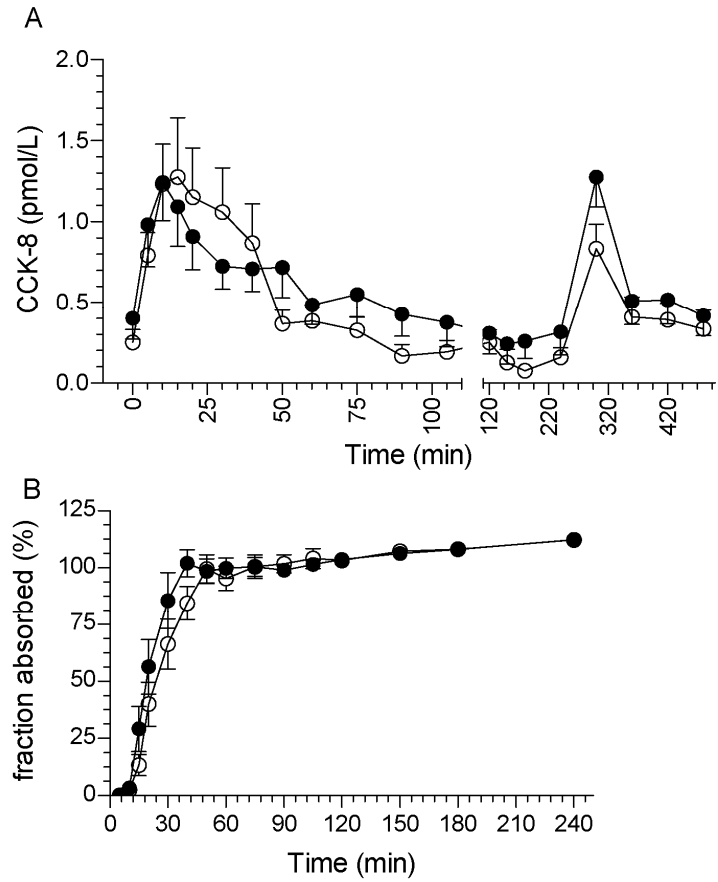

Figure 9.3 Mean ( \pm SEM) plasma concentration of postprandial CCK $(A)$ and the cumulative fraction paracetamol absorbed over time (B) in male subjects following ingestion of a liquid meal $(325 \mathrm{ml}, 145 \mathrm{kcal})$ and nasogastric infusion of $4 \mathrm{~g}$ rapeseed oil (OT, filled circles) and after ingestion of a liquid meal $(325 \mathrm{ml}, 181 \mathrm{kcal})$ containing the rapeseed oil as an emulsion (EM, open circles). In OT and EM the LM was labelled with $1.5 \mathrm{~g}$ paracetamol. In both treatments a commercially available LM (325 ml, $181 \mathrm{kcal})$ was ingested at $\mathrm{t}=270 \mathrm{~min}$. Values are expressed as mean \pm SEM.

\section{Gastric Emptying}

Gastric emptying of the aqueous phase was estimated using the paracetamol absorption test; pharmacokinetic parameters were modeled by non-compartmental analysis of the individual data and using a population based model. In EM and OT, plasma paracetamol concentrations increased very rapidly (Figure 9.3B) with no significant difference in $C_{\max }$ (Table 9.4). $T_{\max }$ was significantly $(\mathrm{P}=0.003$ ) delayed in EM (Table 9.4). There was no difference in the effect of the treatments on other pharmacokinetic parameters such as $T_{1 / 2}$ elimination, $A U C_{0-240}$ and $M R T$ for plasma paracetamol concentrations (Table 9.4). Total gastric emptying, determined as GE half time were not significantly different between EM and OT as derived from the 
cumulative fraction paracetamol absorbed (data not shown). Modeling of the paracetamol concentrations in a population-based analysis revealed that the treatment affected only $T_{1 / 2}$ absorption. The effect of OT on $T_{1 / 2}$ absorption was significant compared to EM ( $p=0.001)$ resulting in a 2.1 times faster absorption of paracetamol in

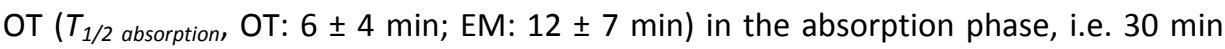
postprandial.

Table 9.4 Paracetamol kinetic measurements in healthy male subjects after consumption of a liquid meal (LM) containing $4 \mathrm{~g}$ rapeseed oil as an emulsion (EM) and after consumption of a fat-free LM and nasogastric administration of $4 \mathrm{~g}$ rapeseed oil (OT).*

\begin{tabular}{|c|c|c|c|}
\hline & \multicolumn{2}{|c|}{ Treatment } & \multirow[b]{2}{*}{$P$ value } \\
\hline & $E M$ & $O T$ & \\
\hline dose paracetamol $g$ & 1.5 & 1.5 & \\
\hline $\mathrm{C}_{\max }, \mu \mathrm{mol} \cdot \Gamma^{-1}$ & $117 \pm 9(59-171)$ & $118 \pm 8(77-169)$ & 1.0 \\
\hline $\mathbf{T}_{\max }, \min$ & $52 \pm 8(20-120)$ & $30 \pm 4(10-60)$ & 0.003 \\
\hline$T_{1 / 2 \text { elimination, }} \min$ & $119 \pm 5(92-144)$ & $121 \pm 9(73-176)$ & 0.8 \\
\hline MRT, $\min$ & $108 \pm 3(94-122)$ & $103 \pm 3(78-119)$ & 0.2 \\
\hline $\mathrm{AUC}_{0-240}, \mu \mathrm{mol} \cdot \min \cdot I^{-1}$ & $12 \pm 2(5-20)$ & $11 \pm 2(5-15)$ & 0.7 \\
\hline$T_{1 / 2 \text { absorption, }} \min$ & $12 \pm 7$ & $6 \pm 4$ & 0.001 \\
\hline
\end{tabular}

* $C_{\max }, T_{\max }, T_{1 / 2}, M R T$ and $A U C$ were calculated using a non-compartment model (WinNonLin version 5.1). Values are expressed as means \pm SEM (range). The $T_{1 / 2}$ of absorption was determined with the software $\mathrm{R}$ with the package nlme (R core team, 2007) using a population based model.

\section{Appetite Perceptions}

Overall, the effects of the treatments on appetite scores were minor (Figure 9.4 and 9.5). Satiety was significantly decreased $(p=0.01)$ in OT when integrated over the whole day $\left(\mathrm{AUC}_{0-480}\right)$ and in particular in the time period after receiving the $2^{\text {nd }} \mathrm{LM}$ $\left(A \cup C_{300-480}\right)$ (Figure 9.5). Self-rated scores of hunger and fullness were not different between OT and EM when integrated over the whole day and the period after the $2^{\text {nd }}$ meal. Although not statistically significant, in the period $A U C_{150-270}$ there was a trend for increased perception of satiety $(p=0.08)$ and fullness $(p=0.07)$, and lower perceptive hunger $(p=0.06)$ in OT compared to EM. 


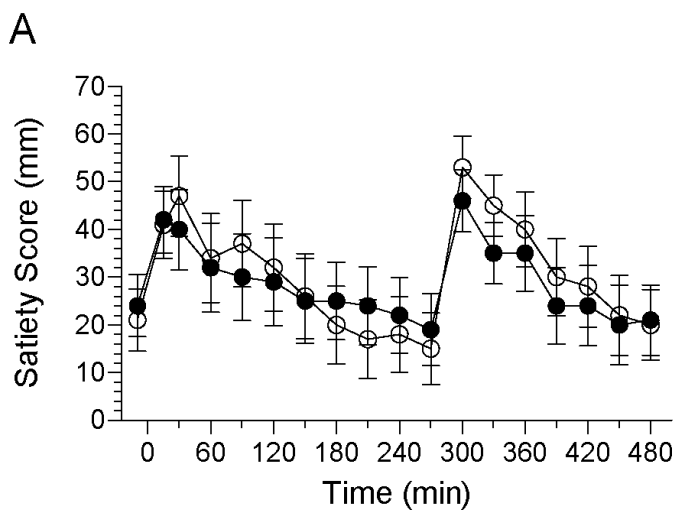

B
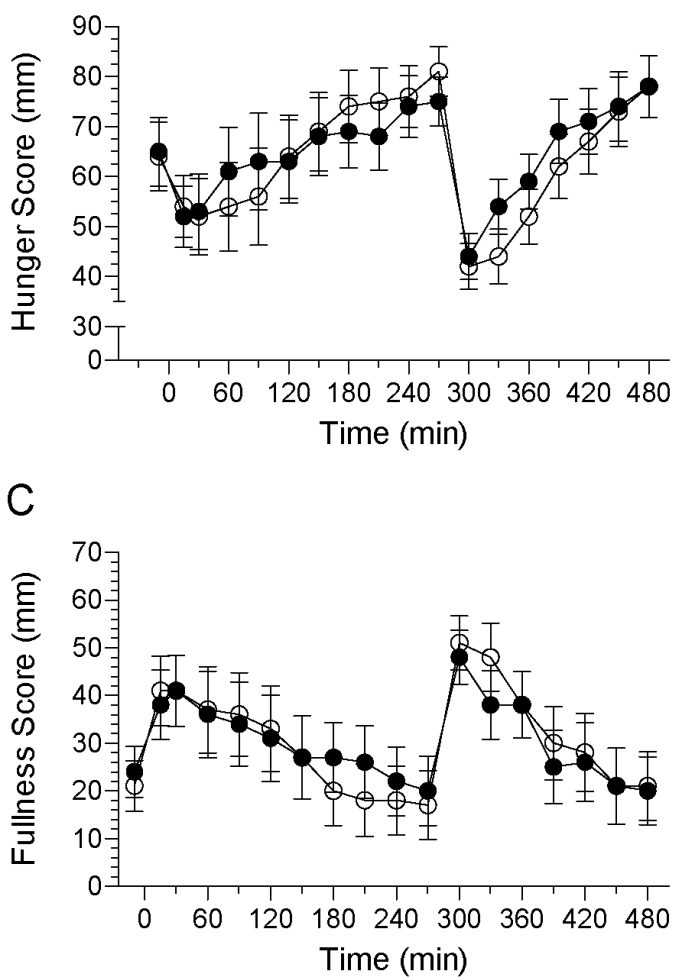

Figure 9.4 Postprandial satiety curves for nasogastrically administered rapeseed oil on top of a liquid meal (LM) (OT, filled circles) and rapeseed oil emulsified in a LM (EM, open circles). In both OT and $E M$ a $2^{\text {nd }} L M$ was ingested at $t=270$ min. The graphs show self-rated scores for satiety (A), hunger (B) and fullness (C). Values are Lsmeans \pm SEM. 
A

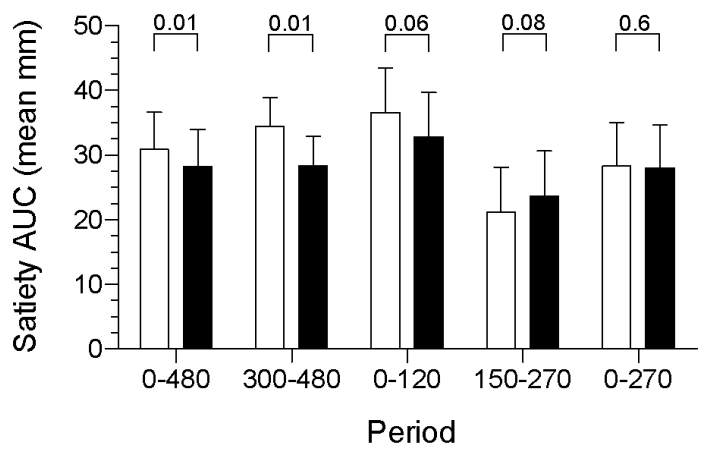

B

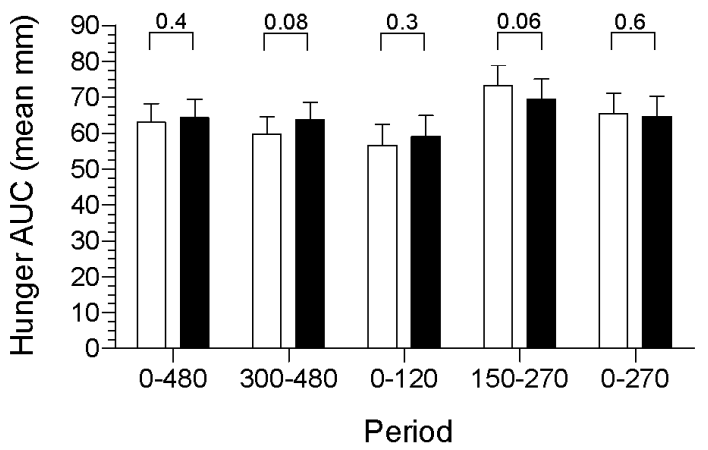

C

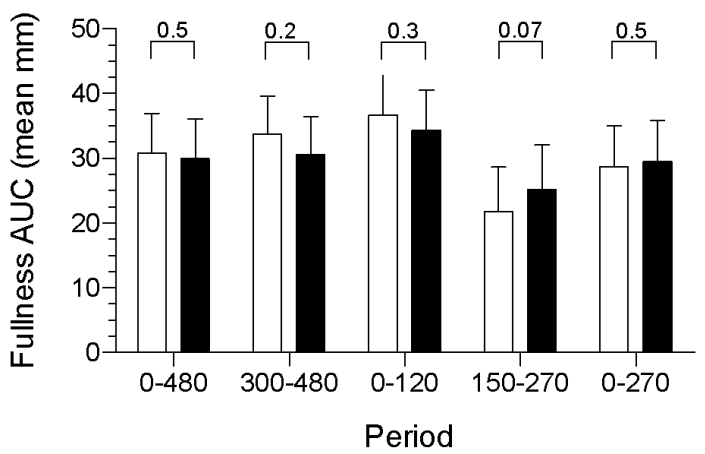

Figure 9.5 Mean weighted satiety scores calculated for various time intervals for OT (filled bars) and EM (open bars) using the data presented in Figure 9.4. P-values for differences between OT and EM were established on the basis of adjusted means using Fisher's least significance difference (two-tailed). 


\section{Discussion}

Structuring of emulsions has been suggested to be useful for weight management purposes ${ }^{25,26,34}$. Postprandial sequential release of lipids from the stomach into the small intestine achieved by food structuring could modulate secretion of gastrointestinal peptides, resulting in an increase in satiety on a calorie-to-calorie basis. We hypothesized that layering of lipids on the aqueous phase of a meal, significantly alters lipid release from the stomach. This will induce changes in CCK, GE and potentially in satiety. The present study demonstrates that very low lipid loads as an integral part of a meal have indeed measurable effects on physiological relevant parameters linked to satiety. The use of markers for determination of lipid absorption and GE of the aqueous phase of the meal in combination with nasogastric intubation to mimic intragastric lipid layering, demonstrated that $4 \mathrm{~g}$ of intragastric layered rapeseed oil affected gastrointestinal physiology. We observed 1) delayed absorption of lipids, 2) initial faster GE of the aqueous phase of the LM and 3) increased postprandial CCK levels. However, the perception of satiety, hunger and fullness was not consistently related to the changes in lipid absorption and CCK throughout the day.

Compared with an equicaloric dose of high oleic rapeseed oil (labeled with ${ }^{13} \mathrm{C}-\mathrm{C} 18: 1$ ) emulsified in a LM (treatment EM), $4 \mathrm{~g}$ of oil when administered via a nasogastric tube on top of a fat-free LM (treatment OT) markedly delayed lipid absorption. The latter was exhibited by a 2-fold increase in $T_{\text {lag }}$ in OT compared to EM. Moreover, also the pulse-time, i.e. the difference between $T_{\max }$ and $T_{\text {lag }}$ was significantly shorter in EM indicating that the bulk of ${ }^{13} \mathrm{C}-\mathrm{C} 18: 1$ reached plasma faster than in the OT group. In addition, the mean time of all ${ }^{13} \mathrm{C}-\mathrm{C} 18: 1$ absorbed residing in plasma (mean residence time, MRT) was in line with the shift in $T_{\text {lag }}$ of about 40 min. This indicates that intestinal delivery and/or absorption of oleic acid occurred in OT at slower rates as compared to EM. The consistently delayed absorption kinetics of oleic acid in OT suggests that the rapeseed oil indeed layered in the stomach and was not mixed with the aqueous phase of the LM by antral grinding, pyloric shearing or low shear in the small intestine. Furthermore, our test conditions would not have favored spontaneous emulsification. At low gastric $\mathrm{pH}$, the protein of the $\mathrm{LM}$ will precipitate and not be available for emulsification processes. All in all this suggests that nasogastric infused lipids stayed as a layer on top of the LM, although very sensitive radiotracer studies combined with scintigraphy would be needed to confirm this.

In our study we achieved layering of the lipid by nasogastric intubation. The question is whether such a separation of lipid from the aqueous phase of the meal can be achieved using food-based approaches. Recent MRI studies point out that a layering effect indeed occurs in vivo after ingestion of high-fat liquid meals. In these studies it was visualized that the lipid forms a layer on top of the aqueous phase. The lipid layer 
markedly accelerated the GE rate as in these studies pure oil in water emulsions were used $^{22,24}$. However, from these studies it is unclear whether the lipid layer consists of layered, but still intact small emulsified lipid droplets (i.e. "creamed droplets or of coalescesed emulsion particles creating larger particles or even a single oil layer. It was also reported in a very recent publication that an in vitro validated, gastric unstable fat emulsion behaved in vivo only partly as an unstable emulsion. A significant part of the oil fraction stayed emulsified in the oil-water meal ${ }^{26}$ suggesting that the creamed oil fraction would at least partly consists of still intact emulsion particles. This is important with respect to the fact that the effect of lipids on inhibition of GE depends on lipid hydrolysis ${ }^{35}$. The degree of gastric lipolysis, which is responsible for up to $25 \%$ of lipid hydrolysis during meal ingestion ${ }^{36,37}$, is strongly dependent on lipid droplet size and micellization. Thus, the inhibition of GE by lipids is most likely not determined only by the rate of emptying of lipid from the stomach but also by the rate and degree of gastric hydrolysis of the lipids. In addition, lingual lipase has been discussed to commence gastric lipid hydrolysis; however, the contribution to overall lipolysis seems to be negligible in humans ${ }^{38-40}$. Taken together this highlights that the effect of nasogastric infusion of rapeseed oil represents an extreme situation of intragastric layering of lipids which most likely can not be achieved in vivo by using gastric unstable emulsions.

Monitoring the intestinal fate of such small amounts of lipids as used in the current study is not possible using the various state-of-the-art MRI technologies. We have therefore chosen to examine emptying of lipids from the stomach indirectly by following plasma concentrations of ${ }^{13} \mathrm{C}$-labeled oleic acid derived from glyceryl- ${ }^{13} \mathrm{C}$ triolein marked rapeseed oil. The observed increase in $T_{\text {lag, }} T_{\max }$ and MRT in the OT treatment could have been caused by 1) a delayed emptying from the stomach, 2) delayed hydrolysis in the gastric and intestinal lumen, 3) prolonged storage in the enterocyte due to delayed chylomicron formation or 4) delayed transport by the lymph. We hypothesize that the deferred ${ }^{13} \mathrm{C}-\mathrm{C} 18: 1$ appearance in plasma was most likely caused by delayed emptying from the stomach and/or retarded gastric and intestinal hydrolysis. This is supported by the faster GE of the LM in the first $30 \mathrm{~min}$ postprandial and by the increased CCK levels $2 \mathrm{~h}$ before ingestion of the second meal in treatment OT. CCK and GE are directly influenced by and strongly dependent on the amount of lipid delivered from the stomach to the duodenum. Absorption of paracetamol was used as a marker of GE of the aqueous phase because of its complete and very fast absorption in the duodenum ${ }^{29}$. The rate constant of absorption was 2.1-fold higher in OT than in EM, reflecting greater inhibition of GE in EM until 30 min postprandial. This was most likely caused by the higher initial caloric outflow induced by the emulsified oil. However, total GE time was not affected by the treatment showing that the inhibition of GE was limited to the early postprandial phase. In line with this, although not statistically significant $(p=0.07)$, was the greater 
AUC value of CCK in EM in the first 45 min after treatment. Concomitantly with the delayed lipid absorption in OT concentrations of CCK were increased 50-90 min postprandial compared to EM. Interestingly, in OT CCK levels were increased after ingestion of the second $L M$ and stayed elevated for the remaining intervention period $\left(A \cup C_{240-480}\right)$. This suggests, but does not confirm, that the second meal provoked hydrolysis of oil retained in the gastrointestinal tract leading to increased CCK concentrations via fatty acid sensing in enteroendocrine cells.

The small, but robust and consistent effect of OT on increased CCK concentrations after the $2^{\text {nd }}$ meal is demonstrated by the individual CCK plasma curves (see supplemental Figure $\mathbf{9 . 2}$ for the individual CCK plasma concentrations). Concurrently ${ }^{13} \mathrm{C}-\mathrm{C} 18: 1$ plasma concentrations increased again after the $2^{\text {nd }}$ meal at $\mathrm{t}=300 \mathrm{~min}$ (Figure 9.3A), although this effect was mainly observed in two of the six subjects. Early triacylglyceride peaks following sequential meals ${ }^{41}$ have been suggested to be partly derived from the previous meal by storage in enterocytes\}. In addition, the contribution of lipids ingested at the previous meal to increase plasma triacylglyceride concentrations after the following meal has been demonstrated recently ${ }^{42}$. In this study lipid ingested at breakfast was partly retained within the stomach/gut and was mobilized after lunch ingestion ${ }^{42}$. Even though it was unclear from these studies whether lipid were stored in the gut lumen or in the enterocytes, our data suggest that in the current study the increase was due to a gastric "wash-out" via the appearance of the $2^{\text {nd }}$ meal causing subsequent increased CCK concentrations.

Although changes in satiety were not a primary outcome of the study, we tested whether changes in biochemical parameters were related to changes in appetite scores. The study however, was not powered to pick up small differences in satiety. With the current design we would have been able to detect statistical significant differences of at least $12 \%$ between the treatments. Thus, the small differences as observed in the current study must be interpreted with care. Notwithstanding the delayed lipid release and concomitantly higher CCK levels, changes in appetite scores were minor and mostly not consistent with changes in CCK. Although CCK is the prototypical satiety hormone, a number of gastrointestinal signals including the peptide hormones PYY and GLP-1 are involved in the regulation of satiety. PYY and GLP-1 are released from more distal cells in the small intestine before nutrients have reached the predominant sites of production possibly by a neural reflex ${ }^{43}$. Possibly, in treatment OT plasma concentrations of GLP-1 and / or PYY were decreased leading to lower satiety as observed over the $8 \mathrm{~h}$ period compared to EM. However, as these hormones were not assessed and as the mean weighted satiety scores differed only by $3 \mathrm{~mm}$ on a $100 \mathrm{~mm}$ scale this remains speculative. We hypothesize that total volume and total energy dominated the satiety perception rather than the intragastric lipid distribution. Perception of satiety is in part modulated by the rate of GE and is at equicaloric loads mainly volume and not macronutrient dependent ${ }^{44}$. The initial GE 
rate of the bulk of the meal differed between both treatments which was reflected by numerical lower satiety scores in OT. The higher CCK levels and the concomitant trend for higher satiety in OT between $t=150$ and 270 min however, can not be attributed to a GE effect as at that time the LM was already emptied ${ }^{23-26,34,44}$. Overall, the marginal effect observed on appetite scores in combination with the slight increase in CCK suggests that the amount of lipid infused was too low in order to exhibit a significant and consistent effect. An escalating dose study should determine which lipid loads are needed in order to achieve physiological meaningful effects on CCK and satiety.

In conclusion, our study demonstrated modest differences in the effects of low, equicaloric doses of oil administered nasogastrically and as fine emulsions both in combination with a LM. Although delivery of $4 \mathrm{~g}$ of oil on top of a LM markedly delayed lipid absorption, plasma CCK concentrations were modestly increased compared to the same amount of oil incorporated as an emulsion into the LM. Intragastric-layered oil, but not emulsified oil, led to an initial increase in GE rate of the aqueous phase. This was most likely due to reduced total energy delivery to the duodenal-jejunal region in the early postprandial phase in the OT study group. Feelings of satiety however were inversely related to lipid absorption and plasma CCK concentrations. Although CCK levels were modestly increased after OT delivery, overall ratings of satiety were lower compared to the emulsion treatment. Although satiety was decreased when integrated over the whole study period ratings of satiety and fullness tended to be higher and ratings of hunger to be lower in OT in the $2 \mathrm{~h}$ before intake of the second meal suggesting that at slightly higher lipid loads the time to return to the hunger baseline can be prolonged. Finally, the current study using physiological doses of lipids lends support to other studies that showed that emulsified lipids behave physically and biochemically different, dependent on the emulsifier type used. It remains to be determined whether higher doses of lipids than were used in the current study mediate changes in both, primary physiological parameters but also in endpoints, i.e. increased CCK and satiety. The present study demonstrates the potential importance of structuring of dietary lipid formulations for controlling hunger. 


\section{References}

1. Anderson JW, Luan J, Hoie LH. Structured weight-loss programs: meta-analysis of weight loss at 24 weeks and assessment of effects of intervention intensity. Adv Ther 2004;21:61-75.

2. Ditschuneit HH, Flechtner-Mors M, Johnson TD, Adler G. Metabolic and weight-loss effects of a longterm dietary intervention in obese patients. Am J Clin Nutr 1999;69:198-204.

3. Womble LG, Williamson DA, Greenway FL, Redmann SM. Psychological and behavioral predictors of weight loss during drug treatment for obesity. Int J Obes Relat Metab Disord 2001;25:340-345.

4. Peters HPF, Mela DJ. The Role of the Gastrointestinal Tract in Satiation, Satiety, and Food Intake: Evidence from Research in Human. In: Harris RBS, Mattes RD, eds. Appetite and food intake: behavioral and physiological considerations. Boca Raton: Taylor \& Francis Group 2008:187-211.

5. Cummings DE, Overduin J. Gastrointestinal regulation of food intake. J Clin Invest 2007;117:13-23.

6. Lal S, McLaughlin J, Barlow J, D'Amato M, Giacovelli G, Varro A, Dockray GJ, Thompson DG. Cholecystokinin pathways modulate sensations induced by gastric distension in humans. Am J Physiol Gastrointest Liver Physiol 2004;287:G72-G79.

7. Raybould HE, Meyer JH, Tabrizi Y, Liddle RA, Tso P. Inhibition of gastric emptying in response to intestinal lipid is dependent on chylomicron formation. Am J Physiol 1998;274:R1834-R1838.

8. Ament ME, Shimoda SS, Saunders DR, Rubin CE. Pathogenesis of steatorrhea in three cases of small intestinal stasis syndrome. Gastroenterology 1972;63:728-747.

9. Borgstrom B, Dahlqvist A, Lundh G, Sjovall J. Studies of intestinal digestion and absorption in the human. J Clin Invest 1957;36:1521-1536.

10. Hunt JN, Knox MT. A relation between the chain length of fatty acids and the slowing of gastric emptying. J Physiol 1968;194:327-336.

11. Feltrin KL, Little TJ, Meyer JH, Horowitz M, Smout AJ, Wishart J, Pilichiewicz AN, Rades T, Chapman IM, Feinle-Bisset C. Effects of intraduodenal fatty acids on appetite, antropyloroduodenal motility, and plasma CCK and GLP-1 in humans vary with their chain length. Am J Physiol Regul Integr Comp Physiol 2004;287:R524-R533.

12. Feltrin KL, Little TJ, Meyer JH, Horowitz M, Rades T, Wishart J, Feinle-Bisset C. Effects of lauric acid on upper gut motility, plasma cholecystokinin and peptide $Y Y$, and energy intake are load, but not concentration, dependent in humans. J Physiol 2007;581:767-777.

13. Little TJ, Doran S, Meyer JH, Smout AJ, O'Donovan DG, Wu KL, Jones KL, Wishart J, Rayner CK, Horowitz M, Feinle-Bisset C. The release of GLP-1 and ghrelin, but not GIP and CCK, by glucose is dependent upon the length of small intestine exposed. Am J Physiol Endocrinol Metab. 2006;291: E647-655.

14. Little TJ, Russo A, Meyer JH, Horowitz M, Smyth DR, Bellon M, Wishart JM, Jones KL, Feinle-Bisset C. Free fatty acids have more potent effects on gastric emptying, gut hormones, and appetite than triacylglycerides. Gastroenterology 2007;133:1124-1131.

15. Meyer JH, Mayer EA, Jehn D, Gu Y, Fink AS, Fried M. Gastric processing and emptying of fat. Gastroenterology 1986;90:1176-1187.

16. Cunningham KM, Baker RJ, Horowitz M, Maddox AF, Edelbroek MA, Chatterton BE. Use of technetium-99m(V)thiocyanate to measure gastric emptying of fat. J Nucl Med 1991;32:878-881.

17. Fried M, Mayer EA, Jansen JB, Lamers CB, Taylor IL, Bloom SR, Meyer JH. Temporal relationships of cholecystokinin release, pancreatobiliary secretion, and gastric emptying of a mixed meal. Gastroenterology 1988;95:1344-1350.

18. Edelbroek M, Horowitz M, Maddox A, Bellen J. Gastric emptying and intragastric distribution of oil in the presence of a liquid or a solid meal. J Nucl Med 1992;33:1283-1290.

19. Jian R, Vigneron N, Najean Y, Bernier JJ. Gastric emptying and intragastric distribution of lipids in man. A new scintigraphic method of study. Dig Dis Sci 1982;27:705-711.

20. Boulby $P$, Gowland P, Adams V, Spiller RC. Use of echo planar imaging to demonstrate the effect of posture on the intragastric distribution and emptying of an oil/water meal. Neurogastroenterol Motil 1997;9:41-47. 
21. Boulby P, Moore R, Gowland P, Spiller RC. Fat delays emptying but increases forward and backward antral flow as assessed by flow-sensitive magnetic resonance imaging. Neurogastroenterol Motil 1999;11:27-36.

22. Kunz $P$, Feinle-Bisset $C$, Faas $H$, Boesiger $P$, Fried $M$, Steingötter A, Schwizer W. Effect of ingestion order of the fat component of a solid meal on intragastric fat distribution and gastric emptying assessed by MRI. J Magn Reson Imaging 2005;21:383-390.

23. Hoad CL, Rayment P, Spiller RC, Marciani L, Alonso Bde C, Traynor C, Mela DJ, Peters HP, Gowland PA. In vivo imaging of intragastric gelation and its effect on satiety in humans. J Nutr 2004;134: 2293-2300.

24. Marciani L, Wickham MS, Bush D, Faulks R, Wright J, Fillery-Travis AJ, Spiller RC, Gowland PA. Magnetic resonance imaging of the behaviour of oil-in-water emulsions in the gastric lumen of man. Br J Nutr 2006;95:331-339.

25. Marciani L, Wickham M, Singh G, Bush D, Pick B, Cox E, Fillery-Travis A, Faulks R, Marsden C, Gowland PA, Spiller RC. Enhancement of intragastric acid stability of a fat emulsion meal delays gastric emptying and increases cholecystokinin release and gallbladder contraction. Am J Physiol Gastrointest Liver Physiol 2007;292:G1607-G1613.

26. Marciani L, Faulks R, Wickham MS, Bush D, Pick B, Wright J, Cox EF, Fillery-Travis A, Gowland PA, Spiller RC. Effect of intragastric acid stability of fat emulsions on gastric emptying, plasma lipid profile and postprandial satiety. Br J Nutr 2009;101:919-928.

27. Van Strien T, Frijters JER, Bergers GPA, Defares PB. The Dutch Eating Behavior Questionnaire (DEBQ) for assessment of restrained, emotional, and external eating behavior. Int J Eat Disord 2008;5:295.

28. Abia R, Pacheco YM, Perona JS, Montero E, Muriana FJ, Ruiz-Gutierrez V. The metabolic availability of dietary triacylglycerols from two high oleic oils during the postprandial period does not depend on the amount of oleic acid ingested by healthy men. J Nutr 2001;131:59-65.

29. Naslund E, Bogefors J, Gryback P, Jacobsson H, Hellstrom PM. Gastric emptying: comparison of scintigraphic, polyethylene glycol dilution, and paracetamol tracer assessment techniques. Scand J Gastroenterol 2000;35:375-379.

30. Lieverse RJ, Masclee AA, Jansen JB, Rovati LC, Lamers CB. Satiety effects of the type A CCK receptor antagonist loxiglumide in lean and obese women. Biol Psychiatry 1995;37:331-335.

31. Morrison WR, Smith LM. Preparation of fatty acid methyl esters and dimethylacetals from lipids with boron fluoride-methanol. J Lipid Res 1964;5:600-608.

32. Nishioka T, Having R, Tazuma S, Stellaard F, Kuipers F, Verkade HJ. Administration of phosphatidylcholine-cholesterol liposomes partially reconstitutes fat absorption in chronically bilediverted rats. Biochim Biophys Acta 2004;1636:90-98.

33. Stratton RJ, Stubbs RJ, Hughes D, King N, Blundell JE, Elia M. Comparison of the traditional paper visual analogue scale questionnaire with an Apple Newton electronic appetite rating system (EARS) in free living subjects feeding ad libitum. Eur J Clin Nutr 1998;52:737-741.

34. Marciani L, Bush D, Wright P, Wickham M, Pick B, Wright J, Faulks R, Fillery-Travis A, Spiller RC, Gowland PA. Monitoring of gallbladder and gastric coordination by EPI. J Magn Reson Imaging 2005;21:82-85.

35. Feinle-Bisset C, Patterson M, Ghatei MA, Bloom SR, Horowitz M. Fat digestion is required for the suppression of ghrelin and stimulation of peptide $Y Y$ and pancreatic polypeptide secretion by intraduodenal lipid. Am J Physiol Endocrinol Metab 2005;289:E948-53.

36. Carriere F, Rogalska E, Cudrey C, Ferrato F, Laugier R, Verger R. In vivo and in vitro studies on the stereoselective hydrolysis of tri- and diglycerides by gastric and pancreatic lipases. Bioorg Med Chem 1997;5:429-435.

37. Carriere F, Barrowman JA, Verger R, Laugier R. Secretion and contribution to lipolysis of gastric and pancreatic lipases during a test meal in humans. Gastroenterology 1993;105:876-888.

38. DeNigris SJ, Hamosh M, Kasbekar DK, Lee TC, Hamosh P. Lingual and gastric lipases: species differences in the origin of prepancreatic digestive lipases and in the localization of gastric lipase. Biochim Biophys Acta 1988;959:38-45. 
39. Moreau H, Laugier R, Gargouri Y, Ferrato F, Verger R. Human preduodenal lipase is entirely of gastric fundic origin. Gastroenterology 1988;95:1221-1226.

40. Hamosh M. Lingual and gastric lipases. Nutrition 1990;6:421-428.

41. Silva KD, Wright JW, Williams CM, Lovegrove JA. Meal ingestion provokes entry of lipoproteins containing fat from the previous meal: possible metabolic implications. Eur J Nutr 2005;44:377-383.

42. Maillot F, Baulieu F, Guilloteau D, Boirie Y, Garrigue MA, Hoinard C, Couet C. Gut emptying affects dietary fat contribution to postprandial lipemia following sequential meals in healthy subjects. Nutrition 2008;24:682-688.

43. Wren AM, Bloom SR. Gut hormones and appetite control. Gastroenterology 2007;132:2116-2130.

44. Goetze O, Steingoetter A, Menne D, van der Voort IR, Kwiatek MA, Boesiger P, Weishaupt D, Thumshirn M, Fried M, Schwizer W. The effect of macronutrients on gastric volume responses and gastric emptying in humans: A magnetic resonance imaging study. Am J Physiol Gastrointest Liver Physiol 2007;292:G11-G17. 


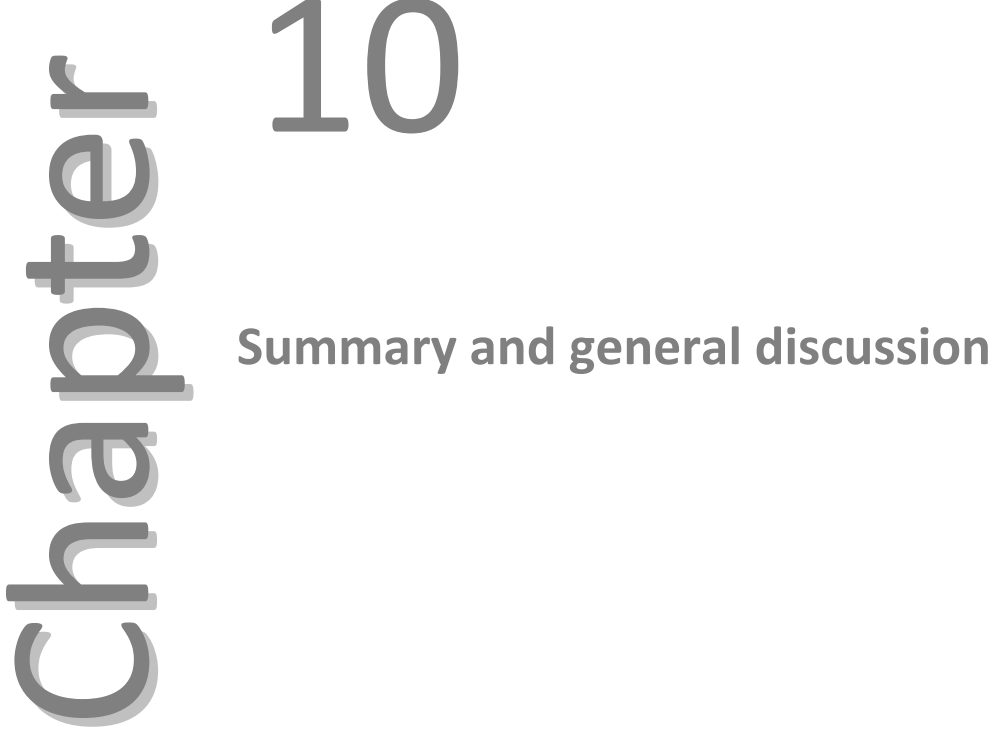

Maljaars J, Masclee AAM 
166 Chapter 10 


\section{Background}

The number of persons with overweight and obesity rapidly increases worldwide. This has led to an increase in research in developing food-based strategies that aim to result in better weight management and weight loss. The most used strategy for weight loss is following a caloric restriction diet. However, due to persistent hunger feelings, compliance to these diets is small. This limits the successfulness of these diets.

The gastrointestinal (GI) tract generates many so-called satiety signals that play a role in the regulation of eating behaviour. The gut is therefore an appealing target for food products to induce an satiety and reduce food intake. Gut peptides, such as CCK and GLP-1, have consistently been demonstrated to reduce food intake and hunger after intravenous administration ${ }^{1-3}$. Food intake increases when an antagonist to these peptides is administrated, pointing towards a physiologic role for these peptides in the regulation of eating behaviour ${ }^{4-6}$. Furthermore, long-term use of a GLP-1 agonist has been shown to reduce body weight in obese individuals ${ }^{7}$. Together, these results illustrate the potential of targeting the gastrointestinal tract in weight management and weight loss strategies.

In order for the different macronutrients (fat, protein, carbohydrates) to influence hunger, food intake and gastrointestinal motor and secretory function, the presence of these nutrients in the small intestine has to be detected, or sensed. Concerning fat, hydrolysis of triacylglycerols (TAG) to fatty acids (FA) is an essential step in this process $^{8}$. Intraluminal fatty acids are sensed by receptors, such as the g-protein coupled receptor-120 (GPR-120), that are present in the intestinal mucosa. Activation of these receptors leads to an intracellular signalling cascade which results in the secretion of a gut peptide or activation of a vagal afferent.

In the small intestine, differences exist in the potency of the different segments in their effects on satiety and food intake. Different studies have suggested that exposure of the ileum, by activating the ileal brake, is the most potent in its effects on satiety and food intake.

In this thesis, we have therefore examined the role that fat-induced ileal brake activation can play in the development of food-based weight management and weight loss strategies. We have used a model in which healthy volunteers were intubated with a $290 \mathrm{~cm}$ long multi lumen naso-ileal catheter. The use of this catheter allowed us to specifically infuse nutrients in the different segments of the small intestine. 


\section{Gastrointestinal satiety signalling}

In Chapters 2 and 3, we reviewed the gastrointestinal mechanisms and peptides that contribute to satiety and food intake. In Chapter 2, we describe that satiety and food intake are influenced by signals from the stomach and signals from the small intestine. Gastric satiety signalling is stimulated by distension of the gastric wall (mechanical stimulus $)^{9,10}$. Previous studies have demonstrated that delaying gastric emptying, by prolonging the distension of the stomach, increases satiety and reduces food intake. Intestinal signals result from nutrient sensing in the gut (chemical stimulus) ${ }^{9}$. The sensing of nutrients leads to activation of neural and humoral pathways. These signals, combined with signals from the stomach, lead to perception of satiety in the brain. We also focussed on the effects of ileal brake activation on hunger and food intake.

In Chapter 3, we have discussed the ileal brake in more detail. The term 'ileal brake' was first defined as a "distal to proximal feedback mechanism to control transit of a meal through the gastrointestinal tract in order to optimise nutrient digestion and absorption"11. Recent studies have pointed to an important role of the ileal brake in the physiological regulation of gastrointestinal function. After a regular size meal, nutrients reach the ileum ${ }^{12,13}$ and entry of nutrients into the ileum was associated with a transition from a fed to a fasted pattern of gastrointestinal motor and secretory function $^{12,14}$.

It is not yet certain which mediators regulate the actions of the ileal brake. At first, attention focused on enteroglucagon and neuroten $\sin ^{15,16}$. Recently, the attention has bend towards Peptide YY (PYY) ${ }^{17}$ and Glucagon-like peptide -1 (GLP-1) ${ }^{18}$. However, a direct neural or neurocrine mechanism may also be involved ${ }^{19}$. Most data on the effects of ileal brake on satiety and food intake have been derived from studying animal models. These data show that infusion of nutrients into the ileum does result in a reduction of food intake ${ }^{20-22}$ and, that this reduction is larger when the nutrients were infused into the ileum compared to infusion in the duodenum ${ }^{23}$. Surgical models, in which a part of the ileum was transposed to the duodenum, demonstrate that increasing ileal exposure to nutrients does indeed reduce food intake and results in weight loss ${ }^{24-26}$, and that the effect of ileal brake activation is maintained over time. Additionally, these studies have demonstrated an improvement in glucose homeostasis after ileal transposition, probably due to GLP-1 secretion ${ }^{25,27}$. Together, these data provide strong evidence that ileal brake activation is an attractive and excellent long term target for weight management and weight loss strategies. 


\section{Ileal brake and satiety}

Few human data have been published with respect to the effects of ileal brake activation on satiety and food intake. In 1985, Welch et al. were the first to demonstrate an inhibitory effect on food intake after delivery of fat to the ileum ${ }^{28}$. In their study, they infused $40 \mathrm{~g}$ of fat into the ileum, which can be considered to be a large dose. Remarkably however, this large dose of fat did not lead to a direct effect on satiety.

Our first aim was therefore to perform a proof-of-principle study to see whether ileal brake activation by a very small fat load would also lead to effects on satiety. Furthermore, we wished to test whether these effects on satiety were dosedependent. Therefore, in the study described in Chapter 4, we compared oral ingestion of $3 \mathrm{~g}$ of fat to ileal infusion of $3 \mathrm{~g}$ and of $10 \mathrm{~g}$ of fat and measured satiety levels. The infusions were scheduled in the physiological postprandial period of maximum ileal exposure to nutrients ${ }^{29}$. In this study, we found that $3 \mathrm{~g}$ of fat did indeed significantly influence satiety. However, no significant difference was found between $3 \mathrm{~g}$ and $10 \mathrm{~g}$. We were therefore not able to demonstrate a dose-dependent effect of ileal fat on satiety. With regard to gastric emptying ${ }^{17}$ and pancreatico-biliary secretion $^{30}$ however, such a dose-dependent effect has previously been demonstrated.

The knowledge that a small dose of fat in the ileum indeed did reduce hunger prompted us to investigate whether the physico-chemical properties of the fat emulsion influences these effects. When fat is infused into the stomach, reducing emulsion droplet size increases fat hydrolysis which results in a delay in gastric emptying $^{31}$. As fat hydrolysis is a crucial step in the effects of fat on satiety, food intake and gastrointestinal motor and secretory function, this suggests that reducing fat droplet size may also affect satiety and food intake. We infused $6 \mathrm{~g}$ of fat either in the duodenum or in the ileum using two different emulsions (Chapter 5). One consisted of small droplets (mean diameter 0.88 micrometer), the other of large droplets (average mean diameter 15.5 micrometer). We found that, when administered in the duodenum, fat droplet size did affect satiety levels, with a stronger reduction in hunger and a further increase in fullness after the smaller droplets. When administered in the ileum, fatty acid sensing was increased after the smaller droplets, as measured by gut peptide secretion. However, this did not lead to an increase in satiety. Droplet size reduced food intake in both the duodenum and in the ileum by $7 \%$. This difference did not reach statistical significance $(p=0.06)$.

When fat is infused into the duodenum, triacylglycerol fatty acid saturation influences food intake ${ }^{32}$. Whether the degree of FA saturation also influences ileal brake 
mediated satiety was unknown. We found (as described in Chapter 6) that compared to control, TAG with predominantly unsaturated FAs increased satiety, whereas TAG with predominantly saturated FAs did not. No significant effects were observed on food intake.

As discussed in Chapter 2 and 3, differences may exist between the proximal and distal small intestine with regard to the potency of the effects of nutrients on satiety and food intake. These data, however, are mainly derived from animal studies. Therefore, we have compared the effects of duodenal and ileal fat infusions on satiety and food intake (Chapter 7). Furthermore, we have tested whether the timing of the infusion, either in the early or in the late postprandial phase, affected these results. We found that, compared to the duodenal fat infusions, the effects of ileal fat on satiety were significantly larger. Furthermore, the effects on satiety were significantly larger after ileal fat infusion in the early vs. the late postprandial phase. No effects were observed on food intake.

From animal studies, we have learned that the effects on a nutrient infusion on food intake $^{23,33}$, but also on gastrointestinal transit ${ }^{34,35}$, can be potentiated by increasing the small intestinal surface area exposed to nutrients. In the study described in Chapter 8 we studied whether increasing the small intestinal surface area exposed to fat would increase the effects on satiety compared to oral ingestion to fat, and how this would relate to ileal fat infusion. In this study, two experiments resulted in an increase in exposed small intestinal surface. In one experiment, all three small intestinal segments (duodenum, jejunum, and ileum) were exposed to fat simultaneously. In the other experiment, the segments were exposed sequentially to fat. As we learned from the study described in Chapter 7 that the effects on an ileal fat infusion on satiety are larger in the early postprandial period, we scheduled all infusions in this study at an earlier time point in the test day. Compared to control, both increasing the exposed surface area to fat in all segments simultaneously, and infusion of fat directly into the ileum significantly reduced hunger, whereas the sequential infusions did not. However, only the ileal fat infusion did significantly reduce food intake.

\section{Gastrointestinal transit}

The ileal brake was initially described as the inhibitory effect of ileal fat infusion on small intestinal (jejunal) transit and motility ${ }^{15,36}$. In the studies described in this thesis, we have measured gastric emptying by stable isotopes, with emptying half time $(t 1 / 2)$ 
as relevant parameter, and small bowel transit time, using the duodenal-coecal transit time. A summary of these results is presented in Table 10.1.

In Chapter 5, we examined the effect of fat emulsion droplet size and found that, in the duodenum, a smaller fat emulsion droplet size was able to inhibit gastric emptying compared to the larger droplets. Studies in animals have demonstrated that the effects of exposure of the distal small intestine on gastrointestinal transit are larger than the signals from the proximal small intestine ${ }^{37}$. In Chapter 7 , we compared gastric emptying and small bowel transit time after equicaloric duodenal and ileal fat infusion. In this study, we observed that inhibition of gastrointestinal transit was more potently inhibited by the ileal vs. the duodenal fat infusion, confirming the results by Lin et al. ${ }^{37}$.

Table 10.1 Gastrointestinal transit.

\begin{tabular}{lccc}
\hline Treatment & Gastric emptying & Small bowel transit \\
\hline Droplet size $\quad$ duodenum & Fine vs. coarse $\downarrow$ & No effect \\
& ileum & n.a. & No effect \\
Location of infusion & lleum $\downarrow$ vs. duodenum & lleum $\downarrow$ vs. duodenum \\
Timing of infusion & n.a. & No effect \\
Fat distribution (surface area) & n.a. & n.a. \\
\hline
\end{tabular}

n.a.: not applicable; this parameter was not assessed. $\downarrow$ denotes extra inhibition of gastric emptying and small bowel transit

\section{Gut peptide secretion}

In this thesis, we evaluated gut peptide secretion upon infusion of different types of fat, at different sites in the small intestine. We have summarized our results in Table 10.2. In this section, we will briefly discuss our findings.

CCK is considered to be a proximal gut peptide. However, in our studies, we found an increase in CCK secretion after ileal fat infusion. As we have demonstrated in Chapter 4, this increase was dose-dependent, and correlated significantly with increases observed in satiety after ileal fat infusion. This may suggest that CCK plays a role in ileal brake mediated satiety. Although the presence of CCK-secreting cells has been demonstrated in the (terminal) ileum ${ }^{38,39}$, secretion of CCK after ileal fat infusion had previously only been demonstrated in animals ${ }^{40}$, and when intrinsic intestinal nerves were severed, CCK-secretion was abolished ${ }^{41}$. This latter finding suggests that, at least in animals, a neural link connecting the distal and proximal small intestine may be involved in secretion of CCK 
Table 10.2 Gut peptide secretion.

\begin{tabular}{lccc}
\hline Treatment & CCK & PYY & GLP-1 \\
\hline Dose-dependency & yes & no & \\
Droplet size duodenum & No effect & No effect & n.a. \\
& Fine vs. coarse $\uparrow \uparrow$ & Fine $\uparrow \uparrow$ & n.a. \\
Location of infusion & Duo $\uparrow$, ileum $\uparrow$ & Duo $\uparrow$, ileum $\uparrow \uparrow$ & n.a. \\
Timing of infusion & n.a. & No effect & n.a. \\
Fat distribution (surface area) & No effect vs. (oral) & No effect vs. (oral) & No effect vs. (oral) \\
& control & control & control \\
\hline
\end{tabular}

n.a.: not applicable; this parameter was not assessed. $\uparrow$ denotes increase in secretion of gut peptide

PYY is considered a candidate mediator peptide for the ileal brake. PYY is a gut peptide, secreted by the enteroendocrine L-cells. The density of these cells increases along the length of the small intestine, with the highest density in the distal small intestine and colon. However, secretion of PYY has repeatedly been demonstrated after duodenal or oral fat administration. In the studies presented in this thesis, we observed an increase in PYY secretion in response to ileal fat infusion. This increase was slightly larger after ileal compared to duodenal fat infusion, and can, after ileal infusion, be increased by reducing emulsion droplet size. We did not find an association between plasma PYY concentrations and satiety, food intake or other ileal brake-related parameters.

Finally, across all studies, the relation between peptide secretion on the one hand and satiety on the other hand has not been consistent. In Chapter 4, we observed a significant correlation between CCK and satiety, but in Chapter 5, a substantial increase in both plasma CCK and PYY was observed without concomitant changes in satiety scores. In Chapter 8 , an increase in satiety was observed without changes in plasma concentrations of GLP-1, CCK and PYY.

Within the gut, multiple satiety signalling mechanisms exist. Of these mechanisms, gut peptide secretion into the systemic circulation is the only one that can be directly measured in humans. Data from previous studies indicates that gut peptides also act local as paracrine or neurocrine agents, and not only as hormone ${ }^{42,43}$. Plasma concentrations of peptides may therefore not truly reflect the local effects of these peptides ${ }^{44}$.

Furthermore, within the small intestine nutrients also have a direct, non-peptidemediated effect on neural afferents that contributes to satiety ${ }^{45}$. These signals, combined with signals from the stomach and gut peptide concentrations are integrated in the satiety centres in the brain, which ultimately leads to the perception of satiety ${ }^{46,47}$. In Chapter 7, we observed that inhibition of gastric emptying was much larger after ileal compared to duodenal fat infusion. We therefore hypothesise that 
the significant effects on satiety found in the studies in this thesis may at least partly be explained by differences in gastric emptying rate, and therefore in gastric distension.

\section{Future perspectives}

In this thesis, we have examined which factors are able to enhance the effects of fatinduced ileal brake activation on satiety and food intake. We have shown that the effects of ileal fat infusion on satiety, food intake and gastrointestinal transit are significantly larger than those of oral fat ingestion or infusion of fat in other small intestinal segments. The type of fat (fatty acid saturation) and emulsion droplet size can significantly affect these results. Furthermore, the timing of exposure of the ileum to fat affects the potency of ileal brake-mediated satiety.

However, questions still remain with regard to the mechanism behind ileal brakemediated satiety and the applicability of ileal brake activation in obese subjects. Another interesting field of study is the potential use of increased ileal brake activation in type 2 diabetes.

As demonstrated in previous studies, ileal perfusion of protein hydrolysate and carbohydrates also leads to activation of the ileal brake ${ }^{16,48}$. However, the effects of ileal infusion of proteins and carbohydrates on satiety have never been tested in humans. As some authors suggest that protein is the macronutrients with the highest satiating potency, investigating the effects of especially protein on ileal brakemediated satiety may be worthwhile.

Another potentially interesting research project would address the observation that, in obese subjects, secretion of both GLP-1 and PYY is reduced compared to healthy controls. This finding is not consistent since other investigators failed to demonstrate any difference between control and obese groups. It is suggested that the presence or absence of reduced insulin sensitivity in obese subjects may play a role in this inconsistency. Therefore, patient (sub)groups should be well defined and phenotyped. Similarly, as both GLP-1 and PYY may play a role in ileal brake-mediated satiety, an eventual reduction in secretion of these peptides may affect the efficacy of ileal brake activation in obese and overweight subjects. Performing a proof-of-principle study in obese subjects in which the effects of ileal brake activation on eating behaviour is tested, is therefore necessary.

The potential of ileal brake activation as a target in the prevention and treatment of obesity and related disorders has been most convincingly demonstrated in animal 
studies employing ileal transposition surgery ${ }^{27}$. In this procedure, a small segment of distal ileum is resected with preservation of innervation and vasculature. This segment is transpositioned more proximal with anastomoses between duodenum and proximal jejunum. Strader et al. demonstrated that ileal transposition not only reduced food intake, but also improved glucose homeostasis ${ }^{27}$ and similar effects have been observed after other bariatric surgical procedures. A potential mechanism and explanation for both these effects is an increase in GLP-1 secretion. GLP-1 is known to reduce food intake and increase satiety in humans, and is assumed to be an important mediator of ileal brake activation. Furthermore, GLP-1 is an incretin that contributes to glucose homeostasis. However, other mechanisms are also being suggested by other authors ${ }^{49,50}$.

A further interesting study object would therefore be to study the effects of ileal brake activation on postprandial glucose concentrations in subjects with reduced insulin sensitivity and in obese subjects. Our intubation model would allow testing different hypotheses (such as increased GLP-1 secretion or duodeno-jejunal exclusion) regarding this rapid improvement in glucose homeostasis.

Apart from these intubation studies, an ex-vivo model may assist in identifying differences between lean subjects, obese subjects and subjects with reduced insulin sensitivity. Furthermore, it may also help in revealing the mechanisms behind these differences.

Ussing chambers, in which a biopsied part of small intestinal mucosa is exposed to nutrients, allow for direct measurement of gut peptides secreted by the mucosa. Furthermore, examination of the tissue after exposure to nutrients enables assessment of processes in these tissues. Exposing the ileal mucosa of lean subjects, obese subjects and subjects with reduced insulin sensitivity will demonstrate whether mucosal factors play a role in the differences in peptide secretion, and examination of mucosal tissue before and after exposure to nutrients may help identify the mechanisms behind these differences.

In conclusion, in this thesis we have shown the potential of increased ileal brake activation as a food target to reduce hunger and food intake. However, not all questions on the mechanism have been resolved. Recent studies have demonstrated the impressive results of ileal interposition surgery on food intake, body weight and glucose homeostasis. These results encourage further studies on the mechanism behind these effects, in order to be able to provide a food-based strategy that can mimic these results.

The use of an intubation model, combined with ex-vivo techniques, can make a valuable contribution to elucidating this mechanism. 


\section{References}

1. Verdich C, Flint A, Gutzwiller JP, Näslund E, Beglinger C, Hellström PM, Long SJ, Morgan LM, Holst JJ, Astrup A. A meta-analysis of the effect of glucagon-like peptide-1 (7-36) amide on ad libitum energy intake in humans. J Clin Endocrinol Metab 2001;86:4382-4389.

2. Lieverse RJ, Jansen JB, van de ZA, Samson L, Masclee AA, Lamers CB. Effects of a physiological dose of cholecystokinin on food intake and postprandial satiation in man. Regul Pept 1993;43:83-89.

3. Lieverse RJ, Jansen JB, Masclee AA, Lamers CB. Satiety effects of a physiological dose of cholecystokinin in humans. Gut 1995;36:176-179.

4. Beglinger C, Degen L, Matzinger D, D'Amato M, Drewe J. Loxiglumide, a CCK-A receptor antagonist, stimulates calorie intake and hunger feelings in humans. Am J Physiol Regul Integr Comp Physiol 2001;280:R1149-R1154.

5. Lieverse RJ, Masclee AA, Jansen JB, Rovati LC, Lamers CB. Satiety effects of the type A CCK receptor antagonist loxiglumide in lean and obese women. Biol Psychiatry 1995;37:331-335.

6. Lieverse RJ, Jansen JB, Masclee AA, Rovati LC, Lamers CB. Effect of a low dose of intraduodenal fat on satiety in humans: studies using the type $A$ cholecystokinin receptor antagonist loxiglumide. Gut 1994;35:501-505.

7. DeFronzo RA, Ratner RE, Han J, Kim DD, Fineman MS, Baron AD. Effects of exenatide (exendin-4) on glycemic control and weight over 30 weeks in metformin-treated patients with type 2 diabetes. Diabetes Care 2005;28:1092-1100.

8. Borovicka J, Schwizer W, Guttmann G, Hartmann D, Kosinski M, Wastiel C, Bischof-Delaloye A, Fried $M$. Role of lipase in the regulation of postprandial gastric acid secretion and emptying of fat in humans: a study with orlistat, a highly specific lipase inhibitor. Gut 2000;46:774-781.

9. Powley TL, Phillips RJ. Gastric satiation is volumetric, intestinal satiation is nutritive. Physiol Behav 2004;82:69-74.

10. Geliebter A. Gastric distension and gastric capacity in relation to food intake in humans. Physiol Behav 1988;44:665-668.

11. Van Citters GW, Lin HC. The ileal brake: a fifteen-year progress report. Curr Gastroenterol Rep 1999; 1:404-409.

12. Keller J, Runzi M, Goebell H, Layer P. Duodenal and ileal nutrient deliveries regulate human intestinal motor and pancreatic responses to a meal. Am J Physiol 1997;272:G632-G637.

13. Borgstrom B, Dahlqvist A, Lundh G, Sjovall J. Studies of intestinal digestion and absorption in the human. J Clin Invest 1957;36:1521-1536.

14. Layer P, Schlesinger T, Groger G, Goebell H. Modulation of human periodic interdigestive gastrointestinal motor and pancreatic function by the ileum. Pancreas 1993;8:426-432.

15. Spiller RC, Trotman IF, Higgins BE, Ghatei MA, Grimble GK, Lee YC, Bloom SR, Misiewicz JJ, Silk DB. The ileal brake--inhibition of jejunal motility after ileal fat perfusion in man. Gut 1984;25:365-374.

16. Read NW, McFarlane A, Kinsman RI, Bates TE, Blackhall NW, Farrar GB, Hall JC, Moss G, Morris AP, O'Neill B, et al. Effect of infusion of nutrient solutions into the ileum on gastrointestinal transit and plasma levels of neurotensin and enteroglucagon. Gastroenterology 1984;86:274-280.

17. Pironi L, Stanghellini V, Miglioli M, Corinaldesi R, De Giorgio R, Ruggeri E, Tosetti C, Poggioli G, Morselli Labate AM, Monetti N, et al. Fat-induced ileal brake in humans: a dose-dependent phenomenon correlated to the plasma levels of peptide YY. Gastroenterology 1993;105:733-739.

18. Schirra J, Goke B. The physiological role of GLP-1 in human: incretin, ileal brake or more? Regul Pept 2005;128:109-115.

19. Van Citters GW, Lin HC. Ileal brake: Neuropeptidergic control of intestinal transit. Curr Gastroenterol Rep 2006;8:367-373.

20. Koopmans HS. The role of the ileum in the control of food intake and intestinal adaptation. Can J Physiol Pharmacol 1990;68:650-655.

21. Glick Z, Modan M. Behavioral compensatory responses to continuous duodenal and upper ileal glucose infusion in rats. Physiol Behav 1977;19:703-705. 
22. Glick Z. Intestinal satiety with and without upper intestinal factors. Am J Physiol 1979;236:R142-R146.

23. Meyer JH, Hlinka M, Tabrizi Y, DiMaso N, Raybould HE. Chemical specificities and intestinal distributions of nutrient-driven satiety. Am J Physiol 1998;275:R1293-R1307.

24. Patriti A, Facchiano E, Annetti C, Aisa MC, Galli F, Fanelli C, Donini A. Early improvement of glucose tolerance after ileal transposition in a non-obese type 2 diabetes rat model. Obes Surg 2005;15: 1258-1264.

25. Strader AD, Vahl TP, Jandacek RJ, Woods SC, D'Alessio DA, Seeley RJ. Weight loss through ileal transposition is accompanied by increased ileal hormone secretion and synthesis in rats. Am J Physiol Endocrinol Metab 2005;288:E447-E453.

26. Strader AD. Ileal transposition provides insight into the effectiveness of gastric bypass surgery. Physiol Behav 2006;88:277-282.

27. Strader AD, Clausen TR, Goodin SZ, Wendt D. Ileal Interposition Improves Glucose Tolerance in Low Dose Streptozotocin-treated Diabetic and Euglycemic Rats. Obes Surg 2009;19:96-104.

28. Welch I, Saunders K, Read NW. Effect of ileal and intravenous infusions of fat emulsions on feeding and satiety in human volunteers. Gastroenterology 1985;89:1293-1297.

29. Goebell H, Klotz U, Nehlsen B, Layer P. Oroileal transit of slow release 5-aminosalicylic acid. Gut 1993; 34:669-675.

30. Keller J, Holst JJ, Layer P. Inhibition of human pancreatic and biliary output but not intestinal motility by physiological intraileal lipid loads. Am J Physiol Gastrointest Liver Physiol 2006;290:G704-G709.

31. Armand M, Pasquier B, André M, Borel P, Senft M, Peyrot J, Salducci J, Portugal H, Jaussan V, Lairon D. Digestion and absorption of 2 fat emulsions with different droplet sizes in the human digestive tract. Am J Clin Nutr 1999;70:1096-1106.

32. French SJ, Conlon CA, Mutuma ST, Arnold M, Read NW, Meijer G, Francis J. The effects of intestinal infusion of long-chain fatty acids on food intake in humans. Gastroenterology 2000;119:943-948.

33. Meyer JH, Tabrizi Y, DiMaso N, Hlinka M, Raybould HE. Length of intestinal contact on nutrient-driven satiety. Am J Physiol 1998;275:R1308-R1319.

34. Lin HC, Doty JE, Reedy TJ, Meyer JH. Inhibition of gastric emptying by sodium oleate depends on length of intestine exposed to nutrient. Am J Physiol 1990;259:G1031-G1036.

35. Lin HC, Doty JE, Reedy TJ, Meyer JH. Inhibition of gastric emptying by glucose depends on length of intestine exposed to nutrient. Am J Physiol 1989;256:G404-G411.

36. Spiller RC, Trotman IF, Adrian TE, Bloom SR, Misiewicz JJ, Silk DB. Further characterisation of the 'ileal brake' reflex in man--effect of ileal infusion of partial digests of fat, protein, and starch on jejunal motility and release of neurotensin, enteroglucagon, and peptide YY. Gut 1988;29:1042-1051.

37. Lin HC, Zhao XT, Wang L. Intestinal transit is more potently inhibited by fat in the distal (ileal brake) than in the proximal (jejunal brake) gut. Dig Dis Sci 1997;42:19-25.

38. Sjolund K, Sanden G, Hakanson R, Sundler F. Endocrine cells in human intestine: an immunocytochemical study. Gastroenterology 1983;85:1120-1130.

39. Capella C., Solcia E., Frigerio B., Buffa R. Endocrine cells of the human intestine. An ultrastructural study. In: Fujita T, editor. Endocrine gut and pancreas.Amsterdam: Elsevier Biomedical; 1976:43-59.

40. Lin HC, Chey WY. Cholecystokinin and peptide YY are released by fat in either proximal or distal small intestine in dogs. Regul Pept 2003;114:131-135.

41. Konturek SJ, Tasler J, Bilski J, de Jong AJ, Jansen JB, Lamers CB. Physiological role and localization of cholecystokinin release in dogs. Am J Physiol 1986;250:G391-G397.

42. Koda S, Date Y, Murakami N, Shimbara T, Hanada T, Toshinai K, Niijima A, Furuya M, Inomata N, Osuye K, Nakazato $\mathrm{M}$. The role of the vagal nerve in peripheral PYY3-36-induced feeding reduction in rats. Endocrinology 2005;146:2369-2375.

43. Abbott CR, Monteiro M, Small CJ, Sajedi A, Smith KL, Parkinson JR, Ghatei MA, Bloom SR. The inhibitory effects of peripheral administration of peptide $Y Y(3-36)$ and glucagon-like peptide-1 on food intake are attenuated by ablation of the vagal-brainstem-hypothalamic pathway. Brain Res 2005;1044:127-131.

44. Maljaars J, Peters HP, Masclee AM. Review article: The gastrointestinal tract: neuroendocrine regulation of satiety and food intake. Aliment Pharmacol Ther 2007;26 Suppl 2:241-50. 
45. Savastano DM, Hayes MR, Covasa M. Serotonin-type 3 receptors mediate intestinal lipid-induced satiation and Fos-like immunoreactivity in the dorsal hindbrain. Am J Physiol Regul Integr Comp Physiol 2007;292:R1063-R1070.

46. Walls EK, Phillips RJ, Wang FB, Holst MC, Powley TL. Suppression of meal size by intestinal nutrients is eliminated by celiac vagal deafferentation. Am J Physiol 1995;269:R1410-R1419.

47. Randich A, Chandler PC, Mebane HC, Turnbach ME, Meller ST, Kelm GR, Cox JE. Jejunal administration of linoleic acid increases activity of neurons in the paraventricular nucleus of the hypothalamus. Am J Physiol Regul Integr Comp Physiol 2004;286:R166-R173.

48. Layer P, Holst JJ, Grandt D, Goebell H. Ileal release of glucagon-like peptide-1 (GLP-1). Association with inhibition of gastric acid secretion in humans. Dig Dis Sci 1995;40:1074-1082.

49. Troy S, Soty M, Ribeiro L, Laval L, Migrenne S, Fioramonti X, Pillot B, Fauveau V, Aubert R, Viollet B, Foretz M, Leclerc J, Duchampt A, Zitoun C, Thorens B, Magnan C, Mithieux G, Andreelli F. Intestinal gluconeogenesis is a key factor for early metabolic changes after gastric bypass but not after gastric lap-band in mice. Cell Metab 2008;8:201-211.

50. Rubino F. Bariatric surgery: effects on glucose homeostasis. Curr Opin Clin Nutr Metab Care 2006; 9:497-507. 



\section{Samenvatting en discussie}

Maljaars J, Masclee AAM 


\section{Achtergrond}

Wereldwijd is sprake van een toename van het aantal personen met overgewicht en obesitas. Dit heeft geleid tot de een toename van onderzoek naar het ontwikkelen van voedsel van verschillende strategieën die behulpzaam zouden kunnen zijn bij 'gewichtsmanagement' en gewichtsverlies. De meest gebruikte behandeling voor overgewicht en obesitas is het volgen van een dieet. Echter, door persisterende hongergevoelens is de therapietrouw vaak gering, wat het resultaat niet ten goede komt. Voedselproducten die meer effect hebben op verzadiging en maaltijdinname dan je op grond van de calorische waarde zou verwachten, zouden een belangrijke rol kunnen spelen bij het verbeteren van de therapietrouw.

Het maag-darmstelsel is de bron van een groot aantal signalen die invloed hebben op hongergevoelens, verzadiging en eetgedrag. Zo leidt intraveneuze toediening van darmpeptiden zoals CCK en GLP-1 tot een vermindering van hongergevoelens en maaltijdinname ${ }^{1-3}$. Omgekeerd neemt de maaltijdinname toe als er een antagonist van deze stoffen wordt toegediend. Dit suggereert dat voornoemde peptiden een rol spelen in de fysiologische regulatie van honger en eetgedrag ${ }^{4-6}$. Daarnaast is aangetoond dat langdurige toediening van een GLP-1 receptor agonist leidt tot gewichtsafname bij obese patiënten ${ }^{7}$. Dit bevestigt de potentiële rol van het maagdarmstelsel in strategieën gericht op gewichtsmanagement en gewichtsverlies.

Voordat macronutriënten (vet, eiwit en koolhydraten) honger, maaltijdinname maar ook maagdarm-motoriek kunnen beïnvloeden, dient de dunne darm de aanwezigheid van deze voedingsstoffen waar te nemen. Bij vetten is aangetoond dat de afbraak van vetten tot vetzeuren een essentiële stap is in dit proces ${ }^{8}$. De aanwezigheid van vetzuren in het lumen van het maagdarmstelsel wordt waargenomen door receptoren die aanwezig zijn in de intestinale mucosa. Activering van deze receptoren leidt tot een intracellulaire signaleringscascade, die uiteindelijk leidt tot ofwel de afgifte van een darmpeptide, ofwel tot activering van een afferent van de N. Vagus.

De dunne darm bestaat uit meerdere segmenten. Studies in zowel mensen als dieren hebben aangetoond dat er verschillen bestaan tussen deze segmenten voor wat betreft de mate waarin ze verzadiging en eetgedrag kunnen beïnvloeden. Blootstelling van het ileum, het meest distale deel van de dunne darm, aan voedingsstoffen lijkt het grootste effect op verzadiging en maaltijdinname te hebben. Dit gebeurt door activering van een mechanisme dat de ileal brake wordt genoemd. 
In de studies beschreven in dit proefschrift hebben we nader onderzoek gedaan naar de mogelijke rol van de ileal brake voor de ontwikkeling van voedingsmiddelen die kunnen worden ingezet in de strijd tegen obesitas en overgewicht. Daarvoor hebben we gebruik gemaakt van een humaan model, waarin bij gezonde vrijwilligers een naso-ileale katheter werd geplaatst. De katheter stelde ons in staat om voedingsstoffen gericht toe te dienen in specifieke segmenten van de dunne darm.

\section{Verzadigingssignalen uit het maag-darmstelsel}

In Hoofdstuk 2 en 3 beschrijven we de gastrointestinale mechanismen en peptiden die een rol spelen bij de regulering van verzadiging en maaltijdinname. In Hoofdstuk 2 beschrijven we dat verzadiging en hongergevoelens beïnvloed worden door signalen uit de maag en uit de dunne darm. Verzadigingssignalen uit de maag worden afgegeven als reactie op uitzetting, ofwel distensie, van de maag ${ }^{9,10}$. Zo is aangetoond dat het vertragen van de lediging van de maag, wat ertoe leidt dat de maag langer uitgezet blijft, leidt tot een toename van verzadiging en een vermindering van maatijdinname. Verzadigingssignalen uit de dunne darm worden afgegeven nadat voedingsstoffen worden waargenomen in de dunne darm ${ }^{9}$. Anders dan in de dunne darm, waar sprake is van een chemische stimulus, is in de maag sprake van een mechanische stimulus. Het opmerken van voedingsstoffen door receptoren in de mucosa van de dunne darm leidt tot activering van een neuraal of humoraal signaal. Deze signalen, samen met die uit de maag, worden gecombineerd in de verzadigingscentra in het brein, waar dit uiteindelijk resulteert in de perceptie van honger en verzadiging.

In Hoofdstuk 3 hebben we ons gericht op de effecten van de ileal brake op verzadiging en maaltijdinname. De term 'ileal brake' werd in eerste instantie gedefinieerd als een "distaal naar proximaal feedback signaal dat de passage van een maaltijd door het maagdarmstelsel reguleert, zodat afbraak en opname van voedingsstoffen geoptimaliseerd wordt" ${ }^{11}$. Studies hebben laten zien dat de ileal brake een belangrijke rol speelt in de fysiologische regulering van de functie van het maag-darmstelsel. Inname van een maaltijd van normale omvang leidt ertoe dat voedingsstoffen het ileum bereiken ${ }^{12,13}$. Bij het bereiken van het ileum wordt het patroon van de maagdarm-peristaltiek omgezet van een post-prandiaal patroon in een nuchter patroon $^{12,14}$.

Het is niet zeker welke peptiden of neurale mechanismen verantwoordelijk zijn voor activering van de ileal brake na blootstelling van het ileum aan voedingsstoffen. Aanvankelijk werd gedacht aan enteroglucagon en neurotensine ${ }^{15,16}$. Recente studies 
richten zich evenwel op PYY ${ }^{17}$ en GLP-1 ${ }^{18}$. Echter, het is goed mogelijk dat een direct neuraal of neuro-endocrien signaal een belangrijke rol speelt ${ }^{19}$. De meeste gegevens over de effecten van ileal brake-activatie op verzadiging en maaltijdinname zijn verkregen door dierexperimenten. Deze studies laten zien dat infusie van voedingsstoffen in het ileum leidt tot een vermindering van de maaltijdinname ${ }^{20-22}$. Tevens hebben deze studies aangetoond dat deze vermindering groter is na infusie van vetten in het ileum dan na infusie van vetten in het duodenum ${ }^{23}$. Chirurgische modellen, waarin een deel van het ileum werd weggenomen en verplaatst naar het duodenum laten inderdaad zien dat deze dieren minder gaan eten en gewicht gaan verliezen ${ }^{24-26}$. Tevens wordt gezien dat dit effect ook in de loop van de tijd blijft bestaan. Verder hebben deze studies laten zien dat de glucose homeostase substantieel verbetert, waarschijnlijk door toename van secretie van glucagon-like peptide-1 (GLP-1 $)^{25,27}$. Op basis van deze onderzoeksresultaten concludeerden wij dat activering van de ileal brake een aantrekkelijk doelwit is voor het creëren van strategieën voor gewichtsmanagement en het bereiken van gewichtsverlies.

\section{Ileal brake en verzadiging}

Er bestaan weinig gegevens over de effecten van ileal brake-activering op verzadiging bij mensen. In 1985 waren Welch et al. de eersten die aantoonden dat infusie van 40 $\mathrm{mg}$ vet in het ileum de maaltijdinname verminderde ${ }^{28}$. Toediening van deze substantiële hoeveelheid vet had geen effect op verzadiging. Ons eerste doel was dan ook het verrichten van een 'proof-of-principle'-studie, om na te gaan of infusie van een kleine hoeveelheid vet in het ileum invloed zou hebben op verzadigingsscores. Tevens wilden we nagaan of de effecten van vet op verzadiging dosisafhankelijk zijn.

In de studie beschreven in Hoofdstuk 4 hebben we het effect op verzadiging van orale inname van 3 gram vet vergeleken met infusie van 3 gram en van 10 gram vet in het ileum. De infusies werden gepland in de periode waarin de fysiologische blootstelling van het ileum aan componenten van een maaltijd maximaal is ${ }^{29}$. Na infusie van 3 gram vet in het ileum nam de verzadiging significant toe, maar een dosis-afhankelijk effect werd niet gezien. Dit, terwijl op maaglediging wel een dosisafhankelijk effect is aangetoond bij vetinfusie in het ileum ${ }^{17}$.

Wetende dat een kleine hoeveelheid vet in het ileum inderdaad effect heeft op verzadiging, zijn we nagegaan of ook de fysisch-chemische eigenschappen van een vetemulsie hierbij een rol spelen. Zo is bijvoorbeeld bekend dat, na infusie in de maag, een kleinere druppelgrootte van een vetemulsie leidt tot een versnelling van de vetafbraak. Dit leidt op zijn beurt weer tot een vertraging van de maaglediging ${ }^{31}$. 
Omdat de gedachte is dat het beïnvloeden van de maaglediging via dezelfde route verloopt als de beïnvloeding van hongergevoelens, suggereert dit dat druppelgrootte ook van invloed kan zijn als gekeken wordt naar de effecten van een vetemulsie op hongergevoelens en maaltijdinname.

In de studie beschreven in Hoofdstuk 5 infundeerden we 6 gram vet in het duodenum of in het ileum. We gebruikten twee verschillende emulsies: In de ene bestond de vetemulsie uit kleine druppels (gemiddeld 0.88 micrometer), in de andere uit grote druppels (gemiddeld 15.5 micrometer). In het duodenum bleek het effect van de kleinere druppels op verzadiging sterker dan van de grote druppels. Na infusie in het ileum nam de vetzuur-sensing, gemeten met een verhoging van plasmaspiegels van darmpeptiden, weliswaar toe, maar dit leidde niet tot een toename van verzadiging.

$\mathrm{Na}$ infusie van vet in het duodenum beïnvloedt de mate van verzadiging van triacylglycerolen (TAG) de grootte van het effect op de maaltijdinname ${ }^{32}$. Of vetzuurverzadiging ook een rol speelt bij ileal brake-gemedieerde verzadigingseffecten was echter onbekend. Uit onze studie (beschreven in Hoofdstuk 6) bleek dat, vergeleken met de controlegroep, triacylglycerolen met overwegend onverzadigde vetzuren hongergevoelens verminderden, terwijl triacylglycerolen met overwegend verzadigde vetzuren dit effect niet hadden. Geen van deze interventies had effect op maaltijdinname.

Zoals aangetoond in Hoofdstukken 2 en 3 lijkt er een verschil te bestaan tussen de proximale en distale dunne darm voor wat betreft de mate waarin ze de maaltijdinname kunnen beïnvloeden. Het probleem is dat deze data voornamelijk afkomstig zijn van dierexperimenteel onderzoek. In Hoofdstuk 7 beschrijven we een humane studie waarin we de effecten van vet in het duodenum en in het ileum op hongergevoelens en maaltijdinname vergelijken. Tevens is geanalyseerd of het tijdstip van de vetinfusie ten opzichte van de maaltijd een rol speelt. Vergeleken met vet in het duodenum leidde vetinfusie in het ileum tot een significante vermindering van hongergevoelens. Daarbij bleek dat de effecten van vetinfusie in het ileum groter waren in de vroege dan in de late postprandiale fase. Geen van de interventies had een significant effect op de maaltijdinname.

Dierexperimenteel werk heeft aangetoond dat de effecten van een vetinfusie in de dunne darm op maaltijdinname $e^{23,33}$ en op maagdarmpassage ${ }^{34,35}$ vergroot kan worden als het dunne darmoppervlak dat blootgesteld wordt aan vet vergroot wordt. In de studie beschreven in Hoofdstuk 8 onderzochten we of een vergroting van het aan vet blootgestelde dunne darmoppervlak zou leiden tot een vergroting van het effect op verzadiging. Daarnaast werd bekeken hoe dit zich verhoudt tot het effect van 
vetinfusie in het ileum. Twee van de interventies leidden tot een vergroot blootgesteld dunne darm-oppervlak: in de ene interventie werden de drie dunne darmsegmenten simultaan blootgesteld aan vet, in de andere werden deze dunne darmsegmenten sequentieel blootgesteld aan vet.

Nadat we in hoofdstuk 7 geleerd hadden dat de effecten van een vetinfusie op de maaltijdinname groter zijn in de vroege postprandiale fase, werden alle infusies vroeg in de testdag gepland. Vergeleken met het controle-experiment leidde zowel de ileum-infusie als de simultane infusie tot een toename van verzadiging. Echter, alleen de ileum-infusie resulteerde in een significante vermindering van de maaltijdinname. Deze afname bedroeg $15 \%$.

\section{Maag-darmpassage}

De ileal brake werd initieel beschreven als het remmende effect van vetinfusie in het ileum op de dunne darmmotoriek en de dunne darm passagetijd ${ }^{15,36}$. In de studies beschreven in dit proefschrift hebben we de maaglediging gemeten door middel van stabiele isotopen met de halfledigingstijd als relevante parameter. Daarnaast hebben we de dunne darm passagetijd gemeten met behulp van de lactulose $\mathrm{H} 2$ ademtest. Een samenvatting van deze resultaten wordt gegeven in Tabel 11.1.

Tabel 11.1 Maagdarm passage.

\begin{tabular}{llll}
\hline experiment & & Maaglediging & Dunne darmpassage \\
\hline druppelgrootte & duodenum & klein vs. groot $\downarrow$ & geen effect \\
& ileum & n.v.t. & geen effect \\
loactie van infusie & lleum $\downarrow$ vs. duodenum & lleum $\downarrow$ vs. duodenum \\
Timing van infusie & n.v.t. & geen effect \\
vetverdeling (oppervlakte) & n.v.t. & n.v.t. \\
\hline
\end{tabular}

n.v.t.: niet van toepassing; deze parameter is niet getest; $\downarrow$ duidt een extra remming van maaglediging of dunne darmpassage aan.

In Hoofdstuk 5 laten we zien dat, na infusie in het duodeum, een kleinere druppelgrootte leidt tot een significant langere maag halfledigingstijd vergeleken met grotere druppels. Dit is waarschijnlijk het gevolg van het versneld verlopen van de vetafbraak doordat een groter emulsieoppervlak beschikbaar is voor hydrolyse. In Hoofdstuk 7 tonen we aan dat de effecten van vetinfusie in het ileum op maaglediging en dunne darmpassage beduidend groter zijn dan die van vetinfusie in het duodenum. Dit bevestigt de resultaten van dierstudies van Lin et al. ${ }^{37}$. 


\section{Secretie van darmpeptiden}

In de in dit proefschrift beschreven studies hebben we bestudeerd hoe de secretie van darmpeptiden verloopt na infusie van verschillende typen vet in verschillende delen van de dunne darm. Onze bevindingen zijn samengevat in Tabel 11.2.

Table 11.2 Secretie van darmpeptiden.

\begin{tabular}{|c|c|c|c|}
\hline Experiment & CCK & PYY & GLP-1 \\
\hline Dosis afhankelijk & ja & no & \\
\hline Druppelgrootte duodenum & geen effect & geen effect & n.v.t. \\
\hline ileum & klein vs groot $\uparrow \uparrow$ & klein vs groot $\uparrow \uparrow$ & n.v.t. \\
\hline Locatie van infusie & $\begin{array}{c}\text { duodenum } \uparrow \uparrow, ~ \\
\text { ileum } \uparrow\end{array}$ & $\begin{array}{c}\text { duodenum } \uparrow, \\
\text { ileum } \uparrow \uparrow\end{array}$ & n.v.t. \\
\hline Timing van de infusie & geen effect & geen effect & n.v.t. \\
\hline Vet verdeling (oppervlak) & $\begin{array}{l}\text { geen effect vs. } \\
\text { controle }\end{array}$ & $\begin{array}{l}\text { geen effect vs. } \\
\text { controle }\end{array}$ & $\begin{array}{c}\text { geen effect vs. } \\
\text { controle }\end{array}$ \\
\hline
\end{tabular}

n.v.t.: niet van toepassing; deze parameter is niet getest; $\uparrow$ staat voor toegenomen secretie van het genoemde peptide.

CCK wordt beschouwd als een darmpeptide dat voornamelijk wordt afgegeven door de proximale dunne darm. Echter, in onze studies zagen we regelmatig een toename van CCK secretie na infusie van vet in het ileum. Zoals aangetoond in Hoofdstuk 4 was de toename in secretie zelfs dosisafhankelijk en correleerde zij significant met de effecten op verzadiging na vetinfusie in het ileum. Dit suggereert dat CCK mogelijk een rol speelt bij ileal brake-gemedieerde verzadiging. Hoewel de aanwezigheid van CCKsecernerende cellen in het (terminale) ileum is aangetoond $d^{38,39}$ is secretie van CCK na vetinfusie in het ileum alleen geobserveerd in dierstudies ${ }^{40}$. In een soortgelijke studie leidde het doornemen van de intrinsieke zenuwvezels in de dunne darm ertoe dat de afgifte van CCK verdween ${ }^{41}$. Dit suggereert dat een neurale verbinding tussen de proximale en distale dunne darm een rol zou kunnen spelen bij de secretie van CCK .

PYY is een darmpeptide dat wordt uitgescheiden door enteroendocriene L-cellen, die zich met name in het distale deel van de darm bevinden. Echter, secretie van PYY wordt ook aangetoond na orale inname of duodenale toediening van vet. In de studies in dit proefschrift zien we een toename van PYY-secretie na vetinfusie in de dunne darm. De secretie van PYY is iets groter na infusie van vet in het ileum dan na infusie van vet in het duodenum. Tevens neemt bij infusie van vet in het ileum de secretie van PYY toe wanneer de druppelgrootte van de emulsie verkleind wordt. Een correlatie tussen plasma PYY concentraties en verzadiging of maaltijdinname werd niet gevonden. 
Tenslotte kan geconcludeerd worden dat de relatie tussen secretie van darmpeptiden aan de ene kant en verzadiging aan de andere kant niet consistent is. In Hoofdstuk 4 is een significante correlatie tussen CCK en verzadiging gevonden, terwijl in Hoofdstuk 5 een significante stijging van CCK en PYY concentraties niet leidt tot een significant effect op verzadiging. In Hoofdstuk 8 zien we weliswaar significante effecten op verzadiging, maar dit gaat niet gepaard met verschillen in peptidesecretie.

In de darm bestaan verschillende mechanismen die kunnen leiden tot beïnvloeding van verzadiging en maaltijdinname ${ }^{42,43}$. Van deze mechanismen zijn plasmaconcentraties van darmpeptiden de enigen die rechtstreeks te meten zijn in mensen. Eerdere studies hebben laten zien dat darmpeptiden ook een lokaal (paracrien of neurocrien) effect kunnen hebben. De plasmaconcentraties van deze peptiden zijn derhalve mogelijk geen adequate weerspiegeling van de lokale effecten van deze peptiden ${ }^{44}$. Daarnaast hebben voedingsstoffen in de dunne darm ook een direct, niet peptide afhankelijk effect op neurale afferenten die een bijdrage kunnen leveren aan verzadiging $^{45}$. Deze signalen, gecombineerd met signalen uit de maag en met lokale of plasmaconcentraties van darmpeptiden, worden in de verzadigingscentra in het brein gecombineerd en geïntegreerd, en dit leidt uiteindelijk tot de perceptie van verzadiging. Onze hypothese is dan ook dat de significante verschillen die gevonden zijn in de studies in dit proefschrift in ieder geval gedeeltelijk verklaard kunnen worden door verschillen in maaglediging en daarmee in maagdistensie.

\section{Conclusie}

In dit proefschrift hebben we onderzocht welke factoren van belang zijn om het effect van de vet-afhankelijke activering van de ileal brake op verzadiging en maaltijdinname te vergroten. We hebben aangetoond dat vetzuurverzadiging een belangrijke rol kan spelen, net als de gemiddelde druppelgrootte van een vetemulsie. Daarnaast is aangetoond dat het tijdstip van de infusie ten opzichte van de maaltijd een belangrijke rol speelt. Bovengenoemde onderzoeksresultaten laten zien dat de ileal brake een interessant doelwit is voor het ontwikkelen van voedingsmiddelen die een rol kunnen spelen in de strijd tegen obesitas en overgewicht. 


\section{Referenties}

1. Verdich C, Flint A, Gutzwiller JP, Näslund E, Beglinger C, Hellström PM, Long SJ, Morgan LM, Holst JJ, Astrup A. A meta-analysis of the effect of glucagon-like peptide-1 (7-36) amide on ad libitum energy intake in humans. J Clin Endocrinol Metab 2001;86:4382-4389.

2. Lieverse RJ, Jansen JB, van de ZA, Samson L, Masclee AA, Lamers CB. Effects of a physiological dose of cholecystokinin on food intake and postprandial satiation in man. Regul Pept 1993;43:83-89.

3. Lieverse RJ, Jansen JB, Masclee AA, Lamers CB. Satiety effects of a physiological dose of cholecystokinin in humans. Gut 1995;36:176-179.

4. Beglinger C, Degen L, Matzinger D, D'Amato M, Drewe J. Loxiglumide, a CCK-A receptor antagonist, stimulates calorie intake and hunger feelings in humans. Am J Physiol Regul Integr Comp Physiol 2001;280:R1149-R1154.

5. Lieverse RJ, Masclee AA, Jansen JB, Rovati LC, Lamers CB. Satiety effects of the type A CCK receptor antagonist loxiglumide in lean and obese women. Biol Psychiatry 1995;37:331-335.

6. Lieverse RJ, Jansen JB, Masclee AA, Rovati LC, Lamers CB. Effect of a low dose of intraduodenal fat on satiety in humans: studies using the type $A$ cholecystokinin receptor antagonist loxiglumide. Gut 1994;35:501-505.

7. DeFronzo RA, Ratner RE, Han J, Kim DD, Fineman MS, Baron AD. Effects of exenatide (exendin-4) on glycemic control and weight over 30 weeks in metformin-treated patients with type 2 diabetes. Diabetes Care 2005;28:1092-1100.

8. Borovicka J, Schwizer W, Guttmann G, Hartmann D, Kosinski M, Wastiel C, Bischof-Delaloye A, Fried M. Role of lipase in the regulation of postprandial gastric acid secretion and emptying of fat in humans: a study with orlistat, a highly specific lipase inhibitor. Gut 2000;46:774-781.

9. Powley TL, Phillips RJ. Gastric satiation is volumetric, intestinal satiation is nutritive. Physiol Behav 2004;82:69-74.

10. Geliebter A. Gastric distension and gastric capacity in relation to food intake in humans. Physiol Behav 1988;44:665-668.

11. Van Citters GW, Lin HC. The ileal brake: a fifteen-year progress report. Curr Gastroenterol Rep 1999; 1:404-409.

12. Keller J, Runzi M, Goebell H, Layer P. Duodenal and ileal nutrient deliveries regulate human intestinal motor and pancreatic responses to a meal. Am J Physiol 1997;272:G632-G637.

13. Borgstrom B, Dahlqvist A, Lundh G, Sjovall J. Studies of intestinal digestion and absorption in the human. J Clin Invest 1957;36:1521-1536.

14. Layer P, Schlesinger T, Groger G, Goebell H. Modulation of human periodic interdigestive gastrointestinal motor and pancreatic function by the ileum. Pancreas 1993;8:426-432.

15. Spiller RC, Trotman IF, Higgins BE, Ghatei MA, Grimble GK, Lee YC, Bloom SR, Misiewicz JJ, Silk DB. The ileal brake--inhibition of jejunal motility after ileal fat perfusion in man. Gut 1984;25:365-374.

16. Read NW, McFarlane A, Kinsman RI, Bates TE, Blackhall NW, Farrar GB, Hall JC, Moss G, Morris AP, O'Neill $B$, et al. Effect of infusion of nutrient solutions into the ileum on gastrointestinal transit and plasma levels of neurotensin and enteroglucagon. Gastroenterology 1984;86:274-280.

17. Pironi L, Stanghellini V, Miglioli M, Corinaldesi R, De Giorgio R, Ruggeri E, Tosetti C, Poggioli G, Morselli Labate AM, Monetti N, et al. Fat-induced ileal brake in humans: a dose-dependent phenomenon correlated to the plasma levels of peptide YY. Gastroenterology 1993;105:733-739.

18. Schirra J, Goke B. The physiological role of GLP-1 in human: incretin, ileal brake or more? Regul Pept 2005;128:109-115.

19. Van Citters GW, Lin HC. Ileal brake: Neuropeptidergic control of intestinal transit. Curr Gastroenterol Rep 2006;8:367-373.

20. Koopmans HS. The role of the ileum in the control of food intake and intestinal adaptation. Can J Physiol Pharmacol 1990;68:650-655.

21. Glick Z, Modan M. Behavioral compensatory responses to continuous duodenal and upper ileal glucose infusion in rats. Physiol Behav 1977;19:703-705. 
22. Glick Z. Intestinal satiety with and without upper intestinal factors. Am J Physiol 1979;236:R142-R146.

23. Meyer JH, Hlinka M, Tabrizi Y, DiMaso N, Raybould HE. Chemical specificities and intestinal distributions of nutrient-driven satiety. Am J Physiol 1998;275:R1293-R1307.

24. Patriti A, Facchiano E, Annetti C, Aisa MC, Galli F, Fanelli C, Donini A. Early improvement of glucose tolerance after ileal transposition in a non-obese type 2 diabetes rat model. Obes Surg 2005;15: 1258-1264.

25. Strader AD, Vahl TP, Jandacek RJ, Woods SC, D'Alessio DA, Seeley RJ. Weight loss through ileal transposition is accompanied by increased ileal hormone secretion and synthesis in rats. Am J Physiol Endocrinol Metab 2005;288:E447-E453.

26. Strader AD. Ileal transposition provides insight into the effectiveness of gastric bypass surgery. Physiol Behav 2006;88:277-282.

27. Strader AD, Clausen TR, Goodin SZ, Wendt D. Ileal Interposition Improves Glucose Tolerance in Low Dose Streptozotocin-treated Diabetic and Euglycemic Rats. Obes Surg 2009;19:96-104.

28. Welch I, Saunders K, Read NW. Effect of ileal and intravenous infusions of fat emulsions on feeding and satiety in human volunteers. Gastroenterology 1985;89:1293-1297.

29. Goebell H, Klotz U, Nehlsen B, Layer P. Oroileal transit of slow release 5-aminosalicylic acid. Gut 1993; 34:669-675.

30. Pilichiewicz AN, Papadopoulos P, Brennan IM, Little TJ, Meyer JH, Wishart JM, Otto B, Horowitz M, Feinle-Bisset F. Load-dependent effects of duodenal lipid on antropyloroduodenal motility, plasma CCK and PYY, and energy intake in healthy men. Am J Physiol Regul Integr Comp Physiol 2007 Oct 17.

31. Armand $M$, Pasquier B, André M, Borel P, Senft M, Peyrot J, Salducci J, Portugal H, Jaussan V, Lairon D. Digestion and absorption of 2 fat emulsions with different droplet sizes in the human digestive tract. Am J Clin Nutr 1999;70:1096-1106.

32. French SJ, Conlon CA, Mutuma ST, Arnold M, Read NW, Meijer G, Francis J. The effects of intestinal infusion of long-chain fatty acids on food intake in humans. Gastroenterology 2000;119:943-948.

33. Meyer JH, Tabrizi Y, DiMaso N, Hlinka M, Raybould HE. Length of intestinal contact on nutrient-driven satiety. Am J Physiol 1998;275:R1308-R1319.

34. Lin HC, Doty JE, Reedy TJ, Meyer JH. Inhibition of gastric emptying by sodium oleate depends on length of intestine exposed to nutrient. Am J Physiol 1990;259:G1031-G1036.

35. Lin HC, Doty JE, Reedy TJ, Meyer JH. Inhibition of gastric emptying by glucose depends on length of intestine exposed to nutrient. Am J Physiol 1989;256:G404-G411.

36. Spiller RC, Trotman IF, Adrian TE, Bloom SR, Misiewicz JJ, Silk DB. Further characterisation of the 'ileal brake' reflex in man--effect of ileal infusion of partial digests of fat, protein, and starch on jejunal motility and release of neurotensin, enteroglucagon, and peptide YY. Gut 1988;29:1042-1051.

37. Lin HC, Zhao XT, Wang L. Intestinal transit is more potently inhibited by fat in the distal (ileal brake) than in the proximal (jejunal brake) gut. Dig Dis Sci 1997;42:19-25.

38. Sjolund K, Sanden G, Hakanson R, Sundler F. Endocrine cells in human intestine: an immunocytochemical study. Gastroenterology 1983;85:1120-1130.

39. Capella C., Solcia E., Frigerio B., Buffa R. Endocrine cells of the human intestine. An ultrastructural study. In: Fujita T, editor. Endocrine gut and pancreas.Amsterdam: Elsevier Biomedical; 1976:43-59.

40. Lin HC, Chey WY. Cholecystokinin and peptide YY are released by fat in either proximal or distal small intestine in dogs. Regul Pept 2003;114:131-135.

41. Konturek SJ, Tasler J, Bilski J, de Jong AJ, Jansen JB, Lamers CB. Physiological role and localization of cholecystokinin release in dogs. Am J Physiol 1986;250:G391-G397.

42. Koda S, Date Y, Murakami N, Shimbara T, Hanada T, Toshinai K, Niijima A, Furuya M, Inomata N, Osuye K, Nakazato $\mathrm{M}$. The role of the vagal nerve in peripheral PYY3-36-induced feeding reduction in rats. Endocrinology 2005;146:2369-2375.

43. Abbott CR, Monteiro M, Small CJ, Sajedi A, Smith KL, Parkinson JR, Ghatei MA, Bloom SR. The inhibitory effects of peripheral administration of peptide $Y Y(3-36)$ and glucagon-like peptide-1 on food intake are attenuated by ablation of the vagal-brainstem-hypothalamic pathway. Brain Res 2005;1044:127-131. 
44. Maljaars J, Peters HP, Masclee AM. Review article: The gastrointestinal tract: neuroendocrine regulation of satiety and food intake. Aliment Pharmacol Ther 2007;26 Suppl 2:241-50.

45. Savastano DM, Hayes MR, Covasa M. Serotonin-type 3 receptors mediate intestinal lipid-induced satiation and Fos-like immunoreactivity in the dorsal hindbrain. Am J Physiol Regul Integr Comp Physiol 2007;292:R1063-R1070. 
List of publications 


\section{List of publications}

The gastrointestinal tract: neuroendocrine regulation of satiety and food intake. Maljaars J, Peters HP, Masclee AM.

Aliment Pharmacol Ther. 2007 Dec;26 Suppl 2:241-50. Review.

Ileal brake: a sensible food target for appetite control. A review.

Maljaars PW, Peters HP, Mela DJ, Masclee AA.

Physiol Behav. 2008 Oct 20;95(3):271-81. Epub 2008 Jul 21. Review.

Effect of ileal fat perfusion on satiety and hormone release in healthy volunteers. Maljaars PW, Symersky T, Kee BC, Haddeman E, Peters HP, Masclee AA. Int J Obes (Lond). 2008 Nov;32(11):1633-9.

Effect of fat saturation on satiety, hormone release, and food intake. Maljaars J, Romeyn EA, Haddeman E, Peters HP, Masclee AA. Am J Clin Nutr. 2009 Apr;89(4):1019-24.

The effect of lipid droplet size on satiety and food intake is intestinal site-specific Maljaars PWJ, van der Wal RJP, Wiersma T, Peters HPF, Haddeman E, Masclee AAM. Submitted

Both intestinal site and timing of fat delivery affect appetite in humans Maljaars J, van der Marel S, Peters HPF, Haddema EH, Masclee AAM.

Submitted

Small intestinal fat distribution influences satiation and food intake.

Maljaars J, Peters HPF, Kodde A, Geraedts M, Troost FJ, Haddeman E, Masclee AAM.

Submitted

Intragastric layering of lipids delays lipid absorption and increases plasma CCK but has minor effects on gastric emptying and appetite.

Foltz M, Maljaars J, Schuring EA, van der Wal RJ, Boer T, Duchateau GS, Peters HP, Stellaard F, Masclee AA.

Am J Physiol Gastrointest Liver Physiol. 2009 May;296(5):G982-91

An ileal brake-through?

Maljaars PJ, Keszthelyi D, Masclee AA.

Am J Clin Nutr. 2010 Sep;92(3):467-8. Editorial. 

Dankwoord 
196 


\section{Dankwoord}

Na 4 jaar onderzoek, en dan ook nog eens op twee verschillende locaties, is het indrukwekkend om te zien hoeveel mensen er geholpen hebben bij het afronden van dit proefschrift. Graag zou ik dan ook iedereen die een rol heeft gespeeld bij het tot stand komen van deze dissertatie willen bedanken. Een aantal hiervan wil ik in het bijzonder noemen.

Op de eerste plaats wil ik alle proefpersonen bedanken die hebben deelgenomen aan de verschillende onderzoeken. Zonder hen waren al deze studies zeker niet mogelijk geweest.

Ad Masclee, jouw vragen en opmerkingen hebben van de stukken betere artikelen gemaakt en van mij een betere onderzoeker.

Harry Peters, altijd nauwkeurig en gewapend met een indrukwekkende kennis van de literatuur, bedankt voor het sparren, je vele feedback en altijd kritische blik.

De leden van de beoordelingscommissie, Prof. dr. W. Saris, Prof. dr. C. Stehouwer, Prof. dr. W. Buurman, Prof. dr. H. Pijl en Prof. dr. M. Westerterp dank ik voor de bereidheid het proefschrift kritisch te lezen en te beoordelen.

Edward Haddeman, jouw optimisme, probleem-oplossend vermogen en energie hebben mij de vier jaren doorgesleept.

Tom Wiersma, vele vragen van mij heb je met engelengeduld beantwoord, zelfs al zaten er veel dezelfde tussen.

Johan Schilt, Martin Foltz, Guus Duchateau, Dave Mela, Sheila Wiseman en vele anderen van het Nutrition \& Health Department van Unilever Research \& Development te Vlaardingen, hartelijk dank voor jullie praktische hulp, theoretische ondersteuning en de kansen die jullie mij geboden hebben.

Jeoffrey Haans, goede vriend en paranimf. Eindeloze uren hebben we op een kamer gezeten, eerst in Leiden, later in Maastricht. Bedankt voor het sparren, het delen van je computerkennis en je vriendschap.

Eduard van Hoboken, al heb je van voetbal niets begrepen, leuk was het wel. 
Carolina, Karen, Daniel, dank voor het sparren, de koffie samen, de heerlijke maaltijden, de plezierige middagen en de leuke avonden.

Steven, Fred, Daisy, Andrea, Maartje, Henrike, Annemieke, Suzanne, jullie maakten mij wegwijs op de UM en maakten mijn tijd aan de Universiteitssingel een plezierige.

De verpleegkundigen van de endoscopie-afdeling van het LUMC, en dan met name Karlien, jullie dank ik hartelijk voor het ter beschikking stellen van jullie kennis en geduld.

Tiny Wouters, het afronden van een proefschrift is denk ik altijd een lastige onderneming, maar zonder jouw overzicht, rust en strengheid was het een onmogelijke geweest.

Lieve pap, mam en Jolande, voor jullie interesse, aandacht en support ben ik jullie zeer dankbaar.

Lieve Eva, jouw steun, humor en optimisme zijn erg belangrijk voor mij. Ik ben zo blij met je. 
Curriculum Vitae 


\section{Curriculum Vitae}

Pieter Wolter Jeroen Maljaars werd geboren op 30 december in Westkapelle. In 1995 behaalde hij het VWO diploma aan het Goese Lyceum. Aansluitend startte hij met de studie Geneeskunde aan de Universiteit Leiden. In augustus 2004 behaalde hij het artsexamen. Hierna startte hij zijn promotietraject (promotor: Prof. dr. A.A.M. Masclee) als arts-onderzoeker bij de afdeling Maag- Darm- Leverziekten in het Leids Universitair Medisch Centrum. In 2006 werd het promotietraject voortgezet in het academisch ziekenhuis Maastricht. In januari 2009 startte hij, in het kader van de opleiding tot maag-darm leverarts, met de vooropleiding Interne Geneeskunde in het Orbis Medisch Centrum (opleider: Dr. B.J. Looij). Hij heeft sinds 2007 een relatie met Eva Hilbrink. 